Glutamate metabolism and supplementation in COPD

\author{
Erica Rutten
}


ISBN 10: 905278-547-3

ISBN 13: 978-905278-547-9

Druk: Datawyse

(C) Erica Petra Alberta Rutten, Maastricht 2006

All rights reserved. No part of this book may be reproduced or transmitted, in any form or by any means without written permission from the outhor..

noutrim

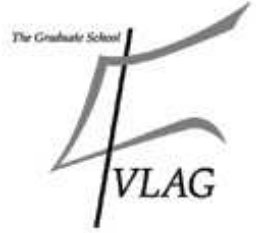

The study presented in this thesis was performed at the Nutrition and Toxicology Research Institute Maastricht (NUTRIM), which participates in the graduate School VLAG (Food Technology, Agrobiotechnology, Nutrition, accredited by the Royal Netherlands Academy of Arts and Sciences (KNAW). 


\title{
Glutamate metabolism and supplementation in COPD
}

\author{
PROEFSCHRIFT
}

ter verkrijging van de graad van doctor aan de Universiteit Maastricht, op gezag van de Rector Magnificus prof. mr. G.P.M.F. Mols volgens het besluit van het College van Decanen in het openbaar te verdedigen op vrijdag 15 september 2006 om 14.00 uur

door

Erica Petra Alberta Rutten

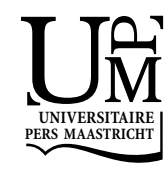




\section{Promotores:}

Prof. Dr. Ir. A.M.W.J. Schols

Prof. Dr. E.F.M. Wouters

\section{Co-promotor:}

Dr. M.P.K.J. Engelen

\section{Beoordelingscommissie:}

Prof. Dr. E.C.M. Mariman (voorzitter)

Prof. Dr. A. Bast

Prof. Dr. M.P. van Dieyen - Visser

Prof. Dr. H.P. Sauerwein (Academisch Medisch Centrum Amsterdam)

Dr. G. Biolo (University of Trieste, Italy)

The scientific work described in this thesis was sponsored by a grant from the Netherlands Asthma Foundation and a research fellowship from ESPEN Nestlé 2003. The publication of this thesis was financially supported by NUMICO research B.V., GlaxoSmithKline, Ciro Horn and the Department of Respiratoy Medicine. 
De arend staat symbool voor de mogelijkheid om de wereld eens vanaf een ander perspectief te bekijken. 


\section{Table of Contents}

Chapter 1 General introduction 9

Chapter 2 Increased myofibrillar protein breakdown in cachectic 23 patients with chronic obstructive pulmonary disease (COPD)

Chapter 3 Altered inter-organ response to feeding in patients with chronic obstructive pulmonary disease (COPD)

Chapter 4 Decreased whole-body and splanchnic glutamate 55 metabolism in healthy elderly men and patients with chronic obstructive pulmonary disease (COPD) in the postabsorptive state and in response of feeding

Chapter 5 The effect of glutamate ingestion on whole body glutamate turnover in healthy elderly and patients with chronic obstructive pulmonary disease (COPD)

Chapter 6 Metabolic effects of glutamine and glutamate ingestion in healthy subjects and in persons with chronic obstructive pulmonary disease (COPD)

Chapter 7 Skeletal muscle GLU metabolism in health and disease: state of the art

Chapter 8 Metabolic and functional effects of glutamate in patients with chronic obstructive pulmonary disease (COPD)

Chapter 9 General discussion

Appendices Summery

Samenvatting

Abbreviations

Vertaling

Publications

Curriculum Vitae

Dankwoord 


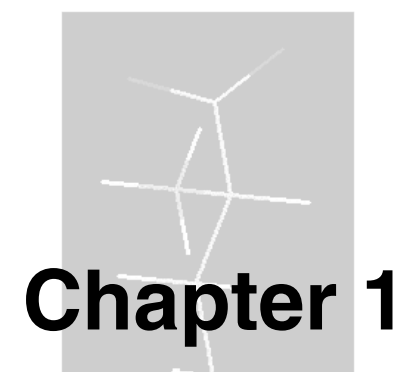

General introduction 
10 | 


\section{Chronic obstructive pulmonary disease}

Chronic obstructive pulmonary disease (COPD) is a complex and irreversible chronic disease of the respiratory system that is highly prevalent in elderly subjects. The most common causal factors for the development of COPD are cigarette-smoke and air pollution. It is predicted that about $90 \%$ of all COPD patients have a smoking history ${ }^{1}$. Although COPD is known as a men's disease, smoking rates in women recently approached that in men in some countries, making the prevalence of the disease increasing and gender unspecific ${ }^{2}$. Where COPD was the $6^{\text {th }}$ largest cause of death worldwide in the year 1990, it has been estimated that it will be the third largest cause of death worldwide by the year 2020 , with an expected mortality of 4.7 million per year ${ }^{3}$. COPD represents a financial burden of $1.3 \%$ of the total health care costs in the Netherlands. It is estimated that, primarily due to an increase in the ageing population, these costs will rise by $60 \%$ by 2010 . Smoking cessation programs however, are estimated to have a relatively small impact of only $4-14 \%$ on reducing cost in the next two decades in the Netherlands ${ }^{4}$.

Typical symptoms of patients with COPD are shortness of breath, first only during exercise and in later stages also at rest ${ }^{5}$, and exercise intolerance ${ }^{6}$. Despite the heterogeneity of COPD and its multicomponent pathophysiology, only 2 subtypes are generally described in clinical practice i.e. chronic bronchitis and emphysema. It is clinically difficult to distinguish between those two types because of the similar symptoms. Chronic bronchitis is defined according to clinical criteria as a cough with recurrent excessive sputum on most days of at least three month per year for at least two years in patients, with no other causes of cough ${ }^{5}$. The pathology of bronchitis includes primarily large airway mucus gland hyperplasia and inflammation ${ }^{7}$. The pathology of emphysema, initially defined according pathological criteria only, is characterized by loss of elasticity of the lungs due to destruction of alveolar tissue distal of the terminal bronchioli, causing a loss of surface for gas exchange and an increase of dead space ${ }^{5}$. A substantial proportion of patients present a combined picture of both emphysema and bronchitis. 
In general, conventional staging of the severity of COPD is still based on the severity of airflow obstruction measured by the forced expiratory volume in one second (FEV1), defined by the Global Initiative for Chronic Obstructive Lung Disease (GOLD) criteria $^{8}$. In the present thesis, patients with GOLD criteria II till III were included, involving moderate to severe COPD with FEV1 ranged from $30-$ $80 \%$ predicted.

\section{COPD as a metabolic disorder}

Apart from local impairment, systemic features like weight loss, loss of fat-free mass (FFM), muscle wasting and muscle weakness are commonly present in COPD patients. The decrease of FFM can be even masked by normal body weight 9 . Because FFM reflects the amount of metabolic active and contracting (skeletal muscle) tissue, FFM depletion is associated with exercise intolerance ${ }^{10-12}$, impaired health status ${ }^{13}$ and decreased survival ${ }^{14,15}$. In terms of the underlying causes of these symptoms, various intramuscular dysfunctions have been detected in COPD patients. Pouw et al ${ }^{16}$ reported a disturbed energy status in COPD patients at rest, indicated by an imbalance between ATP utilization and resynthesis. Moreover, COPD patients are characterized by decreased aerobic energy metabolism related to a shift of type I fibers in favor of type II fibers ${ }^{17}$, and reduced activity of oxidative enzyme activities ${ }^{18}$. In addition, the increased exercise-induced production of lactic acid in COPD patients compared to control subjects is related to decreased oxidative capacity ${ }^{19}$. Recently, quadriceps muscle fatigue in COPD has been related to metabolic disturbances like high muscle lactic acid dehydrogenase activity and high plasma lactic acid concentration ${ }^{20}$. More evidence exists of a disturbed substrate metabolism that can lead to muscle weakness in COPD patients. Both uncoupling protein-3 (UCP3) mRNA ${ }^{21}$ and skeletal muscle concentration of UCP3 ${ }^{22}$ are decreased in COPD patients. The primarily function of UCP3 remains unknown at present, but it is often associated with fuel metabolism. Additional research showed impaired $\beta$-adrenoceptormediated lipolysis in COPD patients ${ }^{23}$. Moreover, several studies indicate a disturbed protein metabolism in COPD patients. Whole body protein breakdown and synthesis has been shown to be increased in normal weight COPD patients ${ }^{24}$, 
while another study with depleted emphysema patients showed decreased levels of whole body protein synthesis ${ }^{25}$. Alternatively, alterations in amino acid profile are often found in COPD patients, with the consistent finding of decreased plasma branched chain amino acid (BCAA: leucine, isoleucine and valine) concentration ${ }^{26}$, 27 and decreased skeletal muscle glutamate concentration ${ }^{28,}{ }^{29}$. Reduced concentrations of muscular glutamate are shown independent of the severity of airflow limitation, and in several skeletal muscle groups. Moreover, resting muscle glutamate concentration was associated with muscle glutathione concentration ${ }^{30}$, and with early acidosis during maximal exercise test in COPD patients ${ }^{31}$. This suggests that the reduced muscle glutamate concentration is associated with metabolic consequences. In chronic disease, no other studies focused on skeletal muscle glutamate concentration and its related metabolism, but research in postsurgery patients support this suggestion as a decreased glutathione concentration was accompanied with decreased muscle glutamate concentration ${ }^{32}$. According to these findings, normalization the muscle glutamate status may be beneficial for the patient.

Increasing skeletal muscle glutamate pool via glutamate supplementation has never been studied in COPD patients as it is suggested that a large amount of oral ingested glutamate is taken up and metabolized by the intestine ${ }^{33}$. In contrast, intravenous infusion of mono-sodium glutamate increased myocardial glutamate uptake ${ }^{34}$ combined with modulation of the lactic acid metabolism ${ }^{35}$ in coronary patients. In addition, bolus ingestion of $150 \mathrm{mg}$ monosodium glutamate/kg wt increased skeletal muscle glutamate concentration by $40 \%{ }^{36}$. Therefore, we hypothesized that oral ingestion of glutamate is a good option to increase muscle glutamate concentration. However, apart from the intramuscular functions of glutamate, glutamate acts as an intermediate in many processes in the whole body. Therefore, it is of importance to receive insight in the glutamate related metabolism on whole body level, and to consider the potential effects of glutamate supplementation. 


\section{The amino acid glutamate}

Glutamate is found in virtually all protein-containing food products both in the free form and bound in protein. Approximately $15 \%$ of the protein content in food is either glutamate or the closely linked amino acid glutamine. Especially products like tomatoes, canned vegetables, fermented cheese and mushrooms are known for its high levels of glutamate ${ }^{37}$. Because the daily protein ingestion in a regular western diet is about $1 \mathrm{~g} / \mathrm{kg} \mathrm{wt}$, the average glutamate/glutamine intake is 150 $\mathrm{mg} / \mathrm{kg}$ wt. Moreover, the salt of glutamate, monosodium glutamate (MSG), is often used in a variety of foods like meat, fish, poultry, many vegetables, sauces, soups and marinades to enhance flavour.

Only free glutamate is taken up by the intestine, and in the body, glutamate is a non-essential amino acid that plays a central role in the formation of all amino acids via amino transamination reactions (figure 1). Moreover, glutamate is also an intermediate in numerous other functions in different organs. The sodiumdependent $\mathrm{X}_{\mathrm{ag}}$-transporter is the main transport system across the cell membranes for glutamate, recognized as a high-affinity, low-capacity carrier. In the section below, various functions of glutamate in the different organs are discussed briefly.

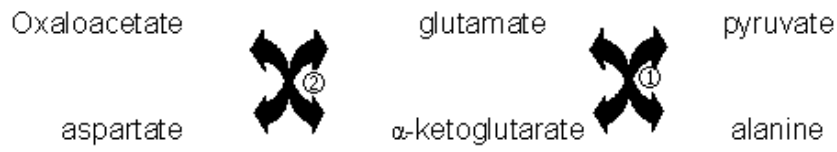

Figure 1: Schematic overview of the central role of glutamate in transamination reactions. (1) alanine amino transferase (2) glutamate oxaloacetate transaminase.

\section{BRAIN}

In the central nervous system, glutamate itself acts as an excitatory (stimulatory) neurotransmitter recognized by various receptors ${ }^{38}$. The functions of glutamate as neurotransmitter are diverse and depend on the activated receptor. Ionotropic receptors (agonists $\mathrm{N}$-methyl D-aspartate (NMDA), alpha-amino-3-hydroxy-5methyl-4-isoxazole propionic acid (AMPA) and kainate receptors) mediate the fast synaptic transmission in the central nervous system, while metabotropic receptors 
take care of the growing organs ${ }^{39}$. Apart from its role as neurotransmitter, glutamate is also a precursor of the inhibitory neurotransmitter GABA ( $\gamma$ aminobutyric acid) that plays an important role in learning processes and in the regulation of muscle contractions. Since the blood-brain barrier leaks only a very small amount of glutamate from the circulation and vice versa, it can be concluded that the brain functions as an isolated and very strongly controlled organ in the body ${ }^{40}$.

\section{INTESTINE}

Glutamate and glutamine act as the main energy source for the intestine ${ }^{33,41}$. Large amounts of luminal and circulatory glutamate and glutamine are absorbed and metabolized by the intestinal cells. The amount of glutamate oxidation by the intestine seems to depend on the amount of intestinal carbohydrate ${ }^{42,} 43$. Carbohydrate is converted to pyruvate that reacts with glutamate in the alanineamino transamination reaction (glutamate + pyruvate $\leftrightarrow$ alanine + a-ketoglutarate). Consequently, in the presence of intestinal pyruvate, the maximal capacity of the intestine for glutamate is delayed. However, besides oxidation, significant amounts of other amino acids are also formed in the intestine ${ }^{44}$. Briefly, intestinal glutamate is converted to glutamate $\gamma$-semialdehyde, and subsequently to proline or ornithine. In mammalians, the intestine appears to be the only organ where those amino acids are formed from glutamate. Proline is poorly metabolized in the intestine, where ornithine plus carbamoyl phosphate yields citrulline. In the liver, citrulline is further metabolized to arginine to produce urea and ornithine in the hepatic ornithine cycle. Therefore, circulating citrulline originates from the intestine rather than from the liver ${ }^{45}$. Because the enzymes that convert citrulline to arginine are not present in the intestine, citrulline is released to the circulation and taken up by the kidneys. Taken together, oral glutamate supplementation increases intestinal glutamate uptake until the oxidative capacity is saturated and its metabolic maximum is reached. At this point, glutamate enters the circulation and is available for other organs. 


\section{LIVER}

The predominant amino acids taken up or released by the liver are the circulating nitrogen $(\mathrm{N})$ transporters alanine and glutamine. Hereby, glutamate participates as a metabolic intermediate in various intrahepatic pathways. In the periportal cells, glutamine and alanine are taken up and participate in the urea cycle to remove the excess nitrogen from the body ${ }^{46}$ (figure 2). In this cycle, glutamate is formed by the amide N-removal of glutamine. Subsequently, the presence of both glutamate and acetyl CoA are of crucial importance for the formation of $\mathrm{N}$-acetyl glutamate, which is suggested to be the rate-limiting step in the hepatic ornithine cycle ${ }^{47}$. In contrast to the liver glutamine uptake in the periportal cells, glutamate is taken up by the perivenous cells ${ }^{48}$. In this side of the liver, glutamine synthetase is highly concentrated, in order to form glutamine directly from glutamate and $\mathrm{NH}_{3}$. Glutamine is than released to the circulation.
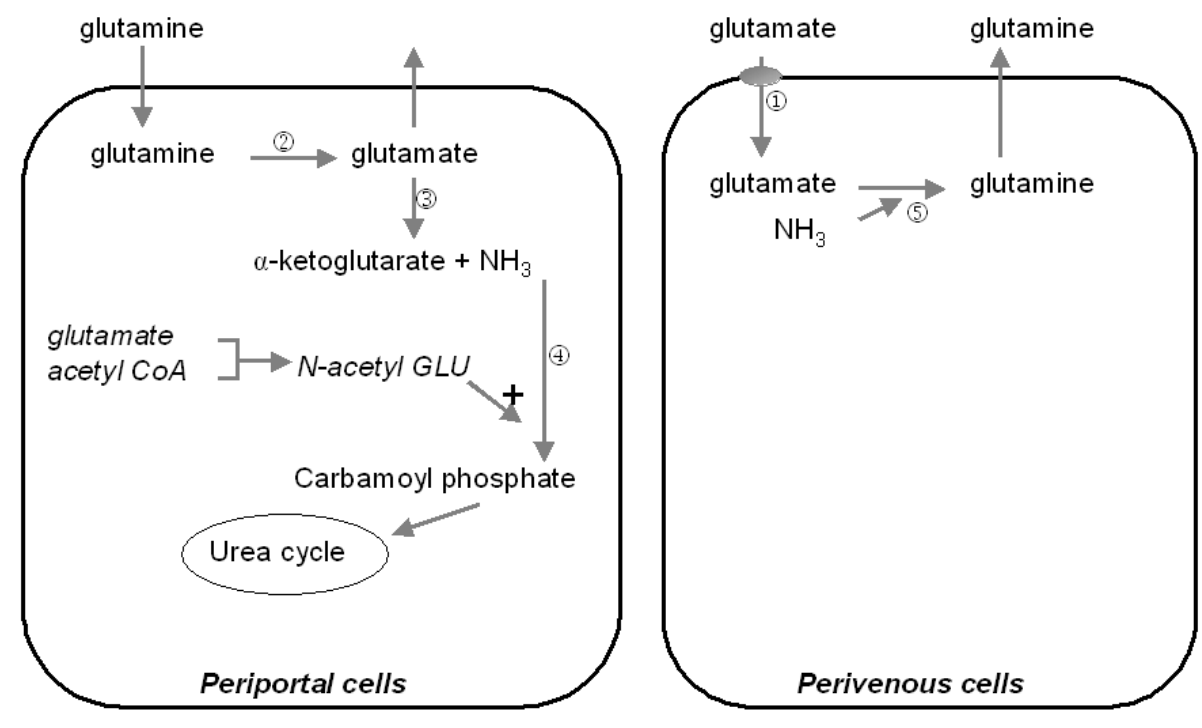

Figure 2: Schematic overview of the glutamate-related intrahepatic metabolism. In the periportal cells, glutamine is taken up to enter the ornithine cycle, while in the perivenous cells, glutamate is taken up to form glutamine. (1) Na-dependent transport, (2) phosphate dependent glutaminase, (3) glutamate dehydrogenase, (4) carbamoyl phosphate synthetase, (5) glutamine synthetase. 


\section{KIDNEY}

Whereas the liver removes toxic nitrogen as urea, the kidneys excrete nitrogen via ammonia $\left(\mathrm{NH}_{3}\right)$. In the first step, glutamine is deaminated to glutamate. Subsequently, the conversion of the amino $\mathrm{N}$ of glutamate to ammonia occurs via a direct and an indirect pathway (figure 3). The direct pathway involves the production of ammonia and a-ketoglutarate by the enzyme glutamate dehydrogenase ${ }^{49}$. In the indirect pathway, glutamate and oxaloacetate transaminate to aspartate, the latter entering the purine nucleotide cycle (PNC). From this anaerobic cycle, $\mathrm{NH}_{3}$ is formed by using catalytic amounts of IMP, adenosuccinate and $\mathrm{AMP}{ }^{50}$. Although glutamate acts as a secondary precursor for the $\mathrm{NH}_{3}$ production in the kidney, Cooper et al ${ }^{50}$ showed that the kidneys were also able to take up and release glutamate.

\section{SKELETAL MUSCLE AND MYOCARDIUM}

The role of glutamate in skeletal muscle is extensively reviewed in chapter 7 of this thesis. Briefly, whereas most other amino acids are released from skeletal muscle in postabsorptive conditions, glutamate is actively taken up ${ }^{51}$. Intracellular, glutamate takes part in various metabolic pathways. Glutamate is one of the precursors of the most abundant intracellular antioxidant glutathione ${ }^{52}$. Various studies showed a correlation between intramuscular glutathione concentration and glutamate concentration ${ }^{30,53}$, suggesting a rate-limiting step of glutamate in the glutathione synthesis. However, contrasting data are also available ${ }^{54}$. On the other hand, glutamate takes action as an intermediate in various energy related routes. Firstly, in the aerobic energy provision, glutamate acts as a supplier of the tricarboxylic acid intermediate (TCAI), a-ketoglutarate via the alanine-amino transferase reaction (glutamate + pyruvate $\leftrightarrow$ alanine + a-ketoglutarate). This transamination reaction is likely the most important reaction for anaplerosis (replenishment of TCAIs) during the first minutes of exercise ${ }^{55}$. Secondly, glutamate has a role in the relative balance of nucleotides, since it participates in the purine nucleotide cycle (PNC) ${ }^{56}$, and the anaerobic apartate / malate shuttle ${ }^{57}$. Based on preceding results ${ }^{34,36}$, there is evidence that muscle glutamate 
metabolism can be modulated by increasing the glutamate availability for skeletal muscle by glutamate ingestion.

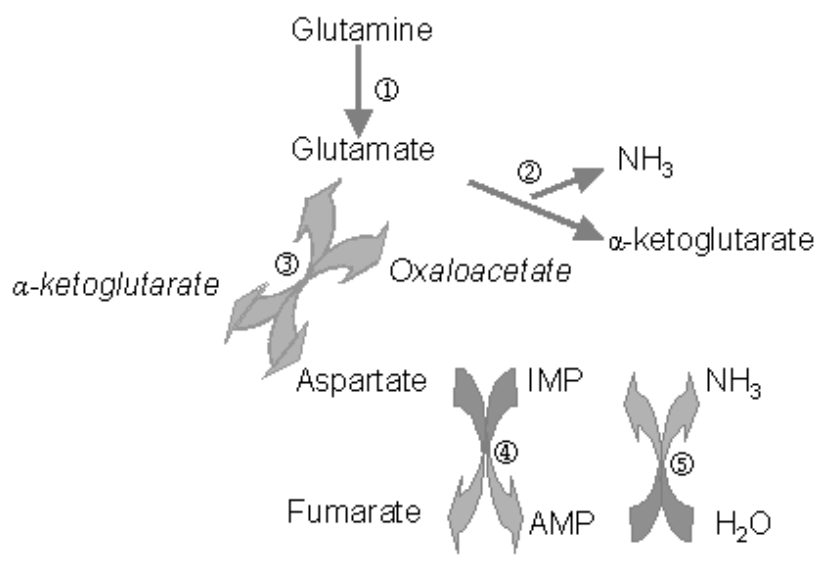

Figure 3: Schematic overview of the indirect and direct release of $\mathrm{NH}_{3}$ from glutamate in the kidneys. (1) phosphate dependent glutaminase, (2)glutamate dehydrogenase, (3) glutamate oxaloacetate transaminase, (4) adenosuccinate synthetase, (5) adenylate deaminase.

\section{Outline of the thesis}

Three main issues have been studied in the current thesis: Firstly, the altered protein and amino acid metabolism in clinically stable COPD patients; secondly, the use of the amino acid glutamate as nutritional supplementation; and thirdly, the effects of glutamate in skeletal muscle.

In the first issue, the primed constant and continuous infusion protocol with various stable isotopes was used to measure protein and amino acid metabolism. In chapter 2, a stable isotope of 3-methylhistidine was used to measure whole body myofibrillar protein breakdown as a measure of skeletal muscle protein breakdown in a cachectic and a non-cachectic subgroup of COPD patients. The dual tracer technique with stable isotopes of phenylalanine was used in chapter 3 to measure splanchnic extraction and endogenous production of phenylalanine in COPD patients vs. healthy control subjects. Additionally, in chapter $\mathbf{4}$, rate of glutamate appearance as a measure for glutamate delivery was measured by infusion of a stable isotope of glutamate. To receive more insight in glutamate turnover and splanchnic glutamate extraction in COPD patients in the postabsorptive state and in response to a meal, the dual tracer technique with a 
stable isotope of glutamate was also applied. As glutamate metabolism was only investigated in young healthy volunteers until now, glutamate turnover in COPD patients was compared with two control groups: an age-matched healthy elderly group, and a young healthy control group.

In the second issue, the use of the amino acid glutamate as nutritional supplementation was investigated. Chapter 5 described the development of a protocol in which repeated glutamate ingestion increased plasma glutamate concentration and whole body glutamate turnover to a new steady state level. The effects of repeated glutamate ingestion on plasma amino acid concentration and whole body protein turnover relative to repeated glutamine and water ingestion were evaluated in chapter 6 .

The third issue involved the effects of glutamate in skeletal muscle. In chapter 7 , the role of glutamate on skeletal muscle in health and disease was reviewed. Finally, chapter 8 concerned the effect of repeated glutamate ingestion on skeletal muscle glutamate concentration in COPD patients and age-matched healthy controls. In addition, the metabolic and functional consequences of glutamate ingestion were evaluated at rest and during submaximal cycle ergometry.

Finally, chapter 9 comprises a general discussion of the preceding chapters. Some relevant aspects not pointed in former chapters were discussed: the role of glutamate metabolism in age- and disease-relating metabolic alterations was debated. Additionally, glutamate as nutritional modulation is discussed and other nutritional options to influence glutamate and glutamate-related pathways in skeletal muscle were provided.

\section{References}

1. Feenstra TL, van Genugten ML, Hoogenveen RT, et al. The impact of aging and smoking on the future burden of chronic obstructive pulmonary disease: a model analysis in the Netherlands. Am J Respir Crit Care Med 2001; 164(4):590-6.

2. Watson L, Vestbo J, Postma DS, et al. Gender differences in the management and experience of Chronic Obstructive Pulmonary Disease. Respir Med 2004; 98(12):1207-13.

3. Murray CJ, Lopez AD. Alternative projections of mortality and disability by cause 1990-2020: Global Burden of Disease Study. Lancet 1997; 349(9064):1498-504.

4. Rutten-van Molken MP, Postma MJ, Joore MA, et al. Current and future medical costs of asthma and chronic obstructive pulmonary disease in The Netherlands. Respir Med 1999; 93(11):779-87.

5. ATS. Standards for the diagnosis and care of patients with chronic obstructive pulmonary disease. Am J Respir Crit Care Med 1995; 152:S77-121. 
6. Skeletal muscle dysfunction in chronic obstructive pulmonary disease. A statement of the American Thoracic Society and European Respiratory Society. Am J Respir Crit Care Med 1999; 159(4 Pt 2):S1-40.

7. Society AT. Chronic bronchitis, asthma, and pulmonary emphysema by the committee on diagnostic standards for nontuberculosis respiratory disease. Am. Rev. Respir. Dis. 1962; 85:762812.

8. Fabbri LM, Hurd SS. Global Strategy for the Diagnosis, Management and Prevention of COPD: 2003 update. Eur Respir J 2003; 22(1):1-2.

9. Schols AMWJ, Soeters PB, Dingemans AMC, et al. Prevalence and characteristics of nutritional depletion in patients with stable COPD eligible for pulmonary rehabilitation. Am.Rev.Respir.Dis. 1993; 147:1151-1156.

10. Engelen MPKJ, Schols AMWJ, Baken WC, et al. Nutritional depletion in relation to respiratory and peripheral skeletal muscle function in out-patients with COPD. Eur. Respir. J. 1994; 7:1793-1797.

11. Gosselink R, Troosters T, Decramer M. Peripheral skeletal muscle weakness contributes to exercise limitation in COPD. Am.J.Respir.Crit.Care Med. 1996; 153:976-980.

12. Allaire J, Maltais F, Doyon JF, et al. Peripheral muscle endurance and the oxidative profile of the quadriceps in patients with COPD. Thorax 2004; 59(8):673-8.

13. Mostert R, Goris A, Weling-Scheepers $C$, et al. Tissue depletion and health related quality of life in patients with chronic obstructive pulmonary disease. Respir Med 2000; 94(9):859-67.

14. Schols AM, Broekhuizen R, Weling-Scheepers CA, Wouters EF. Body composition and mortality in chronic obstructive pulmonary disease. Am J Clin Nutr 2005; 82(1):53-9.

15. Marquis $\mathrm{K}$, Debigare R, Lacasse $\mathrm{Y}$, et al. Midthigh muscle cross-sectional area is a better predictor of mortality than body mass index in patients with chronic obstructive pulmonary disease. Am J Respir Crit Care Med 2002; 166(6):809-13.

16. Pouw EM, Schols AMWJ, Vusse vd GJ, Wouters EFM. Elevated iosine monophosphate levels in resting muscle of patients with stable COPD. Am. J. Respir. Crit. Care Med. 1998; 157:453-457.

17. Gosker HR, van Mameren $\mathrm{H}$, van Dijk PJ, et al. Skeletal muscle fibre-type shifting and metabolic profile in patients with chronic obstructive pulmonary disease. Eur Respir J 2002; 19(4):617-25.

18. Maltais $F$, LeBlanc $P$, Whittom $F$, et al. Oxidative enzyme activities of the vastus lateralis muscle and the functional status in patients with COPD. Thorax 2000; 55(10):848-53.

19. Maltais F, Simard AA, Simard C, et al. Oxidative capacity of the skeletal muscle and lactic acid kinetics during exercise in normal subjects and in patients with COPD. Am.J.Respir.Crit.Care Med. 1996; 153:288-293.

20. Saey D, Michaud A, Couillard A, et al. Contractile fatigue, muscle morphometry, and blood lactate in chronic obstructive pulmonary disease. Am J Respir Crit Care Med 2005; 171(10):1109-15.

21. Russell AP, Somm E, Debigare R, et al. COPD results in a reduction in UCP3 long mRNA and UCP3 protein content in types I and Ila skeletal muscle fibers. J Cardiopulm Rehabil 2004; 24(5):332-9.

22. Gosker HR, Schrauwen $P$, Hesselink MK, et al. Uncoupling protein-3 content is decreased in peripheral skeletal muscle of patients with COPD. Eur Respir J 2003; 22(1):88-93.

23. Schiffelers SL, Blaak EE, Baarends EM, et al. beta-Adrenoceptor-mediated thermogenesis and lipolysis in patients with chronic obstructive pulmonary disease. Am J Physiol Endocrinol Metab 2001; 280(2):E357-64.

24. Engelen MPKJ, Deutz NEP, Wouters EFM, Schols AMWJ. Enhanced levels of whole body protein turnover in patients with chronic obstructive pulmonary disease. Am.J.Respir.Crit. Care Med. 2000; 162(4Pt1):1488-92.

25. Morrison WL, Gibson JNA, Scrimgeour C, Rennie MJ. Muscle wasting in emphysema. Clin.Sci. 1988; 75:415-420.

26. Schols AMWJ, Deutz NEP, Mostert R, Wouters EFM. Plasma amino acid levels in patients with chronic obstructive pulmonary disease. Monaldi Arch. Chest Med. 1993; 48:546-548.

27. Yoneda T, Yoshikawa M, Fu A, et al. Plasma levels of amino acids and hypermetabolism in patients with chronic obstructive pulmonary disease. Nutrition 2001; 17(2):95-9. 
28. Engelen MP, Wouters EF, Deutz NE, et al. Factors contributing to alterations in skeletal muscle and plasma amino acid profiles in patients with chronic obstructive pulmonary disease. Am J Clin Nutr 2000; 72(6):1480-7.

29. Pouw EM, Schols AMWJ, Deutz NEP, Wouters EFM. Plasma and muscle amino-acid levels in relation to resting energy expenditure and inflammation in stable COPD. Am.J.Respir.Crit.Care Med. 1998; 158:797-801.

30. Engelen MPKJ, Schols AMWJ, Does JD, et al. Altered glutamate metabolism is associated with reduced muscle glutathione levels in patients with emphysema. Am.J.Respir.Crit.Care Med. 2000; 161:98-103.

31. Engelen MPKJ, Schols AMWJ, Does JD, et al. Exercise induced lactate increase in relation to muscle substrates in patients with COPD. Am.J.Respir.Crit. Care Med. 2000; 162(5):1697-704.

32. Luo JL, Hammarqvist F, Andersson K, Wernerman J. Skeletal muscle glutathione after surgical trauma. Ann Surg 1996; 223(4):420-7.

33. Matthews DE, Marano MA, Campbell RG. Splanchnic bed utilization of glutamine and glutamic acid in humans. Am J Physiol 1993; 264(6 Pt 1):E848-54.

34. Thomassen A, Nielsen TT, Bagger JP, Henningsen P. Effects of intravenous glutamate on substrate availability and utilization across the human heart and leg. Metabolism 1991; 40(4):37884.

35. Svedjeholm R, Vanhanen I, Hakanson E, et al. Metabolic and hemodynamic effects of intravenous glutamate infusion early after coronary operations. J Thorac Cardiovasc Surg 1996; 112(6):146877.

36. Graham TE, Sgro V, Friars D, Gibala MJ. Glutamate ingestion: the plasma and muscle free amino acid pools of resting humans. Am J Physiol Endocrinol Metab 2000; 278(1):E83-E89.

37. Daniels DH, Joe FL, Jr., Diachenko GW. Determination of free glutamic acid in a variety of foods by high-performance liquid chromatography. Food Addit Contam 1995; 12(1):21-9.

38. Fitzpatrick SM, Cooper AJ, Hertz L. Effects of ammonia and beta-methylene-DL-aspartate on the oxidation of glucose and pyruvate by neurons and astrocytes in primary culture. $\mathrm{J}$ Neurochem 1988; 51(4):1197-203.

39. Waelsch H. Glutamic Acid and Cerebral Function. New York State Psychiatric Institue.

40. Fernstrom JD. Pituitary hormone secretion in normal male humans: acute responses to a large, oral dose of monosodium glutamate. J Nutr 2000; 130(4S Suppl):1053S-7S.

41. Reeds PJ, Burrin DG, Stoll B, Jahoor F. Intestinal glutamate metabolism. J Nutr 2000; 130(4S Suppl):978S-82S.

42. Stegink LD, Filer LJ, Jr., Baker GL. Effect of aspartame plus monosodium L-glutamate ingestion on plasma and erythrocyte amino acid levels in normal adult subjects fed a high protein meal. Am J Clin Nutr 1982; 36(6):1145-52.

43. Stegink LD, Filer LJ, Jr., Baker GL. Effect of carbohydrate on plasma and erythrocyte glutamate levels in humans ingesting large doses of monosodium L-glutamate in water. Am J Clin Nutr 1983; 37(6):961-8.

44. Windmueller HG, Spaeth AE. Intestinal metabolism of glutamine and glutamate from the lumen as compared to glutamine from blood. Arch Biochem Biophys 1975; $171(2): 662-72$.

45. Windmueller HG, Spaeth AE. Source and fate of circulating citrulline. Am J Physiol 1981; 241(6):E473-80.

46. Remesy C, Moundras C, Morand C, Demigne C. Glutamine or glutamate release by the liver constitutes a major mechanism for nitrogen salvage. Am J Physiol 1997; 272(2 Pt 1):G257-64.

47. Meijer AJ, Lamers WH, Chamuleau RA. Nitrogen metabolism and ornithine cycle function. Physiol Rev 1990; 70(3):701-48.

48. Kuo FC, Hwu WL, Valle D, Darnell JE, Jr. Colocalization in pericentral hepatocytes in adult mice and similarity in developmental expression pattern of ornithine aminotransferase and glutamine synthetase mRNA. Proc Natl Acad Sci U S A 1991; 88(21):9468-72.

49. Nissim I, Yudkoff M, Segal S. Metabolism of glutamine and glutamate by rat renal tubules. Study with $15 \mathrm{~N}$ and gas chromatography-mass spectrometry. J Biol Chem 1985; 260(26):13955-67. 
50. Cooper AJL, S F-D, AS G. L-[13N]glutamate metabolism in normal rat kidney. Prog.Hepat.Encephal.Metabol.Nitr.Exch. 1991:341-351.

51. Marliss EB, Aoki TT, Pozefsky T, et al. Muscle and splanchnic glutamine and glutamate metabolism in postabsorptive and starved man. J Clin Invest 1971; 50(4):814-7.

52. Amores-Sanchez MI, Medina MA. Glutamine, as a precursor of glutathione, and oxidative stress. Mol Genet Metab 1999; 67(2):100-5.

53. Flaring UB, Rooyackers OE, Wernerman J, Hammarqvist F. Temporal changes in muscle glutathione in ICU patients. Intensive Care Med 2003; 29(12):2193-8.

54. Richman PG, Meister A. Regulation of gamma-glutamyl-cysteine synthetase by nonallosteric feedback inhibition by glutathione. J Biol Chem 1975; 250(4):1422-6.

55. Gibala MJ, MacLean DA, Graham TE, Saltin B. Tricarboxylic acid cycle intermediate pool size and estimated cycle flux in human muscle during exercise. Am J Physiol 1998; 275(2 Pt 1):E235-42.

56. Lowenstein JM. The purine nucleotide cycle revisited [corrected]. Int J Sports Med 1990; 11 Suppl 2:S37-46.

57. Wiesner RJ, Deussen A, Borst $M$, et al. Glutamate degradation in the ischemic dog heart: contribution to anaerobic energy production. J.Mol.Cell.Cardiol. 1989; 21:49-59. 


\title{
Chapter 2
}

\section{Greater whole-body myofibrillar protein breakdown in cachectic patients with chronic obstructive pulmonary disease}

\author{
Erica P.A. Rutten, Frits M.E. Franssen, Mariëlle P.K.J. Engelen, \\ Emiel F.M. Wouters EFM, Nicolaas E.P. Deutz, Annemie M.W.J. Schols AMWJ
}

Am J Clin Nutr 2006; 83: 829-34

\section{Abstract}

Background: Experimental studies indicate that greater skeletal muscle protein breakdown is a trigger for the cachexia that often is prevalent in chronic obstructive pulmonary disease (COPD).

Objective: We compared myofibrillar protein breakdown (MPB) with whole-body (WB) protein breakdown (PB) in 9 cachectic COPD patients $[\mathrm{X} \pm$ SEM forced expiratory volume in $1 \mathrm{~s}$ (FEV1): $48 \pm$ $4 \%$ of predicted], 7 non-cachectic COPD patients (FEV1: $53 \pm 5 \%$ of predicted) and 7 age-matched healthy control subjects, who were matched by body mass index with the noncachectic patients.

Design: After the subjects fasted overnight $(10 \mathrm{~h})$ and discontinued the maintenance medication, a primed constant continuous infusion protocol was used to infuse L-[ring $\left.{ }_{-}^{2} \mathrm{H}_{5}\right]$-phenylalanine and L-[ring$\left.{ }^{2} \mathrm{H}_{2}\right]$-tyrosine to measure WB protein turnover and L- $\left[{ }^{2} \mathrm{H}_{3}\right]-3$-methylhistidine to measure WB MPB. Three arterialized venous blood samples were taken between 80 and $90 \mathrm{~min}$ of infusion to measure amino acid concentrations and tracer enrichments.

Results: Body composition, WB protein turnover and WB MPB did not differ significantly between the noncachectic COPD and control subjects. Cachectic COPD patients had lower fat mass and fat-free mass values (both: $P<0.01)$ than did the noncachectic COPD patients. WB MPB was significantly $(P<$ $0.05)$ higher in the cachectic COPD group (18 $\pm 3 \mathrm{nmol} \cdot \mathrm{kg} \cdot \mathrm{min})$ than in the combined control and noncachectic COPD groups (10 $\pm 1 \mathrm{nmol} \cdot \mathrm{kg} \cdot \mathrm{min})$, but WB protein turnover did not differ significantly between the groups. Correlation with fat-free mass were significant $(P<0.05)$ for plasma glutamate and branched-chain amino acids, and that for WB MPB trended toward significance $(P=0.07)$.

Conclusion: Cachexia in clinically stable patients with moderate COPD is characterized by increased WB MPB, which indicates that myofibrillar protein wasting is an important target for nutritional and pharmacological modulation.

Key words: cachexia, myofibrillar protein breakdown, chronic obstructive pulmonary disease. 


\section{Introduction}

Weight loss and muscle wasting are prevalent in patients with moderate-to-severe chronic obstructive pulmonary disease (COPD) ${ }^{1,2}$ a combination that is commonly referred to as pulmonary cachexia. Low fat-free mass (FFM), reflecting the amount of skeletal muscle mass, is associated with exercise intolerance ${ }^{3}$ related to less skeletal muscle strength ${ }^{4,5}$, impaired health status ${ }^{6}$ and shorter survival ${ }^{7}$. Experimental studies in acute disease models indicate that increased skeletal muscle protein breakdown (PB) is a typical feature of cachexia, and activation of the ubiquitine-proteasome pathway has been identified as an important trigger of proteolysis ${ }^{8}$. Surprisingly little information is available about protein metabolism in relation to cachexia in clinically stable chronic disease states. In comparing underweight patients with emphysema with healthy control subjects, Morrison et al ${ }^{9}$ found no difference in skeletal muscle PB but lower whole-body (WB) protein synthesis in the emphysema patients. This study was, however, limited by the fact that the control group was significantly younger than the COPD group ( $x$-age: 45 and $62 \mathrm{y}$, respectively) and that no noncachectic COPD patients were included. Recently, elevated concentration of urinary pseudouridine, used as an indirect biomarker for cellular PB, were found in cachectic COPD patients than in noncachectic patients and healthy controls ${ }^{10}$. In addition, the noncachectic patients had also higher urinary pseudouridine concentrations than did the controls. The plasma amino acid profile in cachectic COPD patients is more extensively investigated than is protein metabolism, and it consistently shows a lower concentration of the branched-chain amino acids (BCAA) leucine, isoleucine and valine ${ }^{9,11,12}$.

Measurements on WB protein metabolism do not necessarily reflect skeletal muscle metabolism. Vissers et al ${ }^{13}$ described a technique to measure a rate of myofibrillar PB (MPB) by using the primed constant and continuous infusion protocol with deuterated 3-methylhistidine. Although myofibrillar protein is also present in other tissue such as intestine and skin, it is mainly found in muscle. Therefore, WB MPB gives an indication for skeletal muscle PB. The current study is the first to measure the rate of WB MPB in humans. The main purpose of the 
current study was to investigate whether WB MPB is greater in cachectic COPD patients than in noncachectic COPD patients or healthy controls. The secondary purpose was to study whether WB MPB is reflected in WB PB.

\section{Subjects and methods}

\section{STUDY POPULATION}

In total, 16 clinically stable males with moderate-to-severe COPD ${ }^{14}$ and 7 age- and sex-matched healthy controls were studied. Each member of the healthy control group was matched for BMI with a member of the noncachectic COPD group ( $n=$ 7 , mean BMI: $28 \pm 1)$. The remaining COPD patients $(n=9)$ were defined as the cachectic COPD group (BMI: $20 \pm 1$ ). Exclusion criteria for all subjects were malignancy, cardiac failure, distal arteriopathy, recent surgery, severe endocrine, hepatic or renal disorder. Also, patients who were using systemic corticosteroids $\leq$ 3 mo before the study were excluded because it has been shown that systemic corticosteroids may affect muscle protein metabolism ${ }^{15}$. The following pulmonary maintenance medications were being used by various proportions of patients: inhaled short- and long-acting beta-2 adrenoceptor agonists, 56\%; anticholinergics by inhalation, $54 \%$; combined inhalers of short-acting beta-2 adrenoceptor agonists and short-acting anticholinergics, 8\%; inhalation corticosteroids, 19\%; combined inhalers of sympathicomimetics and corticosteroids, $46 \%$; xanthines, $31 \%$; and oral $\mathrm{N}$-acetylcysteine, $23 \%$. On the evening before the test day and the morning of the test day, the maintenance medication was suspended to avoid potential acute effects of these medications on substrate metabolism ${ }^{16}$,because glucose and glycerol metabolism were also measured in the study (EPA Rutten, unpublished observations, 2005).

Written informed consent was obtained from all subjects. The study was approved by the medical ethical committee of the University Hospital Maastricht.

\section{PULMONARY FUNCTION TESTS}

Before the test day, all subjects underwent spirometry for measurement of forced expiratory volume in $1 \mathrm{~s}\left(\mathrm{FEV}_{1}\right)$ and forced vital capacity; the highest value from $\geq$ 
3 technically acceptable maneuvers being used. Total lung capacity, intrathoracic gas volume and residual volume were assessed by WB plethysmography (Masterlab; Jaeger, Wurzburg, Germany). Diffusion capacity for carbon monoxide was measured by using the single-breath method (Masterlab; Jaeger, Wurzburg, Germany). All values obtained were related to a reference value and expressed as percentages of the predicted value ${ }^{17}$. On the morning of the lung function measurements, the pulmonary maintenance medications were suspended.

\section{EXPERIMENTAL PROTOCOL}

Study design. Subjects were in supine position for $1.5 \mathrm{~h}$. A catheter was placed in an antecubital vein of the arm for tracer infusion (at a rate of $85 \mathrm{~mL} / \mathrm{h}$ ) according to a primed constant and continuous infusion protocol. The stable isotopes L-[ring${ }^{2} \mathrm{H}_{5}$ ]-phenylalanine (PHE), L-[ring- $\left.{ }^{2} \mathrm{H}_{2}\right]$-tyrosine (TYR) were used to measure WB total protein turnover. $\mathrm{L}-\left[{ }^{2} \mathrm{H}_{3}\right]-3-$ methylhistidine $(3 \mathrm{MH})$ was infused to measure WB MPB. The following priming doses (PDs) and infusion rates (IRs) were used: L$\left[\right.$ ring $\left.-{ }^{2} \mathrm{H}_{5}\right]-\mathrm{PHE}: \mathrm{PD}=2.19 \mu \mathrm{mol} \cdot \mathrm{kg}, \mathrm{IR}=3.20 \mu \mathrm{mol} \cdot \mathrm{kg}$ FFM.h, L- $\left[\right.$ ring $\left.^{2}{ }^{2} \mathrm{H}_{2}\right]-\mathrm{TYR}: \mathrm{PD}$ $=0.95 \mu \mathrm{mol} \cdot \mathrm{kg}$ FFM, IR $=0.77 \mu \mathrm{mol} \cdot \mathrm{kg}$ FFM $\cdot \mathrm{h}, \mathrm{L}-\left[{ }^{2} \mathrm{H}_{3}\right]-3 \mathrm{MH}: \mathrm{PD}=0.09 \mu \mathrm{mol} \cdot \mathrm{kg}$ FFM, IR $=0.03 \mu \mathrm{mol} \cdot \mathrm{kg}$ FFM.h. Moreover, a bolus dose of L-[ring- $\left.{ }^{2} \mathrm{H}_{4}\right]-\mathrm{TYR}$ was also given to prime the phenylalanine-derived plasma tyrosine pool $(P D=0.31$ $\mu \mathrm{mol} \cdot \mathrm{kg}$ FFM). The tracers were obtained from Cambridge Isotopic Laboratories (Woburn, MA, USA). After a baseline venous blood sample was collected, the PD was administrated intravenously. Subsequently, constant continuous tracer infusion was started until the end of the test day. A second catheter for arterialized venous blood sampling was placed in a superficial dorsal vein of the hand of the contralateral arm, which was placed in a thermostatically controlled hot box (internal temperature: $60^{\circ} \mathrm{C}$ ), $\geq 20$ min before the first blood sampling. The use of the hot box is a technique to mimic direct arterial sampling ${ }^{18}$. Three arterialized venous blood samples were taken between 80 and $90 \mathrm{~min}$ after the start of the infusion to measure enrichments [the ratio of tracer to tracee (TTR)] of the stable isotopes at plasma steady state level.

Biochemical analyses. Venous and arterialized venous blood samples were collected in a heparinized tube that was immediately put on ice and centrifuged 
(3120 $\mathrm{x} \mathrm{g}$ at $4^{\circ} \mathrm{C}$ for $10 \mathrm{~min}$ ) to obtain plasma. Subsequently, $250 \mu \mathrm{L}$ plasma was deproteinized with $20 \mathrm{mg}$ sulfosalicylic acid to analyze plasma amino acid concentrations and enrichments. All samples were frozen in liquid nitrogen and stored at $-80^{\circ} \mathrm{C}$ until analysis. Amino acid concentrations were analyzed from venous blood by using HPLC ${ }^{19}$. PHE, TYR, and $3 \mathrm{MH}$ enrichments were analyzed by Liquid Chromatography Mass Spectrometry system (LC-MS, Thermoquest, Veenendaal, The Netherlands) ${ }^{20}$.

Calculations. All metabolic data were determined under steady state conditions. Therefore, the WB rate of appearance (Ra) of PHE represents WB PB. Because $3 \mathrm{MH}$ is released only from MPB, the WB Ra of $3 \mathrm{MH}$ gives an indication of WB MPB. The following calculation were used:

(1) WB Ra $=$ I / TTR

Where I represents the tracer infusion rate in plasma.

Moreover, WB protein synthesis was calculated by subtracting the hydroxylation of PHE to TYR [WB Ra TYR $\times$ (TTR TYR4/TTR PHE5)] from WB PB ${ }^{21}$. WB net balance was calculated by subtracting WB protein synthesis from WB PB.

WB FFM was measured in each subject using bioelectrical impedance analyses to express metabolic data per kg FFM. The FFM of the COPD patients was calculated by using each patient's specific regression equation ${ }^{22}$, whereas the FFM of the healthy control subjects was calculated by using a specific regression equation described by Dey et al ${ }^{23}$. Body weight and height were measured to the nearest $0.1 \mathrm{~kg}$ and $0.1 \mathrm{~cm}$ respectively, while the subjects were standing and wearing light indoor clothing but no shoes.

\section{STATISTICAL ANALYSES}

Results are expressed as mean \pm SEM. The mean values of the data obtained from the 3 arterialized venous blood samples were used as WB protein turnover and MPB the postabsorptive state. All data were tested for normality with a normal probability plot. The one-way analysis of variance test with the post-hoc Scheffé 
test was used to test whether there were significant differences in general characteristics, lung function, amino acid concentration and protein turnover. To increase the size of the noncachectic group, which will increase the statistical power for comparison, the noncachectic COPD patients and the control group were taken together (= control + noncachectic COPD group, $n=14$ ) to ascertain the effect of a change in body composition on protein metabolism by using the Scheffé test. The bivariate Pearson correlation coefficient was measured to test data for correlations. All $P$-values $<0.05$ were considered statistically significant. SPSS for Windows (Version 11.0; SPSS Inc., Chicago, II, USA) was used for data analysis.

Table 1: General characteristics of study participants

\begin{tabular}{|c|c|c|c|c|c|c|c|c|c|}
\hline \multirow[b]{3}{*}{ Age (y) } & & & & \multicolumn{6}{|c|}{ COPD group } \\
\hline & \multicolumn{3}{|c|}{$\begin{array}{l}\text { Control group } \\
\qquad(n=7)\end{array}$} & \multicolumn{3}{|c|}{$\begin{array}{c}\text { Noncachectic } \\
(n=7)\end{array}$} & \multicolumn{3}{|c|}{$\begin{array}{c}\text { Cachectic } \\
(\mathrm{n}=9)\end{array}$} \\
\hline & 65 & \pm & 2 & 64 & \pm & 4 & 70 & \pm & 3 \\
\hline Weight (kg) & 86 & \pm & 6 & 82 & \pm & 3 & 59 & \pm & $3^{2,3}$ \\
\hline BMI $\left(\mathrm{kg} / \mathrm{m}^{2}\right)$ & 28 & \pm & 1 & 28 & \pm & 1 & 20 & \pm & $1^{2,3}$ \\
\hline FFM (kg) & 63 & \pm & 3 & 56 & \pm & 2 & 45 & \pm & $1^{2,4}$ \\
\hline FFMI $\left(\mathrm{kg} / \mathrm{m}^{2}\right)$ & 21 & \pm & 1 & 19 & \pm & 1 & 16 & \pm & $0^{2,4}$ \\
\hline $\mathrm{FM}(\mathrm{kg})$ & 25 & \pm & 3 & 26 & \pm & 3 & 14 & \pm & $2^{2,4}$ \\
\hline FMI $\left(\mathrm{kg} / \mathrm{m}^{2}\right)$ & 8 & \pm & 1 & 9 & \pm & 1 & 5 & \pm & $1^{4,5}$ \\
\hline \multicolumn{10}{|c|}{ Lung function ( $\%$ of predicted) } \\
\hline FEV1 & 102 & \pm & 4 & 53 & \pm & $5^{4}$ & 48 & \pm & $4^{4}$ \\
\hline FVC & 109 & \pm & 4 & 101 & \pm & 6 & 109 & \pm & 6 \\
\hline ITGV & 104 & \pm & 9 & 131 & \pm & 10 & 167 & \pm & $7^{2,4}$ \\
\hline RV & 111 & \pm & 8 & 124 & \pm & 10 & 170 & \pm & $9^{2,3}$ \\
\hline Dlco & 113 & \pm & 6 & 62 & \pm & $7^{2}$ & 59 & \pm & $4^{2}$ \\
\hline TLC & 104 & \pm & 5 & 105 & \pm & 6 & 123 & \pm & $5^{4,5}$ \\
\hline
\end{tabular}

All values are means \pm SEM. COPD, chronic obstructive pulmonary disease; FFM, fat free mass; FFMI, fat-free mass index; FM, fat mass; FMI: FM index; FEV ${ }_{1}$, forced expiratory volume in 1 second; FVC, forced vital capacity; ITGV, intrathoracic gas volume; RV, residual volume; Dlco, diffusing capacity for carbon monoxide; TLC, total lung capacity. Definition of the symbols: Significantly different from control group (one-way ANOVA and post hoc Scheffé test): ${ }^{2} P<0.01,{ }^{5} P<0.05$; Significantly different from noncachectic group (one-way ANOVA and post hoc Scheffé test): ${ }^{3} P<0.01,{ }^{4} P<0.05$.

\section{Results}

\section{GENERAL CHARACTERISTICS}

General characteristics of the subjects are shown in table 1. There were no significant differences in FFM, FFM index (FFMI: FFM/ height ${ }^{2}$ ), fat mass (FM) or 
fat mass index (FMI: FM/ height ${ }^{2}$ ) between the noncachectic COPD group and the BMI-matched healthy control group. Cachectic COPD patients had lower values for FFM and FFMI, FM (all $P<0.01)$ and FMI $(P<0.05)$ than did the noncachectic COPD group. All COPD patients were characterized by lower values for FEV1 and diffusion capacity for monoxide $(P<0.01)$. The cachectic COPD group had higher values for residual volume $(P<0.05)$ than did the control group. Moreover, the cachectic COPD group had significantly higher intrathoracic gas volume and residual volume (both: $P<0.01)$ and total lung capacity $(P<0.05)$ than did the noncachectic COPD group, which indicates mild hyperinflation at rest.

Table 2: Whole-body total protein turnover in the control group and chronic obstructive pulmonary disease (COPD) groups

\begin{tabular}{|c|c|c|c|c|c|c|c|c|c|}
\hline & \multirow{2}{*}{\multicolumn{3}{|c|}{$\begin{array}{l}\text { Control group } \\
\qquad(n=7)\end{array}$}} & \multicolumn{6}{|c|}{ COPD group } \\
\hline & & & & \multicolumn{3}{|c|}{$\begin{array}{c}\text { Noncachectic } \\
(\mathrm{n}=7)\end{array}$} & \multicolumn{3}{|c|}{$\begin{array}{c}\text { Cachectic } \\
(\mathrm{n}=9)\end{array}$} \\
\hline & \multicolumn{3}{|c|}{$\begin{array}{c}\mathrm{nmol} \cdot \mathrm{kg} \\
\mathrm{FFM}^{-1} \cdot \mathrm{min}^{-1}\end{array}$} & \multicolumn{3}{|c|}{$\begin{array}{c}\mathrm{nmol} \cdot \mathrm{kg} \\
\mathrm{FFM}^{-1} \cdot \mathrm{min}^{-1}\end{array}$} & \multicolumn{3}{|c|}{$\begin{array}{c}\mathrm{nmol} \cdot \mathrm{kg} \\
\mathrm{FFM}^{-1} \cdot \mathrm{min}^{-1}\end{array}$} \\
\hline WB PB & 839 & \pm & 45 & 769 & \pm & 47 & 774 & \pm & 28 \\
\hline WB PS & 772 & \pm & 54 & 697 & \pm & 46 & 708 & \pm & 26 \\
\hline WB NB & -63 & \pm & 7 & -59 & \pm & 12 & -62 & \pm & 5 \\
\hline
\end{tabular}

All values are means \pm SEM. WB PB, whole-body protein breakdown; WB PS, whole-body protein synthesis; WB NB: whole-body net balance. There were no significant differences in protein turnover between the groups (one-way ANOVA with the post hoc Scheffé test).

WHOLE-BODY TOTAL PROTEIN TURNOVER AND MYOFIBRILLAR PROTEIN BREAKDOWN

Data on WB PB, synthesis, and net balance, shown in table 2, did not differ significantly between the 3 groups. MPB (figure 1) was significantly higher in the cachectic COPD group than in the control group $(P<0.05)$. There was one outlier for MPB in the noncachectic COPD group (BMI: 32, WB MPB: $24 \mathrm{nmol} \cdot \mathrm{kg}$ FFM.min). When the combined control and noncachectic COPD groups $(n=14)$ were compared with the cachectic COPD group, WB MPB was significantly higher in the latter $(P<0.05)$. Moreover, WB MPB tended to significantly correlate with FFM ( $r=-0.38, P=0.07$; figure 2). 


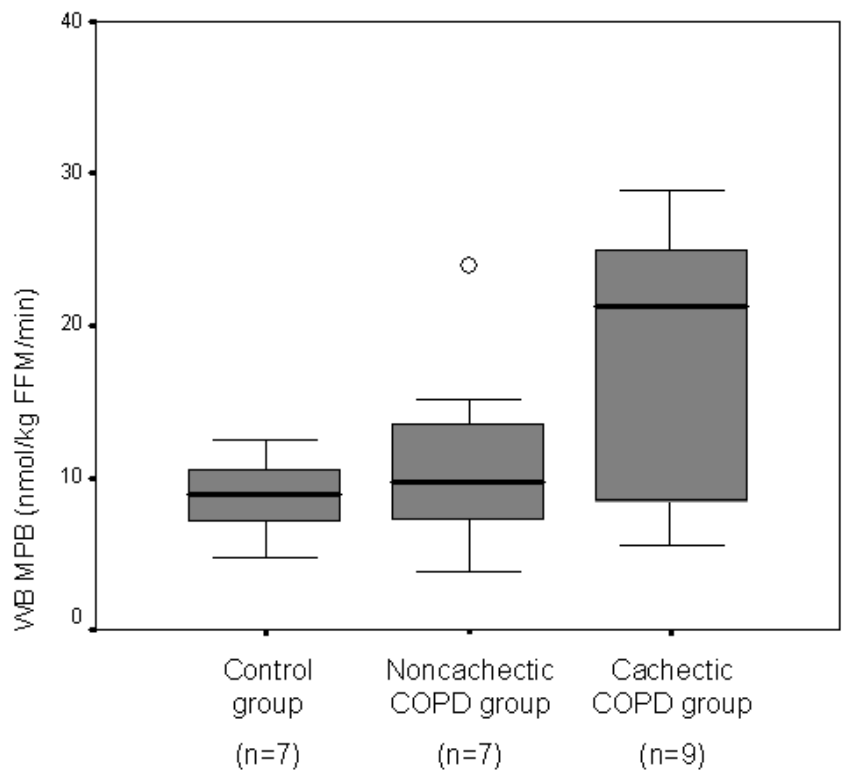

Figure 1: Box-whisker plot of whole-body myofibrillar protein breakdown (wb MPB) between the healthy control, non-cachectic chronic obstructive pulmonary disease (COPD), and cachectic COPD groups. Values indicate minimum, $25^{\text {th }}$ percentile, mean, $75^{\text {th }}$ percentile, maximum, outlier $(0)$. MPB differed significantly between the control group and the cachectic COPD group and between the combined control and noncachectic COPD groups and the cachectic COPD group, $P<0.05$ for both (one-way ANOVA and post-hoc Scheffé test). FFM, fat-free mass.

\section{PLASMA AMINO ACID CONCENTRATIONS}

Plasma concentrations of glutamate were significantly $(P<0.05)$ lower in the cachectic COPD group than in the control group or the noncachectic COPD group (table 3). Plasma tyrosine, isoleucine and BCAA concentrations were significantly lower in the cachectic group than in the noncachectic COPD group $(P<0.05)$. 


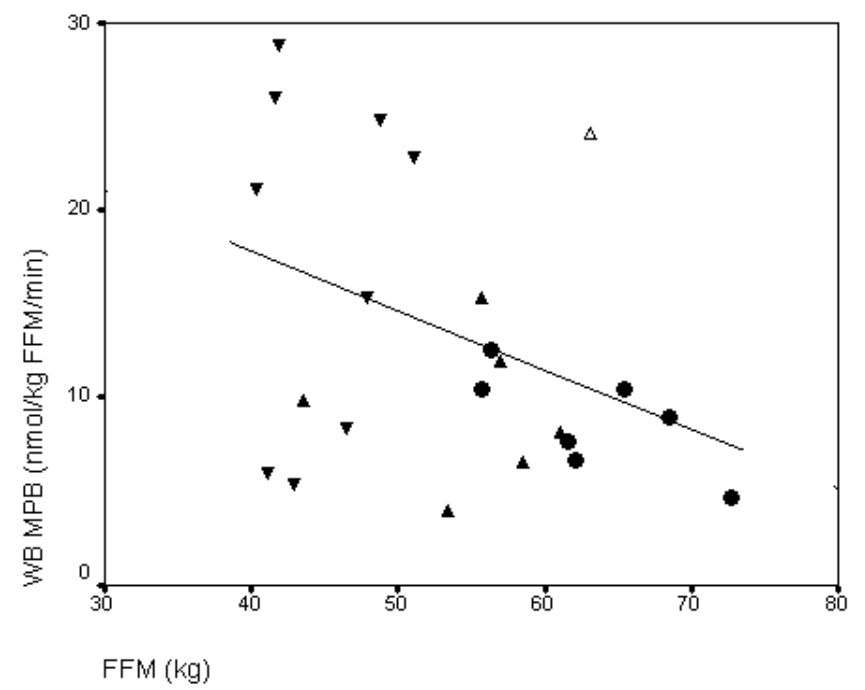

Figure 2: Scatter plot of whole-body myofibrillar protein breakdown (WB MPB) and fat-free mass (FFM) in the healthy control $(\bullet, n=7)$, noncachectic chronic obstructive pulmonary disease $(\boldsymbol{\Delta}, n=7$ with one outlier: $\triangle$ ), and cachectic chronic obstructive pulmonary disease $(\boldsymbol{\nabla}, \mathrm{n}=9)$ groups. Bivariate Pearson's correlation coefficient was measured: $r=-0.38, P=0.07$.

When the cachectic COPD group was compared with the combined control and noncachectic COPD groups, we found that plasma tyrosine and glutamate (both: $P$ $<0.01)$, leucine, isoleucine, valine and the sum of BCAAs $(P<0.05)$ were significantly lower in the former group. Plasma glutamate concentrations were significantly correlated with BMI, FFM and FFMI [BMI: $r=0.67, P<0.01$; FFM: $r=$ $0.70, P<0.01$, (figure 3); FFMI: $r=0.59, P<0.01$ ] but not with FMI. Plasma BCAA concentrations were significantly correlated with FFM and FFMI [FFM: $r=0.55, P<$ 0.01, (figure 3), FFMI: $r=0.52, P<0.01$ ] 
Table 3: Plasma amino acid concentrations in the control group, the noncachectic chronic obstructive pulmonary disease (COPD) group, and the cachectic COPD group

\begin{tabular}{|c|c|c|c|c|c|c|c|c|c|}
\hline \multirow[b]{3}{*}{ Phenylalanine } & & & & \multicolumn{6}{|c|}{ COPD group } \\
\hline & \multicolumn{3}{|c|}{$\begin{array}{c}\text { Control group } \\
(n=7)\end{array}$} & \multicolumn{3}{|c|}{$\begin{array}{c}\text { Noncachectic } \\
(\mathrm{n}=7)\end{array}$} & \multicolumn{3}{|c|}{$\begin{array}{c}\text { Cachectic } \\
(n=9)\end{array}$} \\
\hline & 62 & \pm & 1 & 64 & \pm & 2 & 60 & \pm & 2 \\
\hline Tyrosine & 68 & \pm & 3 & 71 & \pm & 4 & 58 & \pm & $2^{2,3}$ \\
\hline Glutamate & 84 & \pm & 10 & 84 & \pm & 4 & 52 & \pm & $6^{2-4}$ \\
\hline Leucine & 130 & \pm & 7 & 82 & \pm & 5 & 65 & \pm & $1^{5}$ \\
\hline Isoleucine & 74 & \pm & 4 & 82 & \pm & 5 & 65 & \pm & $1^{2,5}$ \\
\hline Valine & 229 & \pm & 13 & 228 & \pm & 11 & 201 & \pm & $3^{5}$ \\
\hline BCAA & 412 & \pm & 24 & 439 & \pm & 19 & 380 & \pm & $4^{2,5}$ \\
\hline
\end{tabular}

All values are means \pm SEM. BCAA, branched-chain amino acids (the sum of leucine, isoleucine and valine). Definition of the symbols: ${ }^{2}$ Significantly different from the noncachectic COPD group, $P<0.05$ (one-way ANOVA and post hoc Scheffé test); Significantly different from both noncachectic COPD groups (one-way ANOVA and post hoc Scheffé test): ${ }^{3} P<0.01,{ }^{5} P<0.05 ;{ }^{4}$ Significantly different the control group, $P<0.05$ (one-way ANOVA and post hoc Scheffé test).

\section{Discussion}

The current study showed that WB MPB is higher in clinically stable cachectic patients with moderate COPD than in noncachectic patients and control subjects. However, no difference in WB total protein turnover was found between the two groups.

\section{WHOLE-BODY MYOFIBRILLAR PROTEIN BREAKDOWN}

The greatest storage of protein in the body occurs in skeletal muscle. However, WB measurements of protein metabolism do not always reflect skeletal muscle protein metabolism ${ }^{24}$. 


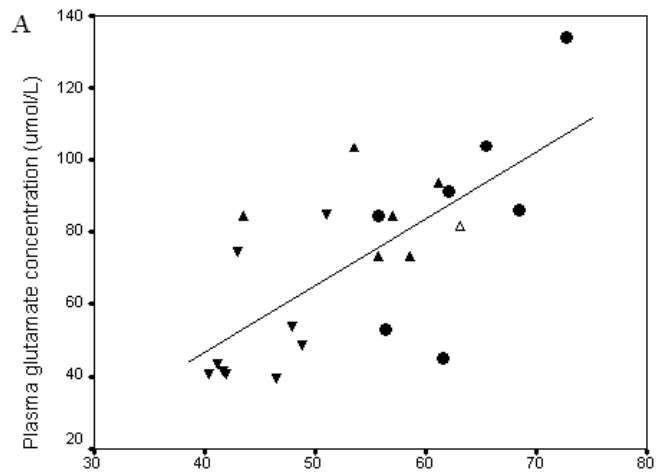

FFM (kg)

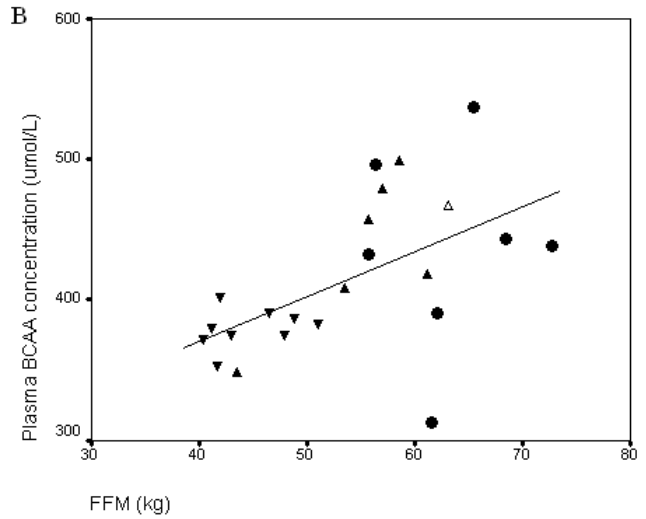

Figure 3: Scatter plots of plasma glutamate (A) and branched-chain amino acids (BCAA, B) concentrations and fat-free mass (FFM) in the healthy control $(\bullet, n=7)$, noncachectic chronic obstructive pulmonary disease $(\boldsymbol{\Delta}, \mathrm{n}=7$ with one outlier: $\triangle$ ), cachectic chronic obstructive pulmonary disease $(\boldsymbol{\nabla}, \mathrm{n}=9)$ groups. Pearson's correlation coefficient was 0.70 for plasma glutamate and 0.55 for BCAAs (both: $P<0.01$ ).

$3 \mathrm{MH}$ is present solely in myofibrillar protein, and the proteolysis of myofibrils releases $3 \mathrm{MH}$ in plasma that cannot be reused. Therefore, measurement of the TTR of $3 \mathrm{MH}$ in plasma can be used as a valid method of measuring MPB. Because $\approx 90 \%$ of the total body pool of $3 \mathrm{MH}$ is present in skeletal muscle ${ }^{25}$, MPB gives an indication for skeletal muscle PB.

The finding of the current study that WB MPB did not differ significantly between noncachectic COPD patients and healthy control subjects is consistent with data from a previous study, in which the measurement of urinary concentrations of $3 \mathrm{MH}$ was used as a noninvasive method of measuring MPB ${ }^{26}$. However, when both methods of measuring MPB are compared, several practical disadvantages to the collection of urinary $3 \mathrm{MH}$ concentrations should be described. First, the amount of $3 \mathrm{MH}$ in the urine is dependent on the amount of meat intake of the subjects. Thus, it is necessary for subjects to follow a meat-restricted diet for $3 d$ before the measurement. Second, because the urine has to be collected for 24 $\mathrm{h}$, the effect of acute stressors on MPB such as feeding or exercise cannot be measured. Both items are covered by measuring MPB by using the tracer technique.

The most striking observation of the current study was that cachexia, characterized by low BMI, FFM and FM, was associated with increased WB MPB 
in COPD patients. MPB in the cachectic COPD patients $(n=9)$ was significantly higher than that in the combined control and noncachectic COPD groups $(n=14)$ and tended to be higher than that in the noncachectic COPD patients if the outlier was excluded $(P=0.06)$. This outlier had a $\mathrm{BMI}$ of 32 , which indicates an obese person. Whether the high MPB was related to the high BMI requires further investigation. The lack of significance between the noncachectic and cachectic COPD groups could also be due to the small study population. The degree of airflow limitation did not differ significantly between the noncachectic and the cachectic COPD patients. Until now, no available study has compared MPB in cachectic and noncachectic patients.

The increased MPB was accompanied with low concentrations of glutamate and BCAA in plasma and both plasma glutamate and BCAA concentrations were highly correlated to FFM and FFMI. In addition, lower plasma glutamate concentrations were found in FFM-depleted COPD patients than in control subjects 11, 27. Moreover, lower BCAA concentrations were shown in underweight COPD patients than in normal-weight COPD patients and control subjects ${ }^{28}$. In that study, the lower BCAA concentrations were associated with enhanced resting energy expenditure. BCAA and glutamate are amino acids whose transamination products can be further oxidized in the skeletal muscle or the liver. The results of the current study and of the study by Yoneda et al ${ }^{28}$ suggest that the transamination of glutamate and BCAA from plasma and from MPB increases in skeletal muscle during wasting.

The higher MPB in cachectic COPD patients is in line with the hypothesis of increased skeletal muscle PB in the muscle-wasting syndrome. The underlying mechanism of muscle proteolysis is thus an important target for therapeutic intervention to prevent or reverse this process. The ubiquitine-proteasome pathway is assumed to provide most of the proteolytic activity required for the degradation of myofibrillar protein ${ }^{29}$. Recently, activation of nuclear factor-kappa B (NF-kB) in skeletal muscle was shown to result in muscle atrophy through increased muscle protein degradation via the ubiquitine-proteasome pathway ${ }^{30}$. Recently, Agusti et al ${ }^{31}$ showed increased NF-KB activation in underweight COPD patients. Tumor necrosis factor- $\alpha$ (TNF- $\alpha$ ) activates NF-KB transcription ${ }^{32}$, and high systemic 
concentrations of TNF- $\alpha$ or the soluble TNF receptors have been consistently shown in COPD patients ${ }^{10}$ and were associated with systemic hypoxia ${ }^{33}$.

This is the first study to measure WB MPB in humans. WB myofibrillar protein synthesis, however, was not measured. Consequently, no conclusions can yet be drawn about net myofibrillar protein balance in cachexia and potential additional disturbances in skeletal muscle anabolism.

\section{WHOLE-BODY TOTAL PROTEIN TURNOVER}

WB protein turnover did not differ significantly between the control group and COPD groups. This is in contrast with the findings of Engelen et al ${ }^{21}$, who showed a higher WB PB and synthesis in normal-weight COPD patients than in healthy control subjects. Two factors may explain this discrepancy between the studies: first, in the study by Engelen et al, patients had more severe disease than did the patients in the current study (FEV1: $37 \pm 12 \%$ and $50 \pm 3 \%$ of predicted, respectively). Second, patients in the current study did not take their maintenance medication on the evening before and on the morning of the test day, whereas the patients in the study by Engelen et al continued their medication. In the past, an effect of the use of inhalation medication on glucose metabolism was shown ${ }^{16}$, and therefore, in the current study, the intake of the medication was stopped. No information is yet available on the acute effect of the withdrawal of medication on substrate metabolism, and, theoretically, an acute effect on protein metabolism cannot be excluded.

As mentioned earlier, Broekhuizen et $\mathrm{al}^{10}$, in a recent large epidemiological study, found significantly higher urinary pseudouridine concentrations in COPD patients than in healthy control subjects. That study also found significantly higher urinary pseudouridine concentrations in cachectic COPD patients or healthy control subjects. Urinary pseudouridine is a stable metabolite of RNA and consequently is used as a marker for cellular PB. As did those in the study by Engelen et al ${ }^{21}$, patients in the study by Broekhuizen et al continued taking their habitual medication; the same differences in WB PB were detected between COPD patients and control subjects in both studies. Caution in the comparison of these studies is necessary, however, because the measurement of urinary pseudouridine as a 
marker for PB has not yet been compared with isotopic protein turnover measurements.

In the current study, WB MPB was not reflected by WB PB. It is likely that a significant proportion of nonmyofibrillar protein degradation, possibly protein in the intestine or the liver, overwhelms the myofibrillar protein degradation. Assuming that muscle contributes to $\approx 25 \%$ of the WB protein turnover in human ${ }^{24}$, an increase in MPB of $\approx 50 \%$, results in an increase of WB PB of $\approx 12 \%$, a difference that may be too low to detect.

In summary, cachectic COPD patients with moderate disease are characterized by higher WB MPB and lower plasma concentrations of glutamate and BCAAs than are those in the combined control and noncachectic COPD groups. Future studies are needed to relate MPB to proteolytic and regulatory markers in skeletal muscle biopsies so as to further unravel the pathogenesis of MPB in COPD and to identify relevant targets for nutritional and pharmacological modulation.

\section{References}

1. Schols AMWJ, Soeters PB, Dingemans AMC, et al. Prevalence and characteristics of nutritional depletion in patients with stable COPD eligible for pulmonary rehabilitation. Am.Rev.Respir.Dis. 1993; 147:1151-1156.

2. Engelen MPKJ, Schols AMWJ, Lamers RJS, Wouters EFM. Different patterns of chronic tissue wasting among patients with chronic obstructive pulmonary disease. Clin. Nutr. 1999; 18:275-280.

3. Baarends EM, Schols AM, Mostert R, Wouters EF. Peak exercise response in relation to tissue depletion in patients with chronic obstructive pulmonary disease. Eur Respir J 1997; 10(12):280713.

4. Gosker HR, Lencer NH, Franssen FM, et al. Striking similarities in systemic factors contributing to decreased exercise capacity in patients with severe chronic heart failure or COPD. Chest 2003; 123(5):1416-24.

5. Engelen MPKJ, Schols AMWJ, Does JD, Wouters EFM. Skeletal muscle weakness is associated with wasting of extremity fat-free mass but not with airflow obstruction in patients with chronic obstructive pulmonary disease. Am.J.Clin.Nutr. 2000; 71:733-738.

6. Mostert R, Goris A, Weling-Scheepers C, et al. Tissue depletion and health related quality of life in patients with chronic obstructive pulmonary disease. Respir Med 2000; 94(9):859-67.

7. Schols AM, Broekhuizen R, Weling-Scheepers CA, Wouters EF. Body composition and mortality in chronic obstructive pulmonary disease. Am J Clin Nutr 2005; 82(1):53-9.

8. Tracey KJ. Lethal weight loss: the focus shifts to signal transduction. Sci STKE 2002; 2002(130):PE21.

9. Morrison WL, Gibson JNA, Scrimgeour C, Rennie MJ. Muscle wasting in emphysema. Clin.Sci. 1988; 75:415-420. 
10. Broekhuizen R, Grimble RF, Howell WM, et al. Pulmonary cachexia, systemic inflammatory profile, and the interleukin 1 bbeta\} -511 single nucleotide polymorphism. Am J Clin Nutr 2005; 82(5):1059-64.

11. Hofford JM, Milakofsky L, Vogel WH, et al. The nutritional status in advanced emphysema associated with chronic bronchitis. A study of amino acid and catecholamine levels. Am.Rev.Respir.Dis. 1990; 141:902-908.

12. Schols AMWJ, Deutz NEP, Mostert R, Wouters EFM. Plasma amino acid levels in patients with chronic obstructive pulmonary disease. Monaldi Arch. Chest Med. 1993; 48:546-548.

13. Vissers YL, von Meyenfeldt MF, Braulio VB, et al. Measuring whole-body actin/myosin protein breakdown in mice using a primed constant stable isotope-infusion protocol. Clin Sci (Lond) 2003; 104(6):585-90.

14. Gross NJ. The GOLD standard for chronic obstructive pulmonary disease. Am J Respir Crit Care Med 2001; 163(5):1047-8.

15. Picado C, Deulofeu R, Lleonart R, et al. Lipid and protein metabolism in asthma. Effects of diet and corticosteroid therapy. Allergy 1999; 54(6):569-75.

16. Guhan AR, Cooper S, Oborne J, et al. Systemic effects of formoterol and salmeterol: a doseresponse comparison in healthy subjects. Thorax 2000; 55(8):650-6.

17. Clausen JL, Coates AL, Quanjer PH. Measurement of lung volumes in humans: review and recommendations from an ATS/ERS workshop. Eur Respir J 1997; 10(6):1205-6.

18. Abumrad NN, Rabin D, Diamond MP, Lacy WW. Use of a heated superficial hand vein as an alternative site for the measurement of amino acid concentrations and for the study of glucose and alanine kinetics in man. Metabolism 1981; 30(9):936-40.

19. Van Eijk HMH, Rooyakkers DR, Deutz NEP. Rapid routine determination of amino acids in plasma by high-performance liquid chromatography with a 2-3 um Sperisorb ODS 2 column. J.Chromat. 1993; 620:143-148.

20. Van Eijk HM, Rooyakkers DR, Soeters PB, Deutz NE. Determination of amino acid isotope enrichment using liquid chromatography-mass spectrometry. Anal Biochem 1999; 271(1):8-17.

21. Engelen MPKJ, Deutz NEP, Wouters EFM, Schols AMWJ. Enhanced levels of whole body protein turnover in patients with chronic obstructive pulmonary disease. Am.J.Respir.Crit. Care Med. 2000; 162(4Pt1):1488-92.

22. Steiner MC, Barton RL, Singh SJ, Morgan MD. Bedside methods versus dual energy X-ray absorptiometry for body composition measurement in COPD. Eur Respir J 2002; 19(4):626-31.

23. Kyle UG, Bosaeus I, De Lorenzo AD, et al. Bioelectrical impedance analysis--part I: review of principles and methods. Clin Nutr 2004; 23(5):1226-43.

24. Deutz NE, Wagenmakers AJ, Soeters PB. Discrepancy between muscle and whole body protein turnover. Curr Opin Clin Nutr Metab Care 1999; 2(1):29-32.

25. Ballard FJ, Tomas FM. 3-Methylhistidine as a measure of skeletal muscle protein breakdown in human subjects: the case for its continued use. Clin Sci (Lond) 1983; 65(3):209-15.

26. Wei IW, McFadden ER, Jr., Hoppel CL. Effect of theophylline on urinary excretion of 3methylhistidine in patients with lung disease. Metabolism 1991; 40(7):702-6.

27. Pouw EM, Schols AMWJ, Deutz NEP, Wouters EFM. Plasma and muscle amino-acid levels in relation to resting energy expenditure and inflammation in stable COPD. Am.J.Respir.Crit.Care Med. 1998; 158:797-801.

28. Yoneda T, Yoshikawa M, Fu A, et al. Plasma levels of amino acids and hypermetabolism in patients with chronic obstructive pulmonary disease. Nutrition 2001; 17(2):95-9.

29. Hasselgren PO, Fischer JE. Muscle cachexia: current concepts of intracellular mechanisms and molecular regulation. Ann Surg 2001; 233(1):9-17.

30. Glass DJ. Skeletal muscle hypertrophy and atrophy signaling pathways. Int J Biochem Cell Biol 2005; 37(10):1974-84.

31. Agusti A, Morla M, Sauleda J, et al. NF-kappaB activation and iNOS upregulation in skeletal muscle of patients with COPD and low body weight. Thorax 2004; 59(6):483-7. 
32. Langen RC, Schols AM, Kelders MC, et al. Inflammatory cytokines inhibit myogenic differentiation through activation of nuclear factor-kappaB. Faseb J 2001; 15(7):1169-80.

33. Takabatake $\mathrm{N}$, Nakamura $\mathrm{H}$, Abe $\mathrm{S}$, et al. The relationship between chronic hypoxemia and activation of the tumor necrosis factor-alpha system in patients with chronic obstructive pulmonary disease. Am J Respir Crit Care Med 2000; 161(4 Pt 1):1179-84. 


\title{
Chapter 3
}

\section{Altered interorgan response to feeding in patients with chronic obstructive pulmonary disease}

\author{
Mariëlle P.K.J. Engelen, Erica P.A. Rutten, Carmen L.N. De Castro, \\ Emiel F.M. Wouters, Annemie M.W.J. Schols and Nicolaas E.P. Deutz
}

Am J Clin Nutr $2005 ; 82: 366-72$

\section{Abstract}

Background: Previously, we reported increased values for whole-body protein turnover in patients with chronic obstructive pulmonary disease (COPD) in the postabsorptive state.

Objective: The objective was to investigate whether intake of a carbohydrate-protein meal influences whole-body protein turnover differently in COPD patients and control subjects.

Design: Eight normal-weight patients with moderate COPD and 8 healthy control subjects were examined in the postabsorptive state and after $2 \mathrm{~h}$ of repeatedly ingesting a maltodextrin casein-based protein meal $\left(0.02 \mathrm{~g} \cdot \mathrm{kg}\right.$ body $\left.\mathrm{wt}^{-1} \cdot 20 \mathrm{~min}^{-1}\right)$. Combined simultaneous, continuous, intravenous infusion of $\mathrm{L}$-[ring- ${ }^{2} \mathrm{H}_{5}$ ]-phenylalanine and $\mathrm{L}$-[ring- $\left.{ }^{2} \mathrm{H}_{2}\right]$-tyrosine tracer and oral repeated ingestion of $1-{ }^{13} \mathrm{C}$ phenylalanine were performed to measure whole-body protein synthesis (WbPS) and first-pass splanchnic extraction of phenylalanine. Endogenous rate of appearance of phenylalanine as the measure of whole-body protein breakdown (WbPB) and netWbPS was calculated as WbPS - WbPB. Arterialized venous blood was sampled for amino acid enrichment and concentration analyses.

Results: Feeding induced an increase in WbPS and a reduction in WbPB. The reduction in WbPB was larger in the COPD group than in the control group $(P<0.05)$ and was related to the lower splanchnic extraction of phenylalanine in the patients. Consequently, netWbPS increased more after feeding in the COPD group than in the control group $(P<0.05)$.

Conclusion: Feeding induces more protein anabolism in normal-weight patients with moderate COPD than in healthy control subjects. This is probably because these COPD patients are characterized by an adaptive interorgan response to feeding to prevent or delay weight loss at this disease stage.

Key Words: Chronic obstructive pulmonary disease • protein feeding • first-pass splanchnic extraction • whole-body protein turnover $\bullet$ endogenous protein metabolism 


\section{Introduction}

Muscle wasting commonly occurs in patients with chronic obstructive pulmonary disease (COPD), but different patterns of tissue depletion are observed. A substantial part of the COPD population is characterized by a normal weight with a shift in body composition toward reduced fat-free mass (FFM) despite a relative or absolute increase of fat mass ${ }^{1,2}$. In this group, functional capacity (ie, exercise capacity, muscle strength) and health status ${ }^{3}$ are even more impaired than in the underweight patients with COPD with a relative preservation of FFM. This bodycomposition pattern is also seen with aging and could therefore be described as (accelerated) sarcopenia that could be reflected in altered whole-body substrate metabolism. Indeed, we showed a reduced B-adrenoceptor-mediated lipolysis rate ${ }^{4}$ and significantly higher amounts of whole-body protein turnover [protein synthesis (WbPS) and protein breakdown (WbPB) rates] in patients with COPD than in healthy, age-matched control subjects after overnight fasting ${ }^{5}$. These data indicate that changes in intermediary metabolism are present in normal-weight patients with COPD that may trigger or reflect sarcopenia.

Although altered whole-body substrate turnover was observed in the postabsorptive state, no studies have yet examined the acute effect of feeding on substrate metabolism in COPD. Feeding is important because the fed state represents $>50 \%$ of the 24-h metabolic activity and corresponds to the reconstitution of the protein lost during fasting. In COPD, the efficiency of maintaining body proteins may be declined as a result of a selective loss in the ability of skeletal muscle to efficiently use exogenous amino acids for protein anabolism. However, it is also possible that the splanchnic area is the compartment that is mainly contributing to the previously observed increased whole-body protein turnover in $\operatorname{COPD}^{5,6}$. The splanchnic tissues could limit the flow and the availability of alimentary amino acids to the peripheral tissues by influencing the absorption of the alimentary amino acids. In previous studies it has been shown that the firstpass splanchnic uptake of the amino acids leucine ${ }^{7}$ and phenylalanine ${ }^{8}$ increases with age. This means that if the splanchnic tissues use more amino acids, fewer amino acids will be available for the other (peripheral) tissues. Until now it was 
unknown whether chronic disease such as COPD further aggravated the agerelated disturbances found in splanchnic extraction of amino acids, thereby negatively influencing the metabolic response to feeding in these patients.

Therefore, the purpose of the present study was to examine the response of whole-body protein turnover and splanchnic amino acid extraction to a given dose of a maltodextrin protein meal in patients with COPD. Milk-based protein (casein) was used because of its high nutritional value (protein quality) and because casein is the protein mostly used (and to the highest degree) in nutritional supplements.

\section{Subjects and methods}

\section{SUBJECTS}

A group of 8 male patients with moderate airflow obstruction and 8 healthy male volunteers were studied. The patients had COPD according to American Thoracic Society guidelines ${ }^{9}$ and chronic airflow limitation, defined as measured forced expiratory volume in $1 \mathrm{~s}\left(\mathrm{FEV}_{1}\right)<70 \%$ of reference $\mathrm{FEV}_{1}$. Furthermore, the patients had irreversible obstructive airway disease $\left(<10 \%\right.$ improvement of $\mathrm{FEV}_{1}$ predicted baseline after inhalation of $B_{2}$-agonist) and were in clinically stable condition and had not experienced respiratory tract infection or exacerbation of their disease at least 4 wk before the study. The patients with COPD were outpatients, attending the hospital for routine pulmonary control every 6 or 12 mo. Exclusion criteria were malignancy, cardiac failure, recent surgery, and severe endocrine, hepatic, or renal disorder. Also, subjects who were using systemic corticosteroids within 3 mo before the beginning of the study were excluded. The number of present smokers in the COPD and control groups was 2 . The number of former smokers in the COPD and control groups was 5 (average number of years stopped was 10.2) and 2 (average number of years stopped was 12.5), respectively. Body mass index (BMl; in $\mathrm{kg} / \mathrm{m}^{2}$ ) was not significantly different between the groups (control group: $25.4 \pm 0.9$; COPD group: $27.2 \pm 0.8$ ). The maintenance treatment of the studied patients consisted of inhaled $B_{2}$ agonists, inhaled anticholinergics, inhaled corticosteroids, oral theophylline, or a combination. Written informed consent was obtained from all subjects, and the study was approved by the medical ethics committee of the University Hospital Maastricht. 


\section{PULMONARY FUNCTION TESTS}

All patients and healthy volunteers underwent spirometry to determine $\mathrm{FEV}_{1}$, and the highest value from at least 3 technically acceptable assessments was used. Diffusing capacity of the lung for carbon monoxide was measured by using the single-breath method (Masterlab; Jaeger, Wurzburg, Germany). All values obtained were related to a reference value and expressed as percentages of the predicted value $^{10}$.

\section{STUDY PROTOCOL}

The protocol started at $07.15 \mathrm{~h}$ after an overnight fast from at least $00.00 \mathrm{~h}$. All subjects were in the supine position for $3 \mathrm{~h}$. After insertion of a catheter into the right antecubital vein, the first blood sample was taken for baseline measurements. Immediately thereafter, a primed-constant intravenous infusion of stable isotopes (80 $\mathrm{mL} / \mathrm{h}$ ) was started with the use of a calibrated pump (IVAC Corporation, San Diego, CA). Primed and constant infusion of the stable isotopes L-[ring- $\left.{ }^{2} \mathrm{H}_{5}\right]$ phenylalanine $\left({ }^{2} \mathrm{H}_{5}\right.$-Phe; prime: $2.19 \mu \mathrm{mol} / \mathrm{kg}$ body wt; infusion: $0.053 \mu \mathrm{mol} \cdot \mathrm{kg}$ $\left.\mathrm{FFM}^{-1} \cdot \mathrm{min}^{-1}\right)$ and L-[ring- ${ }^{2} \mathrm{H}_{2}$ ]-tyrosine $\left({ }^{2} \mathrm{H}_{2}-\mathrm{Tyr}\right.$; prime: $0.95 \mu \mathrm{mol} / \mathrm{kg}$ body wt; infusion: $0.018 \mu \mathrm{mol} \cdot \mathrm{kg} \mathrm{FFM}{ }^{-1} \cdot \mathrm{h}^{-1}$ ) were given through the catheter in the antecubital vein. Primed infusion of L-[ring- $\left.{ }^{2} \mathrm{H}_{4}\right]-\mathrm{Tyr}\left({ }^{2} \mathrm{H}_{4}-\mathrm{Tyr} ; 0.31 \mu \mathrm{mol} / \mathrm{kg}\right.$ body wt) was given in addition through the same catheter. $1-{ }^{13} \mathrm{C}$-Phe was given orally in the postabsorptive state and together with the liquid meal every $20 \mathrm{~min}$ (prime: 0.88 $\mu \mathrm{mol} / \mathrm{kg}$ body wt; infusion: $0.055 \mu \mathrm{mol} \cdot \mathrm{kg} \mathrm{FFM}^{-1} \cdot \mathrm{min}^{-1}$ ). Stable isotopes were purchased from Cambridge Isotopic Laboratories (Woburn, MA).

For sampling arterialized venous blood, a venous catheter was placed in a dorsal vein of the left hand, using the heated box technique ${ }^{11}$, a technique to mimic direct arterial sampling. After $1.5 \mathrm{~h}$ of stable isotope infusion to reach steady state enrichments, enteral nutrition was started by sip feeding every 20 min, for a total duration of $2 \mathrm{~h}$. The test meal involved a liquid casein-based protein meal and was given in an amount of $0.018 \mathrm{~g} \cdot \mathrm{kg}$ body $\mathrm{wt}^{-1} \cdot 20 \mathrm{~min}^{-1}$. Total fluid intake was 0.67 $\mathrm{mL} \cdot \mathrm{kg}$ body $\mathrm{wt}^{-1} \cdot 20 \mathrm{~min}^{-1}$ by enteral nutrition. Arterialized venous blood samples were taken at $80,85,90,200,205$, and 210 min into infusion. Body composition was measured with the use of Bioelectrical Impedance Spectroscopy (BIS Xitron 
4000B; Xitron Technologies, San Diego, CA) to express protein metabolism data per kilogram of FFM. FFM of the patients with COPD was calculated by using a patient's specific regression equation as described by Steiner et $\mathrm{al}^{12}$, whereas FFM of the healthy control subjects was calculated by using a specific equation for elderly men as described by Lukaski et al ${ }^{13}$.

\section{ENTERAL PROTEIN MEALS}

To avoid metabolic changes as a result of recent modifications of the diet, the subjects were instructed to eat their usual diet at least $3 \mathrm{~d}$ before the study. The dietary protein intake of the study subjects was ascertained retrospectively during 5 $\mathrm{d}$ by using the dietary history method (COPD group: $0.95 \pm 0.10 \mathrm{~g}$ protein $\cdot \mathrm{kg}$ body $\mathrm{wt}^{-1} \cdot \mathrm{d}^{-1}$; control group: $0.96 \pm 0.07 \mathrm{~g}$ protein $\cdot \mathrm{kg}$ body $\mathrm{wt}^{-1} \cdot \mathrm{d}^{-1}$ ).

The test meal on the experimental day contained $29.5 \mathrm{~g}$ sodium caseinate (casein protein meal: $4.0 \mathrm{~g} \mathrm{~N}$ ) and $68.5 \mathrm{~g}$ maltodextrin dissolved in ultrapure water to $1000 \mathrm{~mL}$ fluid at $60{ }^{\circ} \mathrm{C}$. In total, $\sim 301 \mathrm{~mL}$ enteral nutrition and $8.1 \mathrm{~g}$ protein (based on a 75-kg subject) was supplied during the study. The protein composition of the casein protein meal was a 1:1:1 mixture of commercially available French, Dutch, and Danish sodium caseinates. All meals were prepared at least $1 \mathrm{~h}$ before the start of the experiment. To ensure a complete dissolution of the proteins and to prevent bacterial growth, the meals were kept at $4^{\circ} \mathrm{C}$ until use.

\section{SAMPLE PROCESSING}

\section{Analysis of arterialized venous blood}

Promptly after sampling, blood was distributed in prechilled, heparinized tubes (Becton Dickinson Vacutainer System, Franklin Lakes, NJ) and kept on ice to minimize enzymatic reactions. All analyses were performed in plasma, obtained by centrifugation of whole blood at $4^{\circ} \mathrm{C}$ for $10 \mathrm{~min}$ at $3120 \times \mathrm{g}$. For amino acid analysis, $250 \mu \mathrm{L}$ plasma was deproteinized by mixing it with $20 \mathrm{mg}$ dry sulfosalicylic acid. For analysis of urea, glucose, lactate, and ammonia, $900 \mu \mathrm{L}$ plasma was deproteinized by mixing with $90 \mu \mathrm{L}$ of a $500 \mathrm{~g} / \mathrm{L}$ trichloroacetic acid solution. All samples were stored at $-80^{\circ} \mathrm{C}$ until further analysis. 


\section{Biochemical analysis}

The enrichments (tracer-to-tracee ratios) of the amino acids phenylalanine and tyrosine in arterialized venous plasma were analyzed by a liquid chromatographymass spectrometry system (Thermoquest LCQ, Veenendaal, The Netherlands) ${ }^{14}$. Plasma concentrations of amino acids were determined with the use of a fully automated HPLC (Pharmacia, Woerden, The Netherlands), after precolumn derivatization with o-phthaldialdehyde ${ }^{15}$.

Plasma glucose, lactate, urea, and ammonia were analyzed spectrophotometrically on a COBAS Mira S (Roche Diagnostica, Hoffmann-La Roche, Basel, Switzerland) by standard enzymatic methods ${ }^{16}$. Plasma insulin was analyzed with a commercially available electrochemiluminescence immunoassay (Hitachi Modular Analyzer; Roche, Mannheim, Germany).

\section{Calculations}

The sum of amino acids (SUM AA) represents the sum of measurable a-amino acids (glutamine, glycine, threonine, histidine, citrulline, alanine, taurine, arginine, a -amino butyric acid, tyrosine, valine, methionine, isoleucine, phenylalanine, tryptophan, leucine, ornithine, and lysine). All the metabolic data were determined under steady state conditions. Tracer:tracee of phenylalanine reached an isotopic steady state within $1.5 \mathrm{~h}$ of infusion and within $2 \mathrm{~h}$ of feeding (data not shown) in both groups.

In the postabsorptive and prandial state, WbPS is calculated as follows ${ }^{5}$ :

(1) WbPS = whole-body Rd of Phe - hydroxylation of Phe to Tyr

Whole-body rate of disappearance $(\mathrm{Rd})$ of phenylalanine is equal to whole body rate of appearance $(\mathrm{Ra})$ of phenylalanine under steady state. Whole-body $\mathrm{Ra}$ of phenylalanine $\left(\mathrm{Ra}_{2 \mathrm{H} 5-\mathrm{Phe}}\right)$ is the infusion rate/tracer:tracee of phenylalanine in plasma.

Splanchnic extraction $\left(\mathrm{SPE}_{\mathrm{Phe}}\right.$ ) represents the fraction (in \%) of ingested phenylalanine, taken up by the gut and liver during its first pass, and is calculated as follows ${ }^{8,17}$ : 
(2) $\mathrm{SPE}_{\text {Phe }}=\left[1-\left(\mathrm{Ra}_{2 \mathrm{H} 5-\mathrm{Phe}} / \mathrm{Ra}_{13 \mathrm{C}-\mathrm{Phe}}\right]{ }^{*} 100 \%\right.$

$\mathrm{Ra}_{2 \mathrm{H} 5-\text {-Phe }}$ and $R \mathrm{R}_{13 \mathrm{C}-\text {-Phe }}$ represent whole-body $\mathrm{Ra}$ of phenylalanine calculated from intravenous ${ }^{2} \mathrm{H}_{5}$-Phe and intragastric ${ }^{13} \mathrm{C}$-Phe isotopes, respectively.

Whole-body $\mathrm{Ra}$ of phenylalanine, not coming from phenylalanine in protein given by the diet [endogenous phenylalanine $\left(R a_{\text {end-Phe }}\right)$ ], is calculated as in equations (3) and (4).

(3) Corrected Phe intake $=$ dietary Phe intake * $\left[1-\left(\mathrm{SPE}_{\mathrm{Phe}}{ }^{*} 0.01\right)\right]$

(4) $R a_{\text {end-Phe }}=R a_{2 H 5-P h e}-$ corrected dietary Phe intake

(5) $\mathrm{WbPS}=R \mathrm{a}_{\text {end-Phe }}$

(6) net $\mathrm{WbPS}=\mathrm{WbPS}-\mathrm{WbPB}$

Summary model used for the calculation of SPE of phenylalanine and protein kinetics is presented in figure 1. Phenylalanine clearance is the amount of plasma that is completely cleared from tracee in $1 \mathrm{~min}$ and is calculated as follows ${ }^{18}$ :

(7) $\mathrm{Rd}$ ( $\mathrm{Ra}$ in steady state) / plasma concentration of the tracee

\section{STATISTICAL ANALYSIS}

Results are expressed as means \pm SEs. The mean value of the measures of protein kinetics and the concentrations of amino acids at the time points 80,85 , and $90 \mathrm{~min}$ was used as the postabsorptive state and at 200, 205, and $210 \mathrm{~min}$ as the fed state. The unpaired Student's $t$ test was used to determine differences in general characteristics between the control and COPD groups and to test whether the changes in status (postabsorptive and prandial) in protein kinetics and amino acid concentrations were significantly different from zero. If the normality or equal variance test failed, data were log-transformed where appropriate. Furthermore, the two-factor analysis of variance (ANOVA; general linear model, SPSS version 12; SPSS Inc, Chicago, IL) was performed with a group (control and COPD) and status (postabsorptive and prandial) effect. The level of significance was set at $P<0.05$, and $P$ values are given for the group effect, status effect, and the group-by-status 
interaction. When an overall significance for group-by-status interaction was observed, unpaired Student's $t$ test was performed.

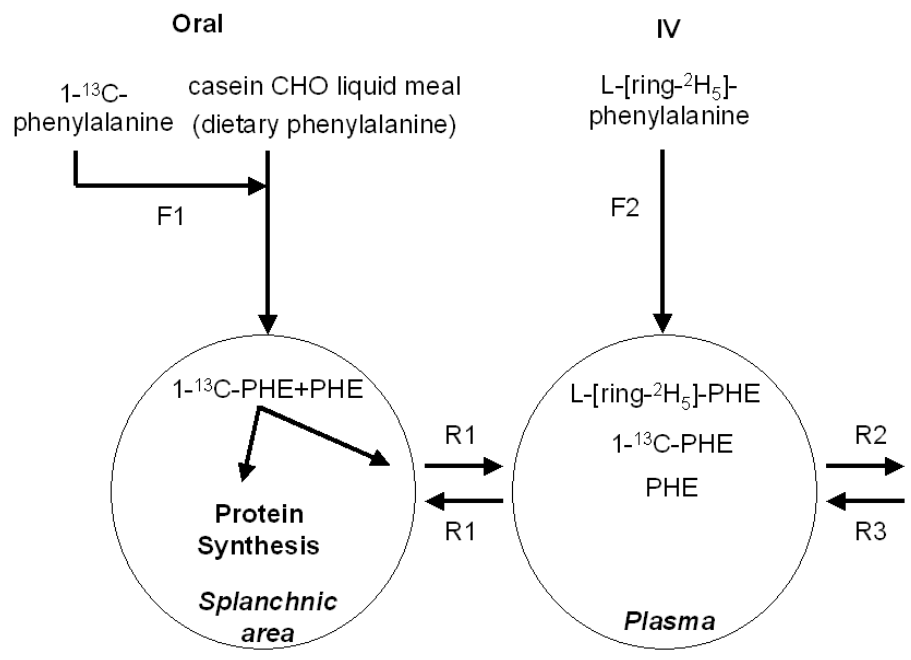

Figure 1: Model used for the calculation of the splanchnic extraction of phenylalanine and protein kinetics. L-[ring- ${ }^{2} \mathrm{H}_{5}$ ]-Phe was infused at a constant and continuous rate by vein (F2). $1{ }^{13} \mathrm{C}$-Phe was orally administered every $20 \mathrm{~min}(\mathrm{~F} 1)$ together with the liquid meal. Splanchnic extraction (SPE $\mathrm{Phe}_{\mathrm{e}}$ represents the fraction (in \%) of ingested phenylalanine taken up by the gut and liver during its first pass and is calculated as $\left[1-\left(R_{2 H 5-P h e} / R a_{13 C-P h e}\right)\right] \times 100 \%$, where $R a$ is the rate of appearance. $R 1$, phenylalanine exchange between splanchnic and plasma amino acid pool; R2 and R3, phenylalanine exchange between the nonsplanchnic tissues and the plasma pool; $\mathrm{CHO}$, carbohydrate; IV, intravenous.

\section{Results}

Eight male patients with COPD and 8 male healthy volunteers participated in the study (table 1). Age, height, body weight, and BMI did not differ significantly between the groups, but a tendency toward a lower FFM index (NS) and higher fat mass index (NS) was found in the COPD group. In the control group, all lung function values were within the normal range. The patients with COPD were characterized by moderate airflow obstruction and a mildly reduced diffusing capacity for carbon dioxide. C-reactive protein concentrations tended $(P=0.095)$ to 
be higher in the COPD group than in the control group, probably because of the large range of $\mathrm{C}$-reactive protein values $(0.5-32 \mathrm{mg} / \mathrm{L})$ in the COPD group.

Table 1: Characteristics of the study population

\begin{tabular}{lrrrrrl}
\hline & \multicolumn{3}{c}{$\begin{array}{c}\text { Control group } \\
(\mathrm{n}=8)\end{array}$} & \multicolumn{3}{c}{ COPD group } \\
$(\mathrm{n}=8)$ & \\
\hline Age $(\mathrm{y})$ & 63.1 & \pm & 3.0 & 68.1 & \pm & 3.5 \\
Height $(\mathrm{m})$ & 1.74 & \pm & 0.02 & 1.74 & \pm & 0.03 \\
Weight $(\mathrm{kg})$ & 77.5 & \pm & 3.7 & 81.8 & \pm & 3.5 \\
BMI $\left(\mathrm{kg} / \mathrm{m}^{2}\right)$ & 25.4 & \pm & 0.9 & 27.2 & \pm & 0.8 \\
FFMI $\left(\mathrm{kg} / \mathrm{m}^{2}\right)$ & 19.4 & \pm & 0.9 & 17.7 & \pm & $0.4^{2}$ \\
FMl $\left(\mathrm{kg} / \mathrm{m}^{2}\right)$ & 6.1 & \pm & 1.4 & 9.5 & \pm & $0.8^{3}$ \\
FEV1 $(\%$ predicted $)$ & 110 & \pm & 5 & 50 & \pm & $4^{4}$ \\
Dlco $(\%$ predicted $)$ & 104 & \pm & 9 & 78 & \pm & $7^{4}$ \\
CRP $(\mathrm{mg} / \mathrm{L})$ & 1.7 & \pm & 0.4 & 8.7 & \pm & $3.9^{5}$ \\
\hline
\end{tabular}

All values are mean \pm SEM. Symbols represent differences between the groups: ${ }^{2} P=0.08,{ }^{3} P=0.07$, ${ }^{4} P<0.05,{ }^{5} P<0.01$. Used abbreviations: FFMI $=$ fat-free mass index $\left(\right.$ FFM/height $\left.{ }^{2}\right) ; \mathrm{FMl}=$ fat mass index $\left(\mathrm{FM} /\right.$ height $\left.^{2}\right)$; FEV1 = forced expiratory volume in $1 \mathrm{~s}$; Dlco = diffusing capacity of the lung for carbon monoxide; $\mathrm{CRP}=\mathrm{C}$-reactive protein.

Plasma concentrations of glucose, lactate, urea, and ammonia (table 2) were not different in the postabsorptive state between the patients with COPD and the healthy control subjects. No group effect and no significant group-by-status interaction were observed for these variables. A status effect was observed for insulin and glucose $(P<0.001)$, indicating that feeding resulted in increased glucose and insulin concentrations. The concentration of urea and ammonia did not significantly change after feeding, although there was a tendency toward a reduction ( $P=0.057$ and $P=0.056$, respectively).

No significant group-by-status interaction was observed for any of the variables for protein metabolism except for netWbPS (table 3). There was a significant group as well as a status effect for SPE and WbPS. SPE was significantly lower in the COPD group than in the control group $(P<0.001)$, whereas WbPS was higher in the COPD group $(P<0.05)$. Moreover, feeding resulted in a decrease in SPE $(P<0.05)$ and an increase in WbPS $(P<0.05)$. The feeding-induced increase in WbPS ( $\triangle \mathrm{WbPS}$ ) was not different between the COPD and the control groups. WbPB $\left(\mathrm{Ra}_{\text {end-Phe }} ; P<0.01\right)$ was lower after feeding. The feeding-induced reduction in WbPB $(\triangle \mathrm{WbPB})$ was significantly larger $(P<0.05)$ in the COPD group than in the control group. As a consequence, feeding resulted in a 
significant increase in netWbPS $(P<0.001)$. The increase in netWbPS ( $\triangle$ netWbPS) was higher in the COPD group than in the control group $(P<0.05)$, resulting in higher absolute values for netWbPS in the prandial state in the COPD group than in the control group $(P<0.05)$.

Table 2: Plasma concentrations in arterialized blood in the postabsorptive state and during feeding

\begin{tabular}{|c|c|c|c|c|c|c|c|c|c|c|c|c|}
\hline \multirow[b]{3}{*}{ Glucose (mmol/L) } & \multicolumn{6}{|c|}{ Control group } & \multicolumn{6}{|c|}{ COPD group } \\
\hline & \multicolumn{3}{|c|}{ Postabsorptive } & \multicolumn{3}{|c|}{ Prandial } & \multicolumn{3}{|c|}{ Postabsorptive } & \multicolumn{3}{|c|}{ Prandial } \\
\hline & 5.4 & \pm & 0.1 & 6.3 & \pm & 0.1 & 5.7 & \pm & 0.1 & 6.8 & \pm & 0.4 \\
\hline Lactate (mmol/L) & 1.1 & \pm & 0.1 & 1.1 & \pm & 0.1 & 1.3 & \pm & 0.1 & 1.3 & \pm & 0.1 \\
\hline Urea (mmol/L) & 5.2 & \pm & 0.4 & 4.6 & \pm & 0.3 & 5.0 & \pm & 0.3 & 4.3 & \pm & 0.3 \\
\hline Ammonia $(\mu \mathrm{mol} / \mathrm{L})$ & 88 & \pm & 3 & 78 & \pm & 7 & 79 & \pm & 3 & 69 & \pm & 6 \\
\hline Insulin (mU/L) & 8.4 & \pm & 1.2 & 21.5 & \pm & 3.4 & 13.2 & \pm & 2.2 & 27.2 & \pm & 4.8 \\
\hline
\end{tabular}

All values are mean \pm SEM. Data show postabsorptive values and values $2 \mathrm{~h}$ after the start of feeding. Two-factor ANOVA showed a significant status effect for glucose and insulin $(P<0.001)$. There was no significant group effect and no significant group-by status interaction.

Phenylalanine concentration and phenylalanine clearance were not different between the COPD and control groups in the postabsorptive state. No significant group-by-status interaction was observed for both variables. There was a status effect for phenylalanine concentration $(P<0.001)$, indicating that feeding resulted in an increase in phenylalanine concentration. The increase in phenylalanine concentration after feeding ( $\triangle$ Phe conc) was higher in the control group than in the COPD group $(P<0.05)$. These findings were also present for SUM AA (data not shown). There was a status effect $(P<0.001)$, and, in addition, there was a tendency toward a difference in $\triangle$ SUM AA between the COPD and control groups $(P=0.085)$. A group effect was observed for phenylalanine clearance $(P<0.01)$, indicating that phenylalanine clearance was lower in the COPD group than in the control group. 
Table 3: Measures of protein metabolism in the postabsorptive state and during feeding

\begin{tabular}{|c|c|c|c|c|c|c|c|c|c|c|c|c|}
\hline \multirow{3}{*}{$\begin{array}{l}\text { WbPS } \\
\text { (nmol/kg FFM/min) }\end{array}$} & \multicolumn{6}{|c|}{ Control group } & \multicolumn{6}{|c|}{ COPD group } \\
\hline & \multicolumn{3}{|c|}{ Postabsorptive } & \multicolumn{3}{|c|}{ Prandial } & \multicolumn{3}{|c|}{ Postabsorptive } & \multicolumn{3}{|c|}{ Prandial } \\
\hline & 727 & \pm & 68 & 826 & \pm & 64 & 805 & \pm & 49 & 948 & \pm & 43 \\
\hline SPE (\%) & 58 & \pm & 7 & 45 & \pm & 4 & 35 & \pm & 7 & 28 & \pm & 3 \\
\hline $\begin{array}{l}\text { WbPB } \\
\text { (nmol/kg FFM/min) }\end{array}$ & 803 & \pm & 62 & 695 & \pm & 50 & 892 & \pm & 49 & 712 & \pm & 50 \\
\hline $\begin{array}{l}\text { NetWbPS } \\
\text { (nmol/kg FFM/min) }\end{array}$ & -82 & \pm & 11 & 156 & \pm & 22 & -87 & \pm & 7 & 226 & \pm & $16^{2}$ \\
\hline Phe conc & 67 & \pm & 3 & 85 & \pm & 2 & 67 & \pm & 3 & 79 & \pm & 3 \\
\hline Phe clear & 8.4 & \pm & 0.7 & 9.5 & \pm & 0.5 & 7.3 & \pm & 0.3 & 7.7 & \pm & 0.3 \\
\hline
\end{tabular}

All values are mean \pm SEM. Two-factor ANOVA showed a significant group affect for WbPS and NetWbPS $(P<0.05)$, Pheclear $(P<0.01)$, and SPE $(P<0.001)$. There was a significant status effect for WbPS and SPE $(P<0.05)$, WbPB $(P<0.01)$, NetWbPS, and Phe conc $(P<0.001)$. There was a significant group-by-status interaction for NetWbPS $(P<0.05) .{ }^{2}$ Significantly different from the control group in the prandial state, $P<0.05$ (unpaired Student's $t$ test). Used abbreviations: WbPS $=$ wholebody protein synthesis; SPE = relative splanchnic extraction of phenylalanine; $\mathrm{WbPB}=$ whole-body protein breakdown; Phe conc $=$ phenylalanine concentration; Phe clear $=$ phenylalanine clearance.

\section{Discussion}

The ability to obtain homeostatic regulation of protein metabolic processes during the day is important to preserve muscle mass and to function long term. Insight into the protein metabolic response to feeding is of importance in COPD because lowintensity exercise has been shown to induce an increased amino acid release from muscle ${ }^{19}$. This finding suggests that physical activity in daily life may induce protein catabolism in COPD. To maintain protein balance on a daily basis and to prevent muscle wasting in COPD for the longer term, a positive protein metabolic response to feeding is therefore of crucial importance. In the present study, feeding increased net WbPS to a higher extent in normal-weight patients with moderate COPD than in healthy control subjects, indicating an enhanced anabolic response to feeding in this patient group.

\section{EFFECT OF FEEDING ON WBPS}

Feeding induced an increase in WbPS, which is in line with data obtained in previous studies that showed a positive effect of mixed feeding on protein synthesis ${ }^{20,}{ }^{21}$. In the present study, $0.11 \mathrm{~g}$ protein $/ \mathrm{kg}$ body wt was ingested in $2 \mathrm{~h}$. On the 
basis of the fed state of $16 \mathrm{~h} / \mathrm{d}, 0.87 \mathrm{~g}$ protein $/ \mathrm{kg}$ body wt will be ingested, which is in line with the current recommended dietary allowances in the elderly $(0.8 \mathrm{~g}$ protein $\cdot \mathrm{kg}$ body $\mathrm{wt}^{-1} \cdot \mathrm{d}^{-1}$ ) 22 and slightly lower than the recorded daily dietary protein intake of the study groups. Earlier, it has been shown that to increase peripheral protein synthesis, high amino acid availability is important ${ }^{23,24}$. We observed a status effect for protein synthesis and the concentration of phenylalanine and SUM AA, indicating that feeding increased systemic amino acid availability and protein synthesis. However, despite the lower feeding-induced increase in the phenylalanine concentration in COPD, the increase in protein synthesis was not different between the groups.

\section{FIRST-PASS SPLANCHNIC EXTRACTION OF PHENYLALANINE}

The splanchnic tissues play an important role in the regulation of protein turnover because these tissues are responsible for absorption of the alimentary amino acids and their release to the peripheral tissues. In a study that compared elderly subjects with young healthy subjects, first-pass SPE of dietary leucine was twice as high in the elderly as in the young men ${ }^{7}$. In line, a study by Volpi et al ${ }^{8}$ showed that the SPE of oral phenylalanine was higher in the elderly than in the young. The exact reason for the elevated SPE of amino acids in the elderly is still unknown. However, it is believed that it may contribute to the development of sarcopenia because it reduces amino acid availability to the periphery.

We also measured SPE of phenylalanine after $2 \mathrm{~h}$ of feeding in the patients with COPD and the healthy control subjects using free $1-{ }^{13} \mathrm{C}$-Phe given orally and together with the liquid meal. Because the meal as well as the oral tracers was administered in the same continuous feeding protocol, no differences in absorption kinetics between phenylalanine in the meal and the oral $1-{ }^{13} \mathrm{C}$-Phe are expected. The data of Volpi et al ${ }^{8}$ on SPE of phenylalanine in the healthy elderly are a bit higher than ours $(47 \pm 3 \%$ compared with $35 \pm 7 \%)$. However, the meal composition used in the 2 studies was different (oral amino acid mixture compared with maltodextrin protein meal). Interestingly, there was a group effect for SPE of phenylalanine. SPE was lower in the patients with COPD than in the control group, indicating that there is lower phenylalanine extraction by the gut, liver, or both during feeding in the patients, which could lead to a higher peripheral availability of 
dietary phenylalanine. Therefore, it was expected that the lower SPE in COPD would induce a higher prandial phenylalanine concentration in these patients. In the present study, a feeding effect for phenylalanine concentration but no group effect was observed. Remarkably, the increase in phenylalanine concentration after feeding was lower in the COPD group than in the control group. As systemic phenylalanine concentration is mainly the result of the capacity of phenylalanine utilization for protein synthesis and hydroxylation, this finding suggests that, besides an increased phenylalanine release in the circulation, there is an increased phenylalanine removal from the circulation in COPD. In contrast, phenylalanine clearance was lower in the COPD group than in the control group and was not affected by feeding. We do not have a good explanation for this observation.

The lower SPE of phenylalanine in the COPD group was associated with a larger reduction of endogenous $\mathrm{Ra}$ of phenylalanine after feeding. Endogenous $\mathrm{Ra}$ of phenylalanine allows an accurate estimation of $\mathrm{WbPB}$, because dietary phenylalanine sequestered by splanchnic tissues during the first pass cannot reach the metabolic pool where ${ }^{2} \mathrm{H}_{5}$-Phe is infused. The data suggest that the lower SPE in COPD positively influences their anabolic response to a given meal, and that the metabolic efficiency of feeding is therefore larger in the COPD group than in the control subjects.

\section{POSSIBLE FACTORS INDUCING A LOWER FIRST-PASS SPLANCHNIC EXTRACTION} IN COPD

At present, we can only speculate about possible mechanisms of the reduced SPE in COPD. Besides an adaptation to increased needs in the body elsewhere as mentioned previously, it is also possible that the reduced SPE in COPD is reflecting a reduced splanchnic protein turnover rate rather than a reduced splanchnic amino acid net utilization. However, the possibility that the splanchnic (liver + gut) protein turnover is reduced in COPD is remarkable when considering that this patient group is generally characterized by a low-grade systemic inflammatory state ${ }^{25}$. In line, C-reactive protein concentrations tended to be higher in the studied patients with COPD than in the control subjects. However, because inflammation is associated with an increased hepatic protein synthesis ${ }^{26}$, one should expect an elevated (but not reduced) protein synthesis in the splanchnic liver compartment in 
COPD. Other factors known to influence splanchnic protein turnover are nicotine use and intake of certain drugs. Nicotine can act as a splanchnic circulation constrictor because it has been shown that smoking aggravates liver injury and that intraportal nicotine infusion in rats decreases hepatic blood flow ${ }^{27}$. However, smoking status and history were not different between the COPD and control groups. The studied patients were clinically stable for at least 3 mo before the study, exhibiting normal blood gases and only using inhalation medication. Still, it is important to highlight that this patient group is regularly experiencing an acute exacerbation of the disease, which is characterized by an increased inflammatory state, changes in blood gases, and use of systemic medication (ie, oral corticosteroids and antibiotics). Nonsteroidal anti-inflammatory drugs are known to reduce blood flow in the splanchnic region ${ }^{28}$. Acute changes in the arterial partial pressures of oxygen and carbon dioxide do not reduce splanchnic blood flow ${ }^{29,30}$ but together with an increased inflammatory state may induce changes in insulin sensitivity and thus influence protein metabolism. A positive association has been found between SPE of dietary leucine and $\mathrm{BMI}^{7}$. Currently, no relation was found between SPE of dietary phenylalanine and body weight or composition. However, it is important to notice that only normal-weight patients with COPD were studied without evidence of muscle wasting.

More research is warranted to get insight into the underlying factors responsible for the lower SPE of amino acids in COPD. The gut plays an important role as buffer of amino acids during fasting ${ }^{31}$. The elevated initial release of amino acids into the circulation in COPD may lead to a reduced buffer of amino acids in a later (fasting) phase. Measurement of protein kinetics after $2 \mathrm{~h}$ of feeding is therefore necessary in COPD to examine whether protein balance after this anabolic phase is still positive.

In conclusion, the anabolic response to feeding is higher in weight-stable moderate patients with COPD than in healthy control subjects. This is related to lower first-pass SPE in COPD, resulting in a larger reduction of WbPB after feeding. This study shows that normal-weight patients with COPD are characterized by a pronounced adaptive interorgan response to feeding, apparently sufficient to prevent or delay weight loss in this stage of their disease. More studies 
are needed to investigate whether this adaptive response to feeding is inadequate or absent in weight-losing patients with COPD.

\section{References}

1. Schols AMWJ, Soeters PB, Dingemans AMC, et al. Prevalence and characteristics of nutritional depletion in patients with stable COPD eligible for pulmonary rehabilitation. Am.Rev.Respir.Dis. 1993; 147:1151-1156.

2. Engelen MPKJ, Schols AMWJ, Baken WC, et al. Nutritional depletion in relation to respiratory and peripheral skeletal muscle function in out-patients with COPD. Eur. Respir. J. 1994; 7:1793-1797.

3. Mostert R, Goris A, Weling-Scheepers C, et al. Tissue depletion and health related quality of life in patients with chronic obstructive pulmonary disease. Respir Med 2000; 94(9):859-67.

4. Schiffelers SL, Blaak EE, Baarends EM, et al. beta-Adrenoceptor-mediated thermogenesis and lipolysis in patients with chronic obstructive pulmonary disease. Am J Physiol Endocrinol Metab 2001; 280(2):E357-64.

5. Engelen MPKJ, Deutz NEP, Wouters EFM, Schols AMWJ. Enhanced levels of whole body protein turnover in patients with chronic obstructive pulmonary disease. Am.J.Respir.Crit. Care Med. 2000; 162(4Pt1):1488-92.

6. Deutz NE, Wagenmakers AJ, Soeters PB. Discrepancy between muscle and whole body protein turnover. Curr Opin Clin Nutr Metab Care 1999; 2(1):29-32.

7. Boirie $\mathrm{Y}$, Gachon P, Beaufrere B. Splanchnic and whole-body leucine kinetics in young and elderly men. Am J Clin Nutr 1997; 65(2):489-95.

8. Volpi E, Mittendorfer B, Wolf SE, Wolfe RR. Oral amino acids stimulate muscle protein anabolism in the elderly despite higher first-pass splanchnic extraction. Am J Physiol 1999; 277(3 Pt 1):E513-20.

9. ATS. Standards for the diagnosis and care of patients with chronic obstructive pulmonary disease. Am J Respir Crit Care Med 1995; 152:S77-121.

10. Quanjer P, Tammeling GJ, Cotes JE, et al. Standardized lung function testing. Eur Respir J 1993; 6:5-40.

11. Abumrad NN, Rabin D, Diamond MP, Lacy WW. Use of a heated superficial hand vein as an alternative site for the measurement of amino acid concentrations and for the study of glucose and alanine kinetics in man. Metabolism 1981; 30(9):936-40.

12. Steiner MC, Barton RL, Singh SJ, Morgan MD. Bedside methods versus dual energy X-ray absorptiometry for body composition measurement in COPD. Eur Respir J 2002; 19(4):626-31.

13. Lukaski HC, Bolonchuk WW, Hall CB, Siders WA. Validation of tetrapolar bioelectrical impedance method to assess human body composition. J Appl Physiol 1986; 60(4):1327-32.

14. Van Eijk HM, Rooyakkers DR, Soeters PB, Deutz NE. Determination of amino acid isotope enrichment using liquid chromatography-mass spectrometry. Anal Biochem 1999; 271(1):8-17.

15. Van Eijk HMH, Rooyakkers DR, Deutz NEP. Rapid routine determination of amino acids in plasma by high-performance liquid chromatography with a 2-3 um Sperisorb ODS 2 column. J.Chromat. 1993; 620:143-148.

16. Neeley WE, Phillipson J. Automated enzymatic method for determining ammonia in plasma, with 14- day reagent stability. Clin Chem 1988; 34(9):1868-9.

17. Matthews DE, Marano MA, Campbell RG. Splanchnic bed utilization of leucine and phenylalanine in humans. Am J Physiol 1993; 264(1 Pt 1):E109-18.

18. Wolfe RR. Tracer studies terminology. In Wiley-Liss, ed. Radioactive and stable isotope tracers in biomedicine. Principles and practice of kinetic analysis. New York, 1992. pp. 19-21. 
19. Engelen MP, Wouters EF, Deutz NE, et al. Effects of exercise on amino acid metabolism in patients with chronic obstructive pulmonary disease. Am J Respir Crit Care Med 2001; 163(4):859-64.

20. De Feo P, Volpi E, Lucidi $\mathrm{P}$, et al. Ethanol impairs post-prandial hepatic protein metabolism. J Clin Invest 1995; 95(4):1472-9.

21. Volpi E, Lucidi $P$, Cruciani G, et al. Contribution of amino acids and insulin to protein anabolism during meal absorption. Diabetes 1996; 45(9):1245-52.

22. Food and Nutrition Board. Recommended Dietary Allowances. National Academicy of Science Press. Washington, DC, 1989.

23. Biolo G, Fleming RY, Maggi SP, Wolfe RR. Transmembrane transport and intracellular kinetics of amino acids in human skeletal muscle. Am J Physiol 1995; 268(1 Pt 1):E75-84.

24. Castellino P, Luzi L, Simonson DC, et al. Effect of insulin and plasma amino acid concentrations on leucine metabolism in man. Role of substrate availability on estimates of whole body protein synthesis. J Clin Invest 1987; 80(6):1784-93.

25. Schols AM, Buurman WA, Staal van den Brekel AJ, et al. Evidence for a relation between metabolic derangements and increased levels of inflammatory mediators in a subgroup of patients with chronic obstructive pulmonary disease. Thorax 1996; 51(8):819-24.

26. Bruins MJ, Soeters PB, Deutz NE. Endotoxemia affects organ protein metabolism differently during prolonged feeding in pigs. J Nutr 2000; 130(12):3003-13.

27. Hashimoto $\mathrm{T}$, Yoneda $\mathrm{M}$, Shimada $\mathrm{T}$, et al. Intraportal nicotine infusion in rats decreases hepatic blood flow through endothelin-1 and both endothelin A and endothelin B receptors. Toxicol Appl Pharmacol 2004; 196(1):1-10.

28. Wennmalm A, Carlsson I, Edlund A, et al. Central and peripheral haemodynamic effects of nonsteroidal anti-inflammatory drugs in man. Arch Toxicol Suppl 1984; 7:350-9.

29. Kiefer P, Nunes S, Kosonen P, Takala J. Effect of an acute increase in PCO2 on splanchnic perfusion and metabolism. Intensive Care Med 2001; 27(4):775-8.

30. Rowell LB, Blackmon JR. Human cardiovascular adjustments to acute hypoxaemia. Clin Physiol 1987; 7(5):349-76.

31. Soeters $\mathrm{PB}$, de Jong $\mathrm{CH}$, Deutz NE. The protein sparing function of the gut and the quality of food protein. Clin Nutr 2001; 20(2):97-9. 


\title{
Chapter 4
}

\section{Decreased whole-body and splanchnic glutamate metabolism in healthy elderly men and patients with chronic obstructive pulmonary disease in the postabsorptive state and in response of feeding.}

\author{
Erica P.A. Rutten, Marielle P.K.J. Engelen, Carmen L.N. Castro, \\ Emiel F.M. Wouters, Annemie M.W.J. Schols, Nicolaas E.P. Deutz
}

J Nutr $2005 ; 135: 2166-2170$

\section{Abstract}

Background: Decreased plasma and muscle glutamate concentrations have been observed in patients with chronic obstructive pulmonary disease (COPD), suggesting disturbances in glutamate metabolism.

Objective: The present study was conducted to further examine glutamate metabolism in 8 male COPD patients $(68 \pm 4 \mathrm{y}$ ) by measurement of whole-body (WB) glutamate production and splanchnic glutamate extraction in the postabsorptive state as well as in response to feeding. Because COPD is particularly prevalent in the elderly and aging per se may also affect glutamate metabolism, 2 male control groups were included: 8 healthy elderly $(63 \pm 3 \mathrm{y})$ and 8 young $(22 \pm 1 \mathrm{y})$ subjects.

Design: On 2 test days, the stable isotope L- ${ }^{15} \mathrm{~N}$-glutamate was infused i.v. or enterally according to a primed constant and continuous infusion protocol. After $90 \mathrm{~min}$ of infusion, subjects ingested a carbohydrate-protein drink (28\% milk protein, $72 \%$ maltodextrin) every 20 min for $2 \mathrm{~h}$. Arterializedvenous blood samples were taken at the end of the postabsorptive and feeding periods.

Results: Postabsorptive WB glutamate production and splanchnic glutamate extraction were significantly lower in the elderly and COPD patients than in the young $(P<0.01)$. Feeding further decreased WB endogenous glutamate production in the elderly and COPD patients, with COPD patients tending $(P=0.07)$ to have a greater decrease. Splanchnic glutamate extraction increased during feeding in the elderly $(P<0.05)$ but did not change in COPD patients.

Conclusion: Aging reduces postabsorptive WB endogenous glutamate production and splanchnic glutamate extraction. COPD does not affect postabsorptive WB glutamate metabolism but may influence splanchnic glutamate metabolism during feeding.

Key words: glutamate, aging, chronic obstructive pulmonary disease, postabsorptive and fed states 


\section{Introduction}

Chronic obstructive pulmonary disease (COPD) is increasingly recognized as a chronic metabolic disorder, characterized by weight loss and abnormalities in body composition. Altered plasma and muscle amino acid profiles have been detected in COPD patients compared with healthy controls ${ }^{1,2}$. Specifically, there is evidence for a disturbed glutamate metabolism because decreased skeletal muscle and plasma glutamate $(\mathrm{Glu})$ concentrations are consistently found in clinically stable patients with $\mathrm{COPD}^{3-5}$. Disturbances in glutamate metabolism could be the result of a chronic disease, but could also reflect age-related metabolic adaptations ${ }^{6}$ because COPD is present predominantly in subjects $\geq 50 \mathrm{y}$ old. To gain insight into the underlying mechanisms of the disturbed glutamate metabolism, it is essential to determine whether glutamate production is decreased or its consumption is increased. The present study focused on glutamate production and thus glutamate delivery to the organs via feeding or endogenous glutamate production.

Matthews et al. ${ }^{7}$ showed that nearly all of an ingested glutamate tracer is absorbed by the splanchnic bed on its first pass in the postabsorptive state. However, plasma glutamate concentration increased after ingestion of $12.7 \mathrm{~g}$ monosodium glutamate ${ }^{8}$, but ingestion of a protein meal did not raise plasma glutamate levels. No data are yet available concerning splanchnic glutamate extraction during feeding. Because nutritional protein comprises $\sim 10 \%$ of glutamate, feeding can still be a source of glutamate for the body. Moreover, the study by Matthews et al. ${ }^{7}$ was performed in healthy young volunteers, and there is no information available whether splanchnic glutamate extraction during feeding differs between the elderly and COPD patients. Because postabsorptive first-pass splanchnic glutamate extraction approaches its maximum in healthy young volunteers, we hypothesized that splanchnic glutamate extraction in the elderly and COPD patients, if different from the young, would be lower. Subsequently, a higher amount of glutamate would be released into the plasma, which suggests that glutamate delivery to the body is more dependent on an external (dietary) glutamate source. 
The purposes of the present study were 2-fold: first, to investigate whether whole-body and endogenous glutamate production and splanchnic glutamate extraction are different in COPD patients compared with healthy elderly people in the postabsorptive state and during feeding, and second, to examine whether aging per se influences glutamate metabolism in the postabsorptive state and in response to feeding.

\section{Subjects and methods}

\section{SUBJECTS}

COPD patients, healthy elderly, and healthy young subjects ( $n=8 /$ group), all men, were studied. The healthy elderly were age-matched with the COPD patients. The patients were in clinically stable condition and suffered from moderate COPD (stage $2+3$ ) according to the recently established GOLD guidelines ${ }^{9}$. Exclusion criteria for all groups were malignancy, cardiac failure, recent surgery, and endocrine, hepatic, or renal disorders. Also, subjects who were using systemic corticosteroids within $3 \mathrm{mo}$ before the study were excluded. Written informed consent was obtained from all subjects, and the study was approved by the medical ethical committee of the University Hospital Maastricht.

\section{PULMONARY FUNCTION TESTS}

Before the study, the healthy elderly and COPD patients underwent spirometry for determination of forced expiratory volume in $1 \mathrm{~s}\left(\mathrm{FEV}_{1}\right)$, as a marker of disease severity, with the highest value from at least 3 technically acceptable maneuvers being used. The diffusion capacity for carbon-monoxide $\left(\mathrm{DL}_{\mathrm{co}}\right)$ as an indirect indicator of emphysema was measured using the single-breath method (Masterlab; Jaeger). All values obtained were related to a reference value and expressed as percentages of the predicted value ${ }^{10}$. The COPD patients had lower values of FEV 1 (COPD patients: $50 \pm 4 \%$ pred; elderly: $110 \pm 5 \%$ pred, $P<0.01$ ) and $\mathrm{DL}_{\mathrm{CO}}$ (COPD patients: $78 \pm 7 \%$ pred; elderly: $104 \pm 9 \%$ pred, $P<0.05$ ) compared with the elderly. 


\section{STUDY DESIGN}

On 2 test days and at least $4 \mathrm{~d}$ apart, subjects were invited to the metabolic ward of the University Hospital Maastricht after an overnight fast. All subjects were instructed to continue their habitual dietary intake for at least $3 \mathrm{~d}$ preceding the study. The food intake of the day before each test day was reported in a food questionnaire. From this, daily habitual protein intake was calculated.

Prior to the test, body weight was measured using an electronic beam scale with digital readout to the nearest $0.1 \mathrm{~kg}$ (model 708; Seca) with the subjects standing barefoot and wearing light indoor clothing. Body height was measured to the nearest $0.1 \mathrm{~cm}$ (model 220, Seca). Whole-body fat-free mass (FFM) was measured in each subject using bioelectrical impedance analyses (Xitron 4000B, Xitron Technologies) to express metabolic data per kilogram of FFM. FFM of the COPD patients was calculated using a patient's specific regression equation ${ }^{11}$, whereas FFM of the healthy elderly and young volunteers was calculated using a specific regression equation described by Dey et al. and Lohman et al., respectively 12 .

On the 1st test day, a catheter was placed in an antecubital vein of the arm for infusion of the tracer $(85 \mathrm{~mL} / \mathrm{h})$, according to a primed constant continuous infusion protocol (figure 1). L- ${ }^{15} \mathrm{~N}$-glutamate $\left({ }^{15} \mathrm{~N}\right.$-Glu) was used to measure WB Glu turnover. The following priming dose and infusion rate were used: $0.73 \mu \mathrm{mol} / \mathrm{kg}$ and $0.03 \mu \mathrm{mol} /(\mathrm{kg} \mathrm{FFM} \cdot \mathrm{min}$ ), respectively. The tracer was obtained from Cambridge Isotopic Laboratories. Before i.v. administration of the priming dose, a venous blood sample was collected to measure baseline Glu enrichment. After administration of the priming dose, a constant continuous tracer infusion was administered until the end of the study day. A second catheter for arterialized venous blood sampling was placed in a superficial dorsal vein of the hand of the contralateral arm, which was placed in a thermostatically controlled hot box (internal temperature: $60^{\circ} \mathrm{C}$ ), at least $20 \mathrm{~min}$ before the first blood sampling. The use of the hot box is a technique to mimic direct arterial sampling ${ }^{13}$. Triple arterialized-venous blood samples were taken between 80 and 90 min after the start of the infusion. Subsequently, continuous nutrition was started via repeated ingestion (every $20 \mathrm{~min}$ ) of a carbohydrate-protein drink for $2 \mathrm{~h}$, when a tracer 
steady state was reached ${ }^{14}$. At the end of the ingestion period, triple arterializedvenous blood samples were taken and the test day ended.

The study design of the 2nd test day was similar to the 1st test day, with the exception that ${ }^{15} \mathrm{~N}$-Glu was given enterally instead of i.v. After the priming dose was infused i.v. (priming dose $=0.73 \mu \mathrm{mol} / \mathrm{kg}$ ), the glutamate tracer was ingested ( 25 $\mathrm{mL} / 20 \mathrm{~min}$ ) according to an infusion rate of $0.06 \mu \mathrm{mol} /(\mathrm{kg} \mathrm{FFM} \cdot \mathrm{min}) .{ }^{15} \mathrm{~N}$-Glu was ingested alone (first $90 \mathrm{~min}$ ) or together with the carbohydrate-protein drink (last 2 h).

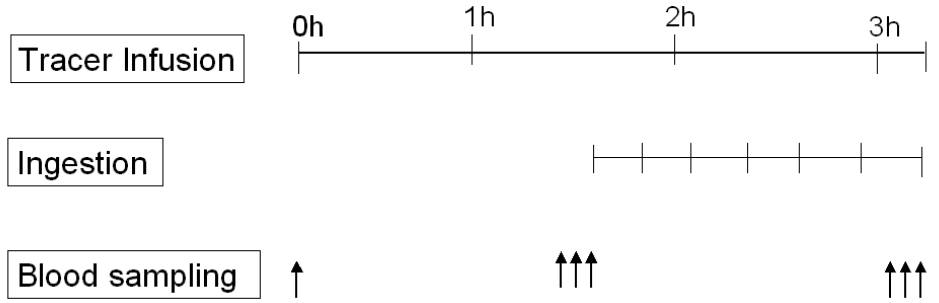

Figure 1: Scheme of the study design. On 2 different test days, glutamate tracer infusion was given i.v. or enterally for $3.5 \mathrm{~h}$. A $0.67-\mathrm{mL}$ carbohydrate-protein drink/kg body weight was ingested every $20 \mathrm{~min}$. Arterialized-venous blood samples were taken between 80 and 90 min after the start of the infusion and between 110 and $120 \mathrm{~min}$ after the start of the ingestion.

\section{COMPOSITION OF THE CARBOHYDRATE-PROTEIN DRINK.}

The drink contained $28 \%$ milk protein ( $80 \%$ protein content, $\sim 10 \%$ glutamate) and $72 \%$ maltodextrin, dissolved in ultrapure water. All intakes consisted of a fluid ingestion of $0.67 \mathrm{~mL} /(\mathrm{kg}$ body weight $\cdot 20 \mathrm{~min}$ ) and contained $18 \mathrm{mg}$ protein $/ \mathrm{kg}$ body weight and $46 \mathrm{mg}$ maltodextrin/ $\mathrm{kg}$ body weight. In total, $\sim 301 \mathrm{~mL}$ enteral nutrition (based on 6 ingestions and a 75-kg subject) was supplied during the study. The complete drink supplied $\sim 8 \mathrm{~g}$ protein and $21 \mathrm{~g}$ maltodextrin, resulting in an ingestion of $\sim 486 \mathrm{~kJ}$ in $2 \mathrm{~h}$. The drink was prepared at $60^{\circ} \mathrm{C}, 1 \mathrm{~h}$ before the start of the experiment and kept at $4^{\circ} \mathrm{C}$ until use to prevent bacterial growth. The absolute glutamate intake during the feeding period was $631 \pm 8,646 \pm 10$, and 768 
$\pm 16 \mathrm{nmol} /(\mathrm{kg} \mathrm{FFM} \cdot \mathrm{min})$ in the young, elderly, and COPD patients, respectively, and did not differ among the groups.

BIOCHEMICAL ANALYSES.

Venous and arterialized venous blood was put in a heparinized tube, immediately put on ice, and centrifuged $\left(4^{\circ} \mathrm{C}, 3120 \times \mathrm{g}\right.$ for $\left.10 \mathrm{~min}\right)$ to obtain plasma. Subsequently, $250 \mu \mathrm{L}$ plasma was deproteinized with $20 \mathrm{mg}$ sulfosalicylic acid. Samples were frozen in liquid nitrogen and stored at $-80^{\circ} \mathrm{C}$ until analysis. Analysis of plasma Glu concentration was performed using a fully automated HPLC (Pharmacia) ${ }^{15}$. Glu enrichment [tracer:tracee ratio (TTR)] was analyzed by LC-MS (Thermoquest) ${ }^{16}$.

\section{CALCULATIONS.}

As described by Darmaun et al. ${ }^{17}$, the rate of glutamate appearance in plasma under steady-state conditions reflects interorgan transport. Therefore, whole-body glutamate metabolism into and out of plasma gives a reflection of whole-body glutamate production in and consumption from plasma, respectively. The following equations were used:

Whole-body glutamate production in the postabsorptive and the fed state:

(1) WB Glu production = WB rate of appearance $\left(R_{a}\right)$ of Glu = infusion rate / TTR in plasma

Splanchnic extraction of Glu $\left(\mathrm{SPE}_{\mathrm{Glu}}\right)$ in the postabsorptive and fed states represents the fraction (\%) of ingested glutamate, taken up by the gut and liver during its first pass ${ }^{18}$ :

(2) $\mathrm{SPE}_{\text {Glu }}=\left[1-\left(\mathrm{Ra}_{\text {(Glu)iv }} / \mathrm{Ra}_{\left(\text {Glu }_{\text {ent }}\right)}\right)\right] \cdot 100$

where $R a_{(\text {Glu)iv }}$ and $R a_{\text {(Glu)ent }}$ are WB Glu production calculated according to equation 1 with either the i.v. or enteral tracer, respectively. 
The WB rate of appearance of endogenous glutamate $\left(R a_{\text {endo-Glu }}\right)$ in the fed state represents the amount of glutamate that is produced in plasma minus the amount of ingested glutamate that reaches plasma (corrected exogenous Glu intake):

(3) $\mathrm{WB} \mathrm{Ra}_{\text {endo-Glu }}=\mathrm{WB} \mathrm{Ra}_{\mathrm{Glu}}$ - corrected exogenous Glu intake

(4) Corrected exogenous Glu intake = dietary Glu intake · [1 - (SPE Glu / 100)]

\section{STATISTICAL ANALYSES.}

Results are expressed as means \pm SEM. To minimize the variance among the triple measurements of glutamate turnover in the postabsorptive and the fed state, values that were $>2$ SD from the median were rejected. The mean values of the remaining data were used as whole-body glutamate turnover in the postabsorptive and fed states. ANOVA with the post-hoc Bonferroni test was used to test whether there were significant differences in general characteristics among the groups. Repeated-measures ANOVA with within variable time (before and after $80 \mathrm{~min}$ ingestion) and between variable group (young, elderly, and COPD group) was performed to test effects for plasma glutamate concentration and whole-body glutamate turnover. If there was a group effect, the post-hoc Bonferroni test was used to compare the 3 groups. When there was a significant group $x$ time effect, Student's paired $t$ test was used to evaluate the effect of the drinks within each group. Differences were considered significant at $P<0.05$. The statistical package SPSS for Windows (Version 11.0; SPSS) was used for data analysis.

\section{Results}

\section{GENERAL CHARACTERISTICS.}

The young group was taller and had lower BMI and fat mass index (FMI) than the elderly and COPD groups [height and BMI (elderly vs. young): $P<0.05$, FMI and BMI (COPD vs. young): $P<0.01$, table 1]. The BMl and FMl were higher in COPD patients compared with the elderly $(P<0.05)$. 
Plasma GLUTAMATE CONCENTRATION.

Baseline plasma glutamate concentration did not differ among the groups (table 2).

Furthermore, in all 3 groups, plasma glutamate concentration did not change during ingestion of the meal.

Table 1: General characteristics of the healthy young and elderly men, and male COPD patients

\begin{tabular}{lrllrllrl}
\hline & \multicolumn{3}{c}{ Young } & \multicolumn{2}{c}{ Elderly } & \multicolumn{2}{c}{ COPD } \\
\hline Age, $\mathrm{y}$ & 22 & \pm & $1^{\mathrm{b}}$ & 63 & \pm & $3^{\mathrm{a}}$ & 68 & $\pm 4^{\mathrm{a}}$ \\
Height, $\mathrm{m}$ & 1.82 & \pm & $0.01^{\mathrm{a}}$ & $1.74^{\mathrm{b}}$ & \pm & 0.02 & 1.74 & $\pm 0.03^{\mathrm{b}}$ \\
Weight, kg & 73.4 & \pm 2.1 & 77.5 & \pm & 3.7 & 81.8 & \pm 3.5 \\
$\mathrm{BMI}, \mathrm{kg} / \mathrm{m}^{2}$ & 22.3 & \pm & $0.7^{\mathrm{c}}$ & $25.4^{\mathrm{b}}$ & \pm & 0.9 & 27.2 & $\pm 0.8^{\mathrm{a}}$ \\
$\mathrm{FFMI}, \mathrm{kg} / \mathrm{m}^{2}$ & 18.4 & \pm & 0.4 & 19.2 & \pm & 0.9 & 18.9 & \pm 0.2 \\
FMI, $\mathrm{kg} / \mathrm{m}^{2}$ & 3.9 & $\pm 0.4^{\mathrm{c}}$ & $6.3^{\mathrm{b}}$ & \pm & 0.5 & 8.4 & $\pm 0.8^{\mathrm{a}}$ \\
\hline
\end{tabular}

Values are means \pm SEM. Means within a row with different superscript letters are significantly different, $\mathrm{p}<0.05$. Definition of abbreviations: $\mathrm{BMI}=$ body mass index, $\mathrm{FFMI}=$ fat-free mass index, $\mathrm{FMI}=$ fat mass index.

WHOLE-BODY RATE OF APPEARANCE OF GLUTAMATE.

WB $R a_{\text {Glu }}$ was lower in the elderly and in the COPD group compared with the young group $(P<0.01$, table 2$)$. WB $R a_{\text {Glu }}$ did not differ between the elderly and COPD groups.

\section{SPLANCHNIC EXTRACTION OF GLUTAMATE.}

There was a significant group $\mathrm{x}$ time interaction for splanchnic glutamate extraction. Postabsorptive splanchnic extraction of glutamate was lower in the elderly and the COPD group compared with the young group (both $P<0.01$, table 2), but did not differ between the elderly and COPD group. Feeding did not alter splanchnic glutamate extraction in the young group and the COPD group, but increased splanchnic glutamate extraction in the elderly group $(P<0.05)$. 


\section{RA OF ENDOGENOUS GLUTAMATE.}

Because $R a_{\text {endo-Glu }}$ was derived using the corrected exogenous glutamate intake, it can be calculated only during feeding (table 2). There was a significant group $\mathrm{x}$

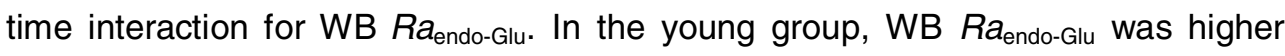
compared with the elderly and COPD groups (both $P<0.01$ ) and did not differ from the postabsorptive $R a_{\mathrm{Glu}}$ in the young group. In the elderly and COPD groups, WB $R a_{\text {endo-Glu }}$ was lower than postabsorptive $R a_{\text {Glu }}(P<0.01)$. WB $R a_{\text {endo-Glu }}$ tended $(P=$ 0.07 ) to increase more in the COPD group than in the elderly group.

Table 2: Glutamate kinetics in the postabsorptive state and in response to a carbohydrate-protein drink in healthy young and elderly men, and male COPD patients

\begin{tabular}{|c|c|c|c|c|c|c|c|c|}
\hline & \multicolumn{3}{|c|}{ T0 } & \multicolumn{3}{|c|}{$\mathrm{T} 2$} & \multicolumn{2}{|c|}{ P-value } \\
\hline \multicolumn{9}{|c|}{ Plasma Glu concentration ( $\mu \mathrm{mol} / \mathrm{L})$} \\
\hline Young & 85.0 & \pm & 7.0 & 78.0 & \pm & 5.0 & & \\
\hline Elderly & 74.6 & \pm & 8.5 & 69.5 & \pm & 7.7 & & \\
\hline COPD & 85.9 & \pm & 4.6 & 85.5 & \pm & 3 & & \\
\hline \multicolumn{9}{|c|}{ WB Ra $a_{\text {Glu }}(\mathrm{nmol} /(\mathrm{kg} F F M \cdot \min ))$} \\
\hline Young & 1635.2 & \pm & $150.7^{\mathrm{a}}$ & 1530.7 & \pm & $337.6^{\mathrm{a}}$ & & G \\
\hline Elderly & 697.8 & \pm & $89.5^{b}$ & 590.7 & \pm & $115.9^{b}$ & & \\
\hline COPD & 769.0 & \pm & $59.1^{b}$ & 585.9 & \pm & $83.7^{b}$ & & \\
\hline \multicolumn{9}{|c|}{$S P E_{G / u}(\%)$} \\
\hline Young & 92.2 & \pm & $5.4^{\mathrm{a}}$ & 91.1 & \pm & $5.4^{\mathrm{a}}$ & & GxT \\
\hline Elderly & 39.9 & \pm & $8.5^{b}$ & 60.5 & \pm & $5.4^{\mathrm{b},{ }^{*}}$ & $\mathrm{~T}$ & \\
\hline COPD & 50.9 & \pm & $5.9^{b}$ & 57.6 & \pm & $10.6^{b}$ & & \\
\hline \multicolumn{9}{|c|}{ WB Ra endo Glu $(\mathrm{nmol} /(\mathrm{kg} F F M \cdot m i n))$} \\
\hline Young & & & & 1474.7 & \pm & $333.8^{\mathrm{a}}$ & & GxT \\
\hline Elderly & & & & 279.5 & \pm & $106.7^{\mathrm{b}, *}$ & $\mathrm{~T}$ & \\
\hline COPD & & & & 221.6 & \pm & $53.5^{\mathrm{b}, *}$ & $\mathrm{~T}$ & \\
\hline
\end{tabular}

Values are mean \pm SEM. Postabsorptive values (T0) and values after $2 \mathrm{~h}$ carbohydrate-protein drink ingestion (T2). Symbols detect significant difference: ${ }^{\text {GXT }}$ significant interaction between group and time, ${ }^{T}$ time effect; "significant different compared to baseline. Means within a row with different superscript letters are significantly different, $p<0.05$. One symbol represents $p<0.05$, two $p<0.01$. Rate of appearance of endogenous glutamate (WB Ra endo Glu) can only be calculated during feeding. To test the effect of feeding, data were compared with rate of appearance of glutamate in fasted state. 


\section{Discussion}

The present study shows that postabsorptive whole-body glutamate production and splanchnic glutamate extraction did not differ between healthy elderly and COPD patients but was lower compared with the healthy young group. This suggests that aging but not COPD influences whole-body glutamate production and splanchnic glutamate extraction in the postabsorptive state. Feeding lowered whole-body glutamate production in the elderly and COPD patients but not in the young, indicating that elderly and COPD patients are more dependent on external glutamate intake. Moreover, splanchnic glutamate extraction increased in the elderly during feeding but remained unchanged in the COPD patients, suggesting a COPD-related effect on splanchnic glutamate extraction in the prandial state.

\section{WHOLE-BODY GLUTAMATE PRODUCTION IN THE POSTABSORPTIVE STATE.}

This study is the first to measure whole-body $R a$ of glutamate in different population groups (healthy young, elderly, and COPD patients) under various conditions (postabsorptive and fed states). Whole-body glutamate production in the young was greater than in the elderly and COPD patients. This finding suggests that less glutamate is delivered to the organs in healthy elderly and COPD patients. However, because we did not measure glutamate consumption, conclusions about glutamate delivery are only speculative.

Matthews et al. ${ }^{19}$ observed that postabsorptive whole-body glutamate production was lower after ingestion of a high-protein diet for $5 \mathrm{~d}$ before the test day compared with a normal- and low-protein diet. In the present study, mean daily habitual protein intake, calculated by a food questionnaire, was $\sim 1 \mathrm{~g} /(\mathrm{kg} \cdot \mathrm{d})$ in all 3 groups, suggesting that the difference in postabsorptive whole-body glutamate production among the groups could not be explained by a difference in habitual protein intake.

FIRST-PASS SPLANCHNIC GLUTAMATE EXTRACTION IN THE POSTABSORPTIVE AND FED STATES.

In this study, the percentage of first-pass glutamate extraction in the postabsorptive state in the young $(\sim 89 \%)$ agreed with the findings of Matthews et al. ${ }^{7}$. 
Interestingly, we found that postabsorptive first-pass splanchnic glutamate extraction in the elderly and COPD group was lower than that in the young (table 2).

Because the intestine may respond differently to a tracer incorporated into a meal than to ingestion of the tracer alone, we also measured splanchnic glutamate extraction during feeding. Although the 3 groups ingested the same amount of glutamate for $2 \mathrm{~h}$, the effect on feeding differed. First-pass splanchnic glutamate extraction in the young group was not affected by feeding, whereas it increased in the elderly but was still lower than in the young. In the COPD group, first-pass splanchnic glutamate extraction remained stable during feeding. The lower splanchnic glutamate extraction during feeding in the elderly and COPD patients compared with the young may indicate that elderly and COPD patients are more dependent on external (dietary) glutamate delivery.

It was reported previously that first-pass splanchnic extraction of other amino acids such as phenylalanine and leucine is higher in the elderly than in the young ${ }^{18,20}$. Glutamate is the main energy substrate for the intestine, whereas phenylalanine and leucine are incorporated predominantly into protein. These findings indicate differences in splanchnic extraction between amino acids with aging.

\section{WHOLE-BODY ENDOGENOUS GLUTAMATE PRODUCTION IN THE FED STATE.}

There was no acute effect of feeding on whole-body endogenous glutamate production in the young group, indicating that it is relatively independent of external dietary glutamate intake. On the other hand, in the healthy elderly and COPD groups, whole-body endogenous glutamate production decreased during feeding. This decrease is noteworthy because some glutamate from the drink also entered the circulation.

Various routes could cause the decreased whole-body endogenous glutamate production. First, feeding decreases whole-body protein breakdown in both the young and elderly 20, 21. Consequently, endogenous amino acid (including glutamate) production and its release in plasma may decrease. However, because glutamate is very compartmentalized ${ }^{17}$, the contribution of this route to whole-body glutamate production might be quite small. Second, skeletal muscle extracts large amounts of glutamate from the circulation. However, muscle glutamate can also be 
formed by the transamination reaction of BCAAs (leucine, isoleucine, and valine) ${ }^{22}$. The test meal of the present study contained $\sim 20.5 \mathrm{~g} \mathrm{BCAA} / 100 \mathrm{~g}$ protein, suggesting that these amino acids can serve as an endogenous source for glutamate in muscle. Consequently, endogenous glutamate production from liver and kidney may decrease. However, more research is warranted to test these hypotheses.

WHOLE-BODY GLUTAMATE PRODUCTION IN THE HEALTHY ELDERLY VS. COPD PATIENTS.

There were no baseline differences in whole-body glutamate production or splanchnic glutamate extraction between COPD patients and the elderly. However, there were some differences during feeding. In the elderly, feeding resulted in increased splanchnic glutamate extraction, whereas prandial splanchnic glutamate extraction was not affected in COPD patients. Furthermore, the decrease in endogenous glutamate turnover after feeding tended to be smaller $(P=0.07)$ in the elderly than in the COPD patients. These differences may indicate a disturbed adaptation of the intestinal glutamate metabolism in response to a meal, whereas endogenous glutamate production may be even more dependent on external glutamate intake in COPD patients compared with the healthy elderly.

The fact that the difference in endogenous glutamate production was not significant may be due to several reasons. First, the number of study subjects may have been too small to detect significant differences in response to feeding. Because this is the first study that examined glutamate turnover in the fed state, the power calculation was based on differences in whole-body protein turnover ${ }^{20}$. Second, the COPD patients in this study were characterized by moderate airflow obstruction with no or only a mild level of emphysema. A previous study ${ }^{23}$ showed that these patients had lower muscle glutamate concentration compared with healthy elderly, but that their concentration was higher than that of emphysema patients. This suggests that disturbances in glutamate metabolism are more pronounced in patients with emphysema. It would be interesting in future studies to compare the present data with data obtained in COPD subgroups such as emphysema patients. 
The present study focused on disturbed whole-body and endogenous glutamate production in COPD patients compared with healthy elderly and young subjects. However, to further clarify the underlying mechanisms for the disturbed glutamate metabolism, it will be essential in future studies to investigate whether specific disturbances are present in glutamate consumption.

To summarize, we showed that aging is associated with changes in wholebody and splanchnic glutamate metabolism in the postabsorptive state. Moreover, we suggest that the elderly, and COPD patients in particular, are more dependent on external glutamate intake than the young.

\section{References}

1. Hofford JM, Milakofsky L, Vogel WH, et al. The nutritional status in advanced emphysema associated with chronic bronchitis. A study of amino acid and catecholamine levels. Am.Rev.Respir.Dis. 1990; 141:902-908.

2. Schols AMWJ, Deutz NEP, Mostert R, Wouters EFM. Plasma amino acid levels in patients with chronic obstructive pulmonary disease. Monaldi Arch. Chest Med. 1993; 48:546-548.

3. Engelen MP, Wouters EF, Deutz NE, et al. Effects of exercise on amino acid metabolism in patients with chronic obstructive pulmonary disease. Am J Respir Crit Care Med 2001; 163(4):85964.

4. Engelen MP, Wouters EF, Deutz NE, et al. Factors contributing to alterations in skeletal muscle and plasma amino acid profiles in patients with chronic obstructive pulmonary disease. Am $\mathrm{J}$ Clin Nutr 2000; 72(6):1480-7.

5. Pouw EM, Schols AMWJ, Deutz NEP, Wouters EFM. Plasma and muscle amino-acid levels in relation to resting energy expenditure and inflammation in stable COPD. Am.J.Respir.Crit.Care Med. 1998; 158:797-801.

6. Hack V, Stutz O, Kinscherf R, et al. Elevated venous glutamate levels in (pre)catabolic conditions result at least partly from a decreased glutamate transport activity. J Mol Med 1996; 74(6):337-43.

7. Matthews DE, Marano MA, Campbell RG. Splanchnic bed utilization of glutamine and glutamic acid in humans. Am J Physiol 1993; 264(6 Pt 1):E848-54.

8. Fernstrom JD. Pituitary hormone secretion in normal male humans: acute responses to a large, oral dose of monosodium glutamate. J Nutr 2000; 130(4S Suppl):1053S-7S.

9. Fabbri LM, Hurd SS. Global Strategy for the Diagnosis, Management and Prevention of COPD: 2003 update. Eur Respir J 2003; 22(1):1-2.

10. Clausen JL, Coates AL, Quanjer PH. Measurement of lung volumes in humans: review and recommendations from an ATS/ERS workshop. Eur Respir J 1997; 10(6):1205-6.

11. Steiner MC, Barton RL, Singh SJ, Morgan MD. Bedside methods versus dual energy X-ray absorptiometry for body composition measurement in COPD. Eur Respir J 2002; 19(4):626-31.

12. Kyle UG, Bosaeus I, De Lorenzo AD, et al. Bioelectrical impedance analysis--part I: review of principles and methods. Clin Nutr 2004; 23(5):1226-43.

13. Abumrad NN, Rabin D, Diamond MP, Lacy WW. Use of a heated superficial hand vein as an alternative site for the measurement of amino acid concentrations and for the study of glucose and alanine kinetics in man. Metabolism 1981; 30(9):936-40.

14. Darmaun D, Manary MJ, Matthews DE. A method for measuring both glutamine and glutamate levels and stable isotopic enrichments. Anal Biochem 1985; 147(1):92-102. 
15. Van Eijk HM, van der Heijden MA, van Berlo CL, Soeters PB. Fully automated liquidchromatographic determination of amino acids. Clin Chem 1988; 34(12):2510-3.

16. Van Eijk HM, Rooyakkers DR, Soeters PB, Deutz NE. Determination of amino acid isotope enrichment using liquid chromatography-mass spectrometry. Anal Biochem 1999; 271(1):8-17.

17. Darmaun D, Matthews DE, Bier DM. Glutamine and glutamate kinetics in humans. Am J Physiol 1986; 251(1 Pt 1):E117-26.

18. Boirie Y, Gachon P, Beaufrere B. Splanchnic and whole-body leucine kinetics in young and elderly men. Am J Clin Nutr 1997; 65(2):489-95.

19. Matthews DE, Campbell RG. The effect of dietary protein intake on glutamine and glutamate nitrogen metabolism in humans. Am J Clin Nutr 1992; 55(5):963-70.

20. Volpi E, Mittendorfer B, Wolf SE, Wolfe RR. Oral amino acids stimulate muscle protein anabolism in the elderly despite higher first-pass splanchnic extraction. Am J Physiol 1999; 277(3 Pt 1):E51320.

21. Boirie $\mathrm{Y}$, Gachon $\mathrm{P}$, Corny $\mathrm{S}$, et al. Acute postprandial changes in leucine metabolism as assessed with an intrinsically labeled milk protein. Am J Physiol 1996; $271(6 \mathrm{Pt}$ 1):E1083-91.

22. Wagenmakers AJ. Protein and amino acid metabolism in human muscle. Adv Exp Med Biol 1998; 441:307-19.

23. Engelen MPKJ, Schols AMWJ, Does JD, et al. Exercise induced lactate increase in relation to muscle substrates in patients with COPD. Am.J.Respir.Crit. Care Med. 2000; 162(5):1697-704. 


\title{
Chapter 5
}

\section{Effect of glutamate ingestion on whole-body glutamate turnover in healthy elderly and patients with chronic obstructive pulmonary disease.}

\author{
Erica P.A. Rutten, Marielle P.K.J. Engelen, Emiel F.M. Wouters, \\ Nicolaas E.P. Deutz, Annemie M.W.J. Schols
}

Nutr 2006;22:496-503

\section{Abstract}

Background: Decreased whole-body glutamate turnover is found in healthy elderly and in patients with chronic obstructive pulmonary disease (COPD). Glutamate supplementation as an option to increase whole-body glutamate turnover and, hence, glutamate availability has never been investigated.

Objective: In the present study, we developed a protocol based on repeated glutamate ingestion to increase plasma glutamate concentration to a steady-state level without inducing toxic side effects, and to evaluate the effect of repeated glutamate ingestion on whole-body glutamate turnover in COPD patients and healthy elderly.

Design: In part 1, the response of plasma glutamate concentration was determined in young healthy volunteers who repeated ingested a glutamate solution. The tolerance of the glutamate drink was evaluated in 26 healthy volunteers by a food tolerance questionnaire. In part 2, 8 male patients with COPD and 8 healthy elderly ingested the glutamate drink, an isomolar amount of a glutamine drink or only water to test the effect on plasma glutamate concentration and whole-body glutamate turnover.

Results: In part 2, repeated ingestion of $30 \mathrm{mg}$ glutamate per kg body weight every $20 \mathrm{~min}$ increased plasma glutamate concentration five-fold to steady-state level within $80 \mathrm{~min}$ and without any side effects. In part 2, repeated ingestion of glutamate significantly increased whole-body glutamate turnover in healthy controls and patients with COPD, although the increase was smaller in patients with COPD than in controls.

Conclusion: We found that repeated ingestion of $30 \mathrm{mg}$ glutamate per $\mathrm{kg}$ body weight every $20 \mathrm{~min}$ can increase glutamate availability in healthy elderly and patients with COPD, who are likely more dependent on external glutamate ingestion than the healthy elderly.

Key words: glutamate, supplementation, chronic obstructive pulmonary disease 


\section{Introduction}

The amino acid glutamate plays a central role in numerous metabolic processes in health and disease. We recently demonstrated that postabsorptive whole-body glutamate production is decreased in elderly compared to young healthy subjects ${ }^{1}$. Moreover, a mixed carbohydrate protein meal (including 10\% glutamate) modulated whole-body glutamate production in the elderly but not in the young ${ }^{1}$, indicating that elderly depend more on external glutamate intake. Comparable results were obtained in elderly patients with chronic obstructive pulmonary disease (COPD). Furthermore, in patients with COPD, consistently decreased levels for glutamate concentration in skeletal muscle have been found ${ }^{2,3}$. This decrease has been associated with a lower muscle glutathione concentration ${ }^{4}$ and with early lactic acidosis during incremental exercise ${ }^{5}$. Because decreased wholebody glutamate production in COPD may contribute to the decreased skeletal muscle glutamate status, we hypothesized that increasing whole-body glutamate availability would be beneficial for these patients.

Several studies have indicated that only a small fraction of the orally ingested glutamate enters the circulation because nearly all of the enteral glutamate is oxidized in the splanchnic bed on the first pass ${ }^{6,7}$. Conversely, when the amount of enteral glutamate was high enough (150 mg/kg body weight [BW]), intestinal glutamate availability exceeded the oxidative capacity of the intestine and plasma glutamate concentration increased $^{8,9}$. Based on these findings, we hypothesized that intake of a large amount of glutamate would increase whole-body glutamate availability.

It has often been assumed that ingestion of monosodium glutamate, the sodium salt of glutamate, can induce specific symptoms called the "Chinese restaurant syndrome" (headache, pain in the back of the neck, and nausea) ${ }^{10,11}$. However, most toxicity studies with monosodium glutamate were performed in study groups who had reported being "sensitive for the Chinese restaurant syndrome". In 1991, the Scientific Committee for Food of the Commission of the European Communities evaluated glutamate and its salts by extensive research of all available literature and allocated an "acceptable daily intake not specified" to the 
natural glutamate and its monosodium, potassium, calcium, and ammonium salts because human studies failed to confirm the involvement of monosodium glutamate in any kind of adverse effect ${ }^{12}$. Oral glutamate supplementation therefore may be a safe option to modify whole-body glutamate availability. However, no study has yet tested possible adverse effects after repeatedly ingesting pure glutamate in elderly.

To investigate whether it is possible to modulate glutamate turnover with oral ingestion of glutamate in healthy elderly and patients with COPD, the present study was performed to (1) develop a protocol in which repeated ingestion of glutamate dissolved in water would results in a significant increase in plasma glutamate concentration to a new steady-state level without inducing toxic side effects and (2) examine whether repeated glutamate ingestion increases whole-body glutamate appearance comparably in patients with COPD and in age-matched healthy controls. The glutamate drink was compared with two control drinks: an isomolar amount of glutamine, which is known to increase plasma glutamate concentration slightly without inducing adverse side effects, and the same amount of only water to correct the effects after glutamate and glutamine ingestion for the amount of water ingestion.

\section{Subjects and methods}

\section{PART 1: DEVELOPMENT OF THE PROTOCOL}

To study the effect of glutamate ingestion on glutamate turnover, plasma glutamate concentration needs to be at steady-state level. Therefore, a repeated glutamate ingesting protocol is required. Based on the study by Graham et al ${ }^{8}$, several pilot studies were performed to obtain the optimal interval and dosage of glutamate ingestion. In the final pilot study, four young healthy volunteers repeatedly ingested $30 \mathrm{mg}$ of glutamate per $\mathrm{kg}$ of BW every $20 \mathrm{~min}$. Glutamate was dissolved in water and heated until it reached $55^{\circ} \mathrm{C}$. The drink was sweetened with an artificial sweetener. Venous blood samples were collected at different time points to evaluate plasma glutamate concentration.

Tolerance of the glutamate drink protocol was tested in 26 healthy volunteers (mean age $39 \pm 2$ y, 8 men and 18 women). All subjects drank an hour-dose of the 
glutamate drink ( $3 \mathrm{X}$ ingestion of $30 \mathrm{mg}$ of glutamate per $\mathrm{kg}$ of BW every $20 \mathrm{~min}$ ) or an isomolar amount of glutamine (29.8 $\mathrm{mg}$ glutamine per $\mathrm{kg}$ of BW). A food tolerance questionnaire was completed every $20 \mathrm{~min}$ until $2 \mathrm{~h}$ after the final ingestion. The questionnaire was adapted from an existing questionnaire ${ }^{13}$, by adding symptoms specific for the Chinese restaurant syndrome i.e. headache, tingling of the face and pain in the breast. In total, 24 complaints were included in the questionnaire. Subjects had to report whether they experienced symptoms; if they did, they had to rate the severity as mild, moderate, severe or very severe. The percentage of symptoms reported after ingestion of the two test drinks was compared and tested by using a paired Student's $t$-test.

\section{PART 2: EVALUATION OF THE PROTOCOL}

Study population. Eight male patients with stable COPD (stage $2+3$ according to the Global Initiative for Chronic Lung Disease (GOLD) guidelines ${ }^{14}$ ) and eight ageand sex-matched healthy controls were studied. Exclusion criteria for both groups were malignancy, cardiac failure, distal arteriopathy, recent surgery, a severe endocrine, hepatic or renal disorder. In addition, patients who were using systemic corticosteroids within 3 mo before the study were excluded because systemic corticosteroids may affect muscle amino acid metabolism ${ }^{15}$. Body weight, fat-free mass (FFM), body mass index (BMI: weight/height ${ }^{2}$ ) and FFM index (FFMI: $\mathrm{FFM} /$ height $^{2}$ ) were significantly lower in the COPD group than in the control group (BW and BMI: $P<0.05$, FFM and FFMI: $P<0.01$, table 1). There were three current smokers in the COPD group and two in the control group. The COPD group was characterized by significantly higher levels of plasma $C$-reactive protein $(P<$ $0.05)$, an indication of low-grade inflammation in the patients. 
Table 1: General characteristics of the study population

\begin{tabular}{|c|c|c|c|c|c|c|c|c|}
\hline & \multicolumn{5}{|c|}{ Controls } & \multicolumn{3}{|c|}{ COPD patients } \\
\hline Age & years & 64 & \pm & 2 & & 65 & \pm & 3 \\
\hline Height & $\mathrm{m}$ & 1.76 & \pm & 0.01 & & 1.72 & \pm & 0.02 \\
\hline Weight & $\mathrm{kg}$ & 82.5 & \pm & 3.6 & $\$$ & 67.0 & \pm & 4.6 \\
\hline BMI & $\mathrm{kg} / \mathrm{m}^{2}$ & 26.6 & \pm & 1.1 & $\$$ & 22.5 & \pm & 1.1 \\
\hline FFM & $\mathrm{kg}$ & 59.0 & \pm & 2.0 & $\$ \$$ & 48.0 & \pm & 2.0 \\
\hline FFMI & $\mathrm{kg} / \mathrm{m}^{2}$ & 19.2 & \pm & 0.8 & $\$ \$$ & 16.3 & \pm & 0.6 \\
\hline FMI & $\mathrm{kg} / \mathrm{m}^{2}$ & 7.5 & \pm & 0.7 & & 6.3 & \pm & 0.8 \\
\hline CRP & $\mathrm{mg} / \mathrm{l}$ & 1.0 & \pm & 0.3 & $\$$ & 3.5 & \pm & 0.8 \\
\hline Smokers & $\mathrm{n}$ & 2 & & & & 3 & & \\
\hline Pack years & years & 15 & \pm & 5 & & 36 & \pm & 6 \\
\hline \multicolumn{9}{|c|}{ Lung function } \\
\hline FEV1 & $\%$ pred & 111 & \pm & 5 & $\$ \$$ & 48 & \pm & 5 \\
\hline $\mathrm{DL}_{\mathrm{CO}}$ & \%pred & 99 & \pm & 10 & $\$ \$$ & 39 & \pm & 7 \\
\hline
\end{tabular}

Definition of abbreviations: $\mathrm{BMI}=$ body mass index, FFM = fat free mass, FFMI fat free mass index, $\mathrm{FMI}=$ fat mass index, CRP $=$ C-reactive protein, FEV1 $=$ forced expiratory volume in $1 \mathrm{sec}, \mathrm{DLco}=$ diffusion capacity for carbonmonoxide. Significant different between the groups: ${ }^{\$} P<0.05,{ }^{\$ \$} P<0.01$.

Pulmonary function tests. All subjects underwent spirometry for determination of forced expiratory volume in $1 \mathrm{~s}$, as marker of aifflow obstruction, with the highest value from at least three technically acceptable manoeuvres being used. Diffusion capacity for carbon monoxide, as a measure of emphysema, was assessed by using the single-breath method (Masterlab; Jaeger, Wurzburg, Germany). All values obtained were compared with a reference value and expressed as percentages of the predicted value ${ }^{16}$. Patients with COPD were characterized by moderately decreased forced expiratory volume in $1 \mathrm{~s}$ and diffusion capacity for carbon monoxide (significantly different from the control group: both $P<0.01$ ). In the control group, all lung function values were within the normal range (table 1).

Study design. On 3 test $d$ and at least $2 d$ apart, subjects were invited to the metabolic ward of the University Hospital Maastricht. Written informed consent was obtained from all subjects and the study was approved by the medical ethical committee of the University Hospital Maastricht. Every test day, subjects ingested one of the three drinks in a randomized order: the glutamate drink $(30.0 \mathrm{mg}$ glutamate per kg of BW every $20 \mathrm{~min})$, an isomolar amount of glutamine $(29.8 \mathrm{mg}$ glutamine per $\mathrm{kg}$ of BW every $20 \mathrm{~min})$, or the same amount of only water $(1.25 \mathrm{~mL}$ per $\mathrm{kg}$ of BW every $20 \mathrm{~min}$ ). 
After an overnight fast, a catheter was placed in an antecubital vein of the arm for tracer infusion ( $85 \mathrm{~mL} / \mathrm{h}$ ) according to a primed constant and continuous infusion protocol. L- ${ }^{15} \mathrm{~N}$-glutamate (Cambridge Isotopic Laboratories, Woburn, MA, USA), was used to measure whole-body glutamate turnover. A priming dose of $0.73 \mu \mathrm{mol} / \mathrm{kg}$ and an infusion rate of $0.03 \mu \mathrm{mol}$ per $\mathrm{kg}$ of FFM per min were used on the day that glutamine or water were ingested, and an infusion rate of $0.09 \mu \mathrm{mol}$ per $\mathrm{kg}$ of FFM per min on the day that glutamate was ingested. A venous blood sample was collected to measure baseline glutamate enrichment. After intravenously administration of the priming dose, a constant continuous tracer infusion was started until the end of the study day. A second catheter for arterialized venous blood sampling was placed in a superficial dorsal vein of the hand of the contra-lateral arm, which was placed in a thermostatically controlled hot box (internal temperature: $60^{\circ} \mathrm{C}$ ), at least $20 \mathrm{~m}$ in before the first blood sampling. The use of the hot box is a technique to mimic direct arterial sampling ${ }^{17}$. Ninety minutes after the start of the tracer infusion, all subjects started to ingest one of the three test drinks for $80 \mathrm{~min}$. Triple arterialized venous blood samples were taken 80 to 90 min after the start of the tracer infusion and 70 to $80 \mathrm{~min}$ after the start of the ingestion. During each test day, the food tolerance questionnaire was completed at baseline and every hour during ingestion.

Biochemical analyses. Venous and arterialized venous blood samples were put in a heparinized tube, immediately put on ice and centrifuged $\left(3120 \times \mathrm{g}\right.$ at $4^{\circ} \mathrm{C}$, for $10 \mathrm{~min}$ ) to obtain plasma. Subsequently, $250 \mu \mathrm{L}$ of plasma was deproteinized with $20 \mathrm{mg}$ of dry sulfosalicylic acid. Samples were frozen in liquid nitrogen and stored at $-80^{\circ} \mathrm{C}$ until analysis. Analysis of plasma glutamate and glutamine concentration was performed using a fully automated high-performance liquid chromatography (Pharmacia, Woerden, The Netherlands) ${ }^{18}$. Glutamate enrichment (tracer-totracee ratio) was analyzed by a liquid chromatography mass spectrometry system (Thermoquest, Veenendaal, The Netherlands) ${ }^{19}$. C-reactive protein was determined in plasma by Synchron LX 20 system (Beckman Coulter, Pennsylvania, USA). 
Calculations. Whole-body glutamate turnover under steady-state conditions provides a reflection of whole-body glutamate production in plasma rather than glutamate turnover within the cells ${ }^{20}$. The following equations were used:

Whole-body glutamate (WB GLU) turnover under steady-state:

(1) $\mathrm{Ra}(\mathrm{GLU})=$ WB GLU turnover $=1 /$ TTR

where $\mathrm{Ra}(\mathrm{GLU})$ represents the WB rate of appearance of $\mathrm{GLU}$, I represents the infusion rate of glutamate tracer, and TTR represents tracer-to-tracee ratio of glutamate in plasma.

Splanchnic extraction of glutamate (SPE[GLU]) after ingestion of the glutamate drink represents the fraction (percentage) of ingested glutamate taken up by the gut and liver during its first pass. Because we did not use an enteral glutamate tracer, the minimal and maximal percentage of the glutamate extraction after glutamate ingestion can be estimated as follows:

Minimal glutamate extraction after glutamate ingestion was calculated by assuming that the endogenous $\mathrm{Ra}(\mathrm{GLU})$ remains unchanged and the increase in $\mathrm{Ra}(\mathrm{GLU})$ after glutamate ingestion is the result of enteral glutamate intake:

(2) Minimal SPE(GLU) $(\%)=100-\left(\operatorname{Ra}\left[G_{\text {after }}\right] / \text { GLU intake }\right)^{*} 100$

Maximal glutamate extraction after glutamate ingestion was calculated by assuming that the endogenous $\mathrm{Ra}(\mathrm{GLU})$ decreases to zero and the total $\mathrm{Ra}(\mathrm{GLU})$ after the glutamate ingestion is the result of the enteral glutamate intake:

(3) Maximal SPE(GLU) (\%) $=100-\left(\left[\operatorname{Ra}\left\{\mathrm{GLU} U_{\text {after }}\right\}-\operatorname{Ra}\left\{\mathrm{GLU}_{\text {before }}\right\}\right] / \mathrm{GLU}\right.$ intake $)^{*} 100$

where $\mathrm{Ra}\left(\mathrm{GLU}_{\text {before }}\right)$ and $\mathrm{Ra}\left(\mathrm{GLU} \mathrm{U}_{\text {after }}\right)$ represent the rate of glutamate appearance before and after glutamate ingestion respectively. GLU intake is the amount of glutamate ingestion when the test day involved the glutamate drink; healthy 
controls ingested $14165 \pm 340 \mathrm{nmol}$ of glutamate per $\mathrm{kg}$ of FFM per min for 80 min, and patients with COPD ingested $14158 \pm 438 \mathrm{nmol}$ of glutamate per $\mathrm{kg}$ of FFM per min for 80 min.

Whole-body FFM was measured in each subject by using bioelectrical impedance analyses to express metabolic data per kg of FFM. FFM of patients with COPD was calculated by using a patient's specific regression equation ${ }^{21}$, and that of healthy controls was calculated by using a specific regression equation described by Dey et al ${ }^{22}$. BW and body height were measured to the nearest $0.1 \mathrm{~kg}$ and 0.1 $\mathrm{cm}$, respectively, with the subjects standing barefoot and wearing light indoor clothing.

Statistical analyses. Results are expressed as mean \pm standard error of the mean. To test a steady-state in the triple measurements of glutamate turnover, we tested whether values were more than 2 standard deviations derived from the median. The mean values of the data represented whole-body glutamate turnover in the postabsorptive state and after repeated ingestion of a drink. Unpaired Student's $t$-test was used to test whether there were significant differences in general characteristics and SPE(GLU). Repeated measure analysis of variance test with within variables time (before and after drink ingestion) and drink (water, glutamine and glutamate) and between variable group (control and COPD group) was performed to test effects on plasma amino acid concentration and glutamate turnover. If there was a group effect, the drink effect was tested within each group. If the interaction time by drink by group was significant, the $\Delta$ change between the groups was tested by using the unpaired Student's $t$-test. In case of a significant interaction of time and drink, paired Student's $t$-test was used to evaluate the effect. SPSS 11.0 for Windows (SPSS Inc., Chicago, IL, USA) was used for data analysis. 


\section{Results}

\section{PART 1: DEVELOPMENT OF THE PROTOCOL}

Figure 1 shows that repeated ingestion of $30 \mathrm{mg}$ of glutamate per $\mathrm{kg}$ of BW every $20 \mathrm{~min}$ in young healthy volunteers increased plasma glutamate concentration significantly from 60 min after the start of ingestion $(P<0.01$, repeated measure analysis of variance). Within $80 \mathrm{~min}$, a new steady-state level was reached that was about $498 \pm 148 \%$ of baseline glutamate concentration.

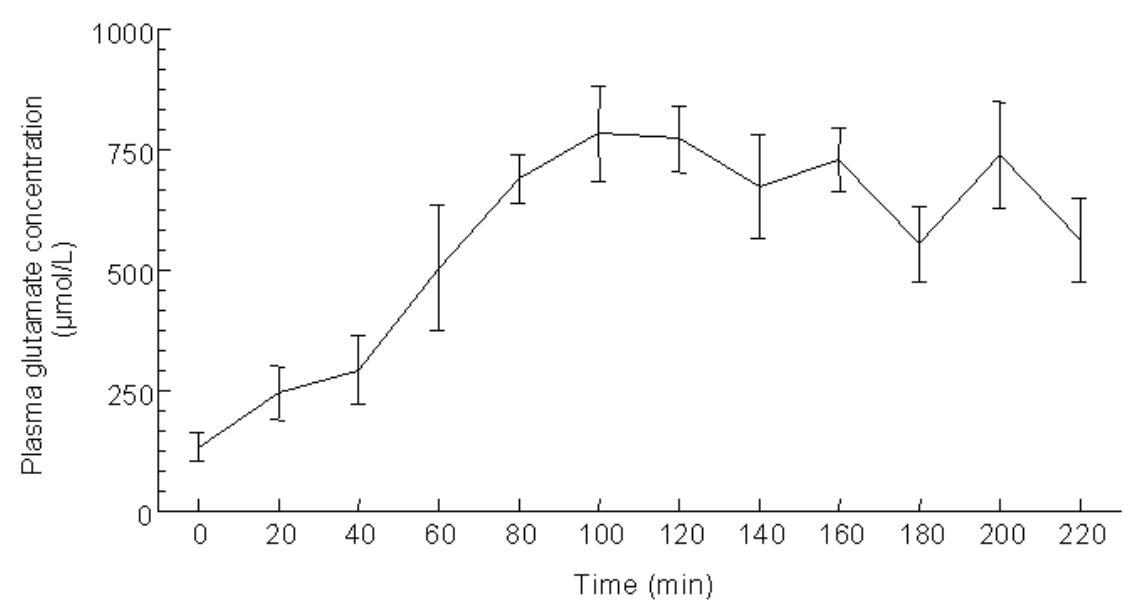

Figure 1: Plasma glutamate concentration after repeated ingestion of $30.0 \mathrm{mg}$ glutamate/kg BW every $20 \mathrm{~min}$ for $220 \mathrm{~min}$ in healthy young volunteers.

Figure 2 presents the tolerance after repeated ingestion of the glutamate drink or an isomolar amount of glutamine in healthy volunteers for $1 \mathrm{~h}$. All reported symptoms were mild. Change of taste was the only symptom that was reported more often after glutamate than after glutamine ingestion $(P<0.05)$. None of the symptoms of the Chinese restaurant syndrome were significantly more present after glutamate than after glutamine ingestion. 


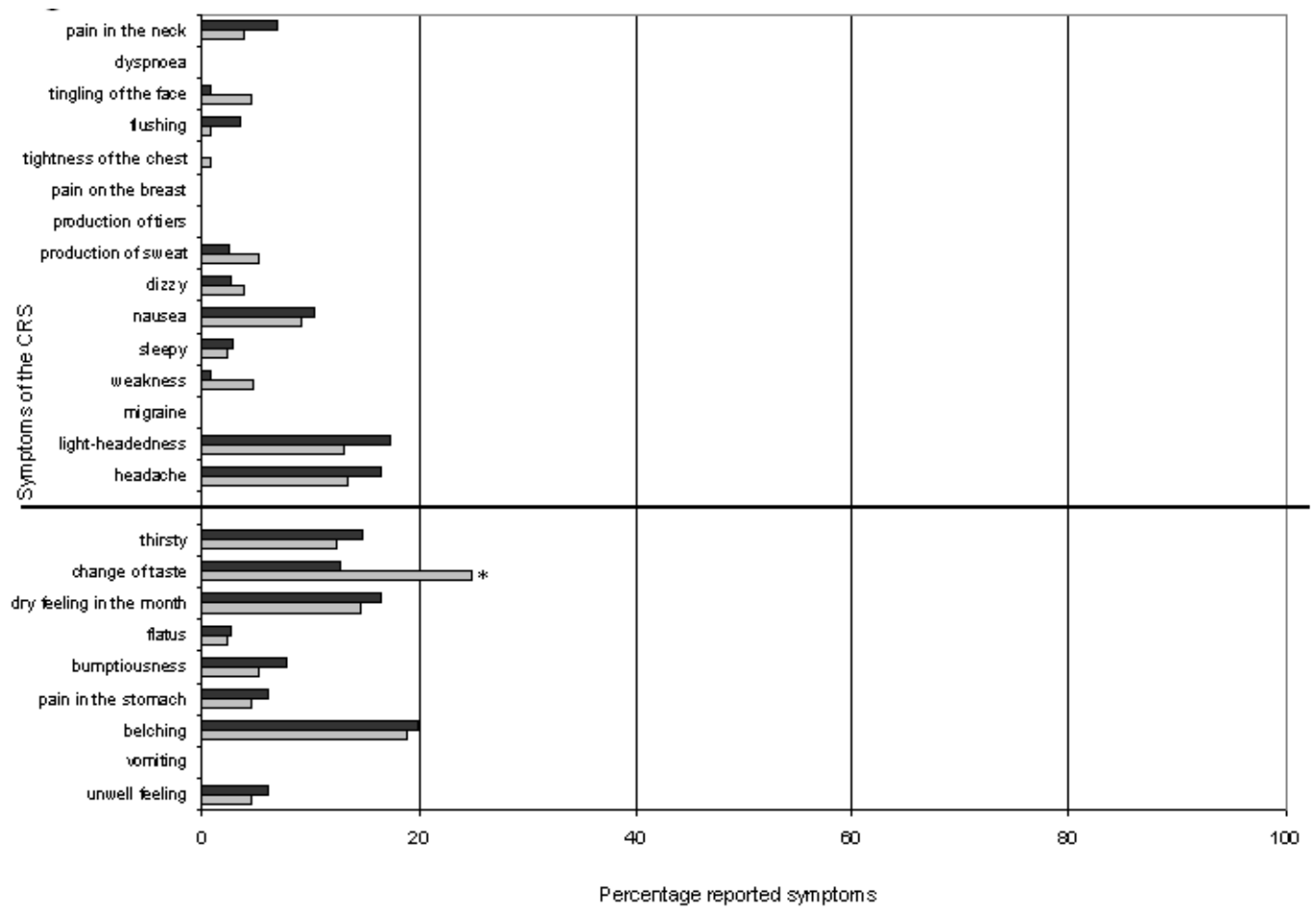

Figure 2: Percentage of mild symptoms reported after ingestion of $30.0 \mathrm{mg}$ glutamate $/ \mathrm{kg}$ body weight/20 min for 1 hour (light bars) or $29.8 \mathrm{mg}$ glutamine/kg body weight (dark bars). The symptoms above the line belong to the Chinese restaurant syndrome (CRS). Significant different from the control group: ${ }^{*} \mathrm{p}<0.05$.

\section{PART 2: EVALUATION OF THE PROTOCOL}

Effects of water, glutamine and glutamate intakes on plasma glutamate and glutamine concentrations

Baseline plasma glutamate and glutamine concentrations were not significant different between the two groups (table 2). There was a group effect for plasma glutamate concentration, indicating that the increase of plasma glutamate concentration after glutamate ingestion was significantly more pronounced in the control group than in the COPD group (increase of $509 \pm 67$ vs. $308 \pm 53 \mu \mathrm{mol} / \mathrm{L}$ respectively, $P<0.05)$. Glutamine ingestion also resulted in a significant increase in plasma glutamate concentration in both groups $(P<0.01)$, but the increase was significantly smaller than after glutamate intake $(P<0.01)$. There was a drink effect for plasma glutamine concentration. Plasma glutamine concentration increased in 
both groups after glutamate $(P<0.05)$ and glutamine $(P<0.01)$ ingestion, but the increase was significantly higher after glutamine than after glutamate ingestion $(P<$ 0.01).

Table 2: Plasma glutamate and glutamine concentrations before and after repeated ingestion of GLU, GLN, or WA in the control and COPD groups.

\begin{tabular}{|c|c|c|c|c|c|c|c|c|c|c|c|c|c|}
\hline \multirow[b]{2}{*}{ Amino acid } & \multirow[b]{2}{*}{ Ingestion } & \multicolumn{6}{|c|}{ Controls } & \multicolumn{6}{|c|}{ COPD patients } \\
\hline & & \multicolumn{3}{|c|}{ T0 } & \multicolumn{3}{|c|}{ T80 } & \multicolumn{3}{|c|}{ T0 } & \multicolumn{3}{|c|}{$\mathrm{T} 80$} \\
\hline \multirow{3}{*}{$\begin{array}{l}\text { Glutamate } \\
(\mu \mathrm{mol} / \mathrm{L})\end{array}$} & WA & 96 & \pm & 6 & 88 & \pm & $5^{\dagger}$ & 82 & \pm & 3 & 88 & \pm & $5^{\star^{\dagger}}$ \\
\hline & GLN & 93 & \pm & 5 & 119 & \pm & $8^{\ddagger \S \uparrow}$ & 71 & \pm & 11 & 109 & \pm & $5^{\S_{* *}}$ \\
\hline & GLU & 92 & \pm & 5 & 601 & \pm & $68^{\#}$ & 87 & \pm & 6 & 395 & \pm & $52^{\#}$ \\
\hline \multirow{3}{*}{$\begin{array}{l}\text { Glutamine } \\
(\mu \mathrm{mol} / \mathrm{L})\end{array}$} & WA & 638 & \pm & 54 & 674 & \pm & 46 & 730 & \pm & 108 & 788 & \pm & $122^{\dagger}$ \\
\hline & GLN & 651 & \pm & 38 & 1007 & \pm & 83 & 803 & \pm & 104 & 1067 & \pm & $99^{\#}$ \\
\hline & GLU & 644 & \pm & 42 & 706 & \pm & 54 & 795 & \pm & 122 & 861 & \pm & $82^{\|}$ \\
\hline
\end{tabular}

COPD, chronic obstructive pulmonary disease; GLN, $29.8 \mathrm{mg}$ of glutamine per kg of body weight every $20 \mathrm{~min}$; GLU, $30.0 \mathrm{mg}$ of glutamate per $\mathrm{kg}$ of body weight every $20 \mathrm{~min}$; TO, before repeated ingestion of drink; T80, 80 min after repeated ingestion of drink; WA, $1.25 \mathrm{~mL}$ of water per $\mathrm{kg}$ pf body weight every 20 min. Definition of hte symbols: *significant group effect; ${ }^{\dagger}$ significant interaction between drink and time; ${ }^{\ddagger} P<0.01$, water vs. Glutamine; ${ }^{\S} P<0.01$, water vs. Glutamate; ${ }^{\|} P<0.05$, water vs. Glutamate; ${ }^{\#} P<0.01$, glutamate vs. glutamine; ${ }^{91} P<0.01$ vs. baseline; ${ }^{\star \star} P<0.05$ vs. baseline.

\section{Effects of water, glutamine and glutamate intakes on whole-body rate of glutamate appearance}

Ninety min after infusion and 80 min after the start of ingestion, WB Ra(GLU) was in steady-state (figure 3). Baseline WB Ra(GLU) was not significantly different between groups (figure 4). In both groups, WB Ra(GLU) increased after glutamate ingestion $(P<0.05)$, but there was a significant interaction of time by drink by group $(P<0.05)$. The $\Delta$ increase in WB $\mathrm{Ra}(\mathrm{GLU})$ was significantly higher in the control group than in the COPD group $(P<0.05)$. Moreover, Ra(GLU) increased after glutamine ingestion in the COPD group $(P$ $<0.05$ ), but not in the control group. 


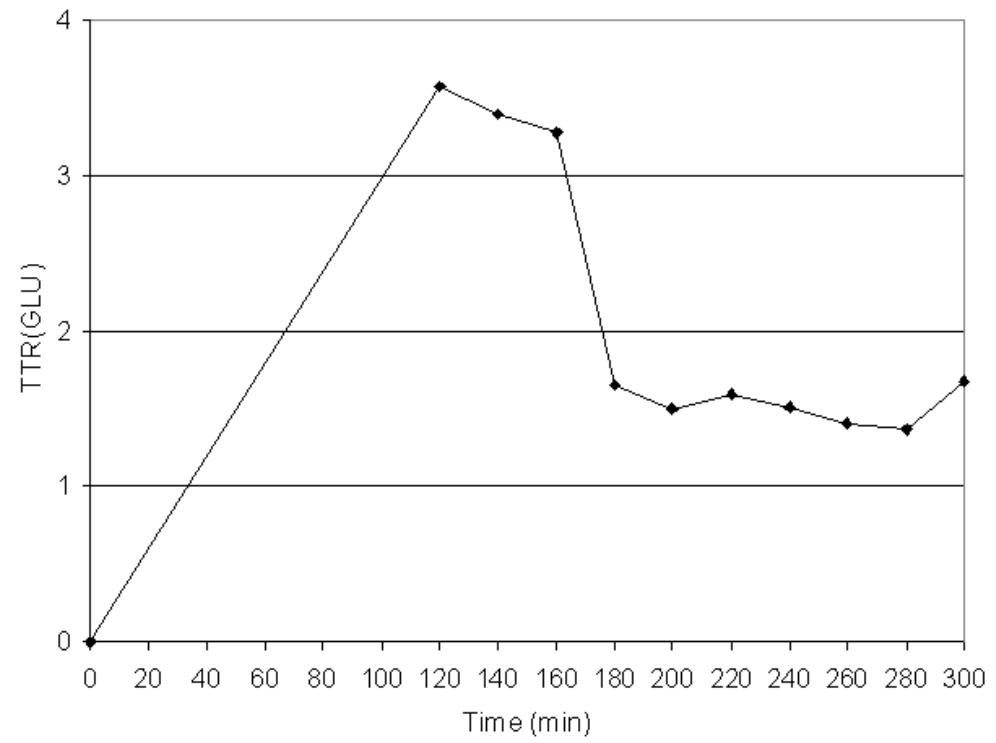

Figure 3: Time curve of plasma ${ }^{15} \mathrm{~N}$-glutamate enrichment in the postabsorptive state and during 2 hours ingesting the glutamate drink. These data were obtained from a pilot study.

\section{First-pass extraction of glutamate after glutamate ingestion}

The range of SPE(GLU) after repeated glutamate ingestion tended to be higher in the COPD group (minimum: $64 \pm 6 \%$, maximum: $78 \pm 6 \%$ ) than in the control group (minimum: $50 \pm 6 \%$, maximum: $63 \pm 6 \%$ ), but no statistical significance was reached $(P=0.083)$.

\section{Discussion}

The present study shows that repeated ingestion of $30 \mathrm{mg}$ of glutamate per $\mathrm{kg}$ of BW every 20 min significantly increased plasma glutamate concentration to a new steady-state level within $80 \mathrm{~min}$ and without inducing any side effects. Repeated glutamate ingestion increased whole-body glutamate production in healthy controls and patients with COPD, although the increase was smaller in patients with COPD than in controls. Moreover, glutamine ingestion resulted in an increased glutamate production in patients with COPD but not in the controls, implying higher glutamine and glutamate metabolisms in the splanchnic area of patients with COPD. 

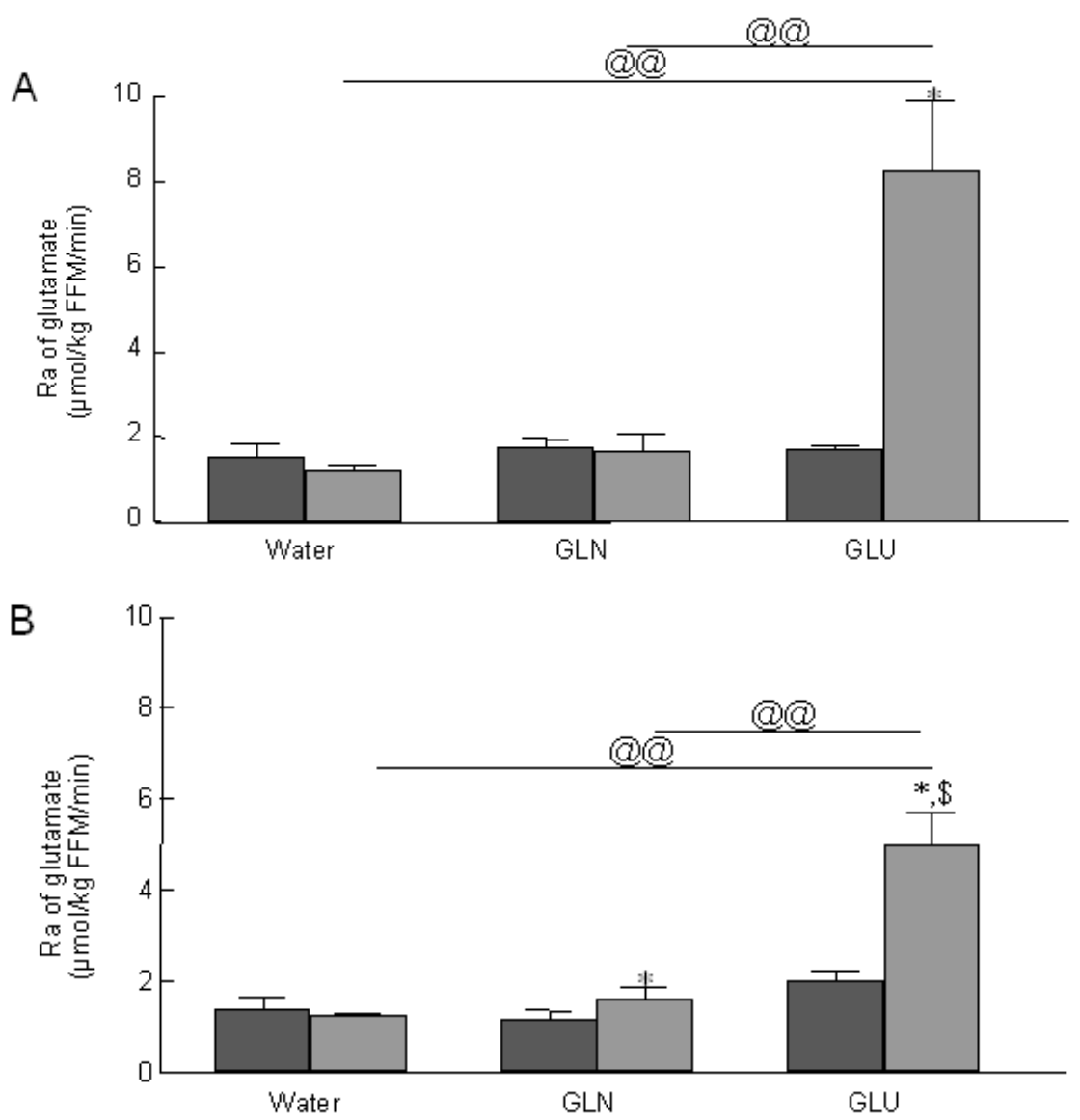

Figure 4: Rate of glutamate appearance after 80 min repeated ingestion of $1.25 \mathrm{~mL}$ water $/ \mathrm{kg} \mathrm{BW}, 29.8$ $\mathrm{mg}$ glutamine/kg BW/20 min (GLN) or $30.0 \mathrm{mg}$ glutamate/kg BW/20 min (GLU) in healthy controls (A) and COPD patients (B). Symbols depict a significant effect: significant different from baseline: ${ }^{*} P<0.05$, significant different between the drinks: ${ }^{\circledR} P<0.01$, significant different between the groups: ${ }^{\$} P<0.05$.

The first part of this study shows that repetitive ingestion of $30 \mathrm{mg}$ of glutamate per $\mathrm{kg}$ of BW every 20 min induced a significant increase in plasma glutamate concentration to a new steady-state level within $80 \mathrm{~min}$ in young healthy volunteers. This amount of ingestion was based primarily on the report by Graham et $\mathrm{al}^{8}$, where a bolus ingestion of $150 \mathrm{mg}$ of monosodium glutamate per $\mathrm{kg}$ of BW was used to induce a significant increase in plasma and muscle glutamate concentrations. Because $15 \%$ of monosodium glutamate is sodium, the total 
amount of glutamate ingestion was $127.5 \mathrm{mg}$ per $\mathrm{kg} \mathrm{BW}$. In the present study, the hour-long dose of glutamate ingestion was lower $(90 \mathrm{mg}$ of glutamate per $\mathrm{kg}$ of $\mathrm{BW})$, although it has to be considered that the glutamate ingestion in the present study continued for $80 \mathrm{~min}$, representing a total glutamate intake of $150 \mathrm{mg}$ per $\mathrm{kg}$ of BW. This amount is in line with the average daily human glutamate intake because the protein content in food contains on average $15 \%$ glutamate and daily protein ingestion in a regular Western diet is about $1 \mathrm{~g}$ per $\mathrm{kg}$ of BW 23,24 . However, it is likely that glutamate used in the present study induces a greater increase in plasma glutamate concentration compared with glutamate intake (by mixed meals) in daily life because SPE (GLU) has been shown to increase when glutamate is ingested together with carbohydrates ${ }^{25}$.

In the present study, ingestion of $30 \mathrm{mg}$ of glutamate per $\mathrm{kg}$ of BW every 20 min did not induce specific adverse symptoms in healthy volunteers. The only symptom that was significantly more present to a mild degree after glutamate ingestion was change of taste, probably due to the specific salty taste of glutamate. Moreover, from all the symptoms specific for the Chinese restaurant syndrome (figure 2), light-headedness was the most reported symptom, which was present in $17 \%$ of subjects after glutamate ingestion vs. $14 \%$ of subjects after ingestion of the control amino acid glutamine. Light-headedness may have been caused by subjects being in the postabsorptive state until the end of the study (until approximately $10 \mathrm{PM})$. In addition, in the second part of the study, a food tolerance questionnaire was reported at baseline and every hour during ingestion. None of the subjects reported adverse effects during ingestion of water, glutamine or glutamate at any point in time.

From the data obtained in the first part of the study, we concluded that $30 \mathrm{mg}$ of glutamate per $\mathrm{kg}$ of BW every 20 min can increase plasma glutamate concentration significantly and to a new steady-state level without inducing any side effects.

Subsequently, repeated glutamate ingestion was evaluated in patients with COPD and age-matched healthy controls. There was no difference in basal plasma glutamate concentration and whole-body glutamate turnover between the groups. Comparable data were found in a previous study 1, although patients' characteristics in both studies were different. In our study, patients had more 
severe airflow obstruction and emphysema. Moreover, they were characterized by lower values of $\mathrm{BMI}$ and FFMI than those in the previous study. This suggests that postabsorptive whole-body glutamate turnover in COPD is rather independent of disease severity and body composition.

Repeated glutamine and glutamate ingestions induced a significant increase in plasma glutamate concentration, although the increase was significantly lower after glutamine ( $50 \%$ vs. $500 \%$ respectively). The splanchnic bed produces small amounts of glutamate from glutamine and vice versa (glutamine $\leftrightarrow$ glutamate + $\left.\mathrm{NH}_{3}\right)^{7}$, resulting in increased plasma glutamate concentration after glutamine ingestion. Remarkably, whole-body glutamate turnover remained unchanged in the control group that ingested glutamine. Repeated glutamate ingestion resulted in increased whole-body glutamate turnover in both groups. Glutamate is highly compartmentalized and rate of glutamate appearance in plasma reflects interorgan transport rather than intracellular metabolism of glutamate. However, because we measured glutamate turnover after glutamate ingestion when plasma glutamate concentration was in steady-state, increased glutamate turnover is linked to increased glutamate disposal. Part of the orally delivered glutamate enters the splanchnic area and is available for consumption by other organs. Because glutamate plays a role in numerous metabolic processes such as glutathione metabolism and energy-related pathways, a greater availability of glutamate may have metabolic effects on these glutamate related substrates. In this study, it is speculative as to which organs consume glutamate because we measured only whole-body glutamate turnover. Glutamate is taken up by perivenous cells of the liver to produce glutamine ${ }^{26}$. However, skeletal muscle also extracts glutamate from the circulation ${ }^{27}$. Glutamate transporters in skeletal muscle are characterized by a high specificity and low capacity with the following kinetic parameters: maximum rate of transport is approximately $80 \mu \mathrm{mol}$ per $\mathrm{kg}$ of wet weight per min and substrate concentration when transport rate at half the maximum rate of transport (kilometers) is approximately $1000 \mu \mathrm{mol} / \mathrm{L}^{28}$. Thus, theoretically, all of the ingested glutamate can be taken up by the skeletal muscle. However, future metabolic studies across organs (i.e. skeletal muscle) are warranted to investigate the contribution of various tissues to glutamate utilization and to show which metabolic pathways are modulated by glutamate supplementation. 
The increase in plasma glutamate concentration and whole-body glutamate turnover after repeated glutamate ingestion was lower in the COPD group than in the control group. Hence, the amount of glutamate available for consumption is lower in the COPD group than in the control group. Therefore, decreased delivery of glutamate to muscle in COPD may at least in part explain the consistently observed decrease in skeletal muscle glutamate concentration in these patients ${ }^{2,3}$. The lower increase of whole-body glutamate turnover after glutamate ingestion in the COPD group implies higher SPE(GLU) in the COPD group. First-pass splanchnic extraction of amino acids like phenylalanine and leucine has been reported to be higher in the elderly than in the young subjects ${ }^{29,30}$. In contrast, splanchnic extraction of phenylalanine was found to be lower in patients with COPD than in healthy elderly subjects ${ }^{31}$. These findings suggest discrepancy in amino acid extraction between young and old and between health and disease. Moreover, recent findings have indicated a difference in splanchnic extraction between various amino acids. SPE (GLU) was lower in the elderly and patients with COPD compared than in young subjects ${ }^{1}$, and tended to be disturbed in response to a meal in patients with COPD. In addition, when we calculated minimal and maximal glutamate extractions after glutamate ingestion, there was a tendency through a higher splanchnic extraction in the COPD group. We have to emphasize that the formula used in the present study is just an estimate and we acknowledge that the dual tracer technique is a more appropriate method to measure splanchnic extraction. In the present study, whole-body glutamate production increased after repeated glutamine ingestion in the COPD group, but not in the control group. This also indicates that there was a higher metabolism for glutamate and glutamine of the splanchnic area in the COPD group than in the control group.

In the present study, we found that it is possible to modulate whole-body glutamate turnover by glutamate supplementation in healthy elderly and patients with COPD, who are likely more dependent on external glutamate than the young. Further research has to elucidate (1) if the decreased glutamate disposal after glutamate ingestion is due to a greater splanchnic activity for glutamate in patients with COPD than in controls; (2) which organs are responsible for the increased glutamate consumption after its supplementation and (3) what are the metabolic effects after glutamate ingestion. 


\section{References}

1. Rutten EP, Engelen MP, De Castro CL, et al. Decreased whole body glutamate turnover in elderly and patients with chronic obstructive pulmonary disease (COPD). J Nutr 2005; 135(9):2166-70.

2. Engelen MP, Wouters EF, Deutz NE, et al. Factors contributing to alterations in skeletal muscle and plasma amino acid profiles in patients with chronic obstructive pulmonary disease. Am J Clin Nutr 2000; 72(6):1480-7.

3. Pouw EM, Schols AMWJ, Deutz NEP, Wouters EFM. Plasma and muscle amino-acid levels in relation to resting energy expenditure and inflammation in stable COPD. Am.J.Respir.Crit.Care Med. 1998; 158:797-801.

4. Engelen MPKJ, Schols AMWJ, Does JD, et al. Altered glutamate metabolism is associated with reduced muscle glutathione levels in patients with emphysema. Am.J.Respir.Crit.Care Med. 2000; 161:98-103.

5. Engelen MPKJ, Schols AMWJ, Does JD, et al. Exercise induced lactate increase in relation to muscle substrates in patients with COPD. Am.J.Respir.Crit. Care Med. 2000; 162(5):1697-704.

6. Reeds PJ, Burrin DG, Stoll B, Jahoor F. Intestinal glutamate metabolism. J Nutr 2000; 130(4S Suppl):978S-82S.

7. Matthews DE, Marano MA, Campbell RG. Splanchnic bed utilization of glutamine and glutamic acid in humans. Am J Physiol 1993; 264(6 Pt 1):E848-54.

8. Graham TE, Sgro V, Friars D, Gibala MJ. Glutamate ingestion: the plasma and muscle free amino acid pools of resting humans. Am J Physiol Endocrinol Metab 2000; 278(1):E83-E89.

9. Fernstrom JD, Cameron JL, Fernstrom MH, et al. Short-term neuroendocrine effects of a large oral dose of monosodium glutamate in fasting male subjects. J Clin Endocrinol Metab 1996; 81(1):18491.

10. Garlick PJ. Assessment of the safety of glutamine and other amino acids. J Nutr 2001; 131(9 Suppl):2556S-61S.

11. Byck R, Schaumburg HH. Monosodium glutamate. N Engl J Med 1969; 281(5):275.

12. Walker R, Lupien JR. The safety evaluation of monosodium glutamate. J Nutr 2000; 130(4S Suppl):1049S-52S.

13. Westerterp-Plantenga MS, Kovacs EM. The effect of (-)-hydroxycitrate on energy intake and satiety in overweight humans. Int J Obes Relat Metab Disord 2002; 26(6):870-2.

14. Fabbri LM, Hurd SS. Global Strategy for the Diagnosis, Management and Prevention of COPD: 2003 update. Eur Respir J 2003; 22(1):1-2.

15. de Blaauw I, Schols AM, Koerts-deLang E, et al. De novo glutamine synthesis induced by corticosteroids in vivo in rats is secondary to weight loss. Clin Nutr 2004; 23(5):1035-42.

16. Clausen JL, Coates AL, Quanjer PH. Measurement of lung volumes in humans: review and recommendations from an ATS/ERS workshop. Eur Respir J 1997; 10(6):1205-6.

17. Abumrad NN, Rabin D, Diamond MP, Lacy WW. Use of a heated superficial hand vein as an alternative site for the measurement of amino acid concentrations and for the study of glucose and alanine kinetics in man. Metabolism 1981; 30(9):936-40.

18. Van Eijk HM, van der Heijden MA, van Berlo CL, Soeters PB. Fully automated liquidchromatographic determination of amino acids. Clin Chem 1988; 34(12):2510-3.

19. Van Eijk HM, Rooyakkers DR, Soeters PB, Deutz NE. Determination of amino acid isotope enrichment using liquid chromatography-mass spectrometry. Anal Biochem 1999; 271(1):8-17.

20. Darmaun D, Matthews DE, Bier DM. Glutamine and glutamate kinetics in humans. Am J Physiol 1986; 251(1 Pt 1):E117-26.

21. Steiner MC, Barton RL, Singh SJ, Morgan MD. Bedside methods versus dual energy X-ray absorptiometry for body composition measurement in COPD. Eur Respir J 2002; 19(4):626-31.

22. Kyle UG, Bosaeus I, De Lorenzo AD, et al. Bioelectrical impedance analysis--part I: review of principles and methods. Clin Nutr 2004; 23(5):1226-43. 
23. Geha RS, Beiser A, Ren C, et al. Review of alleged reaction to monosodium glutamate and outcome of a multicenter double-blind placebo-controlled study. J Nutr 2000; 130(4S Suppl):1058S-62S.

24. Daniels DH, Joe FL, Jr., Diachenko GW. Determination of free glutamic acid in a variety of foods by high-performance liquid chromatography. Food Addit Contam 1995; 12(1):21-9.

25. Stegink LD, Filer LJ, Jr., Baker GL. Effect of carbohydrate on plasma and erythrocyte glutamate levels in humans ingesting large doses of monosodium L-glutamate in water. Am J Clin Nutr 1983; 37(6):961-8.

26. Taylor $\mathrm{P}$, Rennie MJ. Perivenous localisation of $\mathrm{Na}$-dependent glutamate transport in perfused rat liver. FEBS.lett. 1987; 221:370-374.

27. Marliss EB, Aoki TT, Pozefsky $\mathrm{T}$, et al. Muscle and splanchnic glutamine and glutamate metabolism in postabsorptive and starved man. J Clin Invest 1971; 50(4):814-7.

28. Rutten EP, Engelen MP, Schols AM, Deutz NE. Skeletal muscle glutamate metabolism in health and disease: state of the art. Curr Opin Clin Nutr Metab Care 2005; 8(1):41-51.

29. Boirie Y, Gachon P, Beaufrere B. Splanchnic and whole-body leucine kinetics in young and elderly men. Am J Clin Nutr 1997; 65(2):489-95.

30. Volpi E, Mittendorfer B, Wolf SE, Wolfe RR. Oral amino acids stimulate muscle protein anabolism in the elderly despite higher first-pass splanchnic extraction. Am J Physiol 1999; 277(3 Pt 1):E51320.

31. Engelen MP, Rutten EP, De Castro CL, et al. Altered interorgan response to feeding in patients with chronic obstructive pulmonary disease. Am J Clin Nutr 2005; 82(2):366-72. 


\title{
Chapter 6
}

\section{Metabolic effects of glutamine and glutamate ingestion in healthy subjects and in persons with chronic obstructive pulmonary disease}

\author{
Erica P.A. Rutten, Marielle P.K.J. Engelen, Emiel F.M. Wouters, \\ Annemie M.W.J. Schols, Nicolaas E.P. Deutz
}

Am J Clin Nutr 2006;83:115-23

\section{Abstract}

Background: Because low plasma glutamate and glutamine concentrations are often seen in chronic obstructive pulmonary disease (COPD), glutamine or glutamate supplementation may be a good option for preventing further metabolic disturbances in COPD patients. However, the metabolic effects of glutamate supplementation have never been compared with those of glutamine supplementation.

Objective: We compared the metabolic effects of repeated ingestion of glutamine and glutamate in COPD patients and age-matched healthy control subjects.

Design: On $3 \mathrm{~d}$ separated by intervals $\geq 2 \mathrm{~d}$, a protocol of primed constant and continuous infusion of ${ }^{2} \mathrm{H}_{5}$ - phenylalanine and ${ }^{2} \mathrm{H}_{2}$-tyrosine was performed for $3 \mathrm{~h}$ in 8 stable male COPD patients and 8 healthy control subjects. After a 90-min tracer infusion, all subjects ingested a glutamine or glutamate drink or the same amount of water every $20 \mathrm{~min}$ for $80 \mathrm{~min}$. Blood samples were taken at the end of the postabsorptive and ingestion periods to test for effects on plasma amino acid and substrate concentrations and whole-body protein turnover.

Results: Glutamate but not glutamine ingestion resulted in higher plasma ornithine concentrations than did water ingestion $(P<0.01)$. The change in plasma arginine, citrulline and urea concentration was significantly $(P<0.01)$ higher after glutamine ingestion than after water or glutamate ingestion. Wholebody protein turnover decreased overall, independent of the drink consumed.

Conclusion: Repeated ingestion of glutamine and glutamate resulted in different effects on the plasma amino acid concentration. In both groups, ingestion of glutamine but not glutamate increased the plasma concentrations of citrulline and arginine, substrates produced in the intestine and the liver.

Key words: glutamine, glutamate, chronic obstructive pulmonary disease, supplementation, amino acids, protein turnover 


\section{Introduction}

Glutamine is a widely investigated amino acid that is known to play an important role in many metabolic routes in various organs, such as the splanchnic bed and skeletal muscle. Supplementation with glutamine in enteral or parenteral feeding is often suggested to improve disturbed metabolic processes, eg, a low muscle glutathione status or a negative nitrogen balance during illness ${ }^{1,2}$. Glutamine solutions are, however, unstable ${ }^{3}$ and thus not practical for use as food supplement. In addition, disturbances in glutamate status but not glutamine status were found in several diseases ${ }^{4,5}$. Glutamate is stable in water and research by Walker and Lupien ${ }^{6}$ has shown that, in contrast to what was reported in the past ${ }^{7}$, there is no evidence that the intake of glutamate via glutamate-containing food products or dishes prepared with (monosodium) glutamate is responsible for inducing symptoms of the Chinese restaurant syndrome ${ }^{6}$. In this view, supplementation with glutamate may be a good alternative to that with glutamine to improve substrate metabolism during illness.

Glutamine and glutamate are closely linked because they can easily be converted to each other by the enzymes glutamine synthase (glutamate $+\mathrm{NH}_{3} \rightarrow$ glutamine) and glutaminase (glutamine $\rightarrow$ glutamate $\left.+\mathrm{NH}_{3}\right)^{8}$. Although glutamate plays a key role in the transamination reactions, a small number of studies evaluated the effect of glutamine or glutamate supplementation on plasma amino acid concentrations. In general, these studies showed that the concentration of only few plasma amino acids was modified after the ingestion of glutamine ${ }^{9}$ or glutamate ${ }^{10}$. Moreover, in a catabolic state like surgery, glutamine supplementation has been shown to increase protein synthesis ${ }^{11,12}$. A correlation between a low skeletal muscle glutamine concentration in a catabolic state and low protein synthesis is noticed ${ }^{12}$, although the mechanism is not yet completely clear. It is interesting that the addition of glutamate to enteral nutrition also increased mucosal protein synthesis ${ }^{13}$, which suggests that both glutamine and glutamate can modify protein metabolism.

In patients with chronic obstructive pulmonary disease (COPD), the plasma glutamine and glutamate and skeletal muscle glutamate concentrations were low 
14, 15. Moreover, low muscle glutamate status was associated with metabolic disturbances such as a low skeletal muscle glutathione concentration ${ }^{5}$. Supplementation of glutamine or glutamate may be an option to prevent further metabolic disturbances in COPD patients.

The aim of the current study was to compare the effects of oral ingestion of the closely linked amino acids glutamine and glutamate on the plasma amino acid concentrations and whole-body (WB) protein turnover. The study was performed in stable COPD patients and age-matched healthy control subjects to allow simultaneous evaluation of potential disease-specific effects in response to glutamine and glutamate ingestion.

\section{Subjects and methods}

\section{STUDY POPULATION}

Eight healthy male control subjects and 8 stable COPD patients, all age- and sexmatched, were studied. The COPD patients were characterized by significantly lower body weight $(P<0.05)$, fat-free mass (FFM) $(P<0.01)$, body mass index (in $\left.\mathrm{m} / \mathrm{kg}^{2}\right)(P<0.05)$ and FFM index $\left(\mathrm{FFM} /\right.$ height $\left.^{2}\right)(P<0.01)$ (table 1). Exclusion criteria for both groups were malignancy, cardiac failure, distal arteriopathy, recent surgery, and severe endocrine, hepatic or renal disorder. In addition, patients who were using systemic corticosteroids $\leq 3$ mo before the study were excluded because it has been shown that systemic corticosteroids may affect muscle amino acid metabolism ${ }^{16}$. The number of current smokers was 2 in the control group and 3 in the COPD group. The COPD group was characterized by slight but significantly $(P<0.05)$ higher plasma concentrations of $C$-reactive protein.

Written informed consent was obtained from all subjects. The study was approved by the medical ethics committee of the University Hospital Maastricht. 


\section{PULMONARY FUNCTION TESTS}

All subjects underwent spirometry for measurement of forced expiratory volume in $1 \mathrm{~s}$, as a marker of disease severity, and the highest value from $\geq 3$ technically acceptable maneuvers was used. The diffusion capacity of the lung for carbon monoxide, as a marker of emphysema, was measured by using the single-breath method (Masterlab; Jaeger, Wurzburg, Germany). All values obtained were related to a reference value and expressed as percentages of the predicted value ${ }^{17}$. The COPD patients had significantly lower values of forced expiratory volume in $1 \mathrm{~s}$ and diffusion capacity of the lung for carbon monoxide than did the control group $(P<0.01$ for both, table 1$)$.

Table 1: General characteristics of the study population

\begin{tabular}{|c|c|c|c|c|c|c|c|}
\hline \multirow[b]{2}{*}{ Age } & \multirow[b]{2}{*}{ years } & \multicolumn{3}{|c|}{$\begin{array}{l}\text { Control subjects } \\
\qquad N=8\end{array}$} & \multicolumn{3}{|c|}{$\begin{array}{c}\text { COPD patients } \\
\mathrm{N}=8\end{array}$} \\
\hline & & 64 & \pm & 2 & 65 & \pm & 3 \\
\hline Height & $\mathrm{m}$ & 1.76 & \pm & 0.01 & 1.72 & \pm & 0.02 \\
\hline Weight & $\mathrm{kg}$ & 82.5 & \pm & 3.6 & 67.0 & \pm & $4.6^{2}$ \\
\hline BMI & $\mathrm{kg} / \mathrm{m}^{2}$ & 26.6 & \pm & 1.1 & 22.5 & \pm & $1.1^{2}$ \\
\hline FFM & $\mathrm{kg}$ & 59.0 & \pm & 2.0 & 48.0 & \pm & $2.0^{3}$ \\
\hline FFMI & $\mathrm{kg} / \mathrm{m}^{2}$ & 19.2 & \pm & 0.8 & 16.3 & \pm & $0.6^{3}$ \\
\hline FMI & $\mathrm{kg} / \mathrm{m}^{2}$ & 7.5 & \pm & 0.7 & 6.3 & \pm & 0.8 \\
\hline CRP & $\mathrm{mg} / \mathrm{L}$ & 1.0 & \pm & 0.3 & 3.5 & \pm & $0.8^{2}$ \\
\hline Smokers & $\mathrm{n}$ & 2 & & & 3 & & \\
\hline Pack years & years & 15 & \pm & 5 & 36 & \pm & 6 \\
\hline Lung function & \%pred & & & & & & \\
\hline FEV $_{1}$ & & 111 & \pm & 5 & 48 & \pm & $5^{3}$ \\
\hline $\mathrm{DL}_{\mathrm{CO}}$ & & 99 & \pm & 10 & 39 & \pm & $7^{3}$ \\
\hline
\end{tabular}

All values are mean \pm SEM. The unpaired Student's $t$-test was used to test differences in general characteristics between the controls and the COPD patients: ${ }^{2} p<0.05,{ }^{3} p<0.01$. Used abbreviation: BMI = body mass index, FFM = fat-free mass, FFMI fat-free mass index (fat-free mass divided by height ${ }^{2}$ ), $\mathrm{FMI}=$ fat mass index (fat mass divided by height ${ }^{2}$ ), CRP $=$ C-reactive protein, $\mathrm{FEV}_{1}=$ forced expiratory volume in $1 \mathrm{sec}, \mathrm{DLco}=$ diffusion capacity of the lung for carbon monoxide.

\section{STUDY DESIGN}

The test drinks. On 3 test days separated by $\geq 2 \mathrm{~d}$, subjects were invited to the metabolic ward of the University Hospital Maastricht after an overnight fast. On the different test days, the test drink contained glutamate, glutamine or only water in a 
randomized order. The test drinks consisted of a $2.4 \%$ solution to deliver $30.0 \mathrm{mg}$ glutamate $\cdot \mathrm{kg}$ body $\mathrm{wt}^{-1} \cdot 20 \mathrm{~min}^{-1}$ or an isomolar amount of glutamine $(29.8 \mathrm{mg}$ glutamine $\cdot \mathrm{kg}$ body $\left.\mathrm{wt}^{-1} \cdot 20 \mathrm{~min}^{-1}\right)$. The water drink contained the equal amount of only water $\left(1.25 \mathrm{~mL}\right.$ water $\cdot \mathrm{kg}$ body $\left.\mathrm{wt}^{-1} \cdot 20 \mathrm{~min}^{-1}\right)$. The drinks were served at a temperature of $55^{\circ} \mathrm{C}$ to ensure complete solution.

Tracer infusion

Ingestion

Blood sampling

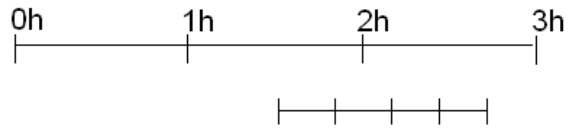

$\pi$

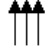

Figure 1: Overview of the study protocol. On 3 test days, intravenous infusion of the stable isotopes was given for $3 \mathrm{~h}$. Ingestion involved $1.25 \mathrm{~mL}$ water $/ \mathrm{kg} \mathrm{wt}, 29.8 \mathrm{mg}$ glutamine $/ \mathrm{kg} \mathrm{wt}$, or $30 \mathrm{mg}$ glutamate/kg wt every $20 \mathrm{~min}$. Arteriovenous blood samples were taken between 80 and $90 \mathrm{~min}$ after the start of the infusion and between 70 and $80 \mathrm{~min}$ after the start of the ingestion.

Study protocol. All subjects were in the supine position for $3 \mathrm{~h}$ (figure 1). A catheter was placed in an antecubital vein of the arm for tracer infusion $(85 \mathrm{~mL} / \mathrm{h})$ according to a primed constant continuous infusion protocol. A venous blood sample was collected to measure baseline enrichment of phenylalanine (Phe) and tyrosine (Tyr). The stable isotopes L-[ring- $\left.{ }^{2} \mathrm{H}_{5}\right]-P h e$ and L-[ring- $\left.{ }^{2} \mathrm{H}_{2}\right]-T y r$ were used to measure WB protein turnover. The following priming doses and infusion rates were used: for $\mathrm{L}-\left[\mathrm{ring}_{-}{ }^{2} \mathrm{H}_{5}\right]-\mathrm{Phe}, 2.19 \mu \mathrm{mol} \cdot \mathrm{kg} \mathrm{FFM}^{-1}$ and $2.26 \mu \mathrm{mol} \cdot \mathrm{kg} \mathrm{FFM}^{-1} \cdot \mathrm{h}^{-}$ ${ }^{1}$; for L-[ring- $\left.{ }^{2} \mathrm{H}_{2}\right]-\mathrm{Tyr}, 0.95 \mu \mathrm{mol} \cdot \mathrm{kg} \mathrm{FFM}^{-1}$ and IR $=0.77 \mu \mathrm{mol} \cdot \mathrm{kg} \mathrm{FFM}^{-1} \cdot \mathrm{h}^{-1}$, respectively. Moreover, a bolus dose of $\mathrm{L}-\left[\right.$ ring- $\left.^{2} \mathrm{H}_{4}\right]-\mathrm{Tyr}$ was given to prime the phenylalanine-derived plasma tyrosine pool (priming dose: $0.31 \mu \mathrm{mol} \cdot \mathrm{kg} \mathrm{FFM}^{-1}$ ). The tracers were obtained from Cambridge Isotopic Laboratories (Woburn, MA). The tracer infusion was begun after intravenous administration of the priming dose, and the infusion continued to the end of the test day. A second catheter for blood sampling was placed in a superficial dorsal vein of the hand of the contralateral arm, which was placed in a thermostatically controlled hot-box (internal temperature: $60^{\circ} \mathrm{C}$ ), $\geq 20 \mathrm{~min}$ before the first blood sampling. The hot-box technique is used to mimic direct arterial sampling ${ }^{18}$. Ninety min after the start of the tracer infusion, all subjects began to ingest 1 of the 3 test drinks every 20 min 
for $80 \mathrm{~min}$. Triple arterialized venous blood samples were taken between 80 and 90 min after the start of the tracer infusion and between 70 and 80 min after the start of the ingestion.

Biochemical analyses. Venous and arterialized venous blood was divided into a tube containing heparin and a cloagulation tube. The heparin-containing tube was immediately put on ice and centrifuged at $3120 \times \mathrm{g}$ and $4^{\circ} \mathrm{C}$ for 10 min to obtain plasma. Subsequently, $250 \mu \mathrm{L}$ plasma was deproteinized with $20 \mathrm{mg}$ dry sulfosalicylic acid for analysis of plasma amino acid concentrations and enrichment. Another $900 \mu \mathrm{L}$ plasma was deproteinized with $90 \mu \mathrm{L}$ trichloroacetic acid for measurement of plasma glucose, ammonia and urea concentrations. All samples were frozen in liquid nitrogen and stored at $-80{ }^{\circ} \mathrm{C}$ until they were analyzed. The amino acid concentrations were analyzed by using an HPLC system 19. Phenylalanine and tyrosine enrichment (tracer-to-tracee ratio (TTR)) was analyzed by using liquid chromatography-mass spectrometry system (LC-MS, Thermoquest, Veenendaal, The Netherlands) ${ }^{20}$. The concentrations of substrate (i.e. glucose, ammonia, urea) were measured by using the COBAS Mira $S$ (Roche Diagnostica, Hoffman-La Roche, Basel, Switserland) ${ }^{21}$. C-reactive protein was measured in plasma by using the Synchron LX 20 system (Beckman Coulter, Mijdrecht, the Netherlands). Blood collected in the cloth tube was stored uncooled for $\geq 20 \mathrm{~min}$ and subsequently centrifuged at $3120 \mathrm{xg}$ and at room temperature for 10 min to obtain serum. The serum was stored at $-80^{\circ} \mathrm{C}$ until it was analyzed with a radioimmunoassay kit to measure insulin concentrations.

Calculations. The amino acids glutamate, asparagine, serine, glutamine, histidine, glycine, threonine, alanine, taurine, tyrosine, methionine, phenylalanine, tryptophan, lysine, valine, isoleucine, leucine, ornithine, citrulline and arginine were analyzed. The sum of the amino acids represents the sum of all analyzed amino acids. The sum of essential amino acids represents the sum of threonine, phenylalanine, trpyptophan, methionine, lysine, isoleucine, valine and leucine. The branched-chain amino acids (BCAA) represent the sum of leucine, isoleucine and valine. 
All metabolic data were determined under steady state conditions. Therefore, whole-body rate of appearance of phenylalanine represents whole-body protein breakdown and is calculated as follows:

(1) Whole-body protein breakdown $=$ WB Ra(Phe) $=1 / T T R(P h e)$

where $R a$ is the rate of appearance and I and TTR(Phe) represent the tracer infusion rate and the tracer-to-tracee ratio of Phenylalanine in plasma respectively.

WB protein synthesis was calculated by subtracting the hydroxylation of phenylalanine to tyrosine from WB protein breakdown ${ }^{22}$. WB net balance was calculated by subtracting WB protein synthesis by WB protein breakdown.

Every test day, WB FFM was measured in each subject by using bioelectrical impedance analyses (Xitron 4000B, Xitron Technologies, San Diego, CA) to express metabolic data (in $\mathrm{kg}$ FFM). The FFM of the COPD patients was calculated by using a regression equation developed for use in COPD patients ${ }^{23}$, whereas the FFM of the healthy control subjects was calculated by using a specific regression equation described by Dey et al ${ }^{24}$. Body weight and height were measured to the nearest $0.1 \mathrm{~kg}$ and $0.1 \mathrm{~cm}$, respectively, while the subjects were standing and wearing light indoor clothing but no shoes.

\section{STATISTICAL ANALYSES}

Results are expressed as mean \pm SEMs. The mean values of the triplicate metabolic data were used as WB protein turnover in the postabsorptive state and after repeated ingestion of the test drink. The unpaired Student's $t$-test was used to ascertain whether general characteristics and baseline values of plasma amino acid and substrate concentrations and protein turnover differed significantly. The change in the data from before to after the 80-min ingestion (delta concentration) was calculated to analyze the drink and group effects on plasma amino acid and substrate concentrations and WB protein turnover by using the univariate analysis of variance and the post hoc Bonferroni test. Together with the variables group and drink as fixed factors, the variable period was included in the test to detect an effect of the subsequent test days, but no significant effect was present. The 
variable subject number was included as a random factor, involving each subject identity number. In case of a significant group $x$ drink effect, the drink effect was tested within each group with the univariate analysis of variance, and the unpaired Student's $t$-test was used to evaluate the drink effect between the groups. The onesample Student's $t$-test was used to ascertain whether the overall change in time was different from zero. If data did not reach normality, they were log transformed. Effects were considered significant when $P<0.05$. We used SPSS for Windows statistical software (version 11.0; SPSS Inc., Chicago, II, USA) for data analysis.

\section{Results}

\section{PLASMA AMINO ACID CONCENTRATION}

At baseline, plasma ornithine concentration was significantly $(P<0.05)$ higher in the COPD group than in the control group (table 2). The change in glutamate and alanine concentrations after glutamine and glutamate ingestion was significantly higher than the change after water ingestion, but the increase in both groups was highest after glutamate ingestion (plasma glutamate, $P<0.01$; plasma alanine, $P<$ 0.05; figure 2). Moreover, the increase of plasma glutamate concentration after repeated glutamate ingestion was significantly $(P<0.05)$ lower in the COPD group than in the control group. Because there was no group effect for the remaining amino acids, statistical effects on the plasma amino acid concentration are presented in the total study group. Glutamine ingestion resulted in a significantly $(P$ $<0.01)$ greater change in plasma glutamine concentrations than did glutamate and water ingestion (figure 2). 
Table 2: Plasma amino acid concentrations at baseline (T0) and after $80 \mathrm{~min}$ of repeated ingestion (T80) of water, glutamine or glutamate in the control subjects and subjects with COPD

\begin{tabular}{|c|c|c|c|c|c|c|c|c|c|c|c|c|c|}
\hline & \multirow[b]{2}{*}{ Ingestion } & \multicolumn{6}{|c|}{$\begin{array}{c}\text { Control subjects } \\
n=8\end{array}$} & \multicolumn{6}{|c|}{$\begin{array}{c}\text { COPD patients } \\
n=8\end{array}$} \\
\hline & & \multicolumn{3}{|c|}{ T0 } & \multicolumn{3}{|c|}{ T80 } & \multicolumn{3}{|c|}{ T0 } & \multicolumn{3}{|c|}{ T80 } \\
\hline \multicolumn{14}{|c|}{ Glutamine / glutamate related amino acids } \\
\hline \multirow[t]{3}{*}{ Taurine } & WA & 50 & \pm & 4 & 48 & \pm & 4 & 51 & \pm & 3 & 52 & \pm & 5 \\
\hline & GLN & 47 & \pm & 3 & 50 & \pm & 4 & 53 & \pm & 4 & 55 & \pm & 5 \\
\hline & GLU & 46 & \pm & 4 & 65 & \pm & 7 & 51 & \pm & 4 & 66 & \pm & 3 \\
\hline \multirow[t]{3}{*}{ Ornithine } & WA & 60 & \pm & 7 & 56 & \pm & 5 & 75 & \pm & $10^{\$}$ & 74 & \pm & 10 \\
\hline & GLN & 57 & \pm & 7 & 56 & \pm & 6 & 72 & \pm & $7^{\$}$ & 70 & \pm & 6 \\
\hline & GLU & 58 & \pm & 6 & 86 & \pm & 9 & 74 & \pm & $8^{\$}$ & 94 & \pm & 7 \\
\hline \multirow[t]{3}{*}{ Citrulline } & WA & 50 & \pm & 4 & 50 & \pm & 4 & 46 & \pm & 6 & 49 & \pm & 6 \\
\hline & GLN & 51 & \pm & 4 & 65 & \pm & 6 & 46 & \pm & 5 & 61 & \pm & 7 \\
\hline & GLU & 49 & \pm & 4 & 35 & \pm & 4 & 48 & \pm & 6 & 35 & \pm & 5 \\
\hline \multirow[t]{3}{*}{ Arginine } & WA & 89 & \pm & 9 & 85 & \pm & 7 & 82 & \pm & 11 & 86 & \pm & 11 \\
\hline & GLN & 84 & \pm & 7 & 97 & \pm & 7 & 78 & \pm & 8 & 90 & \pm & 11 \\
\hline & GLU & 84 & \pm & 6 & 81 & \pm & 6 & 84 & \pm & 13 & 78 & \pm & 5 \\
\hline \multirow[t]{3}{*}{ Valine } & WA & 199 & \pm & 17 & 202 & \pm & 15 & 189 & \pm & 7 & 190 & \pm & 7 \\
\hline & GLN & 205 & \pm & 22 & 191 & \pm & 19 & 208 & \pm & 16 & 192 & \pm & 14 \\
\hline & GLU & 201 & \pm & 14 & 184 & \pm & 16 & 195 & \pm & 9 & 185 & \pm & 9 \\
\hline \multirow[t]{3}{*}{ Isoleucine } & WA & 62 & \pm & 2 & 61 & \pm & 3 & 60 & \pm & 5 & 62 & \pm & 8 \\
\hline & GLN & 64 & \pm & 4 & 56 & \pm & 3 & 62 & \pm & 6 & 54 & \pm & 5 \\
\hline & GLU & 62 & \pm & 2 & 53 & \pm & 3 & 65 & \pm & 6 & 52 & \pm & 3 \\
\hline \multirow[t]{3}{*}{ Leucine } & WA & 118 & \pm & 7 & 117 & \pm & 7 & 118 & \pm & 13 & 124 & \pm & 13 \\
\hline & GLN & 117 & \pm & 9 & 105 & \pm & 8 & 120 & \pm & 10 & 109 & \pm & 9 \\
\hline & GLU & 116 & \pm & 6 & 103 & \pm & 7 & 117 & \pm & 11 & 99 & \pm & 4 \\
\hline \multirow[t]{3}{*}{ BCAA } & WA & 379 & \pm & 26 & 381 & \pm & 24 & 367 & \pm & 21 & 375 & \pm & 24 \\
\hline & GLN & 386 & \pm & 34 & 352 & \pm & 30 & 389 & \pm & 32 & 355 & \pm & 28 \\
\hline & GLU & 379 & \pm & 21 & 341 & \pm & 26 & 376 & \pm & 22 & 337 & \pm & 15 \\
\hline \multicolumn{14}{|c|}{ Non glutamine / glutamate related amino acids } \\
\hline \multirow[t]{3}{*}{ Asparagine } & WA & 58 & \pm & 9 & 56 & \pm & 8 & 59 & \pm & 6 & 62 & \pm & 7 \\
\hline & GLN & 55 & \pm & 8 & 56 & \pm & 7 & 62 & \pm & 8 & 60 & \pm & 7 \\
\hline & GLU & 56 & \pm & 7 & 55 & \pm & 8 & 60 & \pm & 8 & 55 & \pm & 4 \\
\hline \multirow[t]{3}{*}{ Serine } & WA & 116 & \pm & 10 & 110 & \pm & 8 & 115 & \pm & 10 & 120 & \pm & 11 \\
\hline & GLN & 108 & \pm & 9 & 106 & \pm & 8 & 116 & \pm & 11 & 113 & \pm & 12 \\
\hline & GLU & 115 & \pm & 8 & 109 & \pm & 8 & 115 & \pm & 13 & 106 & \pm & 4 \\
\hline Histidine & WA & 86 & \pm & 9 & 84 & \pm & 7 & 75 & \pm & 6 & 79 & \pm & 7 \\
\hline & GLN & 82 & \pm & 9 & 91 & \pm & 9 & 76 & \pm & 5 & 84 & \pm & 6 \\
\hline & GLU & 82 & \pm & 8 & 79 & \pm & 9 & 77 & \pm & 7 & 74 & \pm & 2 \\
\hline Glycine & WA & 238 & \pm & 25 & 226 & \pm & 23 & 244 & \pm & 24 & 254 & \pm & 25 \\
\hline & GLN & 234 & \pm & 24 & 220 & \pm & 20 & 246 & \pm & 29 & 222 & \pm & 24 \\
\hline & GLU & 235 & \pm & 22 & 227 & \pm & 22 & 248 & \pm & 33 & 230 & \pm & 11 \\
\hline Threonine & WA & 116 & \pm & 11 & 108 & \pm & 10 & 122 & \pm & 10 & 122 & \pm & 10 \\
\hline & GLN & 116 & \pm & 14 & 113 & \pm & 12 & 123 & \pm & 15 & 115 & \pm & 15 \\
\hline & GLU & 113 & \pm & 8 & 104 & \pm & 8 & 109 & \pm & 7 & 112 & \pm & 8 \\
\hline Tyrosine & WA & 55 & \pm & 6 & 52 & \pm & 5 & 52 & \pm & 7 & 52 & \pm & 6 \\
\hline & GLN & 51 & \pm & 5 & 49 & \pm & 5 & 50 & \pm & 5 & 48 & \pm & 5 \\
\hline & GLU & 51 & \pm & 4 & 46 & \pm & 4 & 53 & \pm & 6 & 45 & \pm & 2 \\
\hline
\end{tabular}




\begin{tabular}{|c|c|c|c|c|c|c|c|c|c|c|c|c|}
\hline \multirow[t]{3}{*}{ Methionine } & WA & 22 & \pm & 1 & 21 & \pm 2 & 20 & \pm & 2 & 20 & \pm & 2 \\
\hline & GLN & 22 & \pm & 2 & 20 & \pm 2 & 21 & \pm & 2 & 21 & \pm & 2 \\
\hline & GLU & 22 & \pm & 1 & 18 & \pm 1 & 21 & \pm & 2 & 18 & \pm & 1 \\
\hline \multirow[t]{3}{*}{ Phenylalanine } & WA & 52 & \pm & 8 & 58 & \pm 4 & 55 & \pm & 5 & 58 & \pm & 5 \\
\hline & GLN & 57 & \pm & 5 & 53 & \pm 3 & 57 & \pm & 5 & 55 & \pm & 4 \\
\hline & GLU & 57 & \pm & 4 & 51 & \pm 4 & 56 & \pm & 4 & 52 & \pm & 3 \\
\hline \multirow[t]{3}{*}{ Tryptophan } & WA & 45 & \pm & 2 & 45 & \pm 3 & 35 & \pm & 5 & 35 & \pm & 4 \\
\hline & GLN & 47 & \pm & 3 & 42 & \pm 3 & 36 & \pm & 4 & 35 & \pm & 3 \\
\hline & GLU & 47 & \pm & 3 & 42 & \pm 2 & 38 & \pm & 3 & 37 & \pm & 4 \\
\hline \multirow[t]{3}{*}{ Lysine } & WA & 165 & \pm & 14 & 164 & \pm 11 & 176 & \pm & 18 & 183 & \pm & 20 \\
\hline & GLN & 157 & \pm & 14 & 158 & \pm 10 & 174 & \pm & 16 & 168 & \pm & 15 \\
\hline & GLU & 171 & \pm & 10 & 163 & \pm 12 & 178 & \pm & 19 & 163 & \pm & 8 \\
\hline \multirow[t]{3}{*}{ SUM AA } & WA & 2625 & \pm & 163 & 2647 & \pm 151 & 2536 & \pm & 134 & 2729 & \pm & 155 \\
\hline & GLN & 2598 & \pm & 160 & 3041 & \pm 190 & 2665 & \pm & 158 & 3128 & \pm & 182 \\
\hline & GLU & 2582 & \pm & 133 & 3211 & \pm 201 & 2631 & \pm & 152 & 3214 & \pm & 72 \\
\hline \multirow[t]{3}{*}{ SUM EAA } & WA & 779 & \pm & 56 & 777 & \pm 48 & 725 & \pm & 27 & 738 & \pm & 30 \\
\hline & GLN & 784 & \pm & 68 & 738 & \pm 55 & 800 & \pm & 66 & 748 & \pm & 59 \\
\hline & GLU & 789 & \pm & 40 & 718 & \pm 49 & 742 & \pm & 35 & 718 & \pm & 21 \\
\hline
\end{tabular}

All values are means \pm SEM, expressed in $\mu \mathrm{mol} / \mathrm{L}$. Univariate ANOVA and Bonferroni tests were used to test drink and group effects on the change from T0 to T80. There was no significant interaction between group and drink. There was a significant drink effect for plasma concentrations of taurine and ornithine (both: significant difference between glutamine and glutamate ingestion, $P<0.01$, and between glutamate and water ingestion, $P<0.01$ ); citrulline (significant difference between glutamine and water ingestion, $P<0.01$; between glutamine and glutamate ingestion, $P<0.01$; and between glutamate and water ingestion, $P<0.01$ ); arginine (significant difference between glutamine and water ingestion, $P<0.01$ ), valine, isoleucine and BCAA (all: significant difference between glutamine and water ingestion, $P<0.05$, and between glutamine and glutamate ingestion, $P<0.01$ ); and methionine (significant difference between glutamine and glutamate ingestion, $P<0.01$, and between glutamate and water ingestion, $P<0.05$ ). Plasma ornithine concentration was significantly different between the groups, $P<0.05$. Used abbreviations: BCAA: sum of isoleucine, valine and leucine, SUM AA: sum of all measured amino acids, SUM EAA: sum of essential amino acids: threonine, phenylalanine, tryptophan, methionine, lysine, isoleucine, valine and leucine.

Glutamate ingestion resulted in a greater change in taurine and methionine concentrations than did water and glutamine ingestion. The changes in valine, leucine and isoleucine concentrations and the sum of BCAA after glutamine and glutamate ingestion were significantly $(P<0.01)$ greater than those after water ingestion. Glutamine ingestion resulted in a significantly $(P<0.01)$ greater change in citrulline and arginine concentrations than did water and glutamate ingestion, whereas plasma ornithine concentration did not change significantly after glutamine ingestion. Glutamate ingestion, on the other hand, resulted in a significantly $(P<0.01)$ greater change in ornithine concentration than did water and glutamine ingestion, whereas citrulline concentrations decreased after glutamate 
and were significantly $(P<0.01)$ lower than after water and glutamine ingestion. Plasma arginine concentration did not change after glutamate ingestion.
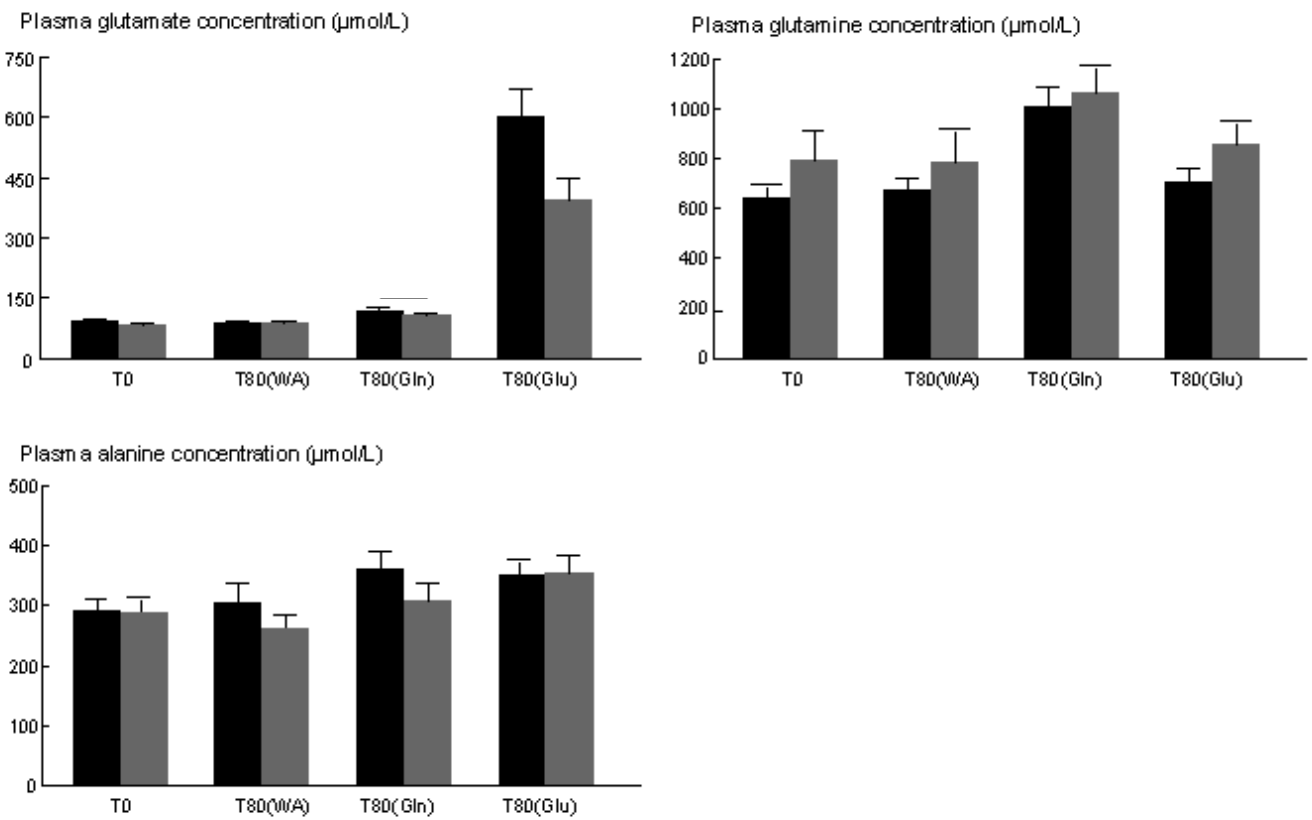

Figure 2: Mean (SEM) plasma concentrations of glutamate, glutamine and alanine at baseline (T0) and after 80 min of ingestion (T80) of water (WA), glutamine (GLN) or glutamate (GLU) in the control (dark bars, $n=8$ ) and COPD (light bars, $n=8$ ) groups. Univariate ANOVA and the Bonferroni tests were used to test drink and group effects on the change from T0 to T80. There was no significant difference between the groups at T0. The group $\mathrm{x}$ drink interaction for plasma glutamate concentration after glutamate ingestion in both groups was significant $(P<0.01)$. Drink effects were significant for plasma concentrations of glutamate (between glutamine and water ingestion and between glutamine and glutamate ingestion; both: $P<0.01$ ), glutamine (between glutamine and water ingestion and between glutamine and glutamate ingestion; both: $P<0.01$ ), and alanine (between glutamine and water ingestion $(P<0.01)$ and between glutamine and glutamate ingestion $(P<0.05)$.

\section{PLASMA SUBSTRATE CONCENTRATION}

At baseline, plasma glucose, ammonia, insulin and urea concentrations did not differ significantly between the COPD group and the control group (table 3). The group $x$ drink interaction for the change in ammonia concentration was significant, which indicated that the drink effect differed significantly between the groups. In the control group, glutamine ingestion resulted in a significantly $(P<0.01)$ greater 
change in ammonia concentration than did water and glutamate ingestion, and this effect differed significantly $(P<0.05)$ between the groups. Glutamate ingestion resulted in a significantly $(p<0.01)$ greater change in insulin concentrations than did water ingestion. The change in urea concentration was significantly greater after glutamine ingestion than after glutamate $(P<0.05)$ and water $(P<0.01)$ ingestion.

Table 3: Plasma glucose, ammonia, insulin and urea concentrations at baseline (T0) and after 80 min of repeated ingestion (T80) of water, glutamine of glutamate in the control subjects and subjects with COPD

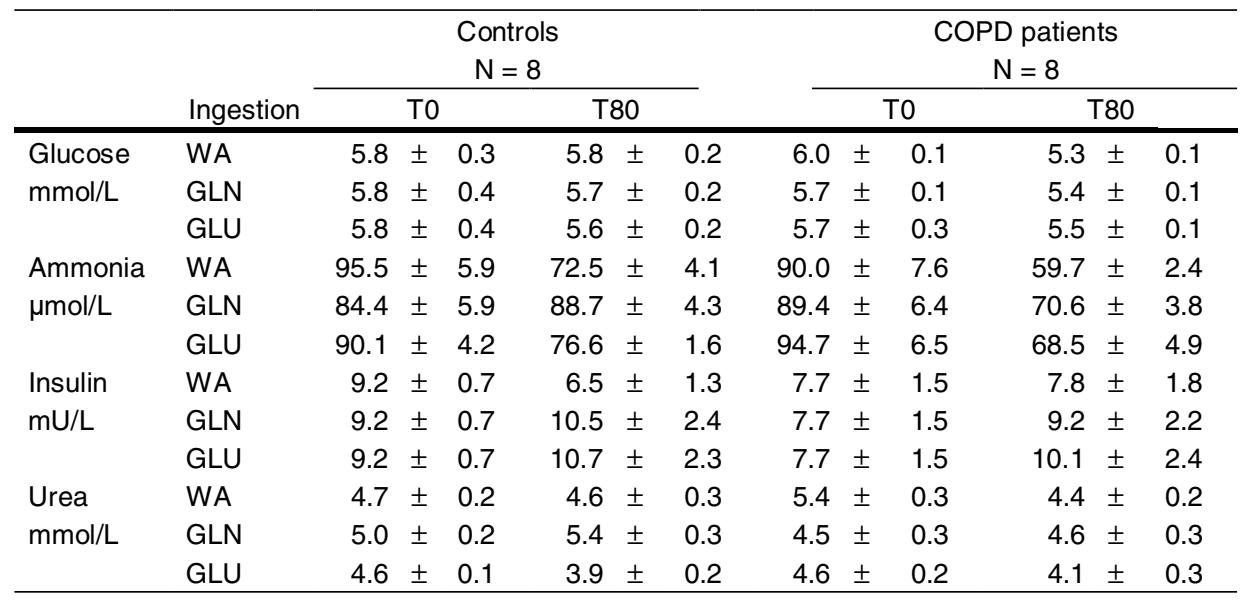

All values are mean \pm SEM. Univariate ANOVA and Bonferroni tests were used to test drink and group effects on the change from T0 to T80. There was no significant difference between the groups at T0. There was a significant group $\mathrm{x}$ drink effect for plasma ammonia concentration, $P<0.05$. In the control group, there was a significant difference between glutamine and glutamate ingestion $(P<0.05)$ and between glutamine and water ingestion $(P<0.01)$. Plasma ammonia concentrations at T80 were significantly different between the COPD group and the control group. There was a significant drink effect for plasma insulin (significant difference between glutamine and water ingestion, $P<0.01$ ) and plasma urea (significant difference between glutamine and water ingestion, $P<0.01$, and between glutamine and glutamate ingestion, $P<0.05$ ).

\section{WHOLE-BODY PROTEIN TURNOVER}

Baseline values for WB protein breakdown, synthesis, and net balance did not differ significantly between the control group and the COPD group (table 4). There was no drink-specific effect on WB protein turnover in either group. However, the overall change in WB protein breakdown and synthesis was significantly different from zero $(P<0.01)$, independent of the drink consumed. 
Table 4: Measures of whole body (WB) protein metabolism at baseline (T0) and after 80 min of repeated ingestion (T80) of water, glutamine or glutamate in control subjects and subjects with COPD

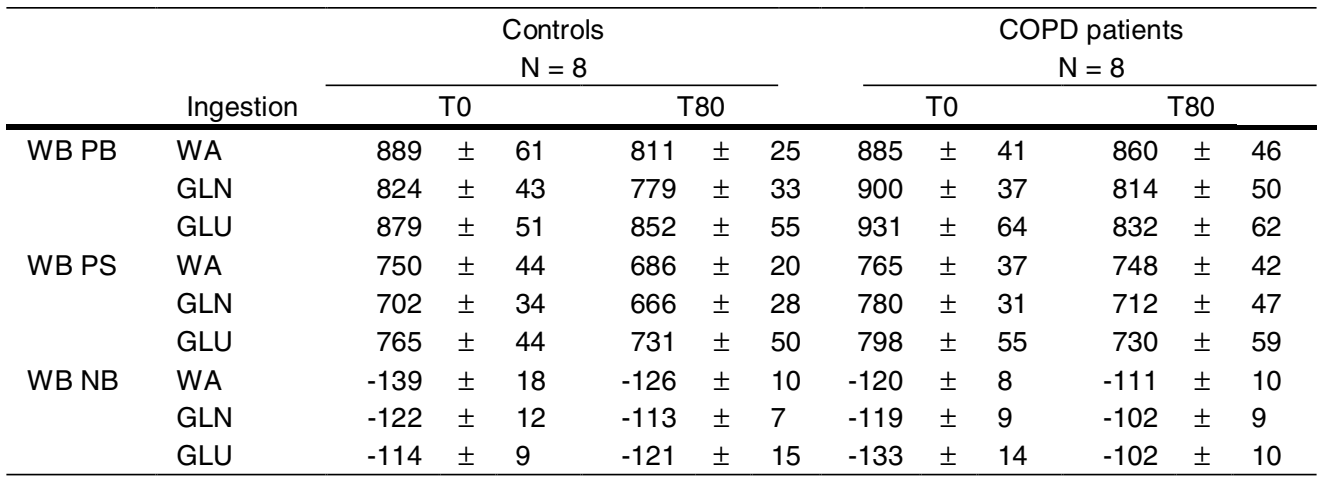

All values are mean \pm SEM, expressed in $\mathrm{nmol} / \mathrm{kg} \mathrm{FFM} / \mathrm{min}$. There was no significant drink effect, no significant interaction between group and drink, and no significant difference between the groups at T0. The one-sample Student's $t$-test test showed an overall change in time: $P<0.01$. Used abbreviations: WB PB = whole body protein breakdown, WB PS = whole body protein synthesis, WB NB = whole body net balance.

\section{Discussion}

Supplementation with glutamine and glutamate had different effects on plasma amino acid and urea concentrations. The effects were similar in healthy control subjects and COPD patients except for the effect of glutamate ingestion on plasma glutamate concentrations. Glutamine ingestion resulted in higher plasma citrulline and arginine concentrations, whereas glutamate ingestion reduced citrulline concentrations, did not increase plasma arginine concentrations but did increase ornithine concentrations. We could not detect a drink-specific effect of glutamine and glutamate supplementation on WB protein turnover compared with water ingestion. Thus, we concluded that supplementation with glutamine and glutamate has different effects on plasma amino acid concentrations. We hypothesized that these changes reflect intestinal metabolism.

\section{PLASMA AMINO ACID AND SUBSTRATE CONCENTRATION}

The only amino acid that was differed significantly between COPD patients and control subjects was ornithine, a finding that is in line with previous findings ${ }^{15}$. It is 
suggested that plasma ornithine concentrations are elevated during inflammation, as a result of enhanced arginase activity ${ }^{25}$. Because our patient group was characterized by high concentrations of C-reactive protein, a marker for systemic inflammatory response, the high plasma ornithine concentrations may well be related to the low-grade clinical inflammation in these patients.

Except for the glutamate concentration, supplementation with glutamine and glutamate resulted in the same effect on plasma amino acids concentrations and WB protein turnover in both groups. The underlying cause of the smaller increase in plasma glutamate concentrations after glutamate ingestion in the COPD group is speculative. That smaller increase may be due to an enhanced extraction of glutamate in the intestine or to a greater consumption of glutamate elsewhere.

Repeated ingestion of glutamine and glutamate (separately) induced a significant increase in plasma glutamate concentrations, although the increase was significantly lower after the intake of glutamine than after that of glutamate ( $50 \%$ vs. 500\% respectively). This finding suggests that the intestinal capacity to oxidize glutamate has reached its maximum and that an increase in the plasma glutamate concentrations follows. Furthermore, it is known that the splanchnic bed produces small amounts of glutamate from glutamine (glutamine $\rightarrow$ glutamate $+\mathrm{NH}_{3}$ ), which results in an increase in plasma glutamate concentrations after glutamine ingestion ${ }^{26}$. The glutamate-specific increase in plasma taurine concentration that we found in the current study is consistent with earlier findings after ingestion of monosodium glutamate ${ }^{27}$. Glutamate is linked with taurine via 2 different routes. In the presence of the enzyme taurine:a-ketoglutarate aminotransferase in skeletal muscle, glutamate can form taurine (glutamate + sulfoacetaldehyde $\leftrightarrow$ taurine $+\alpha-$ ketoglutarate) ${ }^{28}$. More often, however, glutamate has been associated with taurine because the glutamate receptor agonists N-methyl D-aspartate and alpha-amino-3hydroxy-5-methyl-4-isoxazole propionic acid receptors evoke the release of taurine from the brain into the extracellular tissue ${ }^{29}$. The functional importance of the glutamate-induced taurine increase should be investigated further.

In the current study, the ingestion of either glutamine or glutamate resulted in a decrease in plasma BCAA concentrations. In general, BCAA can be transaminated in skeletal muscle, where they act as the most important nitrogen donor in the synthesis of glutamine and alanine ${ }^{30}$. It has been shown in catabolic 
illness that the infusion of glutamine or alanine reduces the release of BCAA from the liver ${ }^{31}$, which may result in a lower plasma BCAA concentration. Moreover, glutamate acts as the precursor for BCAA in the liver via transamination reactions. Therefore, oral ingestion of glutamine and glutamate may have a BCAA-sparing effect that results in less BCAA production in the liver and, hence, in lower plasma BCAA concentrations.

We observed a significantly increased plasma citrulline and arginine concentration after glutamine ingestion. The intestine and the liver are the predominant sources for citrulline production. Glutamine is deaminated to glutamate and ammonia, and the latter stimulates the formation of carbamoyl phosphate (figure 3). Citrulline is formed from the transamination reaction of carbamoyl phosphate and ornithine via the enzyme ornithine carbamoyltransferase. In the liver, citrulline is further metabolized to arginine to produce urea and ornithine in the hepatic ornithine cycle. Therefore, circulating citrulline originated from the intestine rather than from the liver. Because the enzymes that convert citrulline to arginine are not present in the intestine ${ }^{32}$, citrulline is released to the circulation and taken up by the kidneys. In the presence of the enzymes argininosuccinate synthetase (ASS) and argininosuccinate lyase (ASC), citrulline is converted to arginine that is released in the circulation ${ }^{33}$. In the current study, plasma citrulline concentrations decreased after glutamate ingestion, whereas plasma ornithine concentrations increased; the opposite results were seen after glutamine ingestion. This finding implies that the amide amino group of glutamine as source of $\mathrm{NH}_{3}$ could be the rate-limiting substrate for carbamoyl phosphate production in the intestine. In the absence of $\mathrm{NH}_{3}$, glutamate may, instead, convert to glutamate- $y$-semialdehyde and be transaminated to ornithine by the enzyme ornithine-oxo-acid aminotransferase. The decrease of plasma urea concentrations after glutamate ingestion but not after glutamine ingestion in the current study confirms the hypothesis that, in the intestine as well as in the liver, the production of carbamoyl phosphate is dependent on ammonia from glutamine. Bolus ingestion of monosodium glutamate $(150 \mathrm{mg} / \mathrm{kg}$ body wt) did not significantly increase plasma ornithine concentrations in healthy young volunteers ${ }^{27}$, although there was a tendency of an increase of $\sim 33 \%$ after 60 min of ingestion, which is comparable to the $32 \%$ increase observed in the current study. 


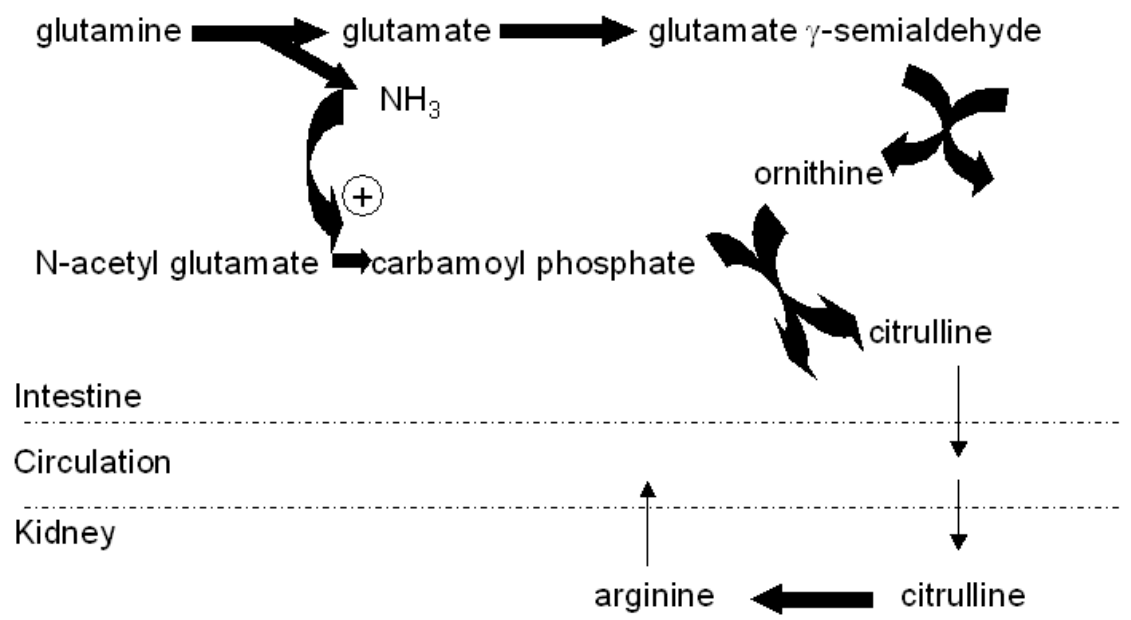

Figure 3: Schematic overview of the ornithine - citrulline - arginine cascade in the intestine and the kidney.

Baseline WB protein breakdown, synthesis and net balance did not differ significantly between the control group and the COPD group. Engelen et al ${ }^{34}$ observed significantly more WB protein synthesis and breakdown in COPD patients than in age-matched healthy control subjects. One factor that may contribute to the different findings in the 2 studies is the fact that the COPD patients had a different disease severity; that is, the patients in the study by Engelen et al had a greater degree of airflow obstruction than did the subjects in the current study. It can be posited that an increase in WB protein turnover is an adaptive process in the disturbed metabolism of patients with more severe COPD.

In time, WB protein breakdown and synthesis decreased overall, independent of the drink consumed. Supplementation of the amino acids glutamine and glutamate dissolved in water had no additional effect on WB protein turnover, although skeletal muscle glutamine concentration is often related to protein synthesis ${ }^{12}$. It is often suggested that preventing tissue glutamine decrease during catabolism could have a sparing effect on muscular amino acid concentrations and hence could increase protein synthesis ${ }^{35}$. Because hypo-osmolarity is known to have a protein-sparing effect ${ }^{36}$, it can be suggested that a water load of $\sim 500 \mathrm{~mL}$ in $80 \mathrm{~min}$, as in the current study, caused a decrease in protein turnover. 
Consequently, under the current circumstances, specific effects of glutamine and glutamate ingestion on WB protein turnover probably could not be detected. Future research is needed to study the effect of these amino acids when supplemented under different conditions - in the form of capsules, for example.

We can conclude that supplementation with glutamate results in a different response of several plasma amino acids than does that with glutamine, both in the healthy elderly and in COPD patients. Ingestion of glutamine but not of glutamate increased plasma concentrations of citrulline and arginine, substrates produced in the intestine and the liver. It may be possible that the amide amino group of glutamine as the source of $\mathrm{NH}_{3}$ is the rate-limiting substrate in this cascade of reactions. Moreover, except for taurine, the other amino acids and WB protein turnover responded similarly to glutamine and glutamate ingestion.

\section{References}

1. Hammarqvist F, Sandgren A, Andersson K, et al. Growth hormone together with glutaminecontaining total parenteral nutrition maintains muscle glutamine levels and results in a less negative nitrogen balance after surgical trauma. Surgery 2001; 129(5):576-86.

2. Flaring UB, Rooyackers OE, Wernerman J, Hammarqvist F. Glutamine attenuates post-traumatic glutathione depletion in human muscle. Clin Sci (Lond) 2003; 104(3):275-82.

3. Coster J, McCauley R, Hall J. Glutamine: metabolism and application in nutrition support. Asia Pac J Clin Nutr 2004; 13(1):25-31.

4. Luo JL, Hammarqvist F, Andersson K, Wernerman J. Skeletal muscle glutathione after surgical trauma. Ann Surg 1996; 223(4):420-7.

5. Engelen MPKJ, Schols AMWJ, Does JD, et al. Altered glutamate metabolism is associated with reduced muscle glutathione levels in patients with emphysema. Am.J.Respir.Crit.Care Med. 2000; 161:98-103.

6. Walker R, Lupien JR. The safety evaluation of monosodium glutamate. J Nutr 2000; 130(4S Suppl):1049S-52S.

7. Byck R, Schaumburg HH. Monosodium glutamate. N Engl J Med 1969; 281(5):275.

8. Newsholme P, Procopio J, Lima MM, et al. Glutamine and glutamate-their central role in cell metabolism and function. Cell Biochem Funct 2003; 21(1):1-9.

9. Bruce M, Constantin-Teodosiu D, Greenhaff PL, et al. Glutamine supplementation promotes anaplerosis but not oxidative energy delivery in human skeletal muscle. Am J Physiol Endocrinol Metab 2001; 280(4):E669-75.

10. Graham TE, Sgro V, Friars D, Gibala MJ. Glutamate ingestion: the plasma and muscle free amino acid pools of resting humans. Am J Physiol Endocrinol Metab 2000; 278(1):E83-E89.

11. Petersson B, von der Decken A, Vinnars E, Wernerman J. Long-term effects of postoperative total parenteral nutrition supplemented with glycylglutamine on subjective fatigue and muscle protein synthesis. Br J Surg 1994; 81(10):1520-3. 
12. Hammarqvist $\mathrm{F}$, Wernerman $\mathrm{J}$, Ali $\mathrm{R}$, et al. Addition of glutamine to total parenteral nutrition after elective abdominal surgery spares free glutamine in muscle, counteracts the fall in muscle protein synthesis, and improves nitrogen balance. Ann Surg 1989; 209(4):455-61.

13. Hasebe M, Suzuki H, Mori E, et al. Glutamate in enteral nutrition: can glutamate replace glutamine in supplementation to enteral nutrition in burned rats? JPEN J Parenter Enteral Nutr 1999; 23(5 Suppl):S78-82.

14. Pouw EM, Schols AMWJ, Deutz NEP, Wouters EFM. Plasma and muscle amino-acid levels in relation to resting energy expenditure and inflammation in stable COPD. Am.J.Respir.Crit.Care Med. 1998; 158:797-801.

15. Engelen MP, Wouters EF, Deutz NE, et al. Factors contributing to alterations in skeletal muscle and plasma amino acid profiles in patients with chronic obstructive pulmonary disease. Am J Clin Nutr 2000; 72(6):1480-7.

16. Picado $\mathrm{C}$, Deulofeu R, Lleonart R, et al. Lipid and protein metabolism in asthma. Effects of diet and corticosteroid therapy. Allergy 1999; 54(6):569-75.

17. Clausen JL, Coates AL, Quanjer PH. Measurement of lung volumes in humans: review and recommendations from an ATS/ERS workshop. Eur Respir J 1997; 10(6):1205-6.

18. Abumrad NN, Rabin D, Diamond MP, Lacy WW. Use of a heated superficial hand vein as an alternative site for the measurement of amino acid concentrations and for the study of glucose and alanine kinetics in man. Metabolism 1981; 30(9):936-40.

19. Van Eijk HMH, Rooyakkers DR, Deutz NEP. Rapid routine determination of amino acids in plasma by high-performance liquid chromatography with a 2-3 um Sperisorb ODS 2 column. J.Chromat. 1993; 620:143-148.

20. Van Eijk HM, Rooyakkers DR, Soeters PB, Deutz NE. Determination of amino acid isotope enrichment using liquid chromatography-mass spectrometry. Anal Biochem 1999; 271(1):8-17.

21. Neeley WE, Phillipson J. Automated enzymatic method for determining ammonia in plasma, with 14- day reagent stability. Clin Chem 1988; 34(9):1868-9.

22. Engelen MPKJ, Deutz NEP, Wouters EFM, Schols AMWJ. Enhanced levels of whole body protein turnover in patients with chronic obstructive pulmonary disease. Am.J.Respir.Crit. Care Med. 2000; 162(4Pt1):1488-92.

23. Steiner MC, Barton RL, Singh SJ, Morgan MD. Bedside methods versus dual energy X-ray absorptiometry for body composition measurement in COPD. Eur Respir J 2002; 19(4):626-31.

24. Kyle UG, Bosaeus I, De Lorenzo AD, et al. Bioelectrical impedance analysis--part I: review of principles and methods. Clin Nutr 2004; 23(5):1226-43.

25. Bachetti T, Comini L, Francolini G, et al. Arginase pathway in human endothelial cells in pathophysiological conditions. J Mol Cell Cardiol 2004; 37(2):515-23.

26. Matthews DE, Marano MA, Campbell RG. Splanchnic bed utilization of glutamine and glutamic acid in humans. Am J Physiol 1993; 264(6 Pt 1):E848-54.

27. Mourtzakis $M$, Graham TE. Glutamate ingestion and its effects at rest and during exercise in humans. J Appl Physiol 2002; 93(4):1251-9.

28. Yonaha K, Toyama S, Soda K. Taurine-glutamate transaminase. Methods Enzymol 1985; 113:102-8.

29. Oja SS, Saransaari P. Modulation of taurine release by glutamate receptors and nitric oxide. Prog Neurobiol 2000; 62(4):407-25.

30. Wagenmakers AJ, Coakley $\mathrm{JH}$, Edwards RH. Metabolism of branched-chain amino acids and ammonia during exercise: clues from McArdle's disease. Int J Sports Med 1990; 11 Suppl 2:S10113.

31. Holecek M. Relation between glutamine, branched-chain amino acids, and protein metabolism. Nutrition 2002; 18(2):130-3.

32. Windmueller HG. Glutamine utilization by the small intestine. Adv Enzymol Relat Areas Mol Biol 1982; 53:201-37.

33. Windmueller HG, Spaeth AE. Source and fate of circulating citrulline. Am J Physiol 1981; 241(6):E473-80. 
34. Engelen MP, Schols AM. Altered amino acid metabolism in chronic obstructive pulmonary disease: new therapeutic perspective? Curr Opin Clin Nutr Metab Care 2003; 6(1):73-8.

35. Thomas S, Prabhu R, Balasubramanian KA. Surgical manipulation of the intestine and distant organ damage-protection by oral glutamine supplementation. Surgery 2005; 137(1):48-55.

36. Berneis K, Ninnis R, Haussinger D, Keller U. Effects of hyper- and hypoosmolality on whole body protein and glucose kinetics in humans. Am J Physiol 1999; 276(1 Pt 1):E188-95. 


\title{
Chapter 7
}

\section{Skeletal muscle glutamate metabolism in health and disease: state of the art}

\author{
Erica P.A. Rutten, Marielle P.K.J. Engelen, Annemie M.W.J. Schols, \\ Nicolaas E.P. Deutz \\ Curr Opin Clin Nutr Metab Care 2005; 8: 41-51
}

\section{Abstract}

Purpose of review: Glutamate is an amino acid of interest because it participates in many metabolic pathways. However, there is evidence that skeletal muscle glutamate metabolism is disturbed in disease. This review presents current knowledge regarding the metabolic function and regulation of glutamate in skeletal muscle under physiological and pathophysiological circumstances. Furthermore, several options for modulating muscle glutamate concentration in order to improve glutamate metabolism are discussed.

Recent findings: The high correlation between muscle glutamate concentration and muscle glutathione concentration suggests that glutamate plays a determining role in the glutathione synthesis pathway. During exercise, glutamate plays a central role in energy provision because it participates in the tricarboxylic acid and the purine nucleotide cycles. However, a consistent finding in several diseases is reduced skeletal muscle glutamate. Remarkably, only few studies focused on modulation of muscle glutamate status either by exercise or by nutritional supplementation. There are several options for modulating glutamate metabolism, but the specific effects of the individual options require further elucidation. Nutritional supplementation of glutamate or its precursors glutamine, (ornithine) $\alpha$ ketoglutarate, or the branched chain amino acids can influence muscle glutamate status.

Summary: Specific intervention studies must be conducted to investigate the effect of supplementation on skeletal muscle glutamate turnover and its related metabolic and functional consequences in healthy individuals and in patients with acute or chronic disease.

Keywords: glutamate, metabolism, skeletal muscle 


\section{Introduction}

Skeletal muscle wasting is often seen in catabolic conditions related to chronic or acute disease. Disturbances in protein and amino acid metabolism are consistently reported under such circumstances. A remarkable finding is reduced skeletal muscle glutamate concentration ${ }^{1,2}$, which was present in different skeletal muscle groups. Glutamate is an amino acid known to play a central role in all transamination reactions in the body as well as in many other metabolic pathways in various organs at rest and during physical activity. However, only few studies have yet focused on the specific role played by glutamate in skeletal muscle or on possible options for modulating skeletal muscle glutamate status in disease. Therefore, this review presents the current knowledge regarding the metabolic function and regulation of glutamate in skeletal muscle under physiological and pathophysiological circumstances. Furthermore, several options for modulating muscle glutamate concentration in order to improve glutamate metabolism are discussed.

\section{Glutamate in skeletal muscle}

The major sink for glutamate is skeletal muscle, where it is involved in various metabolic pathways. Before we discuss glutamate metabolism in skeletal muscle, we consider specific features of glutamate in skeletal muscle.

\section{GLUTAMATE TRANSPORTERS IN SKELETAL MUSCLE}

The three amino acids glutamate, alanine and glutamine (GLN) represent about $79 \%$ of the total free amino acid pool that can be incorporated into protein in humans, with glutamate having the greatest intracellular to plasma gradient ${ }^{3}$. Marliss et al ${ }^{4}$ were the first to show a net glutamate uptake in human skeletal muscle in the postabsorptive state, although muscular glutamate concentration is far higher than plasma glutamate level (in healthy humans the plasma glutamate concentration is about $64 \mathrm{mmol} / \mathrm{L}$ and the muscle glutamate concentration is about $4000 \mathrm{mmol} / \mathrm{kg}$ wet weight ${ }^{5}$ ). Therefore, passive diffusion of glutamate into muscle 
seems unlikely. A specific active transport carrier for the dicarboxic amino acids glutamate and aspartate was first detected in the perfused rat hindlimb ${ }^{6}$. This transporter was termed the $\mathrm{X}_{\mathrm{ag}}$ system and is characterized by a high specificity and low capacity, with the following kinetic parameters: maximum rate of transport (Vmax) of about $80 \mathrm{mmol} / \mathrm{kg}$ wet weight $/ \mathrm{min}$, and substrate concentration where transport rate is half of $\operatorname{Vmax}(\mathrm{Km})$ is about $1000 \mathrm{mmol} / \mathrm{L}$. There is a close relationship between muscular glutamine availability and muscular glutamate uptake, because muscular glutamine deprivation stimulates glutamate uptake by upregulating the $X_{\text {ag }}$ transport system ${ }^{7}$. Furthermore, the activity of the $X_{\text {ag }}^{-}$system is dependent on changes in $\mathrm{pH}$ rather that on sodium or hormones such as insulin. Other transport systems are also involved in muscular glutamate transport, including the $\mathrm{X}_{\mathrm{c}}$ transporter for cysteine transport and the $\mathrm{A}$ transporter for alanine transport ${ }^{8}$. However, most of the glutamate uptake takes place via the $X_{\text {ag }}$ transporter ${ }^{6}$.

\section{GLUTAMATE STATUS IN DIFFERENT MUSCLE FIBERS}

Glutamate is highly compartmentalized in skeletal muscle. Therefore, the question arises of whether there is an association between muscle fiber distribution and muscular glutamate level. Until now, only few studies have examined a potential relationship between amino acid profile and fiber type distribution in muscle. These studies were conducted in various species (rat, human) and in different muscle groups, which makes it difficult to compare studies and to draw firm conclusions. In rat hindlimb, glutamate was among the predominant amino acids responsible for the higher amino acid concentration in soleus muscle (characterized by a higher percentage of slow twitch or type I fibers) than in plantaris and gastrocnemius muscle (characterized by a higher percentage of fast twitch or type II fibers) ${ }^{9}$. Glutamate concentration in soleus muscle was $15.2 \mathrm{mmol} / \mathrm{kg}$ wet weight $(12 \%$ of total measured free amino acids), whereas it was only $4.3 \mathrm{mmol} / \mathrm{kg}$ wet weight $(6 \%$ of total measured free amino acids) in muscle with predominantly fast twitch fibers. Based on these findings, one may speculate that glutamate is of particular importance in aerobic energy provision because slow twitch fibers have numerous mitochondria and high aerobic enzyme capacity whereas fast twitch fibers are characterized by high anaerobic capacity. In contrast, in patients with chronic 
obstructive pulmonary disease ${ }^{10}$, no relationship was found between muscle glutamate concentration and fiber type distribution in quadriceps femoris muscle, which is characterized by a low proportion of type I fibers (26\%), and in diaphragm muscle, which has a higher percentage of type I fibers (70\%). These findings are in accordance with those of another study conducted in humans ${ }^{11}$, in which amino acid concentration in separate pools of different (single) fiber types in vastus lateralis muscle was measured. A $9 \%$ lower glutamate concentration was found in type I than in type II fibers $(2.2 \mathrm{mmol} / \mathrm{kg}$ wet weight versus $2.4 \mathrm{mmol} / \mathrm{kg}$ wet weight, respectively; not statistically significant), and exercise resulted in a decrease in glutamate concentration in both types. In contrast to the animal study, these data from studies conducted in humans suggest that there is no relationship between muscle fiber type distribution and glutamate status in human muscle. More research in this area is clearly warranted.

\section{SOURCES OF INTRAMUSCULAR GLUTAMATE}

Glutamate is delivered to skeletal muscle via different metabolic pathways (figure 1). Firstly, as discussed above, glutamate is actively taken up from the circulation by the $\mathrm{X}_{\text {ag }}$ transporter. Plasma glutamate concentration is much lower than the $\mathrm{Km}$ of the glutamate transporter $(64 \mathrm{mmol} / \mathrm{l}$ versus $1000 \mathrm{mmol} / \mathrm{l})$. With a Vmax of 80 $\mathrm{mmol} / \mathrm{kg}$ wet weight $/ \mathrm{min}$, the rate of glutamate uptake is assumed to have a linear relation with concentration, and is about $2.56 \mathrm{mmol} / \mathrm{kg}$ wet weight/min. For a $70 \mathrm{~kg}$ individual with $40 \%$ free fat mass (FFM), it is estimated that muscular glutamate uptake will be about $72 \mathrm{mmol} / \mathrm{min}$. Secondly, glutamate is released by intracellular protein degradation. Myofibrillar protein, the contracting protein of muscle that consists of actin and myosin filaments in a molar ratio of $5: 2^{12}$, constitutes $50-55 \%$ of muscle protein. If we calculate the amount of glutamate in myofibrillar protein, 1 mol actin contains $1 \mathrm{~mol} 3$-methylhistidine and $28 \mathrm{~mol}$ glutamate, whereas $1 \mathrm{~mol}$ myosin contains $1 \mathrm{~mol} 3$ - methylhistidine and, surprisingly, 284 mol glutamate ${ }^{13,14}$. Taking into account a myofibrillar protein breakdown of $0.01 \mathrm{mmol} / \mathrm{kg} \mathrm{FFM} / \mathrm{min}$, measured with 3 methylhistidine (unpublished data), every minute $1 \mathrm{mmol}$ glutamate/kg FFM is released from myofibrillar protein. A $70 \mathrm{~kg}$ individual with $40 \%$ FFM derives about $28 \mathrm{mmol}$ glutamate/min from myofibrillar protein breakdown, which contributes a significant amount to intramuscular glutamate concentration. 


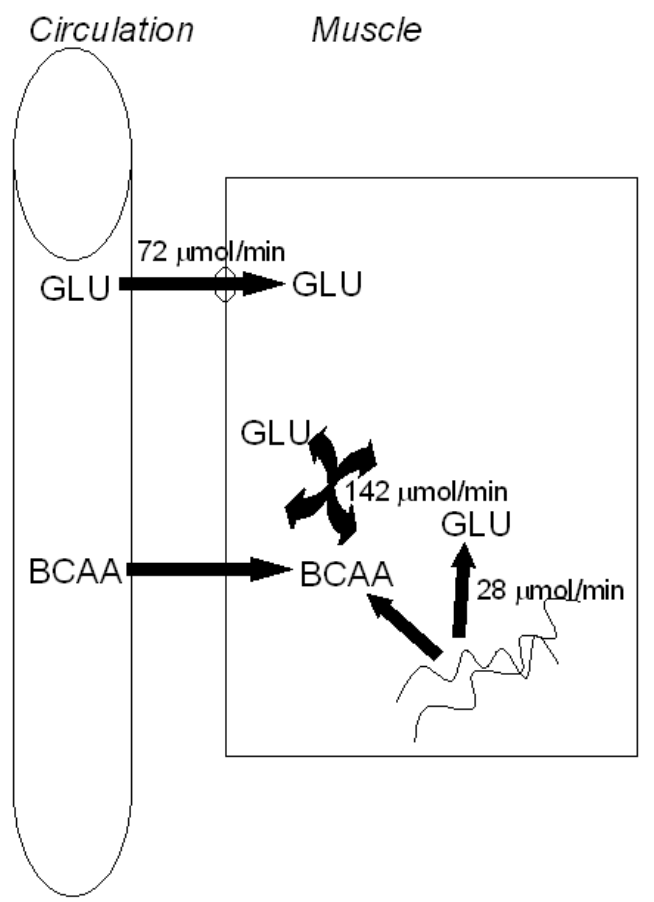

Figure 1: Schematic overview of GLU delivery to skeletal muscle in a $70 \mathrm{~kg}$ subject. Delivery of GLU to skeletal muscle: (1) by uptake from the circulation (about $72 \mu \mathrm{mol} / \mathrm{min}$ ), (2) by muscle protein degradation (about $28 \mu \mathrm{mol} / \mathrm{min}$ ) and (3) from transamination of BCAA (about $142 \mu \mathrm{mol} / \mathrm{min}$ ).

Thirdly, glutamate is synthesized by transamination of the branched-chain amino acids (BCAAs; leucine, isoleucine and valine), which are the predominant amino acids that are oxidized in skeletal muscle. In this reaction, BCAAs react with $\alpha$ ketoglutarate to produce $\alpha$-ketoacids and glutamate in the presence of the BCAA aminotransaminase enzyme ${ }^{15}$. This enzyme accepts all three BCAAs as substrates ${ }^{16}$, but the oxidation rate differs slightly between BCAAs. Matthews and coworkers ${ }^{17}$ suggested that about $122 \mathrm{mmol}$ leucine/kg per $\mathrm{h}$ is transaminated to a-ketoisocaproate in the fasted state. For valine, a lower rate of about $88 \mathrm{mmol} / \mathrm{kg}$ per $\mathrm{h}$ is found ${ }^{18}$. To our knowledge, no data are available about the oxidation rate for isoleucine. Taking into account the transamination rate for leucine, a $70 \mathrm{~kg}$ person will convert about $142 \mathrm{mmol}$ leucine/min to glutamate. Even although it is suggested that $\alpha$-ketoisocaproate is reaminated to leucine in high quantities, this 
reaction mainly occurs in the liver. Therefore, the transamination reaction of leucine in muscle acts as a significant source of intramuscular glutamate.

In summary, uptake, protein breakdown and transamination are the main routes of glutamate delivery in skeletal muscle. Summing the amount of glutamate production by these routes, about $242 \mathrm{mmol}$ glutamate/min is produced in skeletal muscle. With an intramuscular glutamate concentration of $4000 \mathrm{mmol} / \mathrm{kg}$ wet weight, we can conclude that the intracellular glutamate turnover rate is relatively small and that glutamate is highly compartmentalized in muscle.

\section{Skeletal muscle glutamate metabolism}

Glutamate in skeletal muscle participates in various metabolic pathways, both at rest and during contraction. Here we provide an overview of these pathways.

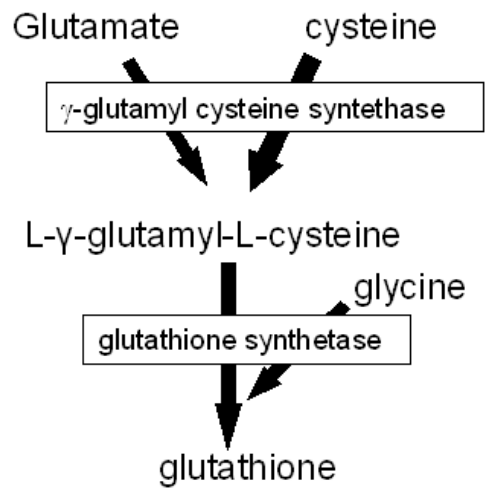

Figure 2: Schematic overview of the gluthatione synthesis.

\section{GLUTAMATE AS A PRECURSOR FOR GLUTATHIONE SYNTHESIS}

Glutamate, cysteine and glycine are the precursor amino acids for the most abundant intracellular antioxidant, namely glutathione (figure 2$)^{19}$. In the first and rate-limiting step of the glutathione synthesis pathway, glutamate is combined with cysteine to form $\mathrm{Y}$-glutamyl-cysteine. Consequently, glutamate and cysteine availability are important to glutathione synthesis. Recent studies ${ }^{20-24}$ conducted in several catabolic conditions showed decreased muscular levels of glutathione together with decreased muscular glutamate levels, but preserved levels of 
cysteine (table 1). When plotting values of muscular glutamate against glutathione concentration from available studies, a high correlation between these parameters ( $r=0.88$; figure $3 a)$ is found, whereas correlations between muscle glutathione concentration and muscle cysteine $(r=0.07$; figure $3 \mathbf{b})$, glycine $(r=0.11)$ and glutamine $(r=0.36)$ concentrations are much lower. These data imply that glutamate concentration is a significant limiting factor in glutathione synthesis. Glutamate can regulate glutathione synthesis in several metabolic pathways. First, it is suggested that there is competition between glutamate and glutathione by a negative feedback mechanism ${ }^{25}$. Glutathione binds to the glutamate binding site of the enzyme $y$-glutamyl-cysteine synthetase, which indicates that glutamate and glutathione compete for $\mathrm{y}$-glutamyl-cysteine synthetase, and thus glutamate plays a determining role in glutathione synthesis. Second, apart from the $\mathrm{X}_{\text {ag }}$ transporter for glutamate uptake in muscle, there is evidence that a small portion of glutamate is also taken up by the cysteine-dependent $\mathrm{X}_{\mathrm{c}}$ transporter via an antiport mechanism ${ }^{7}$. Thus, glutamate and cysteine may compete for muscular uptake. However, as mentioned above, the relationship between muscular cysteine and glutathione concentration is very weak, suggesting that this pathway is of minor importance. Clearly, further research is warranted to unravel the importance and the exact mechanism of glutamate regulation in the glutathione synthesis pathway.

\section{GLUTAMATE INDUCED INSULIN PRODUCTION}

Thomassen et al. ${ }^{26}$ showed enhanced levels of insulin when glutamate is infused intravenously. Insulin concentration increased promptly and prominently after glutamate infusion. These findings are in accordance with amino acid induced insulin secretion ${ }^{27}$. Oral administration of monosodium glutamate (MSG; 150 $\mathrm{mg} / \mathrm{kg}$ ) in healthy human volunteers in the fasted state induced a $175 \%$ increase in plasma insulin concentration ${ }^{28}$. The peak increase in insulin was reached before the glutamate concentration reached its peak in the circulation. These results suggest that there are different mechanisms of the glutamate induced insulin response, depending on the way in which glutamate is administrated. When glutamate is given orally, as in the study by Graham et al. ${ }^{28}$, a preabsorptive phase in or even before the stomach may result in indirect stimulation of insulin secretion. 


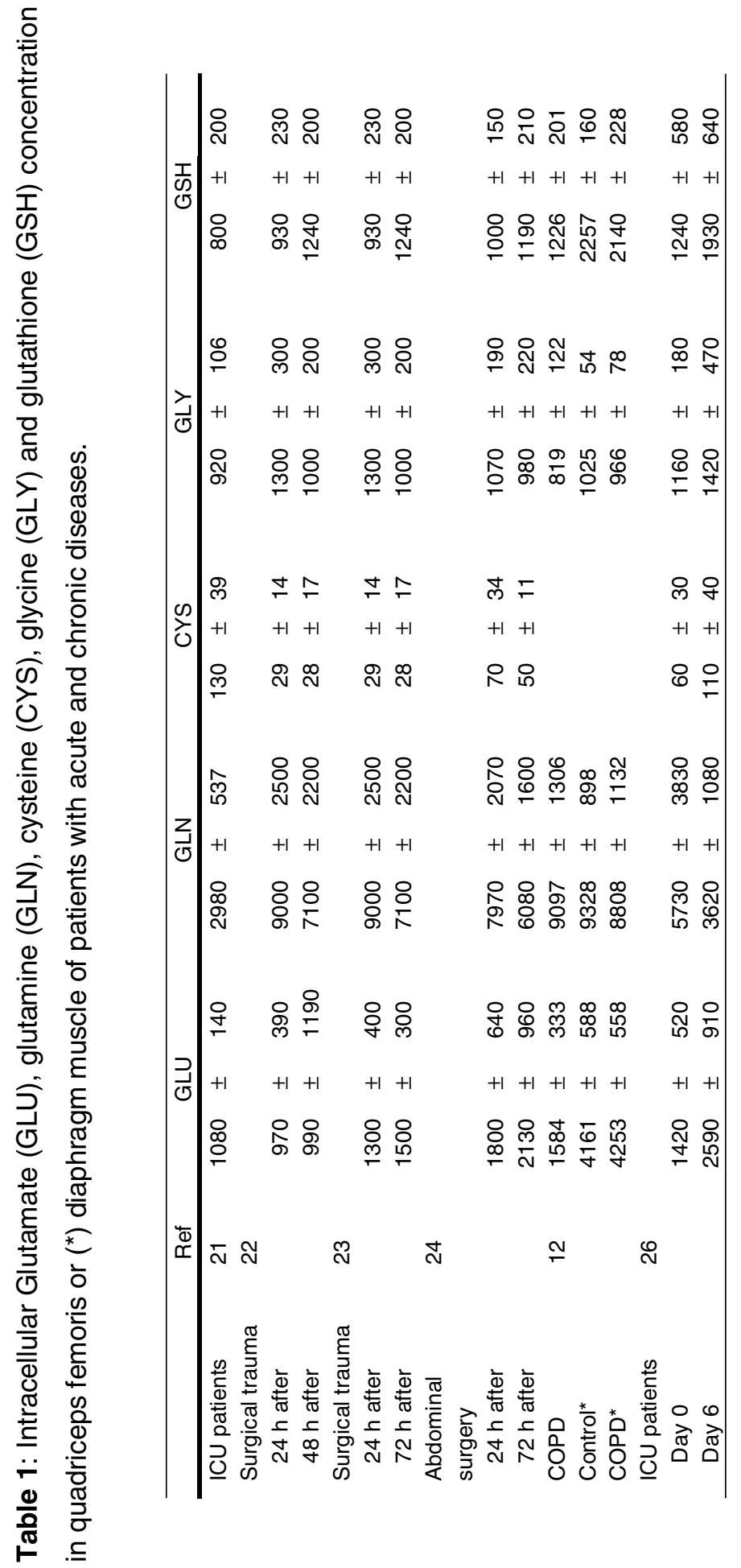


However, Maechler et al. ${ }^{29}$ demonstrated that glutamate also acts as an intracellular messenger that couples glucose production to insulin secretion by an additional effect of intracellular glutamate on intracellular calcium. It can therefore be suggested that glutamate acts as a potentiator, rather than an initiator, for insulin release.

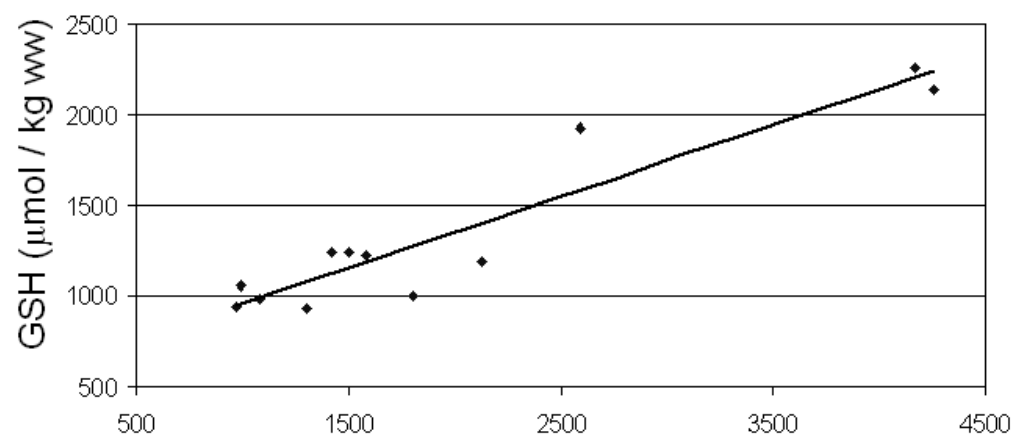

$\mathrm{GLU}(\mu \mathrm{mol} / \mathrm{kg} \mathrm{ww})$

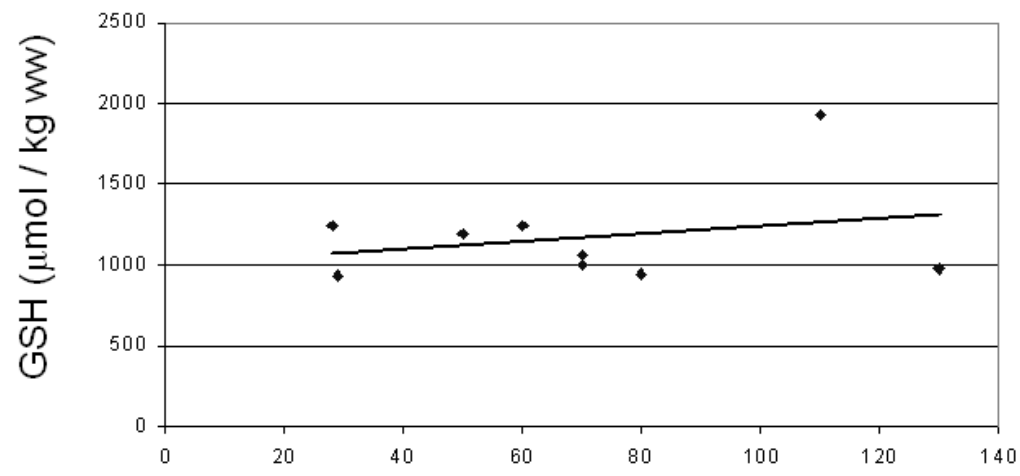

CYS $(\mu \mathrm{mol} / \mathrm{kg} \mathrm{ww})$

Figure 3: a: Scatter plot of muscle glutamate $(r=0.88)$ and glutathione concentration in different patient groups listed in table 1. b: Scatter plot of muscle cysteine $(r=0.07)$ and glutathione concentration in different patient groups listed in table 1.

\section{GLUTAMATE AND THE TRICARBOXYLIC ACID CYCLE}

Although glutamate is the only amino acid that is taken up by contracting muscle, the muscle glutamate concentration decreases during the first minutes of exercise and remains low until fatigue develops ${ }^{30,31}$. This pattern is accompanied by an 
increase in muscle alanine and pyruvate concentrations, and a decrease in muscle glycogen concentration ${ }^{31,32}$. Furthermore, at the onset of exercise, tricarboxylic acid intermediates (TCAls) and tricarboxylic acid (TCA) flux increase rapidly ${ }^{31,33}$. In accordance with these findings, the alanine aminotransaminase (AAT) reaction (glutamate + pyruvate $\rightarrow$ alanine + a-ketoglutarate; figure 4 ) is generally accepted to be the most prominent reaction for anaplerosis (replenishment of TCAls) during the first minutes of exercise. Glutamate may play an important role in the anaplerotic process during exercise, because formation of a-ketoglutarate by AAT could be the driving force for TCA flux. In addition, the increased TCAI pool is the result of the sum of the increased TCAls in the second span of the TCA cycle, specifically malate, fumarate and succinate. These TCAls are derived from $\alpha-$ ketoglutarate, and because muscle a-ketoglutarate concentration decreases during exercise, there may be a very rapid turnover of $\alpha$-ketoglutarate ${ }^{34}$. In contrast, the TCA flux increases at a much higher level than do TCAls ${ }^{34}$, and it remains speculative whether TCAls are the driving force for TCA flux or whether pool expansion only occurs when the rate of pyruvate production from glycolysis exceeds its rate of oxidation (entering the TCA cycle via acetyl-coenzyme A; figure 4 ) in the TCA cycle ${ }^{35}$. Hence, glutamate functions as a scavenger for pyruvate and produces a-ketoglutarate and its derivatives. More research is needed to determine whether modulating the TCAls by substrates of the AAT may affect TCA flux, and hence muscle energy provision.

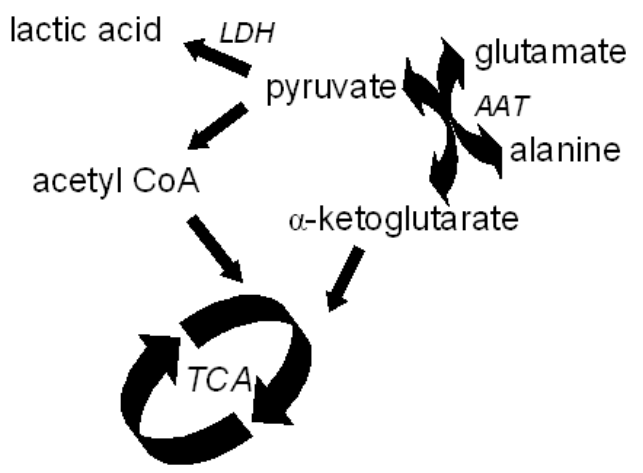

Figure 4: Schematic overview of the role of glutamate in the energy metabolism in skeletal muscle. Abbreviations: $\mathrm{LDH}=$ lactate dehydrogenase, $\mathrm{AAT}=$ alanine aminotransaminase, $\mathrm{TCA}=$ tricarboxic acid cycle. 


\section{GLUTAMATE AND THE PURINE NUCLEOTIDE CYCLE}

The transamination reaction of glutamate with oxaloacetate results in the formation of aspartate, the amino acid that is involved in the purine nucleotide cycle (PNC) ${ }^{36}$. The net reaction of the PNC is as follows: aspartate + guanosine triphosphate $\rightarrow$ fumarate + guanine diphosphate + inorganic phosphate $+\mathrm{NH}_{3}$. However, this cycle involves a whole cascade of reactions (figure 5) and covers several functions. Firstly, it has been suggested that net formation of $\mathrm{NH}_{3}$ via the PNC plays a significant role in free nitrogen production in muscle, especially during exercise ${ }^{36}$.

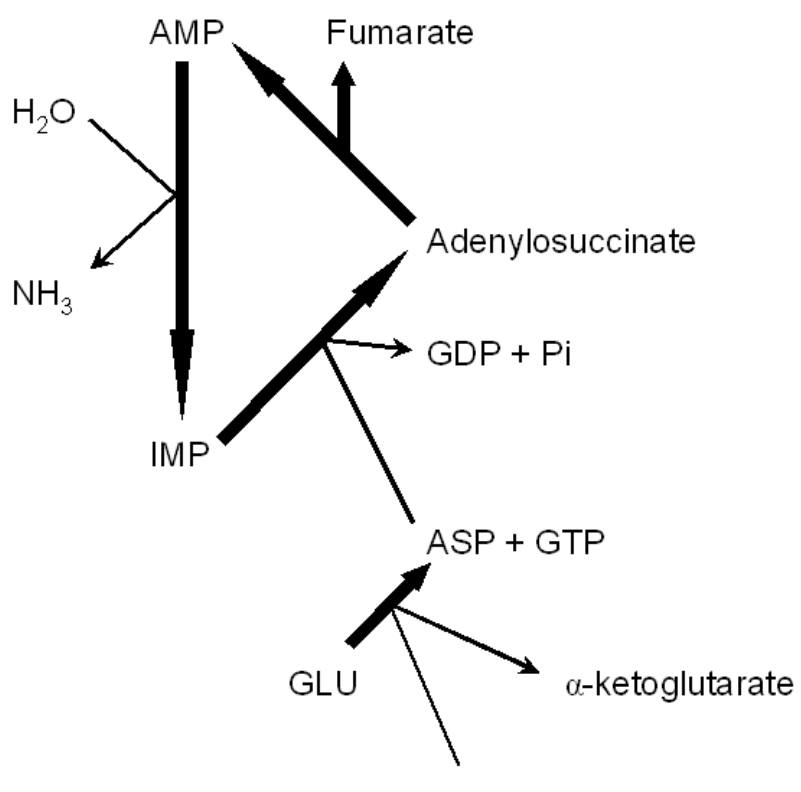

Oxaloacetate

Figure 5: Schematic overview of the purine nucleotide cycle in skeletal muscle. Abbreviations: AMP = adenosine monophosphate, IMP $=$ inosine monophosphate, $\mathrm{H}_{2} \mathrm{O}=$ water, $\mathrm{NH}_{3}=$ ammonia, $\mathrm{ASP}=$ aspartate, $\mathrm{GLU}=$ glutamate, $\mathrm{GTP}=$ guanosine triphosphate, GDP $=$ guanosine diphosphate, $\mathrm{Pi}=$ phosphate

Secondly, the PNC is a regulatory pathway for relative balance of the adenine nucleotides adenosine monophosphate, adenosine diphosphate and adenosine triphosphate via recycling of inosine monophosphate (IMP) in the following reaction: IMP $\rightarrow$ adenylosuccinate $\rightarrow$ adenosine monophosphate $\rightarrow$ IMP. Finally, the PNC involves delivery of TCAls as fumarate from adenosylsuccinate and a- 
ketoglutarate from glutamate. As discussed above, these intermediates are thought to be responsible for increased TCA flux, particularly during the first minutes of exercise. However, release of free $\mathrm{NH}_{3}$ and muscle IMP concentration increased much more at the end of exercise than at the beginning, whereas muscle glutamate concentration decreased continuously during exercise ${ }^{31}$. These data indicate that PNC activation is especially enhanced at the end of exercise through exhaustion.

\section{Altered muscle glutamate metabolism during acute and chronic disease}

Decreased skeletal muscle glutamate concentration is consistently observed in many acute and chronic diseases (table 2). To gain more insight into the mechanism of decreased glutamate concentration in muscle and the potential factors involved, it is essential to first address the question of whether decreased glutamate concentration is the result of decreased delivery of glutamate by muscle, decreased glutamate uptake from the circulation, or enhanced consumption of glutamate by the muscle cell. In general, glutamate is the only amino acid that is actively taken up by muscle in the postabsorptive state. A study in cancer patients 37 showed decreased muscle glutamate uptake, as measured by arteriovenous differences. It remains to be determined whether this is related to the decreased glutamate level in muscle. In contrast, the muscle protein degradation that often accompanies acute and chronic stress leads to increased intracellular glutamate concentration ${ }^{38}$, and would therefore serve as a source of muscular glutamate. In acute disease, decreased muscular glutamate levels are accompanied by a parallel increase in muscle alanine concentration. This may reflect greater consumption of glutamate via increased AAT reaction. In this way, glutamate may act as a compensatory mechanism to provide enough energy substrate for muscle. The underlying mechanism responsible for the reduced intracellular glutamate concentration in these disease states is probably multifactorial. In this review, two factors that are involved in disturbed muscle glutamate status are discussed. However, possible other disease-related factors may also be involved in disturbed glutamate metabolism. 
Table 2: Overview of studies reporting muscle GLU concentration in the quadriceps femoris of several diseases and disease states.

\begin{tabular}{lll}
\hline & Muscle [GLU] & Ref \\
\hline Abdominal surgery & & 1 \\
$12 \mathrm{~h}$ after & $\downarrow$ & \\
$24 \mathrm{~h}$ after & $\downarrow$ & \\
Surgical trauma & & 23 \\
$24 \mathrm{~h}$ after & $\downarrow$ & \\
$72 \mathrm{~h}$ after & $\downarrow$ & \\
Stress hormone infusion & & 40 \\
$6 \mathrm{~h}$ after & $\downarrow$ & \\
$12 \mathrm{~h}$ after & $\downarrow$ & \\
$24 \mathrm{~h}$ after & $=$ & \\
COPD & & 2 \\
Emphysema & $\downarrow$ & \\
Bronchitis & $=$ & \\
\hline
\end{tabular}

\section{HYPOXIA}

\section{Myocardium}

Several chronic diseases such as chronic obstructive pulmonary disease, cardiovascular and peripheral vascular diseases are characterized by the presence of hypoxia. Several studies have examined the role of hypoxia on myocardial glutamate metabolism. Myocardial glutamate extraction was found to be increased during ischaemia or hypoxia induced by cardiovascular disease ${ }^{37,38}$. Increased myocardial glutamate extraction was associated with increased glucose and lactate extraction and glutamine release, whereas ammonia release was decreased ${ }^{37}$. Pietersen et al ${ }^{39}$ evaluated the fate of myocardial glutamate in patients undergoing coronary arterial bypass grafting. They reported that approximately $85 \%$ of the glutamate tracer in the myocardium was released as ${ }^{13} \mathrm{CO}_{2}$. This finding led to the suggestion that there is greater consumption or utilization of glutamate in ischaemic myocardium. In accordance with this is that myocardial glutamate may be of importance to maintenance of increased glucose extraction in these patients via shunting of pyruvate into alanine instead of lactate. However, because the myocardial extraction fraction of glutamate reached $90 \%$ of the arterial glutamate concentration, insufficient supply and thus depletion of tissue glutamate content may occur during hypoxia ${ }^{40-42}$. Several studies ${ }^{43-45}$ have evaluated the effect of 
glutamate infusion on myocardial glutamate uptake and glutamate (related) metabolism in cardiovascular patients. Overall, glutamate infusion induced increased myocardial uptake of glutamate, which reached a maximum that was independent of arterial glutamate level ${ }^{39}$. In addition, arterial insulin and glucose levels increased, whereas those of lactate, alanine and free fatty acids decreased. Svedjeholm et al ${ }^{45}$ demonstrated enhanced myocardial lactic acid consumption after glutamate infusion, again suggesting that glutamate plays a role in energy provision in the hypoxic myocardium.

\section{Skeletal muscle}

Few human data are available on the effects of hypoxia on glutamate metabolism in skeletal muscle. In patients with chronic obstructive pulmonary disease, the reduced muscle glutamate concentration was associated with reduced lactic acid threshold, which is the level of oxygen consumption (Vo2) beyond which lactic acid concentration increases linearly ${ }^{46}$. Furthermore, patients who were characterized by a lower resting arterial oxygen tension did have lower values for muscle glutamate and lactic acid threshold than did those with normal values for oxygen tension. These findings suggest a role for glutamate in glycolysis during anaerobic conditions. However, supplementation of glutamate in healthy volunteers performing cycle exercise did not result in a change in plasma lactic acid concentration ${ }^{47}$. The effect of glutamate supplementation on lactic acid metabolism in hypoxic patients performing exercise is not yet known. Therefore, research is needed to investigate whether glutamate supplementation can play a functional role in preventing early lactic acid production by skeletal muscle during hypoxic conditions.

\section{OXIDATIVE STRESS}

Glutamate availability may be crucial for intracellular glutathione synthesis (see above). Decreased glutamate concentrations were detected in muscle biopsies taken from intensive care unit patients before and $24 \mathrm{~h}$ and $72 \mathrm{~h}$ after surgery ${ }^{23}$. In addition, muscular total glutathione concentration was also decreased compared with baseline, but there was no correlation between the two parameters. Three days after surgery muscle glutathione concentration normalized to baseline levels 
and even reached higher values 6 days after surgery ${ }^{24}$. This normalization of glutathione was accompanied by a parallel increase in muscular glutamate level but not of glutamine or cysteine. In accordance with this, Engelen and Schols ${ }^{21}$ detected a relation between decreased muscular glutamate levels in patients with chronic obstructive pulmonary disease and decreased muscular glutathione level. Flaring et al. ${ }^{48}$ investigated whether glutamine infusion, as a precursor of glutamate, could prevent glutathione depletion after trauma. Glutamine infusion did not have an effect on muscular glutamine or glutamate concentration but depletion of muscular glutathione concentration was prevented. Because the change in muscular glutamine and glutamate concentration correlated with the change in glutathione, those investigators suggested that the attenuation in glutathione was accompanied by an increased flux through the glutamine and glutamate pools without increasing their pool size. The exact mechanism of this increase in muscle glutathione is not yet clear, but it has been observed that skeletal muscle glutamine uptake is lower than muscle glutamine release, both in the fasted state and after an amino acid mixture with or without glucose ${ }^{49}$. This leads to a net release of glutamine, while glutamate is actively taken up by muscle. Consequently, direct infusion of glutamate would be more efficient in restoring the muscular glutathione pool. In conclusion, it is clear that intracellular glutathione is decreased by stressful events/states such as surgery, trauma, or chronic disease, and this may be due to decreased muscular glutamate levels. Glutamate supplementation itself may be an option for preventing muscular glutathione depletion during situations of stress.

\section{Possible options for modulating muscle glutamate metabolism}

Physical activity and nutritional modulation are possible ways to improve the disturbed skeletal muscle glutamate metabolism that occurs during disease. Little was known about specific modulation of muscle glutamate metabolism. The reported studies are summarized below. 


\section{PHYSICAL ACTIVITY}

Only a small number of studies have investigated the effect of physical activity on muscle glutamate concentration and metabolism. Graham et al ${ }^{5}$ studied amino acid status in the vastus lateralis muscle of trained and untrained young healthy volunteers. Participants were stratified based on their Vo2 peak (60 ml/kg per min). Resting muscular glutamate concentration was significantly higher in the trained group as compared with the untrained group $(4500 \mathrm{mmol} / \mathrm{kg}$ wet weight versus $3500 \mathrm{mmol} / \mathrm{kg}$ wet weight, respectively). These findings are in accordance with those reported by Engelen et al ${ }^{46}$, who observed higher levels for muscle glutamate level in active healthy elderly individuals than in sedentary healthy elderly individuals (2150 mmol/kg wet weight versus $1908 \mathrm{mmol} / \mathrm{kg}$ wet weight). Physically active and sedentary elderly healthy men were stratified based on a physical activity questionnaire (Beacke questionnaire), and they had a Vo2 peak of $33 \mathrm{~mL} / \mathrm{kg}$ per min versus $25 \mathrm{~mL} / \mathrm{kg}$ per min. These data suggest that physical activity probably influences glutamate level in muscle. The direct effects of exercise training on muscle glutamate status in humans, however, were poorly investigated until recently. To our knowledge only one study, that by Dawson et al ${ }^{50}$, has investigated the effect of short-term aerobic training on glutamate status in women. Participants performed daily seven bouts of cycle exercise for $45 \mathrm{~min}$ at $70 \%$ of their Vo2 peak for 5 days. On the first and the last training days, muscle biopsies were taken before and during the cycle exercise. Resting muscular glutamate level after exercise was not increased, as expected, over the findings cited above. A potential reason for this may be that only 5 days of training was performed, which might not have been enough to increase muscle glutamate status significantly. However, the degree of glutamate decrease in muscle during the first $5 \mathrm{~min}$ of exercise was significantly lower after training than before training ( $31 \%$ versus $53 \%$ ). These data are in accord with findings reported by Graham et al ${ }^{5}$. They examined trained and untrained individuals after $2 \mathrm{~h}$ of prolonged dynamic one-leg knee extension exercise, and observed a muscle glutamate reduction of $33 \%$ versus $50 \%$, respectively. In addition, they observed that net uptake of glutamate across muscle was smaller in the trained group than in the untrained group. Graham et al speculated that this observation could be explained by an additional source for glutamate formation in the trained group, namely BCAAs. More active 
BCAA transamination in the trained individuals was suggested, although the arterial plasma BCAA concentration did not change during exercise. These studies indicate that exercise training reduces the exercise-induced reduction in muscular glutamate, but it is not known whether training also influences resting glutamate levels.

\section{NUTRITIONAL SUPPLEMENTATION}

As discussed above, glutamate plays a broad functional and metabolic role in resting and contracting skeletal muscle. A reduced muscle glutamate status is seen in both acute and chronic disease. Therefore, restoring muscle glutamate pool and thereby modulating glutamate metabolism may be beneficial in patients. Several studies evaluated the effect of intravenous glutamate infusion in myocardium of coronary patients. The net myocardial uptake of glutamate increased in a dose-dependent manner with arterial glutamate concentration ${ }^{25,44,}$ 45, 51. However, maximal myocardial uptake was reached when plasma glutamate increased by $300-400 \mathrm{mmol} / \mathrm{l}^{51}$. Arteriovenous changes in lactic acid, free fatty acid and alanine suggested improved myocardial oxidative metabolism after glutamate infusion ${ }^{44}$. Thomassen et al ${ }^{26}$ showed that arteriovenous difference in glutamate across the leg also increased in a dose-dependent manner. Therefore, the available studies indicate that increasing arterial glutamate concentration can also enhance uptake of glutamate by skeletal muscle. Until now, studies examining the effect of oral glutamate supplementation have not been conducted for two reasons. First, it is assumed that MSG, the sodium salt of glutamate that is often used in food to enhance flavour, can induce specific symptoms, called the Chinese restaurant syndrome. However, there is a lack of human studies to confirm the involvement of MSG in any kind of adverse effect, and an 'acceptable daily intake not specified' status has been attributed to natural glutamate and its salts since 1991. Second, it is thought that oral glutamate ingestion does not reach the circulation because nearly all of the ingested glutamate is oxidized in the splanchnic bed on the first pass ${ }^{52}$. In contrast, Graham et al ${ }^{28}$ showed that a bolus oral ingestion of a high dose of MSG resulted in significant increases in plasma and muscle glutamate levels in healthy volunteers. These findings support oral 
glutamate supplementation as a way to restore the depleted muscle glutamate pool in patients, and thereby possibly improve disturbed glutamate metabolism.

Another way to influence glutamate and its related metabolism is by supplementing with glutamate related substrates such as glutamine, $\mathbf{\alpha}-$ ketoglutarate and BCAAs. Many studies have been performed to investigate the effect of intravenous glutamine supplementation in postoperative patients $48,53,54$. Glutamine is easily converted to glutamate with the glutaminase enzyme that is present in nearly all cells ${ }^{55}$. Despite the fact that glutamine attenuated the depleted muscle glutathione concentration in postraumatic patients ${ }^{48}$, no study has yet shown an increase in muscular glutamate concentration, suggesting that glutamine as a precursor of muscular glutamate may not be adequate. $\alpha$-Ketoglutarate and ornithine $\alpha$-ketoglutarate are two other precursors of glutamate, given the facts that a-ketoglutarate participates in the AAT reaction and that ornithine contributes in the ornithine aminotransamination reaction. Although total parenteral nutrition enriched with a-ketoglutarate did not have a significant effect on muscle glutamate level, the tendency toward decreased muscle glutamate concentration after surgery was eliminated in these patients ${ }^{56}$. However, other studies found no effect of addition of a-ketoglutarate ${ }^{54}$ or ornithine a-ketoglutarate ${ }^{57}$ to total parenteral nutrition on muscle glutamate concentration. Thus, the available studies yielded inconsistent results regarding the ability of $\alpha$-ketoglutarate and/or ornithine $\alpha$-ketoglutarate to restore the depleted glutamate pool in skeletal muscle during illness.

As BCAAs are the main oxidative amino acids in skeletal muscle, their transamination delivers significant amounts of glutamate to muscle (see above) ${ }^{15}$. Therefore, we hypothesize that oral supplementation of BCAAs improves muscle glutamate concentration and metabolism. However, total parenteral nutrition enriched with BCAAs did not have a significant effect on muscle glutamate concentration in postoperative patients ${ }^{57}$. It must be mentioned that surgery did not decrease muscle glutamate concentration in that study. On the other hand, ingestion of BCAAs by healthy volunteers performing a prolonged submaximal exercise test resulted in a smaller decrease in muscle glutamate concentration than in a control group ${ }^{58}$. Furthermore, plasma concentrations of alanine and arginine (both of which are glutamate related amino acids) increased after BCAA supplementation, suggesting that BCAAs may modulate glutamate concentration 
via different routes. To summarize, several nutritional modalities may restore muscle glutamate pool in healthy conditions during exercise and in disease, even at rest. We reviewed above the effect of supplementation on muscle glutamate concentration. It is possible, however, that a precursor influences glutamate turnover without affecting muscle glutamate concentration. More research is warranted to examine the effect of supplementation on (muscle) glutamate metabolism.

\section{Conclusion}

The published studies concerning skeletal muscle glutamate function and characteristics reveal that, apart from glutamate incorporation in muscle protein, glutamate has numerous other functions in skeletal muscle. The high correlation between muscle glutamate concentration and muscle glutathione concentration suggests that glutamate plays a determining role in the glutathione synthesis pathway. During exercise glutamate plays a central role in energy provision via different metabolic pathways. However, a consistent finding of several diseases is reduced muscle glutamate status. Several disease-related factors such as hypoxia and oxidative stress were found to be involved in disturbed glutamate metabolism. Remarkably, only few studies focused on the modulation of muscle glutamate status by exercise or by nutritional supplementation. There are several options for modulating glutamate metabolism, but the specific effects of the individual options must be further elucidated. Nutritional supplementation of glutamate or its precursors [glutamine, (ornithine) a-ketoglutarate and BCAAs] can influence muscle glutamate status. However, specific intervention studies must be conducted to investigate the effect of supplementation on muscle glutamate turnover and its related metabolic and functional consequences in healthy individuals and in patients with acute or chronic diseases.

\section{References}

1. Essen $\mathrm{P}, \mathrm{W}$ ernerman $\mathrm{J}$, Sonnenfeld $\mathrm{T}$, et al. Free amino acids in plasma and muscle during 24 hours post-operatively--a descriptive study. Clin Physiol 1992; 12(2):163-77. 
2. Engelen MP, Wouters EF, Deutz NE, et al. Factors contributing to alterations in skeletal muscle and plasma amino acid profiles in patients with chronic obstructive pulmonary disease. Am J Clin Nutr 2000; 72(6):1480-7.

3. Bergstrom J, Furst P, Noree LO, Vinnars E. Intracellular free amino acid concentration in human muscle tissue. J Appl Physiol 1974; 36(6):693-7.

4. Marliss EB, Aoki TT, Pozefsky T, et al. Muscle and splanchnic glutamine and glutamate metabolism in postabsorptive and starved man. J Clin Invest 1971; 50(4):814-7.

5. Graham TE, Turcotte LP, Kiens B, Richter EA. Training and muscle ammonia and amino acid metabolism in humans during prolonged exercise. J Appl Physiol 1995; 78(2):725-35.

6. Hundal HS, Rennie MJ, Watt PW. Characteristics of acidic, basic and neutral amino acid transport in the perfused rat hindlimb. J Physiol 1989; 408:93-114.

7. Low SY, Rennie MJ, Taylor PM. Sodium-dependent glutamate transport in cultured rat myotubes increases after glutamine deprivation. Faseb J 1994; 8(1):127-31.

8. Rennie MJ, Khogali SE, Low SY, et al. Amino acid transport in heart and skeletal muscle and the functional consequences. Biochem Soc Trans 1996; 24(3):869-73.

9. Turinsky $\mathrm{J}$, Long CL. Free amino acids in muscle: effect of muscle fiber population and denervation. Am J Physiol 1990; 258(3 Pt 1):E485-91.

10. Engelen MP, Orozco-Levi M, Deutz NE, et al. Glutathione and glutamate levels in the diaphragm of patients with chronic obstructive pulmonary disease. Eur Respir J 2004; 23(4):545-51.

11. Essen-Gustavsson B, Blomstrand E. Effect of exercise on concentrations of free amino acids in pools of type I and type II fibres in human muscle with reduced glycogen stores. Acta Physiol Scand 2002; 174(3):275-81.

12. Bates PC, Grimble GK, Sparrow MP, Millward DJ. Myofibrillar protein turnover. Synthesis of protein-bound 3-methylhistidine, actin, myosin heavy chain and aldolase in rat skeletal muscle in the fed and starved states. Biochem J 1983; 214(2):593-605.

13. Weiss A, Schiaffino S, Leinwand L. Comparative sequence analysis of the complete human sacromeric myosin heavy chain family: implications for functional diversity. J Mol Biol 1999; 290:61-75.

14. NCBI. Pubmed. National Center for Biotechnology Information.

15. Goldberg AL, Chang TW. Regulation and significance of amino acid metabolism in skeletal muscle. Fed Proc 1978; 37(9):2301-7.

16. Birkhahn $\mathrm{RH}$, Robertson LA, Okuno M. Isoleucine and valine oxidation following skeletal trauma in rats. J Trauma 1986; 26(4):353-8.

17. Matthews DE, Bier DM, Rennie MJ, et al. Regulation of leucine metabolism in man: a stable isotope study. Science 1981; 214(4525):1129-31.

18. Staten MA, Bier DM, Matthews DE. Regulation of valine metabolism in man: a stable isotope study. Am J Clin Nutr 1984; 40(6):1224-34.

19. Amores-Sanchez MI, Medina MA. Glutamine, as a precursor of glutathione, and oxidative stress. Mol Genet Metab 1999; 67(2):100-5.

20. Hammarqvist $F$, Luo JL, Cotgreave IA, et al. Skeletal muscle glutathione is depleted in critically ill patients. Crit Care Med 1997; 25(1):78-84.

21. Engelen MPKJ, Schols AMWJ, Does JD, et al. Altered glutamate metabolism is associated with reduced muscle glutathione levels in patients with emphysema. Am.J.Respir.Crit.Care Med. 2000; 161:98-103.

22. Luo JL, Hammarqvist F, Andersson K, Wernerman J. Skeletal muscle glutathione after surgical trauma. Ann Surg 1996; 223(4):420-7.

23. Luo JL, Hammarqvist $F$, Andersson K, Wernerman J. Surgical trauma decreases glutathione synthetic capacity in human skeletal muscle tissue. Am J Physiol 1998; 275(2 Pt 1):E359-65.

24. Flaring UB, Rooyackers OE, Wernerman J, Hammarqvist F. Temporal changes in muscle glutathione in ICU patients. Intensive Care Med 2003; 29(12):2193-8.

25. Richman PG, Meister A. Regulation of gamma-glutamyl-cysteine synthetase by nonallosteric feedback inhibition by glutathione. J Biol Chem 1975; 250(4):1422-6. 
26. Thomassen A, Nielsen TT, Bagger JP, Henningsen P. Effects of intravenous glutamate on substrate availability and utilization across the human heart and leg. Metabolism 1991; 40(4):378-84.

27. Floyd JC, Jr., Fajans SS, Conn JW, et al. Stimulation of insulin secretion by amino acids. J Clin Invest 1966; 45(9):1487-502.

28. Graham TE, Sgro V, Friars D, Gibala MJ. Glutamate ingestion: the plasma and muscle free amino acid pools of resting humans. Am J Physiol Endocrinol Metab 2000; 278(1):E83-E89.

29. Maechler $\mathrm{P}$, Wollheim $\mathrm{CB}$. Mitochondrial glutamate acts as a messenger in glucose-induced insulin exocytosis. Nature 1999; 402(6762):685-9.

30. Wagenmakers AJ. Muscle Amino Acid Metabolism at Rest and During Exercise: Role in Human Physiology and Metabolism. Exercise and Sport sciences review, Vol. 26. New York: Academic Press, 1998. pp. 287-314.

31. Sahlin K, Katz A, Broberg S. Tricarboxylic acid cycle intermediates in human muscle during prolonged exercise. Am J Physiol 1990; 259(5 Pt 1):C834-41.

32. Gibala MJ, MacLean DA, Graham TE, Saltin B. Anaplerotic processes in human skeletal muscle during brief dynamic exercise. J Physiol 1997; 502 ( Pt 3):703-13.

33. Gibala MJ, Tarnopolsky MA, Graham TE. Tricarboxylic acid cycle intermediates in human muscle at rest and during prolonged cycling. Am J Physiol 1997; 272(2 Pt 1):E239-44.

34. Gibala MJ, MacLean DA, Graham TE, Saltin B. Tricarboxylic acid cycle intermediate pool size and estimated cycle flux in human muscle during exercise. Am J Physiol 1998; 275(2 Pt 1):E235-42.

35. Constantin-Teodosiu D, Simpson EJ, Greenhaff PL. The importance of pyruvate availability to PDC activation and anaplerosis in human skeletal muscle. Am J Physiol 1999; 276(3 Pt 1):E472-8.

36. Lowenstein JM. The purine nucleotide cycle revisited [corrected]. Int J Sports Med 1990; 11 Suppl 2:S37-46.

37. Hack V, Stutz O, Kinscherf R, et al. Elevated venous glutamate levels in (pre)catabolic conditions result at least partly from a decreased glutamate transport activity. J Mol Med 1996; 74(6):337-43.

38. Morrison WL, Gibson JNA, Scrimgeour C, Rennie MJ. Muscle wasting in emphysema. Clin.Sci. 1988; 75:415-420.

39. Pietersen HG, Langenberg CJ, Geskes G, et al. Glutamate metabolism of the heart during coronary artery bypass grafting. Clin Nutr 1998; 17(2):73-5.

40. Thomassen AR. Myocardial uptake and effects of glutamate during non-ischaemic and ischaemic conditions. A clinical study with special reference to possible interrelationships between glutamate and myocardial utilization of carbohydrate substrates. Dan Med Bull 1992; 39(6):471-88.

41. Pisarenko OI, Solomatina ES, Ivanov VE, et al. On the mechanisms of enhanced ATP formation in hypoxic myocardium caused by glutamic acid. Basic Res.Cardiol. 1985; 80:126-134.

42. Pisarenko OI, Solomatina ES, Studneva IM, Kapelko VI. The relationship between the cardiac contractile function, adenine nucleotides and amino acids of cardiac tissue and mitochondria at acute respiratory hypoxia. Pflugers Arch 1987; 409(1-2):169-74.

43. Pisarenko OI, Baranov AV, Pomerantsev EV, et al. Myocardial metabolism of glutamate and left ventricular function in patients with coronary arterial disease. Int J Cardiol 1989; 23(1):43-52.

44. Langenberg CJ, Pietersen HG, Geskes G, et al. The effect of glutamate infusion on cardiac performance is independent of changes in metabolism in patients undergoing routine coronary artery bypass surgery. Clin Sci (Lond) 2001; 101(6):573-80.

45. Svedjeholm R, Vanhanen I, Hakanson E, et al. Metabolic and hemodynamic effects of intravenous glutamate infusion early after coronary operations. J Thorac Cardiovasc Surg 1996; 112(6): 1468-77. 
46. Engelen MPKJ, Schols AMWJ, Does JD, et al. Exercise induced lactate increase in relation to muscle substrates in patients with COPD. Am.J.Respir.Crit. Care Med. 2000; 162(5):1697704.

47. Mourtzakis M, Graham TE. Glutamate ingestion and its effects at rest and during exercise in humans. J Appl Physiol 2002; 93(4):1251-9.

48. Flaring UB, Rooyackers OE, Wernerman J, Hammarqvist F. Glutamine attenuates post-traumatic glutathione depletion in human muscle. Clin Sci (Lond) 2003; 104(3):275-82.

49. Mittendorfer B, Volpi E, Wolfe RR. Whole body and skeletal muscle glutamine metabolism in healthy subjects. Am J Physiol Endocrinol Metab 2001; 280(2):E323-33.

50. Dawson KD, Howarth KR, Tarnopolsky MA, et al. Short-term training attenuates muscle TCA cycle expansion during exercise in women. J Appl Physiol 2003; 95(3):999-1004.

51. Vanhanen I, Svedjeholm R, Hakanson E, et al. Assessment of myocardial glutamate requirements early after coronary artery bypass surgery. Scand Cardiovasc J 1998; 32(3):145-52.

52. Matthews DE, Marano MA, Campbell RG. Splanchnic bed utilization of glutamine and glutamic acid in humans. Am J Physiol 1993; 264(6 Pt 1):E848-54.

53. Tjader I, Rooyackers O, Forsberg AM, et al. Effects on skeletal muscle of intravenous glutamine supplementation to ICU patients. Intensive Care Med 2004; 30(2):266-75.

54. Blomqvist $\mathrm{BI}$, Hammarqvist $\mathrm{F}$, von der Decken A, Wernerman J. Glutamine and alphaketoglutarate prevent the decrease in muscle free glutamine concentration and influence protein synthesis after total hip replacement. Metabolism 1995; 44(9):1215-22.

55. Newsholme P, Procopio J, Lima MM, et al. Glutamine and glutamate-their central role in cell metabolism and function. Cell Biochem Funct 2003; 21(1):1-9.

56. Hammarqvist F, Wernerman J, von der Decken A, Vinnars E. Alpha-ketoglutarate preserves protein synthesis and free glutamine in skeletal muscle after surgery. Surgery 1991; 109(1):28-36.

57. Hammarqvist F, Wernerman J, Ali R, Vinnars E. Effects of an amino acid solution enriched with either branched chain amino acids or ornithine-alpha-ketoglutarate on the postoperative intracellular amino acid concentration of skeletal muscle. Br J Surg 1990; 77(2):214-8.

58. Blomstrand E, Ek S, Newsholme EA. Influence of ingesting a solution of branched-chain amino acids on plasma and muscle concentrations of amino acids during prolonged submaximal exercise. Nutrition 1996; 12(7-8):485-90. 


\title{
Chapter 8
}

\section{Metabolic and functional effects of glutamate in patients with chronic obstructive pulmonary disease}

\author{
Erica P.A. Rutten, Marielle P.K.J. Engelen, Harry Gosker, Aalt Bast, Kirsten \\ Cosemans, Yvonne L.J. Vissers, Emiel F.M. Wouters, Nicolaas E.P. Deutz, \\ Annemie M.W.J. Schols
}

\section{Submitted}

\section{Abstract}

Rationale: Quadriceps weakness and reduced aerobic energy metabolism are often present in patients with chronic obstructive pulmonary disease (COPD). Patients with contractile quadriceps fatigue are characterized by elevated glycolytic metabolism possibly due to less substrate availability. Decreased muscle glutamate concentration has been associated with early lactic acidosis and decreased muscle glutathione concentration in COPD.

Objectives: We hypothesized that oral glutamate ingestion increases muscle glutamate concentration in COPD and leads to metabolic and functional improvements.

Methods: In experiment 1 , in two groups of 6 male COPD patients (FEV1:44.8 $\pm 3.4 \%$ pred) \& 6healthy controls blood samples and muscle biopsies were taken at baseline, after $80 \mathrm{~min}$ repeated ingesting a glutamate or control drink, and after $20 \mathrm{~min}$ cycling at $50 \%$ peak workload. In experiment 2 , in $10 \mathrm{COPD}$ patients (FEV1:36.1 $2.5 \%$ pred), the effect of the drinks was tested on contractile quadriceps fatigue by using magnetic stimulation and on cycle endurance time at $75 \%$ peak workload until voluntary exhaustion.

Results: In both groups, glutamate ingestion increased glutamate concentration in plasma $(P<0.01)$ but not in muscle. Muscle total and reduced glutathione and plasma lactate concentration were not affected by glutamate ingestion. Irrespective of intervention, patients had lower 3-hydroxyacyl-CoA dehydrogenase concentration than controls $(P<0.05)$ and exercise decreased glutathione/glutathione disulfide $(P<0.01)$ in controls but not in patients. Glutamate ingestion did not acutely influence contractile muscle fatigue and endurance time.

Conclusion: Glutamate ingestion did not affect skeletal muscle substrate concentration at rest nor after exercise in COPD patients characterized by decreased aerobic energy metabolism and impaired antioxidative response during exercise.

Key words: Skeletal muscle, glutathione, lactate, supplementation, quadriceps twitch force 


\section{Introduction}

Chronic obstructive pulmonary disease (COPD) is a serious and common disease and a high burden for health care. It is increasingly recognized that COPD is a systemic disorder and exercise intolerance, often present in moderate and severe COPD, results in disability ${ }^{1}$. Quadriceps weakness, independent of lung function, is associated with higher utilization of healthcare resources ${ }^{2}$. Besides a decrease quadriceps mass, intramuscular alterations are also related to muscle weakness. Various studies showed reduced aerobic energy metabolism in COPD patients, based on a decreased proportion type I fibers ${ }^{3}$ and reduced activity of oxidative enzymes ${ }^{4}$.

Recently, it was elegantly demonstrated that part of the COPD patients develop contractile quadriceps fatigue during exercise, defined as a reversible post-exercise fall in quadriceps muscle strength measured by magnetic stimulation ${ }^{5}$. In contrast to the non-fatiguers, cycle endurance time of the fatiguers did not improve after nebulization of a bronchodilator ${ }^{6}$. Furthermore, the fatiguers were characterized by increased lactate dehydrogenase activities and higher exerciseinduced plasma lactate levels compared to the non-fatiguers, despite similar fiber type distribution and oxidative enzyme activities ${ }^{7}$. These findings suggest that glycolytic metabolism is enhanced in the fatiguers due to less substrate availability rather than to morphologic alterations.

There is indeed evidence in the literature for presence of altered substrate metabolism in moderate to severe COPD patients. A consistent finding has been a decreased skeletal muscle glutamate concentration ${ }^{8,9}$, which was associated with several metabolic consequences. Particularly, muscle glutamate levels were associated with muscle glutathione levels in COPD patients ${ }^{10}$, and with early lactic acidosis during maximal cycle ergometry ${ }^{11}$. Glutamate is largely taken up by muscle at rest ${ }^{12}$ and even to a higher extent during exercise ${ }^{13}$. Moreover, during the first minutes of exercise, muscle glutamate concentration decreases ${ }^{14}$, suggesting that glutamate acts as an important intermediate in substrate metabolism during exercise. 
Recent data show that oral glutamate ingestion is able to increase glutamate availability for skeletal muscle ${ }^{15}$. We hypothesized that increasing glutamate availability by oral glutamate ingestion increases skeletal muscle glutamate concentration in COPD and leads to metabolic and functional improvements. There are only few studies examining glutamate supplementation on skeletal muscle as it is expected that a large amount of the amino acid is absorbed and metabolized by the splanchnic area ${ }^{16}$. In contrast, intravenous infusion of mono-sodium glutamate showed increased myocardial glutamate uptake ${ }^{17}$ and modulation of lactate metabolism ${ }^{18}$ in coronary patients.

We conducted two experiments to test our hypothesis. In the first experiment, we investigated if repeated glutamate ingestion increases muscle glutamate concentration in COPD patients and age-matched healthy volunteers. The agematched control group was included since we previously reported altered glutamate metabolism in old compared to young healthy subjects. Moreover, based on the previously reported associations between muscle glutamate, muscle glutathione and plasma lactate response during exercise, the effect of repeated glutamate ingestion was evaluated on muscle glutathione and plasma lactate concentrations in rest and after submaximal cycle ergometry. In the second experiment, the acute effect of glutamate ingestion was evaluated on contractile quadriceps fatigue and cycle endurance time.

\section{Methods and materials}

\section{STUDY POPULATION}

All patients recruited in experiment $1(n=10)$ and $2(n=16)$ had COPD according to GOLD guidelines ${ }^{19}$ defined as measured forced expiratory volume in one second $\left(\mathrm{FEV}_{1}\right)$ less than $70 \%$ of reference $\mathrm{FEV}_{1}$. Exclusion criteria for all subjects were malignancy, cardiac failure, distal arteriopathy, recent surgery, severe endocrine, hepatic or renal disorder. Also, patients who were using systemic corticosteroids within three months prior to the study were excluded as it is shown that systemic corticosteroids may affect muscle protein metabolism ${ }^{20}$. The medical ethical committee of the University Hospital Maastricht approved both experiments and all subjects obtained written informed consent. 


\section{PULMONARY FUNCTION TESTS.}

Prior to the test day, all subjects underwent spirometry for determination of FEV 1 and forced vital capacity (FVC) with the highest value from at least three technically acceptable maneuvers being used. Diffusion capacity for carbon monoxide $\left(\mathrm{DL}_{\mathrm{cO}}\right)$ was measured using the single-breath method (Masterlab; Jaeger, Wurzburg, Germany). All values obtained were related to a reference value and expressed as percentages of the predicted value ${ }^{21}$.

\section{INCREMENTAL CYCLE ERGOMETRY}

In order to determine each subject's peak workload, all subjects performed a symptom limited incremental cycle ergometer test under supervision of a physician prior to the test day. After one minute of unloaded cycling power, power was increased by 10 Watts every minute for the COPD patients. For control subjects, the load was increased with 15-25 Watts every minute, so that the duration of the exercise test was comparable for the two groups. None of the subjects knew the exercise load and all were encouraged to cycle at $60 \mathrm{revs} / \mathrm{min}$ until exhaustion. Peak workload was monitored at the end of the exercise.

\section{BODY COMPOSITION}

On the morning of the test day, in all subjects, body weight was measured by using an electronic beam scale with digital readout to the nearest $0.1 \mathrm{~kg}$ (model 708; Seca, Hamburg, Germany) with the subjects standing bare-food and wearing light indoor clothing. Body height was measured to the nearest $0.1 \mathrm{~cm}$ (model 220, Seca). Whole body fat-free mass (FFM) was measured in each subject using bioelectrical impedance analyses (BIA) (Xitron 4000B, Xitron Technologies, San Diego, CA). FFM of the COPD patients was calculated using a regression equation developed for COPD patients ${ }^{22}$, whereas FFM of the healthy controls was calculated using a specific regression equation for elderly men as described by Dey et $\mathrm{al}^{23}$. 


\section{STUDY DESIGN}

Experiment 1: One group of 6 male COPD patients and 6 age- and sex-matched healthy controls, recruited by a local magazine, ingested the glutamate drink (30 $\mathrm{mg}$ glutamate $/ \mathrm{kg}$ body weight $/ 20 \mathrm{~min}$ ), while another group of 6 COPD patients and 6 controls ingested the water drink $(1.25 \mathrm{ml}$ water $/ \mathrm{kg}$ BW/20min). From these subjects, 2 COPD patients and 4 controls participated in both the glutamate and water intervention, so in total, 10 COPD patients and 8 healthy controls were enrolled. After overnight fast and one hour resting, the subjects started to ingest the test drink every 20 minutes for 80 minutes. Subsequently, submaximal cycle ergometry was performed on $50 \%$ of subject's peak workload for 20 minutes. Blood samples and muscle biopsies were taken just before the ingestion period, and just before and after the exercise to analyze plasma glutamate and lactate concentrations, and skeletal muscle amino acid and glutathione concentrations respectively. Muscle biopsies were taken from the lateral part of the quadriceps femoris by using the needle-biopsy technique ${ }^{24}$ after administration of local anesthetic while the subjects lied in the supine position. The first biopsy was taken in the non-dominant leg; the second in the other leg and the third biopsy was taken in the same incision of the second biopsy.

Experiment 2: During a screening test, clinically stable moderate to severe COPD patients performed a submaximal cycle ergometer test at $75 \%$ of their peak workload until voluntary exhaustion. Subject's quadriceps twitch force (TwQ) was measured just before and after the exercise test using a magnetic stimulator (Magstim 200; Magstim Co Ltd, Whitland, Dyfed, Wales, UK) to assess contractile quadriceps muscle fatigue. A decrease in quadriceps twitch force of at least $15 \%$ was considered potentially indicative of contractile quadriceps muscle fatigue ${ }^{5}$. In total, 16 clinically stable patients with COPD were screened and 10 patients $(8 \hat{\delta})$ who developed fatigue were included in experiment 2. The experiment involved two test days at least one week apart, during which the glutamate or the control drink was ingested in randomized order. After an overnight fast, subjects started to sip the test drink every 20 minutes for 80 minutes. Subsequently, the subjects performed a submaximal cycle ergometer test of $75 \%$ of their peak workload until voluntary exhaustion. Endurance time and the exercise-induced fall in TwQ were determined as outcome measurements. 


\section{TEST DRINK}

Conform to a previous study that showed that repeated glutamate ingestion is able to increase glutamate delivery to muscle ${ }^{15}$, the test drink involved a $2.4 \%$ solution of $30.0 \mathrm{mg}$ glutamate/ $\mathrm{kg}$ body weight/20 $\mathrm{min}$. The control drink was the equal amount of only water $(1.25 \mathrm{~mL}$ water $/ \mathrm{kg}$ BW/20 $\mathrm{min})$. The drinks were flavoured with sweetener and served at $55^{\circ} \mathrm{C}$ to assure complete dissolution. As the same ingestion protocol was used in other metabolic studies with stable isotopes, the ingestion was continued for $80 \mathrm{~min}$.

\section{SAMPLE PROCESSING IN EXPERIMENT 1}

Analyses of blood samples. Blood was collected in a heparinized tube, immediately put on ice and centrifuged $\left(3120 \times \mathrm{g}, 4^{\circ} \mathrm{C}\right.$ for $\left.10 \mathrm{~min}\right)$ to obtain plasma. Subsequently, $250 \mu \mathrm{L}$ plasma was deproteinized with $20 \mathrm{mg}$ dry sulfosalicylic acid to analyze plasma glutamate concentration. Another $900 \mu \mathrm{L}$ plasma was deproteinized with $90 \mu \mathrm{L}$ trichloroacetic acid to examine plasma lactic acid concentration. All blood samples were frozen in liquid nitrogen and stored at $-80^{\circ} \mathrm{C}$ until analysis.

Analyses of muscle biopsies. Muscle biopsies were frozen in liquid nitrogen as soon as possible after the biopsy. The samples were stored at $-80^{\circ} \mathrm{C}$ until analysis. Before analyses, part of the biopsies was dissolved in $250 \mu \mathrm{L}$ sulfosalicylic acid solution. Glass parts were added and the biopsies were beated. Subsequently, samples were centrifuged ( $3120 \times \mathrm{g}, 4^{\circ} \mathrm{C}$ for $\left.10 \mathrm{~min}\right)$ and the supernatant was used for analyses.

Biochemical analyses. Plasma and muscle amino acid concentrations were analyzed by High-Performance Liquid Chromatography (HPLC) system ${ }^{25}$. Plasma lactic acid concentration was analysed by COBAS Mira S (Roche Diagnostica, Hoffman-La Roche, Basel, Switserland). In baseline muscle biopsies, enzyme activities and myosin heavy chain (MyHC) isoforms were analysed for characterization of the study group. All samples were centrifuged $\left(10,000 \times \mathrm{g}, 4^{\circ} \mathrm{C}\right.$ for $10 \mathrm{~min}$ ) and the supernatant was used for enzyme activity assays. Citrate 
synthase (CS; EC 2.3.3.1) ${ }^{26}$, 3-hydroxyacyl-CoA dehydrogenase (HAD; EC 1.1.1.35) ${ }^{27}$ and phospho-fructo kinase (PFK; EC 2.7.11) ${ }^{28}$ were analysed spectrophotometrically (Multiskan Spectrum, Thermo Labsystems, Breda, The Netherlands). The remaining pellet was resuspended in three volumes of ice-cold extraction buffer (100 mM Na${ }_{4} \mathrm{O}_{7} \mathrm{P}_{2} \cdot 10 \mathrm{H}_{2} \mathrm{O}, 5 \mathrm{mM}$ EDTA, $1 \mathrm{mM}$ DTT, pH8.5), incubated on ice for 30 minutes, and centrifuged $\left(10,000 \times \mathrm{g}, 4^{\circ} \mathrm{C}\right.$ for $\left.10 \mathrm{~min}\right)$. From this, the supernatant was used for MyHC isoform analysis as described by Talmadge \& Roy ${ }^{29}$. Muscle GSH and GSSG were measured according to Vandeputte et al ${ }^{30}$. In short, for the total glutathione concentration (GSH + GSSG), the muscle samples were homogenized in $1.3 \%$ sulfosalicylic acid. NADPH and 5,5' dithiobis(2-nitrobenzoic acid) were added and after the addition of glutathione reductase, the rate of change in absorption at $412 \mathrm{~nm}$ was measured. The measurement of GSSG is possible after preincubation of the homogenized muscle samples for $1 \mathrm{~h}$ with 2-vinylpyridine that reacts with $\mathrm{GSH}$ and repeating the measurement for total glutathione.

\section{MEASUREMENT OF THE QUADRICEPS TWITCH FORCE (TWQ) EXPERIMENT 2}

Before and after the submaximal cycle ergometer test, subjects lied supine on a bed with the knee flexed at 90 degrees and the leg passively stabilized to prevent lateral motion. Measurements were performed in the dominant leg, unless otherwise recommended. Force was measured via a non-elastic ankle strap attached to a strain gauge (LSH-200-C3, AE sensors, Dordrecht, the Netherlands) and the amplified signal was recorded at $1 \mathrm{kHz}$ on a $\mathrm{PC}$ with a data acquisition board ( $\mathrm{NI} \mathrm{PCl-6023E,} \mathrm{National} \mathrm{Instruments,} \mathrm{USA)} \mathrm{running} \mathrm{Labview} \mathrm{software}$ (National Instruments, USA). The femoral nerve was stimulated with a magnetic stimulator (Magstim 200; Magstim Co Ltd, Whitland, Dyfed, Wales, UK) using a 45$\mathrm{mm}$ figure-of-eight coil ${ }^{31}$. The coil was placed in the femoral triangle just lateral to the femoral artery and repositioned to determine the best location for subsequent stimulations, which was marked and used for the remainder of the study. A series of 22 twitches were randomly obtained at $60,80,90,95$ and $100 \%$ of power output to assure supramaximal stimulation. After every twitch, a resting period of 20 seconds assured depolarization of the quadriceps muscle. The average of the outputs at $100 \%$ was used as the TwQ. 


\section{STATISTICAL ANALYSES}

Data are presented as mean (SEM). All data were checked for normality. In experiment 1, the unpaired Student's $t$-test was used to ascertain whether general characteristics were significant different between the COPD patients and controls. Repeated measurements ANOVA test with within variables time (baseline, 80minutes ingestion, 20minutes exercise) and between variables group (COPD and control group) and drink (water and glutamate ingestion) was performed to test effects on plasma and muscle substrate concentrations. If there was a significant interaction for time $x$ group or time $x$ drink, the effect in time was tested within each group or drink. In experiment 2, the paired Student's $t$-test was used to test differences in endurance time and contractile muscle fatigue between the drinks. The statistical package SPSS for Windows (Version 11.0, SPSS Inc., Chicago, IL, USA) was used for data analysis. A p-value $<0.05$ was considered statistically significant.

\section{Results}

There was no difference in body composition between the COPD patients and the controls in experiment 1 (table 1). The patients were characterized by decreased exercise capacity compared to the controls (peak workload COPD patients = $51.8 \%$ peak workload controls). 3-Hydroxyacyl-CoA dehydrogenase was significantly reduced in the patients $(p<0.05)$, indicating a decreased fat oxidative capacity. Other markers as muscle glutamate concentration, citrate synthase and phospho-fructo kinase tended to be lower in the patients, but they did not reach significance since the sample size for the present study was measured on effects in time and not on cross-sectional comparisons.

There was no difference in baseline plasma glutamate concentration and its effect on the drinks between the COPD patients and the control subjects. Glutamate ingestion resulted in a significant increase in plasma glutamate concentration $(P<0.01$, figure 1$)$ but skeletal muscle glutamate concentration remained unchanged. 
Table 1. Baseline characteristics of the healthy controls and COPD patients included in experiment 1 and 2 .

\begin{tabular}{|c|c|c|c|c|c|c|c|c|}
\hline & \multicolumn{5}{|c|}{ Experiment 1} & \multirow{2}{*}{\multicolumn{3}{|c|}{$\begin{array}{l}\text { Experiment } 2 \\
\text { COPD patients }\end{array}$}} \\
\hline & \multicolumn{3}{|c|}{ Controls } & \multicolumn{2}{|c|}{ COPD patients } & & & \\
\hline Amount & 8 & & & 10 & & 10 & & \\
\hline Age, years & 61.4 & \pm & 1.6 & 66.7 & \pm 1.4 & 61.5 & \pm & 3.4 \\
\hline Weight, kg & 76.5 & \pm & 2.9 & 72.1 & \pm 4.2 & 78.8 & \pm & 4.8 \\
\hline FFM, kg & 57.8 & \pm & 1.5 & 55.9 & \pm 2.3 & 55.9 & \pm & 3.3 \\
\hline $\mathrm{BMI}, \mathrm{kg} / \mathrm{m}^{2}$ & 25.3 & \pm & 0.7 & 23.3 & \pm 0.9 & 25.5 & \pm & 1.5 \\
\hline FFMI, $\mathrm{kg} / \mathrm{m}^{2}$ & 18.9 & \pm & 0.3 & 18.1 & \pm 0.4 & 18.6 & \pm & 0.7 \\
\hline $\mathrm{VO}_{2} \max , \mathrm{L} / \mathrm{min}$ & 2597.6 & \pm & 231.5 & 1491.0 & $\pm 141.1^{*}$ & 1176.6 & \pm & 119.8 \\
\hline Wpeak, Watt & 201.7 & \pm & 18.3 & 97.3 & $\pm 10.0^{* *}$ & 75.6 & \pm & 6.5 \\
\hline $\mathrm{FEV}_{1}, \%$ pred & 108.9 & \pm & 3.6 & 44.8 & $\pm 3.4^{\star \star}$ & 36.1 & \pm & 2.5 \\
\hline FVC, \%pred & 117.9 & \pm & 4.7 & 87.4 & $\pm 20.0^{* *}$ & 86.8 & \pm & 5.5 \\
\hline Dlco, \%pred & 113.4 & \pm & 6.2 & 67.1 & $\pm 7.0^{\star}$ & 41.4 & \pm & 4.9 \\
\hline \multicolumn{9}{|l|}{ Muscle glutamate } \\
\hline concentration, $\mu \mathrm{mol} / \mathrm{kg} w \mathrm{w}$ & 2338.3 & \pm & 209.5 & 2038.9 & $\pm \quad 151.3$ & & & \\
\hline Citrate synthetase, & 39.1 & \pm & 6.9 & 29.3 & \pm 6.3 & & & \\
\hline \multicolumn{9}{|l|}{$\mathrm{U} / \mathrm{mg}$ protein } \\
\hline \multicolumn{9}{|l|}{ 3-Hydroxy-acyl de- } \\
\hline hydrogenase, $\mathrm{U} / \mathrm{mg}$ protein & 91.5 & \pm & 9.4 & 56.2 & $\pm 10.9^{*}$ & & & \\
\hline \multicolumn{9}{|l|}{ Phospho-fructo kinase, } \\
\hline $\mathrm{U} / \mathrm{mg}$ protein & 576.1 & \pm & 82.1 & 423.6 & \pm 126.6 & & & \\
\hline$\%$ MyHC type I fibers & 37.6 & \pm & 1.5 & 40.1 & \pm 3.0 & & & \\
\hline$\%$ MyHC type lia fibers & 49.7 & \pm & 1.6 & 47.5 & \pm 1.9 & & & \\
\hline$\%$ MyHC type lix fibers & 13.3 & \pm & 2.0 & 13.8 & \pm 2.5 & & & \\
\hline TwQ, kg & & & & & & 7.6 & \pm & 0.8 \\
\hline \multicolumn{9}{|l|}{ Amount of quadriceps } \\
\hline fatigue, $\%$ & & & & & & 27.7 & \pm & 3.7 \\
\hline Endurance time, $\min$ & & & & & & 7.2 & \pm & 0.7 \\
\hline
\end{tabular}

Values are means \pm SEM. Used abbreviations: FFM = fat-free mass, $\mathrm{BMI}=$ body mass index (weight $/$ length $\left.{ }^{2}\right), \mathrm{FFMI}=$ fat-free mass index $\left(\mathrm{FFM} /\right.$ length $\left.^{2}\right)$, VO2max $=$ maximal oxygen uptake during maximal cycle ergometry, Wpeak $=$ peak workload during a maximal cycle ergometer test, $\mathrm{FEV}_{1}=$ forced expiratory volume in one second, FVC = forced vital capacity, DLco = diffusion capacity for carbon monoxide, $w w=$ wet weight, $M y H C=$ myosin heavy chain, $T w Q=$ quadriceps twitch force. Symbols depict a significant effect: *significant different between the COPD group and the control group, One symbol represents $p<0.05$, two $p<0.01$.

Exercise resulted in a decreased plasma glutamate concentration after water ingestion in both groups $(P<0.05)$, and a decreased muscle glutamate concentration independent of treatment and group $(P<0.01)$. 
Table 2. Skeletal muscle concentrations of exercise-related amino acids at baseline (TO), after 80 minutes ingestion the glutamate (GLU) or the water (WA) drink (T80) and after 20 minutes submaximal cycle ergometry (T100) in healthy subjects (A) and in COPD patients (B).

\begin{tabular}{|c|c|c|c|c|c|c|c|c|c|c|c|}
\hline \multirow{3}{*}{$\begin{array}{c}\text { A } \\
\text { Amino acid } \\
\mu \mathrm{mol} / \mathrm{kg} \mathrm{ww}\end{array}$} & \multicolumn{11}{|c|}{ Healthy controls } \\
\hline & \multirow[t]{2}{*}{ Ingestion } & \multicolumn{9}{|c|}{ Time (min) } & \\
\hline & & \multicolumn{3}{|c|}{ T0 } & \multicolumn{3}{|c|}{ T80 } & \multicolumn{3}{|c|}{ T100 } & \\
\hline & $\mathrm{Wa}$ & 2118 & \pm & 294 & 2538 & \pm & 300 & 2116 & \pm & $513^{*}$ & \\
\hline & GLU & 2559 & \pm & 295 & 2349 & \pm & 307 & 1784 & \pm & $429^{*}$ & $\mathrm{~T}$ \\
\hline \multirow[t]{2}{*}{ Glutamine } & Wa & 8456 & \pm & 903 & 8590 & \pm & 286 & 7762 & \pm & $1968^{*}$ & $\mathrm{~T}$ \\
\hline & GLU & 9066 & \pm & 715 & 9862 & \pm & 804 & 7325 & \pm & $1416^{\star}$ & \\
\hline \multirow[t]{2}{*}{ Alanine } & Wa & 856 & \pm & 49 & 827 & \pm & 74 & 933 & \pm & 132 & \\
\hline & GLU & 1381 & \pm & 145 & 1375 & \pm & 114 & 1307 & \pm & 201 & \\
\hline \multirow[t]{2}{*}{ Taurine } & Wa & 5612 & \pm & 788 & 7316 & \pm & 869 & 5862 & \pm & 1329 & \\
\hline & GLU & 10097 & \pm & 1315 & 7983 & \pm & 1189 & 6308 & \pm & $1190^{\$}$ & \\
\hline \multirow[t]{2}{*}{ Valine } & Wa & 202 & \pm & 17 & 201 & \pm & 11 & 239 & \pm & $14^{*}$ & G, TxD \\
\hline & GLU & 223 & \pm & 17 & 192 & \pm & 17 & 182 & \pm & 11 & \\
\hline \multirow[t]{2}{*}{ Isoleucine } & Wa & 103 & \pm & 26 & 112 & \pm & 13 & 123 & \pm & 18 & \\
\hline & GLU & 105 & \pm & 18 & 81 & \pm & 9 & 74 & \pm & 8 & \\
\hline \multirow[t]{2}{*}{ Leucine } & $\mathrm{Wa}$ & 166 & \pm & 24 & 165 & \pm & 8 & 201 & \pm & $12^{*}$ & $G, T \times D$ \\
\hline & GLU & 133 & \pm & 15 & 109 & \pm & 7 & 100 & \pm & 9 & \\
\hline \multirow[t]{2}{*}{ BCAA } & $\mathrm{Wa}$ & 471 & \pm & 56 & 477 & \pm & 21 & 563 & \pm & $32^{*}$ & $\mathrm{G}, \mathrm{TxD}$ \\
\hline & GLU & 460 & \pm & 47 & 382 & \pm & 28 & 355 & \pm & 23 & \\
\hline \multirow{3}{*}{$\begin{array}{c}\text { B } \\
\text { Amino acid } \\
\mu \mathrm{mol} / \mathrm{kg} \mathrm{ww} \\
\end{array}$} & \\
\hline & \multicolumn{11}{|c|}{ Time (min) } \\
\hline & Ingestion & & T0 & & & $\mathrm{T} 80$ & & & T10 & & \\
\hline \multirow[t]{2}{*}{ Glutamate } & Wa & 1808 & \pm & 160 & 1713 & \pm & 270 & 1134 & \pm & $198^{*}$ & $\mathrm{~T}$ \\
\hline & GLU & 2270 & \pm & 232 & 2357 & \pm & 144 & 1896 & \pm & $110^{*}$ & \\
\hline \multirow[t]{2}{*}{ Glutamine } & Wa & 9281 & \pm & 914 & 7425 & \pm & 1192 & 6498 & \pm & $1589^{*}$ & $\mathrm{~T}$ \\
\hline & GLU & 11560 & \pm & 1125 & 11075 & \pm & 1398 & 10809 & \pm & $1137^{*}$ & \\
\hline \multirow[t]{2}{*}{ Alanine } & Wa & 1086 & \pm & 128 & 873 & \pm & 157 & 969 & \pm & 233 & \\
\hline & GLU & 1477 & \pm & 174 & 1630 & \pm & 269 & 1801 & \pm & 220 & \\
\hline \multirow[t]{2}{*}{ Taurine } & Wa & 5887 & \pm & 805 & 6171 & \pm & 1031 & 4751 & \pm & $1278^{*}$ & $\mathrm{~T}$ \\
\hline & GLU & 9176 & \pm & 1050 & 8239 & \pm & 568 & 7894 & \pm & $423^{*}$ & \\
\hline \multirow[t]{2}{*}{ Valine } & Wa & 189 & \pm & 9 & 179 & \pm & 21 & 167 & \pm & 19 & \\
\hline & GLU & 199 & \pm & 14 & 191 & \pm & 9 & 193 & \pm & 13 & \\
\hline \multirow[t]{2}{*}{ Isoleucine } & Wa & 129 & \pm & 11 & 117 & \pm & 13 & 111 & \pm & 10 & \\
\hline & GLU & 97 & \pm & 13 & 85 & \pm & 5 & 86 & \pm & 8 & \\
\hline \multirow[t]{2}{*}{ Leucine } & $\mathrm{Wa}$ & 158 & \pm & 13 & 146 & \pm & 15 & 149 & \pm & 11 & \\
\hline & GLU & 118 & \pm & 23 & 117 & \pm & 4 & 116 & \pm & 10 & \\
\hline BCAA & Wa & 477 & \pm & 31 & 441 & \pm & 48 & 426 & \pm & 36 & \\
\hline & GLU & 414 & \pm & 44 & 393 & \pm & 11 & 395 & \pm & 27 & \\
\hline
\end{tabular}

Values are means \pm SEM. Used abbreviation: BCAA: sum of leucine, isoleucine and valine. Symbols depict a significant effect: ${ }^{G}$ signidicant groups effect, ${ }^{\top}$ significant time effect, ${ }^{\mathrm{T} \times \mathrm{D}}$ significant interaction between time and drink, ${ }^{\$}$ significantly different from T0, *significantly different from T80. 
Glutamate ingestion did not affect skeletal muscle concentrations of the exercise related amino acid in rest (table 2). During exercise, skeletal muscle BCAA (isoleucine and valine) concentration increased significantly in the control group during water ingestion $(P<0.05)$, but remained unchanged during glutamate ingestion.
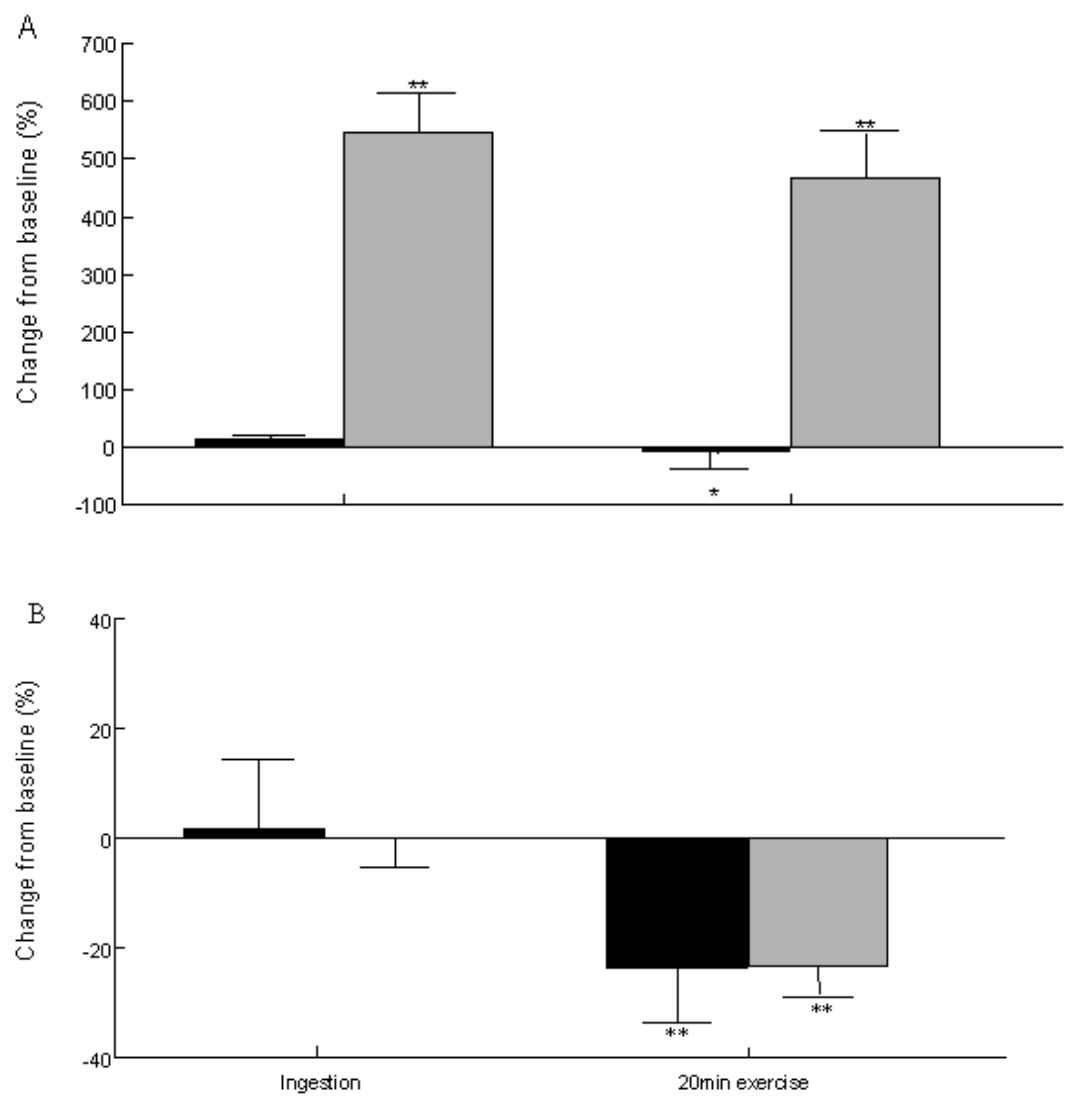

Figure 1: Percentage change from baseline of plasma (A) and skeletal muscle (B) glutamate concentration after ingesting the water (dark bars) or glutamate (light bars) drink for 80 min and after 20 min submaximal cycle ergometry in the control subjects and COPD patients together $(n=18)$. Significant different from zero: ${ }^{\star} p<0.05,{ }^{*} p<0.01$.

There was no baseline difference in skeletal muscle total, reduced or oxidized glutathione concentration and its effect on the drinks between the COPD patients and the controls. Muscle total and reduced glutathione, and GSSG concentration was not affected by glutamate ingestion on at rest or during exercise (figure 2). However a difference in redox response was observed between patients and 
controls. In the controls, GSH/GSSG ratio significantly decreased during exercise independent of the drink $(P<0.02$, figure $3 \mathrm{~A})$, while this effect was not seen in the patients. Glutamate ingestion had no effect on plasma lactate concentration during exercise. Plasma lactate concentration increased in both groups during exercise, but to a higher level in the patients compared to the controls $(P<0.05$, figure 3B).

In the fatiguers of experiment 2, there was no effect of the treatment on mean endurance time and contractile muscle fatigue (figure 4).

\section{Discussion}

The present study showed that glutamate ingestion had only minor effects on skeletal muscle amino acid and glutathione and plasma lactate concentrations in COPD patients, although plasma glutamate concentration significantly increased. Moreover, there was no effect of glutamate ingestion on contractile quadriceps fatigue and cycle endurance time. Similar findings were observed in the healthy control group. Irrespective of glutamate ingestion, exercise resulted in a significantly decreased muscle GSH/GSSG concentration in the healthy controls, but not in the COPD patients.

\section{MUSCLE GLUTAMATE CONCENTRATION}

The first question of the present research was to investigate whether oral glutamate ingestion increases skeletal muscle glutamate concentration in clinically stable COPD patients. Repeated ingestion of $30 \mathrm{mg}$ glutamate/kg body weight $/ 20$ min for $80 \mathrm{~min}$ did not result in increased skeletal muscle glutamate concentration. This finding is in contrast with the study by Graham et al ${ }^{32}$ who showed an increase in muscle glutamate concentration of about $40 \%$ per $\mathrm{kg}$ dry weight after a bolus ingestion of $150 \mathrm{mg}$ mono-sodium glutamate/ $\mathrm{kg}$ body weight in young healthy volunteers. The continuous ingestion of glutamate in the present study differs from the bolus ingestion in the study by Graham et al. Nevertheless, the increase in plasma glutamate concentration was comparable between both studies (till about $533 \mu \mathrm{mol} / \mathrm{L}$ in the present study vs. about $450 \mu \mathrm{mol} / \mathrm{L}$ in ${ }^{32}$ ), indicating that glutamate availability for skeletal muscle increases by glutamate ingestion. 

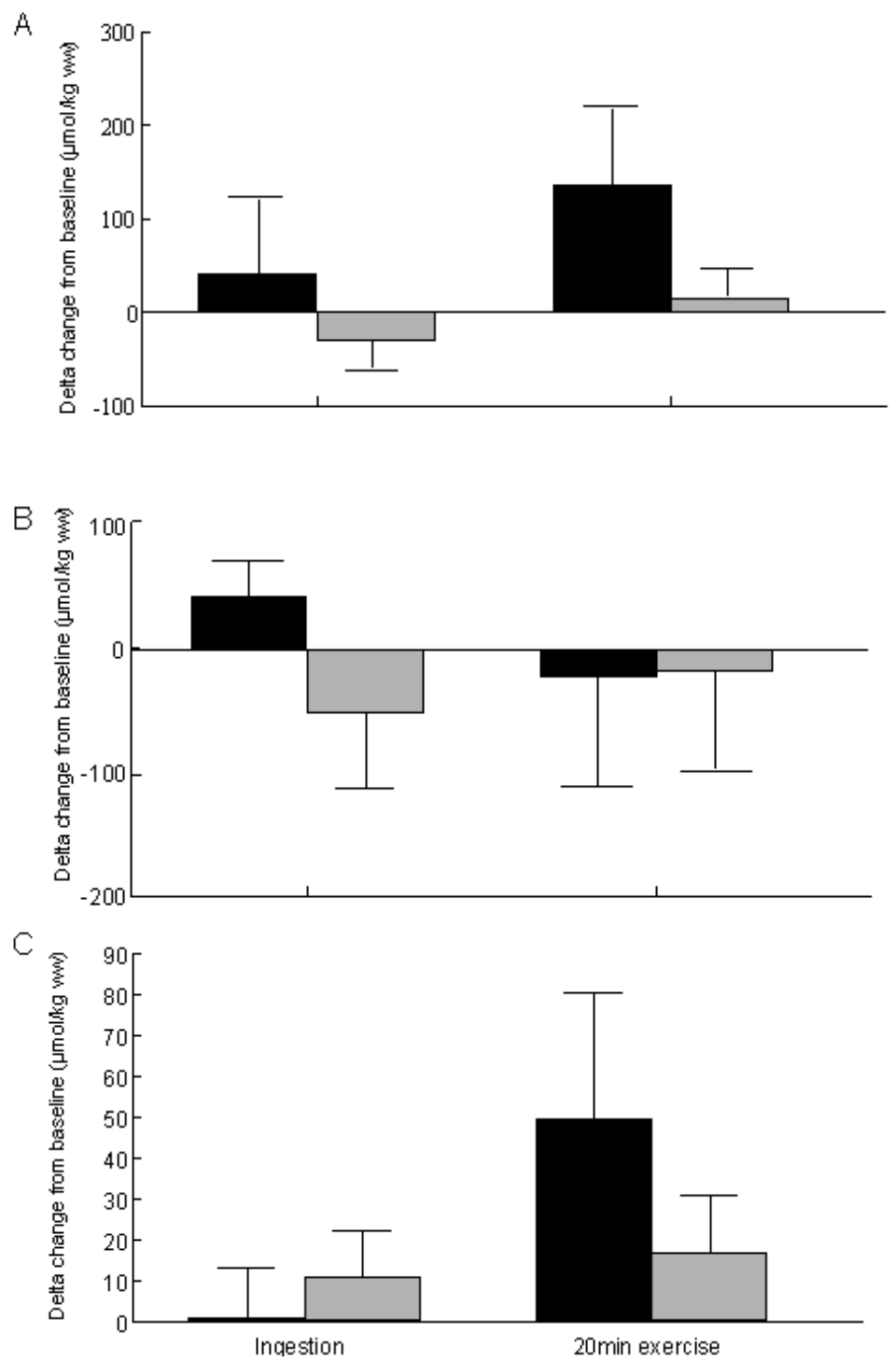

Figure 2: Delta change from skeletal muscle total (A), reduced (B) and oxidized (C) glutathione concentration after ingesting the water (dark bars) or glutamate (light bars) drink for 80 min and after 20 min submaximal cycle ergometry in the control subjects and COPD patients together $(n=18)$.

A positive correlation between the arterial glutamate concentration and the relative glutamate uptake has been detected ${ }^{33}$, suggesting that circulating glutamate is the determining factor for its uptake in skeletal muscle. Muscle glutamate uptake takes place through the sodium dependent $X_{\text {ag }}$ transporter. Based on a $\mathrm{Km}$ (substrate concentration where transport rate is on its half) of $1000 \mu \mathrm{mol} / \mathrm{L}^{34}$, the transport 
velocity reached in the present study was even not half of its maximum after glutamate ingestion. Recently, it is shown that whole body glutamate turnover was affected by ageing ${ }^{35}$. As the volunteers in the study by Graham et al ${ }^{32}$ were younger than the present subjects, we cannot exclude an age-dependent effect on muscular glutamate transporter. Besides this, intramuscular glutamate metabolism can overwhelm the increase in muscle glutamate concentration. However, this would be reflected in glutamate related metabolic substrates, like glutamine, via the enzyme glutamine synthase (glutamate $+\mathrm{NH}_{3} \rightarrow$ glutamine), or alanine via the alanine amino transferase (glutamate + pyruvate $\leftrightarrow$ alanine + a-keto glutarate). In the present study however, neither plasma, nor muscle glutamine, alanine nor other substrate concentrations were modulated by glutamate ingestion. The question if glutamate ingestion increases skeletal muscle glutamate uptake, has to
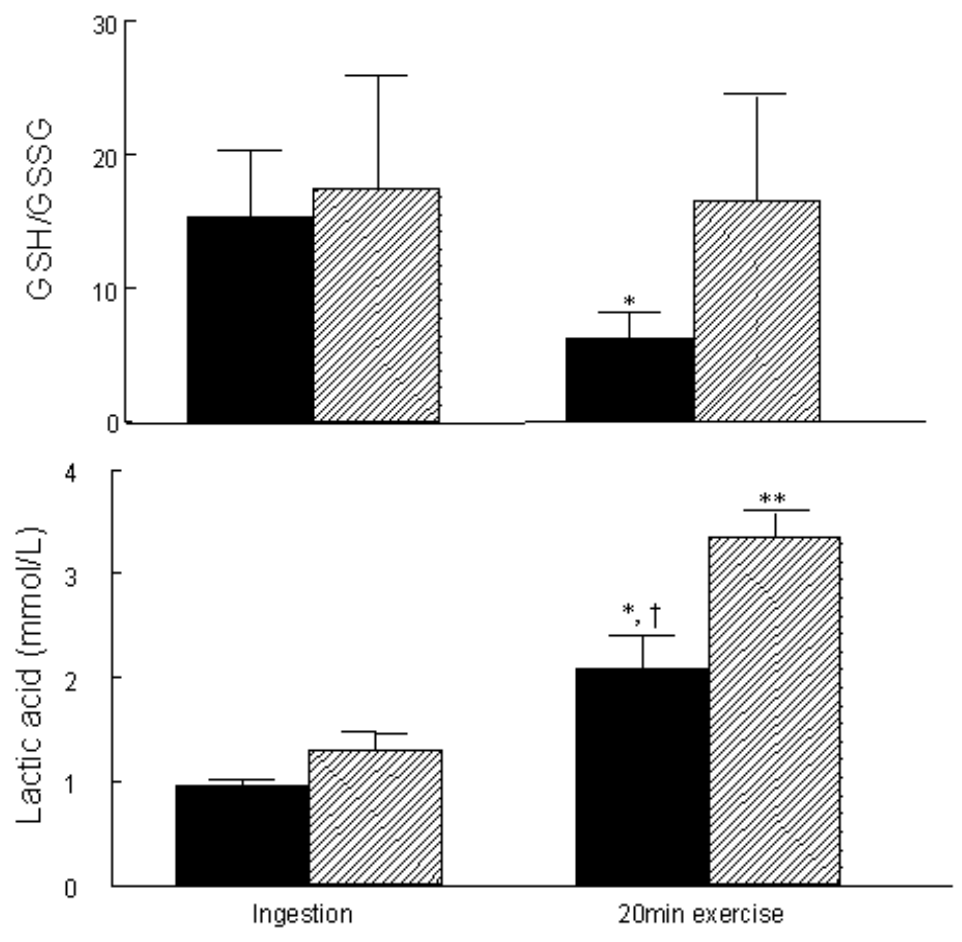

Figure 3: Muscle GSH/GSSG ratio (A) and plasma lactate concentration (B) at baseline and after 20 min submaximal cycle ergometry in the complete control group $(n=8$, solid bars) and the complete COPD group ( $n=10$, striped bars). Significant different from baseline: ${ }^{*} p<0.05,{ }^{\star *} p<0.01$, significant different between the groups: ${ }^{\dagger} p<0.05$. 
In the present study, muscle total and reduced glutathione concentrations were not affected by glutamate ingestion, implying that at least also other factors than glutamate are rate limiting in muscle glutathione synthesis. In the past, correlations between muscle glutathione and glutamate concentrations have been shown ${ }^{36}$. We expected an acute effect of glutamate ingestion on muscle glutathione concentration, as $\mathrm{N}$-acetyl cysteine supplementation, another precursor for glutathione, was able to immediately increase muscle glutathione concentration in healthy subjects ${ }^{37}$. On the other hand, glutamine supplementation to post-surgical patients increased muscle glutathione concentration without affecting muscle glutamate concentration ${ }^{38}$. Glutamate is very compartmentalized in skeletal muscle, and it is suggested that glutamate exchange with intracellular space is slowly ${ }^{39}$. It is therefore likely that external glutamate ingestion is not able to modulate skeletal muscle glutathione metabolism.

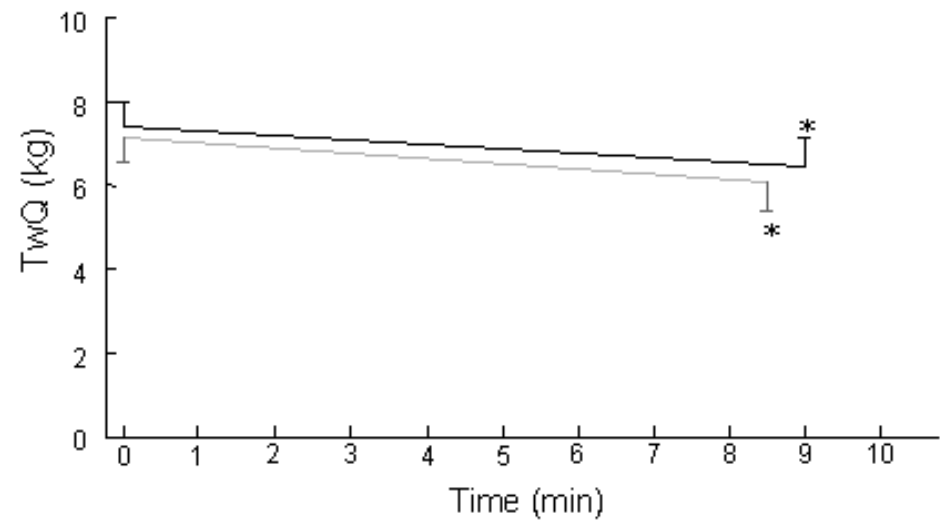

Figure 4: Mean exercise duration and quadriceps twitch force before and after a submaximal cycle ergometry after ingesting the water (dashed line) or glutamate drink (solid line) in the COPD patients. Significant different from baseline: ${ }^{*} p<0.05$.

The only glutamate specific effect was present in muscle branched chain amino acid (BCAA) concentration during exercise. Exercise increased muscle valine and leucine concentration in the controls ingesting water, but remained constant after glutamate ingestion. Other studies showed unchanged ${ }^{14,} 40$ muscle BCAA concentration after exercise. Glutamate and BCAA are taken up by the contracting 
muscle to participate in transamination reactions ${ }^{13}$. We could speculate that muscle glutamate uptake competes with that of BCAA, but this is unlikely since the amino acids are transported by different mechanisms ${ }^{34}$. The reason for the unchanged BCAA concentration during glutamate ingestion after exercise remains unclear.

Since the activity of the alanine amino transferase reaction increases during exercise ${ }^{41}$, we hypothesized that increasing the glutamate availability leads to less lactate production from pyruvate (figure 5). In our study, glutamate ingestion did not affect plasma lactate concentration after exercise, in line with plasma and muscle alanine concentration. Other studies where aerobic energy metabolism was modulated were also unable to show an effect on plasma lactate concentration ${ }^{42}$, ${ }^{43}$ ), suggesting a well-controlled mechanism. However, plasma lactate concentration represents the net effect between lactate production in the exercising muscle and lactate clearance by the liver, thus no hard conclusions about lactate production after glutamate ingestion in the exercising muscle can be made.

\section{QUADRICEPS MUSCLE MEASUREMENTS}

In the present study, we evaluated the effects of glutamate ingestion on contractile quadriceps fatigue and cycle endurance time in fatiguers, as Saey et al ${ }^{7}$ showed that fatiguers had higher glycolytic metabolism compared to the non-fatiguers. We hypothesized that glutamate supplementation decreases lactate production and delays lactic acidosis during exercise, resulting in less quadriceps fatigue and higher endurance time. However, in line with the plasma lactate concentration, glutamate ingestion had no effect on contractile quadriceps fatigue or endurance time. Moreover, endurance time of the non-fatiguers in the present study was significantly lower than the fatiguers $(2.8 \pm 0.3 \min v s .7 .2 \pm 0.7 \mathrm{~min}$ resp., $P<$ 0.05). This exercise protocol used in the present study was adapted from a previously employed protocol ${ }^{5,6}$. However, in order to exclude the effect and variability of ventilatory limitation, it would be interesting in future studies to compare this test with a local quadriceps muscle exercise test. 


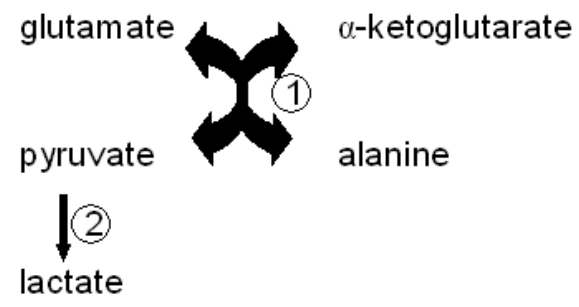

Figure 5: Schematic overview of the alanine amino transferase reaction and the conversion of pyruvate to lactate. 1) alanine aminotransaminase (AAT), 2) lactate dehydrogenase (LDH).

Irrespective of the glutamate ingestion, submaximal cycle ergometry resulted in decreased skeletal muscle reduced vs. oxidized glutathione ratio (GSH/GSSG) in the healthy elderly but not in the COPD patients. Decreased GSH/GSSG was caused by increased muscle GSSG concentration, probably due to exerciseinduced production of reactive oxygen species via the oxidative metabolism. In addition, Steiner et al ${ }^{44}$ recently showed that COPD patients have a greater mobilization of non-oxidative energy production during exercise compared to controls, due to the failure of their oxidative metabolism. In this view, it can be assumed that COPD patients produce less oxidative stress during exercise, because of their higher glycolytic activity. Supporting this hypothesis, plasma lactate concentration after exercise was significantly higher in the COPD patients compared to the controls, even though the controls exercised on a higher absolute workload compared to the COPD patients. On the other hand, glutathione Stransferase activity is increased in COPD patients ${ }^{45}$, and it can be speculated that the available GSH is required for this conjugation reaction rather than the formation of GSSG. Following this hypothesis, we would expect higher concentration of lipid peroxidation products in the COPD patients after exercise. In contrast, exercise did not increase muscle malon-dialdehyde concentration in the present study (muscle malon-dialdehyde concentration before exercise: $0.11 \pm 0.02 \mu \mathrm{mol} / \mathrm{kg} w \mathrm{w}$, after exercise: $0.06 \pm 0.02 \mu \mathrm{mol} / \mathrm{kg} \mathrm{ww}$ ).

In conclusion, although glutamate ingestion significantly increased plasma glutamate concentration, no acute effects could be shown on skeletal muscle glutamate concentration, and concentrations of glutamate related substrates at rest and after exercise in a group of COPD patients that was characterized by 
decreased aerobic energy metabolism and impaired antioxidative response during exercise.

\section{References}

1. Franssen FM, Broekhuizen R, Janssen PP, et al. Effects of Whole-Body Exercise Training on Body Composition and Functional Capacity in Normal-Weight Patients With COPD. Chest 2004; 125(6):2021-8.

2. Decramer $M$, Gosselink R, Troosters $T$, et al. Muscle weakness is related to utilization of health care resources in COPD patients. Eur Respir J 1997; 10(2):417-23.

3. Gosker HR, van Mameren H, van Dijk PJ, et al. Skeletal muscle fibre-type shifting and metabolic profile in patients with chronic obstructive pulmonary disease. Eur Respir J 2002; 19(4):617-25.

4. Maltais $F$, LeBlanc $P$, Whittom $F$, et al. Oxidative enzyme activities of the vastus lateralis muscle and the functional status in patients with COPD. Thorax 2000; 55(10):848-53.

5. Mador MJ, Kufel TJ, Pineda L. Quadriceps fatigue after cycle exercise in patients with chronic obstructive pulmonary disease. Am J Respir Crit Care Med 2000; 161 (2 Pt 1):447-53.

6. Saey D, Debigare R, LeBlanc $\mathrm{P}$, et al. Contractile leg fatigue after cycle exercise: a factor limiting exercise in patients with chronic obstructive pulmonary disease. Am J Respir Crit Care Med 2003; 168(4):425-30.

7. Saey D, Michaud A, Couillard A, et al. Contractile fatigue, muscle morphometry, and blood lactate in chronic obstructive pulmonary disease. Am J Respir Crit Care Med 2005; 171(10):1109-15.

8. Engelen MP, Wouters EF, Deutz NE, et al. Factors contributing to alterations in skeletal muscle and plasma amino acid profiles in patients with chronic obstructive pulmonary disease. Am J Clin Nutr 2000; 72(6):1480-7.

9. Pouw EM, Schols AMWJ, Deutz NEP, Wouters EFM. Plasma and muscle amino-acid levels in relation to resting energy expenditure and inflammation in stable COPD. Am.J.Respir.Crit.Care Med. 1998; 158:797-801.

10. Engelen MPKJ, Schols AMWJ, Does JD, et al. Altered glutamate metabolism is associated with reduced muscle glutathione levels in patients with emphysema. Am.J.Respir.Crit.Care Med. 2000; 161:98-103.

11. Engelen MPKJ, Schols AMWJ, Does JD, et al. Exercise induced lactate increase in relation to muscle substrates in patients with COPD. Am.J.Respir.Crit. Care Med. 2000; 162(5):1697-704.

12. Marliss EB, Aoki TT, Pozefsky T, et al. Muscle and splanchnic glutamine and glutamate metabolism in postabsorptive and starved man. J Clin Invest 1971; 50(4):814-7.

13. Van Hall G, Saltin B, Wagenmakers AJ. Muscle protein degradation and amino acid metabolism during prolonged knee-extensor exercise in humans. Clin Sci (Lond) 1999; 97(5):557-67.

14. Gibala MJ, MacLean DA, Graham TE, Saltin B. Anaplerotic processes in human skeletal muscle during brief dynamic exercise. J Physiol 1997; 502 ( Pt 3):703-13.

15. Rutten EP, Engelen MP, Schols AM, et al. The effect of repeated ingestion of glutamate or glutamine on plasma glutamate levels. Clin Nutr 2003; 22(S1):S27.

16. Matthews DE, Marano MA, Campbell RG. Splanchnic bed utilization of glutamine and glutamic acid in humans. Am J Physiol 1993; 264(6 Pt 1):E848-54.

17. Thomassen A, Nielsen TT, Bagger JP, Henningsen P. Effects of intravenous glutamate on substrate availability and utilization across the human heart and leg. Metabolism 1991; 40(4):37884.

18. Svedjeholm R, Vanhanen I, Hakanson E, et al. Metabolic and hemodynamic effects of intravenous glutamate infusion early after coronary operations. J Thorac Cardiovasc Surg 1996; 112(6):146877. 
19. Gross NJ. The GOLD standard for chronic obstructive pulmonary disease. Am J Respir Crit Care Med 2001; 163(5):1047-8.

20. Picado C, Deulofeu R, Lleonart R, et al. Lipid and protein metabolism in asthma. Effects of diet and corticosteroid therapy. Allergy 1999; 54(6):569-75.

21. Clausen JL, Coates AL, Quanjer PH. Measurement of lung volumes in humans: review and recommendations from an ATS/ERS workshop. Eur Respir J 1997; 10(6):1205-6.

22. Steiner MC, Barton RL, Singh SJ, Morgan MD. Bedside methods versus dual energy X-ray absorptiometry for body composition measurement in COPD. Eur Respir J 2002; 19(4):626-31.

23. Kyle UG, Bosaeus I, De Lorenzo AD, et al. Bioelectrical impedance analysis--part I: review of principles and methods. Clin Nutr 2004; 23(5):1226-43.

24. Bergstrom L. Muscle electrolytes in man. Determination by neutron activation analysis on needle biopsy specimens. A study on normal subjects, kidney patients, and patients with chronic diarrhea. Scand.J.Clin.Lab.Invest. 1962; 68:7-110.

25. Van Eijk HMH, Rooyakkers DR, Deutz NEP. Rapid routine determination of amino acids in plasma by high-performance liquid chromatography with a 2-3 um Sperisorb ODS 2 column. J.Chromat. 1993; 620:143-148.

26. Shephard D, Garland P. Citrate synthase from rat liver. Methods in Enzymology. 1969; 13:11-16.

27. Bergmeyer H, Gawehn K, Grassl M. 3-Hydroxyacyl-CoA dehydrogenase. Weinheim, 1974.

28. Ling K, Pastkau V, Marcus F, Lardy H. Phosphofructokinase. I. Skeletal muscle. Methods in Enzymology 1966; 9:425-429.

29. Talmadge RJ, Roy RR. Electrophoretic separation of rat skeletal muscle myosin heavy-chain isoforms. J Appl Physiol 1993; 75(5):2337-40.

30. Vandeputte C, Guizon I, Genestie-Denis I, et al. A microtiter plate assay for total glutathione and glutathione disulfide contents in cultured/isolated cells: performance study of a new miniaturized protocol. Cell Biol Toxicol 1994; 10(5-6):415-21.

31. Polkey Ml, Kyroussis D, Hamnegard $\mathrm{CH}$, et al. Quadriceps strength and fatigue assessed by magnetic stimulation of the femoral nerve in man. Muscle Nerve 1996; 19(5):549-55.

32. Graham TE, Sgro V, Friars D, Gibala MJ. Glutamate ingestion: the plasma and muscle free amino acid pools of resting humans. Am J Physiol Endocrinol Metab 2000; 278(1):E83-E89.

33. Hack V, Stutz O, Kinscherf R, et al. Elevated venous glutamate levels in (pre)catabolic conditions result at least partly from a decreased glutamate transport activity. J Mol Med 1996; 74(6):337-43.

34. Hundal HS, Rennie MJ, Watt PW. Characteristics of acidic, basic and neutral amino acid transport in the perfused rat hindlimb. J Physiol 1989; 408:93-114.

35. Rutten EP, Engelen MP, De Castro CL, et al. Decreased whole body glutamate turnover in elderly and patients with chronic obstructive pulmonary disease (COPD). J Nutr 2005; 135(9):2166-70.

36. Rutten EP, Engelen MP, Schols AM, Deutz NE. Skeletal muscle glutamate metabolism in health and disease: state of the art. Curr Opin Clin Nutr Metab Care 2005; 8(1):41-51.

37. Medved I, Brown MJ, Bjorksten AR, et al. N-acetylcysteine enhances muscle cysteine and glutathione availability and attenuates fatigue during prolonged exercise in endurance-trained individuals. J Appl Physiol 2004; 97(4):1477-85.

38. Flaring UB, Rooyackers OE, Wernerman J, Hammarqvist F. Glutamine attenuates post-traumatic glutathione depletion in human muscle. Clin Sci (Lond) 2003; 104(3):275-82.

39. Darmaun D, Matthews DE, Bier DM. Glutamine and glutamate kinetics in humans. Am J Physiol 1986; 251(1 Pt 1):E117-26.

40. van Hall G, MacLean DA, Saltin B, Wagenmakers AJ. Mechanisms of activation of muscle branched-chain alpha-keto acid dehydrogenase during exercise in man. J Physiol 1996; 494 ( Pt 3):899-905.

41. Gibala MJ, Peirce N, Constantin-Teodosiu D, Greenhaff PL. Exercise with low muscle glycogen augments TCA cycle anaplerosis but impairs oxidative energy provision in humans. J Physiol 2002; 540(Pt 3):1079-86.

42. Mourtzakis $M$, Graham TE. Glutamate ingestion and its effects at rest and during exercise in humans. J Appl Physiol 2002; 93(4):1251-9. 
43. Op 't Eijnde B, Van Leemputte $M$, Brouns $F$, et al. No effects of oral ribose supplementation on repeated maximal exercise and de novo ATP resynthesis. J Appl Physiol 2001; 91(5):2275-81.

44. Steiner MC, Evans R, Deacon SJ, et al. Adenine nucleotide loss in the skeletal muscles during exercise in chronic obstructive pulmonary disease. Thorax 2005.

45. Gosker HR, Bast A, Haenen GR, et al. Altered antioxidant status in peripheral skeletal muscle of patients with COPD. Respir Med 2005; 99(1):118-25. 


\section{Chapter 9}

General Discussion 
In this thesis, we demonstrated alterations in protein and amino acid metabolism in COPD patients and tried to modulate these to improve patients' physical functioning. Three topics have been studied; firstly, we wanted to obtain more insight in the altered protein and amino acid metabolism with special notice for glutamate in patients with clinically stable COPD (chapters $2-4$ ); secondly, supplementation of the amino acid glutamate was studied in COPD patients and healthy control subjects (chapter $5 \& 6$ ); and thirdly, the metabolic and functional effects of glutamate supplementation in skeletal muscle were evaluated in different conditions (chapter $7 \&$ 8). Not all relevant issues related to these topics have been discussed in detail in the preceding chapters. Therefore, in this final chapter, we elaborate more on the following items:

1. What is the influence of ageing on glutamate metabolism?

2. How to apply glutamate as nutritional supplement

3. What other possibilities are (theoretically) available to modulate glutamate and glutamate related metabolism? 


\section{What is the influence of ageing on glutamate metabolism?}

\section{GLUTAMATE METABOLISM AND SARCOPENIA}

In chapter 4 of this thesis, we showed that decreased whole-body glutamate turnover is more of an age-dependent phenomenon than disease-specific. Ageing is characterized by many metabolic changes and generally reflected in a decrease of skeletal muscle mass with preserved or increased amount of fat mass, defined as sarcopenia ${ }^{1}$. The underlying mechanism of sarcopenia and its physiological implications in otherwise healthy elderly people is still not fully understood, however many potential factors have already been documented. The activities of various anabolic hormones follow a stable pattern in life. For example, the levels of testosterone and growth hormone decrease during ageing ${ }^{2,3}$, possibly contributing to the reduction of muscle mass. However, a causal role of the decreased concentration of these hormones on the development of sarcopenia has so far not been proven. Additionally, ageing is associated with increased vulnerability for insulin resistance and this could be related to increased fat mass ${ }^{4}$. Ageing is also characterized by morphologic and structural changes in skeletal muscle. Adult mammalian skeletal muscle contains three myosin heavy chain isoforms, namely types I, IIA and IIX. The type I or 'slow twitch' fibers rely predominantly on oxidative metabolism, and the type II or 'fast twitch' fibers rely mainly on glycolytic metabolism. Fiber type IIA has a mixed oxidative-glycolytic metabolism. While the type I fibers are mildly affected, the number of type II fibers decreases with ageing ${ }^{5}$. In addition, the cross sectional area of the quadriceps femoris muscle decreases during ageing and is correlated with muscle strength ${ }^{6}$. Alterations in the denervation - reinervation process in the elderly is a factor contributing to the decreased amount of type II fibers, which possibly participates in the development of sarcopenia ${ }^{7}$. Regeneration of muscle fibers happens through a whole cascade of reactions, beginning with the activation of satellite cells ${ }^{8}$. In several conditions, the proliferation of satellite cells can become the rate-limiting step in the regeneration process. Recent data showed a correlation between age and the decreased number of satellite cells ${ }^{9}$ and also between age and the reduced rate of 
cell proliferation ${ }^{10}$. However, the precise contribution of the decreased regenerative capacity of muscle fibers during ageing in the progress of sarcopenia is not fully clear. All these age-relating factors are to some extents involved in the development of sarcopenia.

A decrease of muscle mass is however, generally the result of an imbalance between muscle protein synthesis and breakdown. Research showed no differences between whole-body and skeletal muscle protein breakdown in the elderly when compared to the young ${ }^{11,12}$. On the other hand, we recently demonstrated that whole-body glutamate turnover reduces with ageing (chapter 4). Glutamate turnover on whole-body level is a reflection of the glutamate delivery to the organs rather than the intracellular glutamate metabolism and thus, ageing is associated with a decreased postabsorptive glutamate delivery. This suggests that glutamate specific pathways, independent of protein breakdown, are affected by ageing. With the knowledge that glutamate is highly present in skeletal muscle and participates in many metabolic routes, altered glutamate availability in the elderly may be associated with factors involved in the development of sarcopenia. Taking this in consideration, a decreased antioxidative capacity often observed in the elderly ${ }^{13}$ could be due to a reduced availably of glutamate for glutathione synthesis. We showed however in chapter 8 that oral supplementation with glutamate does not affect skeletal muscle glutathione concentration in healthy elderly. Moreover, postabsorptive splanchnic glutamate extraction was also lower in the elderly compared to the young, despite having the same amount of external delivered glutamate (chapter 4). Apart from skeletal muscle, the intestine is the largest consumer of glutamate and the finding of decreased splanchnic glutamate extraction suggests that a smaller amount of glutamate is necessary for intestinal oxidation in the elderly. From this point of view, we can hypothesize that wholebody glutamate needs decrease during ageing, resulting in a decreased glutamate turnover. More research is necessary to unravel the question if the altered glutamate turnover in the elderly is a factor that takes part in the development of sarcopenia or that it is only an adaptive mechanism to ageing. 


\section{COPD SPECIFIC ALTERATIONS IN GLUTAMATE METABOLISM}

Recent findings showed that a number of the COPD patients develops contractile muscle fatigue, defined as a reversible post-exercise fall in quadriceps muscle strength while others do not and that this fatigue is not reversible by acute administration of a bronchodilator ${ }^{14}$. Patients suffering from exercise induced muscle fatigue were characterized by enhanced plasma lactic acid concentration after exercise and elevated lactic acid dehydrogenase activity, despite similar fiber type distribution and oxidative enzyme activities when compared to the nonfatiguers ${ }^{15}$. These findings suggest that glycolytic metabolism is enhanced in the fatiguers due to less substrate availability rather than to morphologic alterations.

Earlier studies showed decreased skeletal muscle glutamate concentration in COPD patients, independent of airflow limitation 16, 17. This reduction was associated with early lactic acidosis ${ }^{18}$. Therefore, a possible limiting substrate in the COPD patients who develop contractile muscle fatigue can be glutamate via decreased glutamate delivery for the muscles. Nevertheless, postabsorptive wholebody glutamate turnover as a measure for glutamate delivery was not different between clinically stable COPD patients and age-matched healthy control subjects (chapter 5). Other factors such as enhanced glutamate consumption in muscle must contribute to the decreased muscle glutamate concentration.

Based on the observed decreased glutamate turnover in the elderly and the reduced skeletal muscle glutamate concentration in COPD patients, we hypothesize that glutamate delivery decreases with ageing due to reduced glutamate requirement, but disease-related factors may however increase glutamate requirement. If glutamate turnover is not able to cover the enhanced glutamate needs, skeletal muscle glutamate concentration decreases. Following this hypothesis, a number of the COPD patients, reflected in those patients who develop contractile muscle fatigue, are unable to maintain muscle glutamate levels, due to decreased glutamate delivery. Consequently in these patients, the activity of the glycolytic metabolism enhances. Future metabolic studies with the threecompartment model have to determine the factors contributing to enhance glutamate needs in the skeletal muscle of patients with COPD. 


\section{GLUTAMATE METABOLISM AND CACHEXIA}

COPD patients frequently suffer from cachexia. A clear definition for cachexia does not exist. Cachexia is caused by an underlying disease and is characterized by loss of fat-free mass with or without loss of fat mass ${ }^{19}$. The precise mechanism of cachexia is still unclear, but various factors are associated with metabolic alterations contributing to the progression of cachexia. Muscle wasting during disease has been related with increased activities of catabolic hormones such as cortisol ${ }^{20}$. In addition, underweight patients with COPD had higher levels of norepinephrine compared to patients with a normal weight ${ }^{21}$. Hypoxia is often present in COPD patients and has been related with increased levels of tumor necrose factor alpha (TNF- $\alpha)^{22}$, a cytokine that has been implicated in the cachexia process. Besides morphological changes in the elderly, disease-specific morphologic and structural changes in skeletal muscle fibers have been detected in COPD patients. While the proportion of type I fibers relative to type II fibers is decreased in patients with COPD ${ }^{23}$, the cross sectional area of predominantly type IIX fibers is reduced and this is associated with decreased muscle mass ${ }^{24}$. COPD is characterized by systemic inflammation ${ }^{25,26}$ and this has been associated with hypermetabolism ${ }^{16}$, indicating a role of inflammation in the development of cachexia. A relation between hypermetabolism and decreased levels of plasma branched chain amino acids has also been detected in COPD patients ${ }^{27}$, suggesting that alterations in substrate metabolism contribute to the progress of cachexia. However, surprisingly limited information is available on substrate metabolism in relation to cachexia.

In this thesis, we showed that cachectic COPD patients had higher levels of myofibrillar protein breakdown, suggesting that skeletal muscle proteolysis is increased in these patients (chapter 2). The increased myofibrillar protein breakdown was accompanied with a decreased plasma glutamate concentration. In chapter 2, we hypothesized that cachectic COPD patients have higher activity of amino acid transamination, resulting in higher myofibrillar protein breakdown and lower plasma glutamate concentration. Following this hypothesis and in line with the earlier stated hypothesis of increased glutamate needs in a subgroup of COPD patients, glutamate consumption would increase, depending on the degree of muscle wasting. It has to be further investigated whether there is an association 
between increased glutamate consumption, the development of cachexia and an altered substrate metabolism in COPD patients.

\section{How to apply glutamate as nutritional supplement}

In view of potential enhanced glutamate requirement due to increased glutamate consumption in skeletal muscle of COPD patients, it seems reasonable to supplement COPD patients with glutamate. Our glutamate ingestion protocol consisted of the repeated ingesting of $30 \mathrm{mg}$ glutamate $/ \mathrm{kg}$ body weight every 20 $\mathrm{min}$. This ingesting protocol increased plasma glutamate concentration 4 to 5 -fold, suggesting that glutamate reaches the circulation as the amount of glutamate ingestion exceeds the oxidative capacity of the intestine. Surprisingly, although glutamate availability increased, skeletal muscle glutamate concentration remained remarkably constant in both the COPD patients and the healthy elderly. An interesting point of discussion is therefore to consider the metabolic end point of external ingested glutamate.

In contrast to the present findings, a bolus ingestion of $150 \mathrm{mg}$ mono-sodium glutamate/kg body weight in young healthy volunteers (mean age: 26 years) resulted in an increased muscle glutamate concentration of about $40 \%{ }^{28}$. As the COPD patients and the healthy control subjects of our studies had an age of at least 50 years, it cannot be excluded that glutamate uptake in skeletal muscle alters with ageing, but until now, there is no evidence to support this notion. In a pilot study, we measured the arterio-venous balance across the forearm of 4 elderly volunteers during $80 \mathrm{~min}$ of water ingestion $(1.25 \mathrm{~mL}$ water $/ \mathrm{kg}$ body weight/20 $\mathrm{min}$ ) followed by $80 \mathrm{~min}$ of glutamate ingestion $(30 \mathrm{mg}$ glutamate/ $\mathrm{kg}$ body weight/20 min, figure 1). These data indicates that a significant amount of ingested glutamate was indeed taken up by the skeletal muscle $(P<0.01)$, but that this is not reflected in an increased glutamate concentration in muscle. 


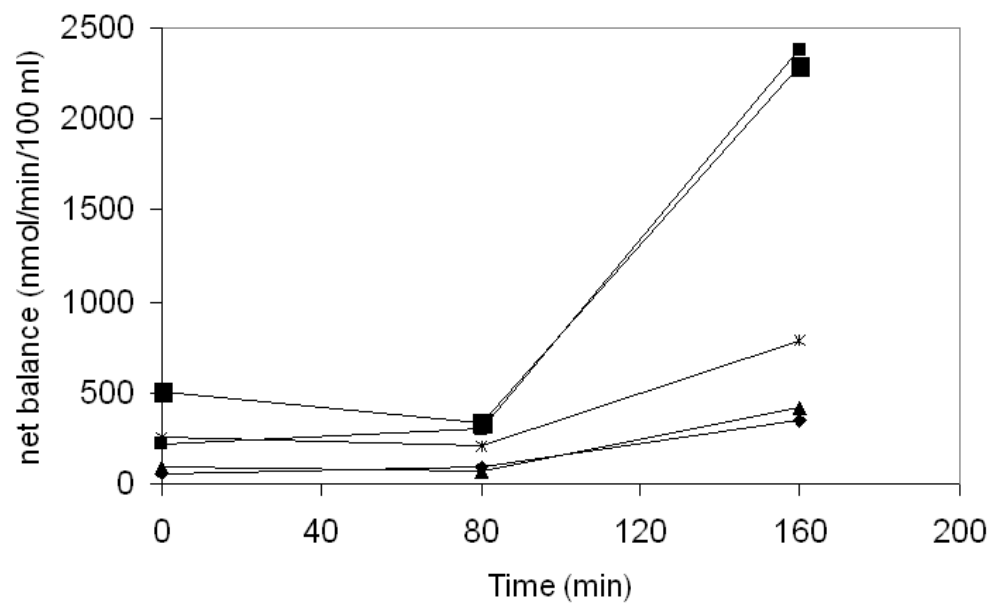

Figure 1: individual arterio-venous net balance across the forearm after 80 min ingesting a water drink followed by 80 min ingesting a glutamate drink.

As shown in the chapter 1 , the general introduction, glutamate participates in many metabolic pathways on whole-body level. Chapters 6 and 8 demonstrated that, except for some plasma amino acids, only few glutamate specific metabolic effects could be detected after glutamate ingestion. Irrespective of the organs where glutamate is metabolized, glutamate was ingested in the postabsorptive state and therefore, glutamate might have been used as an energy source. During short-term starvation, glucose oxidation decreases ${ }^{29}$ and the contribution of gluconeogenesis increases ${ }^{30}$. In contrast, other studies detecting an effect of supplementing single amino acids like leucine ${ }^{31}$, or a combination of essential amino acids ${ }^{32}$ on protein metabolism were also performed in the postabsorptive state. We can hypothesize that glutamate is an oxidative amino acid, which is oxidized in preference to leucine, or other amino acids as glutamate can act as a precursor for the tricarboxylic acid intermediate (TCAl) a-ketoglutarate, although the amount of energy in the glutamate drink was very low (about $45 \mathrm{kCal}$ or $191 \mathrm{~kJ}$ in $80 \mathrm{~min}$ ). It would be interesting to perform a study in which the glutamate drink was ingested during the infusion of the $1-{ }^{13} \mathrm{C}$-glutamate tracer to measure the amount of labeled $\mathrm{CO}_{2}$ in the expired air (figure 2). 

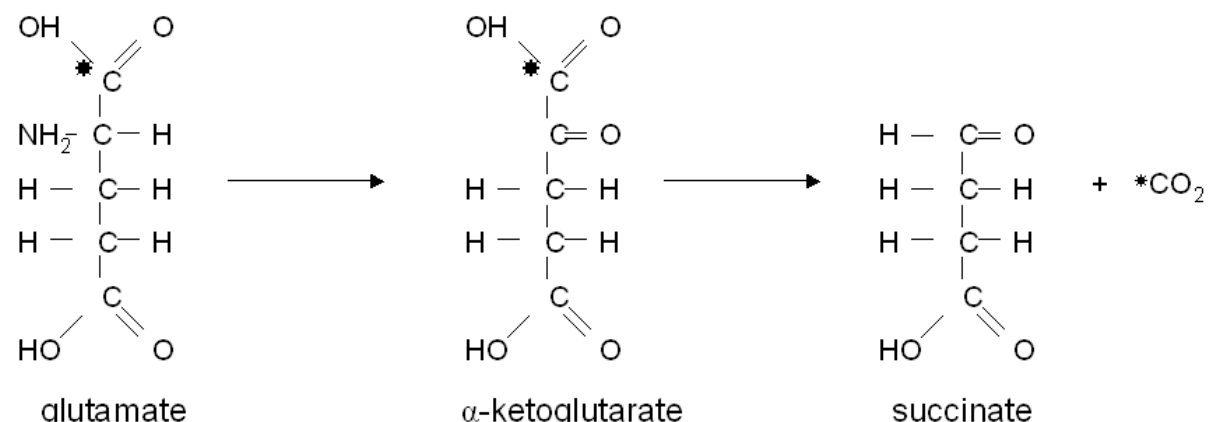

Figure 2: Fate of the labeled $\mathrm{C}$-atom in the glutamate molecule in the tricarboxylic acid cycle.

The ingestion protocol used in the previous chapters is difficult to compare with daily life, as the ingestion existed in a solution of pure glutamate without other nutrients. To make the glutamate drink more palatable, we decided to supplement glutamate with an artificial sweetener instead of adding carbohydrates, because Stegink et al ${ }^{33}$ have shown that glutamate reacts with the available pyruvate from carbohydrates in the intestine. As a consequence, less glutamate is available for the circulation. Glutamate supplementation in combination with a meal would be another option to modulate glutamate and glutamate related metabolism. However, the amount of glutamate in food did not affect plasma glutamate concentration ${ }^{34}$. In addition, glutamate ingestion in the prandial state did not result in an increased plasma glutamate concentration ${ }^{35}$, indicating that a potential effect of glutamate is attenuated when glutamate is ingested with food. On the other hand, glutamate related metabolism has never been investigated after glutamate supplementation combined with a meal. The additional amino acids in the meal can be crucial to cause an anabolic effect. The shiitake mushroom may provide a medium to investigate glutamate supplementation in combination with a meal. Glutamate is highly present in shiitake mushrooms ${ }^{36}$ and these mushrooms are widely investigated for their therapeutic properties such as their ability to improve the immune system ${ }^{37}$. Fresh mushrooms contain high levels of glutamate $(\sim 71 \mathrm{mg} / 100 \mathrm{~g})$, but when they are dried they even contain 10 times or more than the normal level of glutamate $(\sim 1060 \mathrm{mg} / 100 \mathrm{~g})$. Surprisingly, the high glutamate concentration has never been related to the therapeutic value so far. Future research could be interesting to investigate if the amount of glutamate in edible 
mushrooms, particularly in shiitake, plays a role in their suggested therapeutic properties.

\section{What other possibilities are (theoretically) available to modulate glutamate and glutamate related metabolism?}

In this thesis, the amino acid glutamate is used as a supplement to improve skeletal muscle glutamate related metabolism and patients' functional performance. Oral ingestion of glutamate was not able to modulate skeletal muscle glutamate related parameters. In the previous paragraph, we provided possible explanations, while in the section below, various other possible nutrients are discussed to modulate muscle glutamate concentration and glutamate related metabolism, i.e. muscular glutathione and energy metabolism.

\section{OPTIONS TO INCREASE SKELETAL MUSCLE GLUTAMATE CONCENTRATIONS}

There are various other options than glutamate supplementation to modulate skeletal muscle glutamate concentrations. Glutamate is very compartmentalized and glutamate inter-organ transport mainly happens via its closely related amino acid glutamine. Glutamine supplementation as an option to increase skeletal muscle glutamate status is not likely, as the skeletal muscle is known to release large amounts of glutamine ${ }^{38}$. In addition, enteral glutamine supplementation did not increase skeletal muscle glutamate concentrations in post-surgical patients ${ }^{39}$.

Supplementation of precursors of glutamate, the branched-chain amino acids (BCAA) leucine, isoleucine and valine or ornithine a-ketoglutarate are other options to increase skeletal muscle glutamate concentration. The BCAA are transaminized in skeletal muscle to form their a-keto acids and glutamate. During exercise and nutrition, BCAA are actively taken up by the skeletal muscles. However, there is no study so far that was able to show increased muscle glutamate concentrations after BCAA supplementation ${ }^{40}$. Ornithine $\alpha$-ketoglutarate has been proven to be an efficient nutritional support during traumatic situations as a-ketoglutarate is a precursor of glutamine via glutamate ${ }^{41}$. However, neither plasma nor skeletal muscle glutamate concentrations were increased after ornithine a-ketoglutarate 
infusion in post-surgical patients ${ }^{40,42}$. Hence, there remains no ideal nutritional supplement to increase skeletal muscle glutamate concentration.

\section{MOdULATING MUSCLE GLUTATHIONE METABOLISM}

The decreased skeletal muscle glutamate concentrations in COPD patients were associated with reduced levels for muscle glutathione concentrations ${ }^{43}$. Glutamate is one of the precursors in the glutathione synthesis. In chapter 8 of this thesis, we showed that oral ingestion of glutamate was not able to increase muscle glutathione concentration in COPD patients who did not showed decreased baseline muscle glutamate concentration when compared to the healthy control subjects. Intravenous infusion of glutamine was able to increase muscle glutathione concentrations in post-surgical patients without affecting muscle glutamate concentrations $^{39}$. Two other amino acids cysteine and glycine are also involved in the glutathione synthesis pathway and until now, no consistency has been reached about the rate-limiting factor in this pathway. In healthy exercising men, intravenous infusion of $\mathrm{N}$-acetylcysteine (NAC) resulted in increased muscle glutathione concentration at rest and attenuated the glutathione decrease during exercise ${ }^{44}$. In line, oral supplementation of NAC in COPD patients decreased superoxide anion release both at rest and during exercise ${ }^{45}$. This data indicate that cysteine can also play a regulatory role in the muscle glutathione synthesis.

\section{MODULATING ENERGY METABOLISM}

Resting muscle glutamate concentration was correlated with the lactic acid threshold during incremental ergometry in COPD patients ${ }^{18}$. As glutamate can act as a precursor for the tricarboxy acid intermediate a-ketoglutarate ${ }^{46}$, it is hypothesized that glutamate positively influences oxidative energy metabolism in COPD patients during exercise. In contrast, chapter 8 of this thesis showed that glutamate supplementation did not affect plasma lactic acid concentration, contractile quadriceps fatigue and cycle endurance time. In line with other nutritional substrates suggested to increase muscle strength or endurance in COPD patients, there is so far no clear evidence that nutritional supplementation solely can significantly improve patients physical condition. For example, oral ingestion of ribose in healthy exercising volunteers was suggested to increase ATP 
recovery after maximal muscle contractions ${ }^{47}$, however it had no effect. Contrary to these findings, oral supplementation of creatine in COPD patients improved muscle strength and endurance, but not exercise capacity ${ }^{48}$. Creatine is no substrate as such, but it promotes muscular substrate uptake and increases fatfree mass. It can therefore be questioned if it is possible to modulate substrate utilization by enhancing external substrate availability, or if the body acts as a very well controlled and regulated system.

In summary, it is clear that even controlled clinical experiments on nutritional supplementation in chronic disease are complex. General every day food contains numerous different nutrients, which all interact with each other. Many nutrients have potentially beneficial effects in patients but it is difficult to determine their specific effect without affecting other nutrient-relating routes. Nevertheless, research in clinical nutrition is of importance as it is one of the safest options for influencing patients' metabolism. In clinical intervention studies involving nutritional modulation, it is crucial to build up the most efficient study design in order to be able to specifically measure the outcome parameters one will focus on. An important factor is the development of an effective supplementation protocol in terms of the condition in which the supplement is given: in the postabsorptive state or after a meal; as one single nutrient, in combination with other nutrient compounds or in combination with a meal; the amount of nutrient necessary to receive a physiologic effect; etc. Eventually, one has to evaluate if supplementing the nutrient is sufficient to affect the outcome parameters, or if the combination with exercise or medication is preferable.

\section{References}

1. Roubenoff R. The pathophysiology of wasting in the elderly. J Nutr 1999; 129(1S Suppl):256S$259 S$.

2. Lamberts SW, van den Beld AW, van der Lely AJ. The endocrinology of aging. Science 1997; 278(5337):419-24.

3. Gooren LJ. Endocrine aspects of ageing in the male. Mol Cell Endocrinol 1998; 145(1-2):153-9.

4. Beaufrere B, Morio B. Fat and protein redistribution with aging: metabolic considerations. Eur $\mathrm{J}$ Clin Nutr 2000; 54 Suppl 3:S48-53.

5. Beaufrere B, Boirie Y. Aging and protein metabolism. Curr Opin Clin Nutr Metab Care 1998; 1(1):85-9. 
6. Izquierdo M, Ibanez J, Gorostiaga E, et al. Maximal strength and power characteristics in isometric and dynamic actions of the upper and lower extremities in middle-aged and older men. Acta Physiol Scand 1999; 167(1):57-68.

7. Deschenes MR. Effects of aging on muscle fibre type and size. Sports Med 2004; 34(12):809-24.

8. Fulle S, Protasi F, Di Tano G, et al. The contribution of reactive oxygen species to sarcopenia and muscle ageing. Exp Gerontol 2004; 39(1):17-24.

9. Thornell LE, Lindstrom M, Renault V, et al. Satellite cells and training in the elderly. Scand J Med Sci Sports 2003; 13(1):48-55.

10. Renault V, Piron-Hamelin G, Forestier C, et al. Skeletal muscle regeneration and the mitotic clock. Exp Gerontol 2000; 35(6-7):711-9.

11. Boirie Y, Gachon P, Beaufrere B. Splanchnic and whole-body leucine kinetics in young and elderly men. Am J Clin Nutr 1997; 65(2):489-95.

12. Volpi E, Lucidi P, Bolli GB, et al. Gender differences in basal protein kinetics in young adults. J Clin Endocrinol Metab 1998; 83(12):4363-7.

13. Fulle S, Di Donna S, Puglielli C, et al. Age-dependent imbalance of the antioxidative system in human satellite cells. Exp Gerontol 2005; 40(3):189-97.

14. Mador MJ, Kufel TJ, Pineda L. Quadriceps fatigue after cycle exercise in patients with chronic obstructive pulmonary disease. Am J Respir Crit Care Med 2000; 161(2 Pt 1):447-53.

15. Saey D, Michaud A, Couillard A, et al. Contractile fatigue, muscle morphometry, and blood lactate in chronic obstructive pulmonary disease. Am J Respir Crit Care Med 2005; 171(10):1109-15.

16. Pouw EM, Schols AMWJ, Deutz NEP, Wouters EFM. Plasma and muscle amino-acid levels in relation to resting energy expenditure and inflammation in stable COPD. Am.J.Respir.Crit.Care Med. 1998; 158:797-801.

17. Engelen MP, Wouters EF, Deutz NE, et al. Factors contributing to alterations in skeletal muscle and plasma amino acid profiles in patients with chronic obstructive pulmonary disease. Am J Clin Nutr 2000; 72(6):1480-7.

18. Engelen MPKJ, Schols AMWJ, Does JD, et al. Exercise induced lactate increase in relation to muscle substrates in patients with COPD. Am.J.Respir.Crit. Care Med. 2000; 162(5):1697-704.

19. Kotler DP. Cachexia. Ann Intern Med 2000; 133(8):622-34.

20. Debigare $\mathrm{R}$, Marquis $\mathrm{K}$, Cote $\mathrm{CH}$, et al. Catabolic/anabolic balance and muscle wasting in patients with COPD. Chest 2003; 124(1):83-9.

21. Itoh $\mathrm{T}$, Nagaya $\mathrm{N}$, Yoshikawa $\mathrm{M}$, et al. Elevated plasma ghrelin level in underweight patients with chronic obstructive pulmonary disease. Am J Respir Crit Care Med 2004; 170(8):879-82.

22. Takabatake N, Nakamura H, Abe S, et al. The relationship between chronic hypoxemia and activation of the tumor necrosis factor-alpha system in patients with chronic obstructive pulmonary disease. Am J Respir Crit Care Med 2000; 161(4 Pt 1):1179-84.

23. Gosker HR, van Mameren H, van Dijk PJ, et al. Skeletal muscle fibre-type shifting and metabolic profile in patients with chronic obstructive pulmonary disease. Eur Respir J 2002; 19(4):617-25.

24. Gosker HR, Engelen MP, van Mameren H, et al. Muscle fiber type IIX atrophy is involved in the loss of fat-free mass in chronic obstructive pulmonary disease. Am J Clin Nutr 2002; 76(1):113-9.

25. Broekhuizen R, Vernooy $\mathrm{JH}$, Schols $\mathrm{AM}$, et al. Leptin as local inflammatory marker in COPD. Respir Med 2005; 99(1):70-4.

26. Schols A. Nutritional modulation as part of the integrated management of chronic obstructive pulmonary disease. Proc Nutr Soc 2003; 62(4):783-91.

27. Yoneda T, Yoshikawa M, Fu A, et al. Plasma levels of amino acids and hypermetabolism in patients with chronic obstructive pulmonary disease. Nutrition 2001; 17(2):95-9.

28. Graham TE, Sgro V, Friars D, Gibala MJ. Glutamate ingestion: the plasma and muscle free amino acid pools of resting humans. Am J Physiol Endocrinol Metab 2000; 278(1):E83-E89.

29. Romijn JA, Godfried MH, Hommes MJ, et al. Decreased glucose oxidation during short-term starvation. Metabolism 1990; 39(5):525-30. 
30. Giesecke K, Magnusson I, Ahlberg M, et al. Protein and amino acid metabolism during early starvation as reflected by excretion of urea and methylhistidines. Metabolism 1989; 38(12):1196200.

31. Blomstrand E, Saltin B. BCAA intake affects protein metabolism in muscle after but not during exercise in humans. Am J Physiol Endocrinol Metab 2001; 281(2):E365-74.

32. Tipton KD, Borsheim E, Wolf SE, et al. Acute response of net muscle protein balance reflects 24-h balance after exercise and amino acid ingestion. Am J Physiol Endocrinol Metab 2003; 284(1):E76-89.

33. Stegink LD, Filer LJ, Jr., Baker GL. Effect of carbohydrate on plasma and erythrocyte glutamate levels in humans ingesting large doses of monosodium L-glutamate in water. Am J Clin Nutr 1983; 37(6):961-8.

34. Tsai PJ, Huang PC. Circadian variations in plasma and erythrocyte glutamate concentrations in adult men consuming a diet with and without added monosodium glutamate. J Nutr 2000; 130(4S Suppl):1002S-4S.

35. Ghezzi P, Bianchi M, Gianera L, et al. Kinetics of monosodium glutamate in human volunteers under different experimental conditions. Food Chem Toxicol 1985; 23(11):975-8.

36. Dijkstra FY. Submerged cultures of mushroom mycelium as source of protein and flavour compounds. Algemene en toegepaste microbiologie. Delft: Technische Hogeschool, 1976. pp. 75.

37. Jong SC, Birmingham JM. Medicinal and therapeutic value of the shiitake mushroom. Adv Appl Microbiol 1993; 39:153-84.

38. Wagenmakers AJ. Protein and amino acid metabolism in human muscle. Adv Exp Med Biol 1998; 441:307-19.

39. Flaring UB, Rooyackers OE, Wernerman J, Hammarqvist F. Glutamine attenuates post-traumatic glutathione depletion in human muscle. Clin Sci (Lond) 2003; 104(3):275-82.

40. Hammarqvist F, Wernerman J, Ali R, Vinnars E. Effects of an amino acid solution enriched with either branched chain amino acids or ornithine-alpha-ketoglutarate on the postoperative intracellular amino acid concentration of skeletal muscle. Br J Surg 1990; 77(2):214-8.

41. Le Boucher J, Coudray-Lucas C, Lasnier E, et al. Enteral administration of ornithine alphaketoglutarate or arginine alpha-ketoglutarate: a comparative study of their effects on glutamine pools in burn-injured rats. Crit Care Med 1997; 25(2):293-8.

42. Hammarqvist F, Wernerman J, von der Decken A, Vinnars E. Alpha-ketoglutarate preserves protein synthesis and free glutamine in skeletal muscle after surgery. Surgery 1991; 109(1):28-36.

43. Engelen MPKJ, Schols AMWJ, Does JD, et al. Altered glutamate metabolism is associated with reduced muscle glutathione levels in patients with emphysema. Am.J.Respir.Crit.Care Med. 2000; 161:98-103.

44. Medved I, Brown MJ, Bjorksten AR, et al. N-acetylcysteine enhances muscle cysteine and glutathione availability and attenuates fatigue during prolonged exercise in endurance-trained individuals. J Appl Physiol 2004; 97(4):1477-85.

45. Koechlin C, Couillard A, Simar D, et al. Does oxidative stress alter quadriceps endurance in chronic obstructive pulmonary disease? Am J Respir Crit Care Med 2004; 169(9):1022-7.

46. Gibala MJ, Tarnopolsky MA, Graham TE. Tricarboxylic acid cycle intermediates in human muscle at rest and during prolonged cycling. Am J Physiol 1997; 272(2 Pt 1):E239-44.

47. Op 't Eijnde B, Van Leemputte M, Brouns F, et al. No effects of oral ribose supplementation on repeated maximal exercise and de novo ATP resynthesis. J Appl Physiol 2001; 91(5):2275-81.

48. Fuld JP, Kilduff LP, Neder JA, et al. Creatine supplementation during pulmonary rehabilitation in chronic obstructive pulmonary disease. Thorax 2005; 60(7):531-7. 
Appendices 


\section{Summary}

Chronic obstructive pulmonary disease (COPD) is primarily a chronic disease that affects the respiratory system. Generally, two subtypes of COPD are described: emphysema and chronic bronchitis. Typical symptoms of COPD are shortness of breath, first only during exercise, in later stages also at rest and exercise intolerance. Apart from local impairment, systemic features like loss of fat-free mass (FFM), and muscle weakness are commonly present in COPD patients. The decrease in FFM can even be masked by a normal body weight. Due to the fact that FFM reflects the amount of metabolic active and contracting (skeletal muscle) tissue, FFM depletion is associated with skeletal muscle wasting, exercise intolerance, impaired health status and decreased survival.

The cause of skeletal muscle wasting is not yet totally clear. Skeletal muscle is build up of proteins, which consist of amino acids. A decrease of skeletal muscle mass only occurs when protein breakdown exceeds protein synthesis. Recent papers indeed showed disturbances in protein and amino acid metabolism in COPD patients. Furthermore, there is consistent evidence that the skeletal muscle concentration of the amino acid glutamate is reduced in COPD patients compared to age-matched healthy subjects. The reduced muscle glutamate concentration was associated with a decreased muscle glutathione concentration and with early anaerobiosis during exercise. As glutamate plays a central role in many metabolic pathways in the skeletal muscles at rest and during exercise, the decreased muscle glutamate concentration in COPD can contribute to functional impairment. We hypothesized that normalization of the skeletal muscle glutamate concentration can improve physical functioning and therefore be of benefit for COPD patients.

The aim of the studies in the present thesis was to investigate alterations in protein and amino acid metabolism in COPD patients with special emphasis for the amino acid glutamate. Protein and amino acid metabolism was investigated using the primed constant and continuous infusion protocol of stable isotopes both in the postabsorptive state and during feeding. In addition to measurements on wholebody level, we measured interorgan protein metabolism and obtained insight in the 
metabolic response to feeding in different body compartments [ie splanchnic area and endogenous (muscle) compartment]. Moreover, we studied the metabolic and functional effects of glutamate supplementation in COPD patients.

The following section summarizes the main results of the experiment described in this thesis.

Using stable isotopes of the amino acids phenylalanine and 3-methylhistidine, we were able to measure the rate of whole-body and myofibrillar protein breakdown, respectively in two subgroups of COPD patients (cachectic and non-cachectic patients) and an age-matched healthy control group. Cachexia is characterized by a decreased body weight due to both a reduction of fat-free mass and fat mass. 3methylhistidine is solely present in myofibrillar protein, and proteolysis of myofibrils releases 3-methylhistidine that cannot be reutilized. Therefore, the appearance of 3-methylhistidine in plasma can be used as a valid method to measure myofibrillar protein breakdown. As myofibrillar protein is mainly present in skeletal muscle, myofibrillar protein breakdown can be used as a marker for skeletal muscle protein breakdown. We found no differences in whole-body protein breakdown between the 3 groups. Myofibrillar protein breakdown however was increased in the cachectic COPD group compared to the non-cachectic group and the healthy control group. Furthermore, the increased myofibrillar protein breakdown was associated with a decreased plasma glutamate concentration, suggesting that the increased myofibrillar protein breakdown in cachectic COPD patients is related to alterations in glutamate metabolism. In a group of normal-weight COPD patients, we investigated the effect of protein feeding on whole-body protein metabolism and splanchnic amino acid extraction. Splanchnic amino acid extraction can be measured using the dual tracer technique where a stable isotope of phenylalanine was simultaneously intravenously and enterally administrated. COPD patients had a lower splanchnic extraction of phenylalanine compared to the healthy control subjects, subsequently leading to a higher anabolic response to feeding in this group. We concluded that the higher anabolic response to feeding in the normalweight COPD group can be an adaptive mechanism to prevent or delay loss of body weight and skeletal muscle mass. 
Next, we focused on the metabolism of the amino acid glutamate in COPD patients. Until now, glutamate metabolism was only measured in young subjects. However, COPD patients are in general older than 50 years. To detect possible age-related effects on glutamate metabolism, we compared the COPD group with an age-matched healthy control group and a young healthy control group. Glutamate production and splanchnic glutamate extraction were measured using a stable isotope of glutamate in the three study groups in the postabsorptive state and during feeding. Postabsorptive glutamate production and splanchnic glutamate extraction were not different between the COPD patients and age-matched healthy control subjects, but were lower in the healthy elderly compared to the healthy young. During feeding, splanchnic glutamate extraction increased in the healthy elderly, but remained unchanged in the COPD patients. These findings indicate that alterations in glutamate metabolism in COPD in the postabsorptive state are age-related. However, the results during feeding suggest that glutamate in food has more impact in the healthy elderly than in the young, and that COPD patients are more dependent on glutamate in food than the healthy elderly. From the findings mentioned above, we can conclude that protein and glutamate metabolism alters during ageing and COPD. It is of importance to gain knowledge about the metabolic alterations in COPD patients to receive insight if the patients' condition can be improved by a food supplement enriched with glutamate or other amino acids.

Based on the present findings and the earlier results of decreased skeletal muscle glutamate concentrations in COPD patients, we intended to positively modulate metabolism of COPD patients with supplementation of glutamate. To measure protein and amino acid metabolism during glutamate ingestion, we first developed a glutamate ingestion protocol to increase plasma glutamate concentration significantly to a new steady state level. Based on the data from several pilot studies, we concluded that continuous ingestion of $30 \mathrm{mg}$ of glutamate per $\mathrm{kg}$ body weight every $20 \mathrm{~min}$ for $80 \mathrm{~min}$ increased systemic plasma glutamate levels in both the healthy elderly and the COPD patients indicating an increased glutamate availability to the periphery in both groups. Glutamate is closely linked to the amino acid glutamine that is often used as a supplement to increase the immune function 
in surgery patients. We compared the metabolic effects of glutamate ingestion with those of glutamine ingestion in a group of stable COPD patients and age-matched healthy control subjects. In both groups, glutamate ingestion increased plasma ornithine concentration and decreased plasma citrulline concentration, whereas glutamine ingestion increased plasma concentration of citrulline and arginine, both amino acids related to the intestine and the liver. The observed results are thus glutamate specific and therefore glutamate supplementation cannot be replaced by glutamine supplementation. Subsequently, we investigated the metabolic and functional effects of repeated glutamate ingestion in rest and during exercise. Using muscle biopsies, we tested if the ingested glutamate increased skeletal muscle glutamate concentration and glutamate related metabolic parameters at rest and during submaximal ergometry. Muscle biopsies were taken from the lateral part of the quadriceps femoris by using the needle-biopsy technique after administration of local anesthetic while the subjects were in supine position. Glutamate ingestion did not increase skeletal muscle glutamate concentration or glutamate-related metabolic parameters like muscle glutathione concentration and plasma lactate concentration. In addition, we couldn't detect an effect of glutamate ingestion on functional parameters like muscle quadriceps strength and cycle endurance time. It is possible that other metabolic pathways than measured in the present research are affected by glutamate ingestion, or that glutamate supplementation to a complete meal has different effects. Future research is necessary to study the other potential effects of glutamate supplementation. 


\section{Samenvatting voor niet-ingewijden}

Chronisch obstructief longlijden, of ook COPD genoemd, is een chronische longaandoening die gekenmerkt wordt door een progressieve vernauwing van de luchtwegen. COPD is een verzamelnaam voor emfyseem en chronische bronchitis. De patiënten vertonen een versnelde kortademigheid, eerst tijdens inspanning, maar later ook in rust. Uitgezonderd van een longtransplantatie, bestaat er nog steeds geen genezende therapie voor COPD, slechts een behandeling van de symptomen. De ziekte tast niet alleen de longen aan maar heeft een weerslag op het hele lichaam. Patiënten met COPD in een verder gevorderd stadium van de ziekte worden vaak gekenmerkt door gewichtsverlies waarbij zowel de spieromvang als de vetmassa vermindert. Afname van spiermassa in COPD is een proces dat zich over jaren ontwikkelt en dat onopgemerkt kan plaatsvinden wanneer er geen sprake is van gewichtsverlies. Spiermassaverlies draagt in belangrijke mate bij tot mobiliteitsverlies van de patiënt en de daarmee gepaard gaande vermindering van de levenskwaliteit.

De exacte oorzaak van het spiermassaverlies in COPD is nog niet helemaal duidelijk. Aangezien spierweefsel is opgebouwd uit eiwitten die op hun beurt uit aminozuren bestaan, treedt spierafbraak enkel op als de eiwitopbouw lager is dan de eiwitafbraak. Verstoringen in het eiwit- of aminozuurmetabolisme van COPD patiënten kunnen dus bijdragen tot spierafbraak. Voorgaande onderzoeken hebben aangetoond dat er inderdaad veranderingen aanwezig zijn in zowel het eiwit- als het aminozuurmetabolisme bij COPD patiënten. Een veel gerapporteerde bevinding is de verlaagde concentratie van het aminozuur glutamaat in de spieren van deze patiënten in vergelijking met gezonde personen. De verlaagde spierglutamaatconcentratie bij COPD was geassocieerd met een verminderde antioxidatieve capaciteit en een versnelde verzuring tijdens inspanning. Aangezien glutamaat een centrale rol speelt in veel verschillende processen in de spier, kan de verlaagde glutamaatconcentratie bij COPD bijdragen tot mobiliteitsverlies van deze patiënten en normalisatie van deze concentratie in de spier kan een functionele verbetering bij COPD patiënten bewerkstelligen. 
De onderzoeken beschreven in dit proefschrift hadden als doel om de verstoringen in het eiwit- en aminozuurmetabolisme bij COPD patiënten beter in kaart te brengen met speciale aandacht voor het aminozuur glutamaat. We hebben het eiwit- en aminozuurmetabolisme zowel in nuchtere als in gevoede toestand bestudeerd aangezien een persoon in het dagelijkse leven meer in gevoede dan in nuchtere toestand verkeert. Naast metingen op heel lichaamsniveau hebben we tevens een onderscheid gemaakt tussen het metabolisme in darm en lever, en het metabolisme in de spier. Tevens hebben we de effecten van glutamaatsupplementatie op het metabolisme en de spierfunctie van COPD patiënten onderzocht.

Welke methoden hebben we gebruikt in deze onderzoeken om bovenstaande doelen te bereiken? Het eiwit- en aminozuurmetabolisme hebben we onderzocht met behulp van aminozuren waar stabiele isotopen van waterstof $(\mathrm{H} 2)$, koolstof (C13) of stikstof (N15) zijn ingebouwd. Deze gemodificeerde aminzoren zijn volkomen onschadelijk en kunnen in het lichaam geïnfundeerd worden via een infuus in de ader (intraveneus, figuur 1) en/of via inname van een drankje (oraal). Deze gemodificeerde aminozuren betreffen specifieke aminozuren die van nature in lichaamseiwit voorkomen, maar omdat hun massa verzwaard is, kunnen ze onderscheiden worden van de 'natuurlijk veel voorkomende aminozuren'. De eiwitafbraak wordt gemeten aan de hand van de verschijningssnelheid van aminozuren omdat, tijdens infusie van de 'verzwaarde aminozuren', de ratio tussen de verzwaarde en natuurlijke aminozuren de snelheid van eiwitafbraak weergeeft. Als deze uitkomstparameters in het bloed gemeten worden, is het een algemene maat voor de eiwitafbraak en niet specifiek voor de spierafbraak, want de eiwitafbraak van andere delen van het lichaam (bv darm, lever, huid) wordt dan ook weergegeven. Post-translationeel gemodificeerde aminozuren (histidine naar 3-methylhistidine) die vrijkomen tijdens de afbraak van spierweefsel worden gebruikt als maat voor spierafbraak. Indien de gemodificeerde aminozuren zowel intraveneus als oraal worden toegediend, kan de eiwitstofwisseling in de darm en lever gemeten worden. 


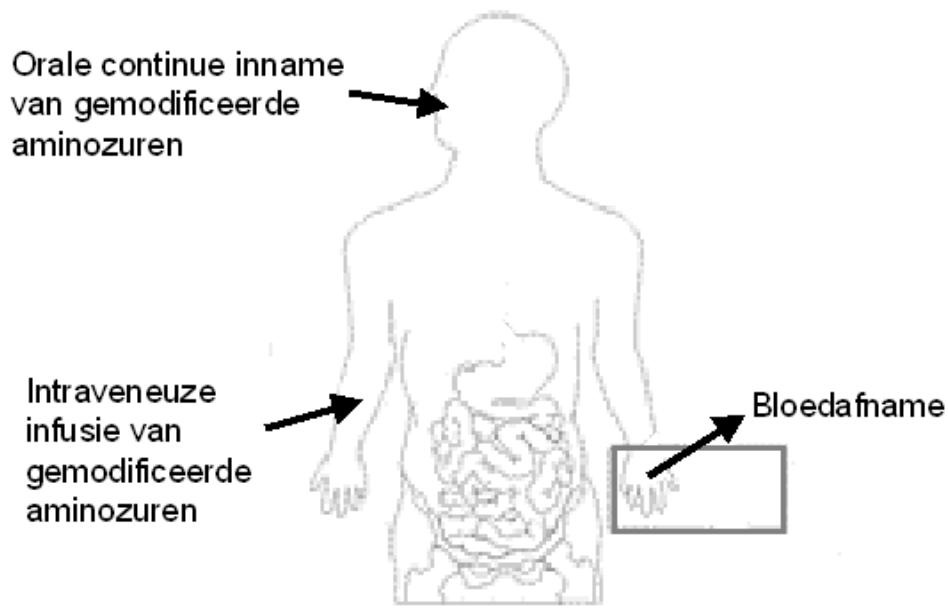

Figuur 1: De met stabiele isotopen verzwaarde aminozuren kunnen zowel intraveneus als oraal toegediend worden. De concentratie van deze aminozuren wordt in het bloed gemeten.

Om de techniek met stabiele isotopen te kunnen toepassen, moet het metabolisme van het lichaam in een stabiele toestand zijn. In nuchtere toestand en in rust is dit geen probleem. Indien we echter het eiwitmetabolisme in de gevoede toestand willen meten, moet ervoor gezorgd worden dat het lichaam dan ook weer stabiel is. Dit is mogelijk met een continue inname; dit wil zeggen dat kleine porties voeding gedurende een langere tijd ( \pm 2 uur) in een bepaald tijdsinterval (20 min) worden ingenomen zodat er een continue opname van de voeding in de darm plaatsvindt. $\mathrm{Na}$ een bepaalde tijd van inname is het lichaam stabiel in gevoede toestand en kunnen we het eiwitmetabolisme meten. De continue inname hebben we ook toegepast om de effecten van glutamaatsupplementatie te onderzoeken. Eerst hebben we in verschillende vooronderzoeken getest welke concentratie glutamaat en welk tijdsinterval noodzakelijk zijn om de gewenste glutamaatstijging in het bloed te verkrijgen. Onze conclusie was dat een inname van $30 \mathrm{mg}$ glutamaat per $\mathrm{kg}$ lichaamsgewicht elke 20 minuten gedurende 80 minuten voor een verhoogd stabiel plateau in de plasma glutamaatconcentratie zorgt. Hierbij hebben we aangetoond dat glutamaatinname de beschikbaarheid van glutamaat voor de organen (bijvoorbeeld de spieren) doet stijgen.

De metabole effecten van glutamaatinname hebben we op verschillende niveaus gemeten. Enerzijds hebben we het effect van glutamaatinname op het eiwit- en aminozuurmetabolisme getest op heel lichaamsniveau door diverse 
parameters in het bloed te meten. Anderzijds hebben we lokaal naar de effecten van glutamaatinname in de spier gekeken met behulp van een spierbiopt, dit wil zeggen dat er onder lokale verdoving een klein stukje spier uit het bovenbeen wordt weggenomen. Op deze manier kunnen we testen of het glutamaat dat we via een drankje toedienen daadwerkelijk een verhoging van de spierglutamaat tot gevolg heeft.

De volgende alinea beschrijft de belangrijkste bevindingen van dit proefschrift.

Gebruik makend van een stabiel isotoop van het aminozuur 3-methylhistidine, hebben we de afbraaksnelheid van een eiwit dat voornamelijk in de spier voorkomt gemeten. Dit wordt de myofibrillaire eiwitafbraak genoemd. We hebben de myofibrillaire eiwitafbraak gemeten in 2 subgroepen van COPD patiënten (patiënten met en zonder cachexie) en in een gezonde leeftijdsgematchte controle groep. Cachexie wordt gekenmerkt door ondergewicht waarbij zowel de spiermassa als de vetmassa verminderd zijn. Op heel lichaamsniveau vonden we geen verschil in eiwitmetabolisme tussen de verschillende groepen. De myofibrillaire eiwitafbraak was bij cachectische COPD patiënten echter hoger dan bij de niet-cachectische COPD patiënten en de gezonde controle personen. De verhoogde myofibrillaire eiwitafbraak was geassocieerd met een verlaagde glutamaatconcentratie in het bloed. Deze bevinding impliceert dat de verhoogde myofibrillaire eiwitafbraak in cachectische COPD patiënten gepaard gaat met een verstoring in het glutamaatmetabolisme. In de pre-cachectische fase, dus bij COPD patiënten met een normaal stabiel gewicht hebben we het effect van voeding op het eiwitmetabolisme op heel lichaamsniveau en op de aminozuuropname in de darm en lever onderzocht. Deze COPD patiënten hadden een lagere aminozuuropname in de darm en lever tijdens voeding in vergelijking met gezonde personen, wat gepaard ging met een verhoogde eiwitopbouw. Hieruit kunnen we concluderen dat de stofwisseling in de darm en lever bij gewichtsstabiele COPD patiënten reeds veranderd is tijdens voeding. De hogere eiwitopbouw tijdens voeding in deze patiënten kan een adaptief mechanisme zijn om gewichtsafname en spiermassaverlies uit te stellen of te vertragen. 
Vervolgens hebben we onze aandacht gericht op het metabolisme van het aminozuur glutamaat bij COPD patiënten. Tot nu toe was het glutamaatmetabolisme namelijk uitsluitend onderzocht bij jongeren, maar COPD patiënten zijn over het algemeen ouder dan 50 jaar. Leeftijd an sich gaat gepaard met metabole veranderingen. Om de effecten van veroudering op het glutamaatmetabolisme te onderzoeken, hebben we daarom de patiëntengroep niet alleen vergeleken met gezonde ouderen maar ook met een jongere controle groep. Door middel van glutamaat met daarin een stabiel isotoop ingebouwd hebben we de glutamaatproduktie in het lichaam en de opname van glutamaat in de darm en lever gemeten bij deze 3 groepen zowel in nuchtere als gevoede toestand. In de nuchtere toestand hebben we geen verschil kunnen aantonen in glutamaatstofwisseling tussen gezonde ouderen en COPD patiënten. Wel vonden we een leeftijdsgerelateerd verschil. Er was een verlaagde glutamaatproduktie in het lichaam en een verminderde opname van glutamaat in de darm en lever bij gezonde ouderen in vergelijking met de jongeren. Tijdens voeding stijgt de glutamaatopname in de darm en lever bij gezonde ouderen, terwijl deze gelijk blijft in de COPD groep. Hieruit blijkt dat de veranderingen in het glutamaatmetabolisme in nuchtere toestand leeftijdsspecifiek zijn. De bevindingen tijdens voeding impliceren dat glutamaat in voeding meer invloed heeft bij ouderen dan bij jongeren en mogelijkerwijs zijn COPD patiënten nog meer afhankelijk van glutamaat in de voeding. Uit bovenstaande bevindingen kunnen we samenvatten dat het eiwit- en aminozuurmetabolisme zowel verandert tijdens veroudering als bij COPD. Het in kaart brengen van de veranderingen in het metabolisme is van belang om inzicht te krijgen in hoeverre de conditie van de patiënt verbeterd kan worden door middel van het geven van voedingssupplementen die verrijkt zijn met glutamaat of andere aminozuren.

Op basis van bovenstaande resultaten en eerder onderzoek, hebben we in het tweede deel van dit proefschrift getracht het metabolisme van COPD patiënten positief te beïnvloeden met behulp van glutamaatsupplementatie volgens het eerder beschreven protocol van glutamaatinname. Glutamaat is zeer verwant aan het aminozuur glutamine dat bij patiënten vaak wordt gegeven als supplement om het immuunsysteem te verhogen rondom een operatieve ingreep. We hebben de 
metabole effecten van beide aminozuren vergeleken in stabiele COPD patiënten en gezonde controle personen. Beide groepen reageerden hetzelfde op het supplement, maar er waren wel verschillende metabole reacties tussen de aminozuren. Glutamaatinname resulteerde $\mathrm{nl}$. in een daling van de plasma citrullineconcentratie en een stijging van de plasma ornithineconcentratie, terwijl glutamineinname de plasma concentraties van citrulline en arginine (aminozuren die gelinkt zijn aan het metabolisme in de darm of de lever) deed stijgen. De waargenomen effecten zijn dus specifiek voor glutamaat en daarom kan supplementatie van glutamaat niet vervangen worden door glutaminesupplementatie. Vervolgens hebben we metabole en functionele effecten van glutamaatinname in rust en tijdens inspanning onderzocht. Met behulp van spierbiopten hebben we gemeten of het glutamaat dat gedronken werd de spierglutamaatconcentratie doet stijgen. Het bleek echter dat glutamaatinname zowel de glutamaatconcentratie als de concentratie van glutamaat-gerelateerde stoffen in de spier niet deed stijgen. Tevens konden we ook geen effect van glutamaatinname op functionele parameters zoals het uithoudingsvermogen en de spiervermoeidheid na een fietstest aantonen. Het is mogelijk dat andere processen dan deze die wij hebben onderzocht gemoduleerd worden door glutamaatinname, of dat glutamaatinname in combinatie met voeding een ander effect heeft. Toekomstig onderzoek zal hierin duidelijkheid dienen te brengen.

Concluderend kunnen we samenvatten dat zowel veroudering als COPD het eiwiten aminozuurmetabolisme veranderen. Toekomstig onderzoek moet echter nog uitwijzen welke van deze veranderingen een fysiologische of een pathofysiologische rol spelen en wat de indicaties en mogelijkheden zijn voor aminozuursupplementatie. 


\section{Abbreviations}

\begin{tabular}{|c|c|}
\hline AAT & Alanine aminotransferase \\
\hline AMP & Adenosine mono-phosphate \\
\hline ATP & Adenosine tri-phosphate \\
\hline BCAA & Branched-chain amino acids \\
\hline $\mathrm{BIA}$ & Bioelectrical impedance analyses \\
\hline BMI & Body mass index \\
\hline BW & Body weight \\
\hline COPD & Chronic obstrucive pulmonary disease \\
\hline $\mathrm{FEV}_{1}$ & Forced expiratory volume in $1 \mathrm{~s}$ \\
\hline FFM & Fat-free mass \\
\hline Gln / GLN & glutamine \\
\hline Glu / GLU & Glutamate \\
\hline GOLD & Global Initiative for Chronic Lung Disease \\
\hline GSH & Glutathione \\
\hline GSSG & Glutathione disulfide \\
\hline IMP & Inosine mono-phosphate \\
\hline MPB & Myofibrillar protein breakdown \\
\hline MSG & Monosodium glutamate \\
\hline MyHC & Myosin heavy chain \\
\hline $\mathrm{N}$ & Nitrogen \\
\hline$N F-\kappa B$ & Nuclear factor- кB \\
\hline $\mathrm{NH}_{3}$ & Ammonia \\
\hline Phe & Phenylalanine \\
\hline PNC & Purine nucleotide cycle \\
\hline $\mathrm{Ra}$ & Rate of appearance \\
\hline $\mathrm{Rd}$ & Rate of disappearance \\
\hline SPE & Splanchnic extraction \\
\hline TCAI & Tricarboxylic acid intermediates \\
\hline TNF- $a$ & Tumor necrose factor- $\alpha$ \\
\hline TTR & Tracer-to-tracee ratio \\
\hline
\end{tabular}




\begin{tabular}{l|l} 
TwQ & Quadriceps twitch force \\
Tyr & Tyrosine \\
UCP3 & Uncoupling protein 3 \\
Vo2 & Oxygen consumption \\
WB PB & Whole-body protein breakdown \\
WB PS & Whole-body protein synthesis \\
Wpeak & Peak workload
\end{tabular}




\section{Vertaling Vlaams - Nederlands}

Als Belg in Nederland gaan promoveren wil zeggen dat je je naast de mentaliteit, ook een beetje aan de taal moet aanpassen. Hieronder geef ik de meest voorkomende verschillen tussen Belgisch en Nederlands Nederlands:

\begin{tabular}{lll}
\hline \multicolumn{1}{l}{ Vlaams } & Nederlands \\
\hline Autotrade & Snelweg \\
Tas & Mok \\
Seffens & Straks \\
Pint & Pils \\
$! ! \quad$ Een artikel overlopen & Een artikel doornemen \\
Bloed trekken & Bloed afnemen \\
Wijsheidstand & Verstandskies \\
Assortie & Samenhorend \\
Radiopost & Radiozender \\
Grenadine & Carban sevitan \\
Nistel & Veter \\
Smoutebol & Oliebol \\
Personeelszaken & Personele zaken \\
Plezant & Leuk \\
Doctoreren & Promoveren \\
Zeker en vast & Vast en zeker \\
Chauffage & Verwarming \\
Frigo & Koelkast \\
Microgolfoven & Magnetron \\
Diepvries & Vriezer \\
Botten & Laarzen \\
Curry & Kerrie \\
Boterham & Broodje \\
Verleden week & Vorige week \\
\hline & \\
& & \\
& &
\end{tabular}




\section{Publications}

\section{6}

Rutten EPA, Engelen MPKJ, Gosker H, Bast A, Cosemans K, Vissers YLJ, Wouters EFM, Deutz NEP, Schols AMWJ. Metabolic and functional effects of glutamate in patients with chronic obstructive pulmonary disease. Submitted

Rutten EPA, Franssen FME, Engelen MPKJ, Wouters EFM, Deutz NEP, Schols AMWJ. Greater whole-body myofibrillar protein breakdown in cachectic patients with chronic obstructive pulmonary disease. Am J Clin Nutr 2006;83:829-34

Rutten EPA, Engelen MPKJ, Wouters EFM, Deutz NEP, Schols AMWJ. Effect of glutamate ingestion on whole body glutamate turnover in healthy elderly and patients with chronic obstructive pulmonary disease. Nutrition 2006;22:496-503

Rutten EPA, Engelen MPKJ, Wouters EFM, Schols AMWJ, Deutz NEP. Metabolic effects of glutamate and glutamate ingestion in healthy subjects and persons with chronic obstructive pulmonary disease. Am J Clin Nutr 2006;83:115-23

Rutten EPA, Engelen MPKJ, Schols AMWJ, Deutz NEP. Skeletal muscle glutamate metabolism in health and disease: state of the art. Curr Opin Clin Nutr Metab Care 2005;8:41-51

Engelen MPKJ, Rutten EPA, Castro CLN, Wouters EFM, Schols AMWJ, Deutz NEP. Altered inter-organ response to feeding in patients with chronic obstructive pulmonary disease. Am J of Clin Nutr 2005;82:366-72 
Rutten EPA, Engelen MPKJ, Castro CLN, Wouters EFM, Schols AMWJ, Deutz NEP. Decreased whole body and splanchnic glutamate metabolism in healthy elderly men and patients with chronic obstructive pulmonary disease in the postabsorptive state and in response of feeding. J Nutr, 2005;135:21662170

\section{Abstracts}

\section{5}

Rutten EPA, Engelen MPKJ, Castro CLN, Wouters EFM, Schols AMWJ, Deutz NEP. Decreased whole body glutamate turnover in elderly and patients with chronic obstructive pulmonary disease. ATS congress, San Diego, USA and ESPEN congress, Brussels, Belgium

\section{4}

Rutten EPA, Engelen MPKJ, Wouters EFM, Deutz NEP, Schols AMWJ. Reduced myofibrillar protein breakdown in stable patients with chronic obstructive pulmonary disease (COPD). ERS congress, Glasgow, Scotland

Rutten EPA, Engelen MPKJ, Wouters EFM, Deutz NEP, Schols AMWJ. Reduced myofibrillar protein breakdown in stable patients with chronic obstructive pulmonary disease (COPD). FASEB congress, Washington, USA

Rutten EPA, Engelen MPKJ, Wouters EFM, Schols AMWJ, Deutz NEP. Glutamate ingestion reduces non-protein leucine turnover in patients with chronic obstructive pulmonary disease (COPD). FASEB congress, Washington, USA

Rutten EPA, Engelen MPKJ, Wouters EFM, Schols AMWJ, Deutz NEP. Glutamate ingestion reduces non-protein leucine turnover in patients with chronic obstructive pulmonary disease (COPD). NAF symposium, Amersfoort, the Netherlands 


\section{3}

Rutten EPA, Engelen MPKJ, Deutz NEP, Wouters EFM, Schols AMWJ. The effect of a glutamate load on symptoms of the Chinese restaurant syndrome. ESPEN congress, Cannes, France

Rutten EPA, Engelen MPKJ, Schols AMWJ, Wouters EFM, Deutz NEP. The effect of repeated ingestion of glutamate or glutamine on plasma glutamate levels. ESPEN congress, Cannes, France

Rutten EPA, Engelen MPKJ, Deutz NEP, Wouters EFM, Schols AMWJ. The effect of repeated ingestion of glutamate on symptoms of the Chinese restaurant syndrome, plasma glutamate levels and protein metabolism in COPD patients and healthy age-matched controls. NAF symposium, Amersfoort, the Netherlands

\section{Awards}

\section{4}

European Respiratory Society (ERS) Young scientist sponsorship 2003

European Society for Parenteral and Enteral Nutrition (ESPEN) Nestle fellowship 


\section{Curriculum Vitae}

Erica Rutten is geboren op 17 oktober 1978 in België. Toen ze 18 jaar was, is ze aan de Katholieke Universiteit Leuven beginnen te studeren aan de richting Voeding- en dieetleer. Tijdens een stage gedurende het laatste jaar, heeft ze onderzoek gedaan naar het effect van chronische ijzersuppletie op de darmpermeabiliteit aan de Universiteit Maastricht. $\mathrm{Na}$ het behalen van haar diploma in 2000, heeft Erica nog een jaar ervaring opgedaan als onderzoeksassistente bij de afdeling Humane Biologie. In augustus 2001 is ze met een doctoraatsopleiding begonnen bij de afdeling Longziekte, ook aan de Universiteit Maastricht. Tijdens deze periode voerde ze complexe klinische interventiestudies uit die beschreven staan in de huidige thesis.

Erica Rutten was born on October 17, 1978 in Maaseik, Belgium. At the age of 18, Erica started studying Food and Diet at the Catholic University Leuven. During her scholarship at the University Maastricht in the Netherlands, she performed a clinical study concerning the effect of chronic iron supplementation on the intestinal permeability. After she obtained her masters degree in 2000 , she work as a research assistant for one year at the department of Human Biology of the University Maastricht. In August 2001, she started a PhD-project at the department of Respiratory Medicine of the same university. During this period, she performed complex clinical human intervention studies with stable isotopes described in the present thesis. 


\section{Dankwoord}

Promoveren is meer dan werken, je moet van je werk een tijdje je hobby kunnen maken. Het knutselen aan een proefschrift vergt veel tijd, passie, inspanning en geduld. Natuurlijk is een promotieonderzoek niet mogelijk als je er alleen voorstaat. Ik was een speler in een team, een onderzoeksteam van allemaal onmisbare spelers. Aan al deze mensen die rechtstreeks of onrechtstreeks hebben meegeholpen met het tot stand komen van mijn proefschrift, wil ik graag mijn dank betuigen.

Allereerst wil ik al de vrijwilligers, die zich kandidaat hebben gesteld om deel te nemen aan een van de onderzoeken die ik heb uitgevoerd, hartelijk danken. Ik moet bekennen dat het een drempel was om sommigen letterlijk als proefkonijn te moeten gebruiken tijdens mijn leerperiode voor het leggen van infusen. Ik heb echter genoten van onze gesprekken gedurende het onderzoek wanneer jullie waren vastgeketend aan het bed. De mate van flexibiliteit en de levenswijsheid van 'mijn' oudere vrijwilligers is een van de belangrijkste ervaringen die ik heb opgedaan tijdens mijn aio-periode.

Grote dank gaat uit naar mijn promotor Prof. Annemie Schols. Ondanks een ontzettend drukke agenda en vele andere bezigheden, kon ik telkens op korte termijn even binnenspringen. Ik ben zeker niet de eerste die dit schrijt, maar je enthousiasme en flexibiliteit in het onderzoek werken echt aanstekelijk. Bedankt Annemie voor deze degelijke begeleiding op momenten dat het nodig was. Naar promotor Prof. Wouters gaat mijn dank voor het leggen van de laatste hand aan de artikelen. Ik heb respect voor de overkoepelende blik die u kunt werpen over de vele facetten van de 'longwereld'. Mariëlle Engelen, mijn co-promotor, ik heb genoten van een begeleidster zoals jij en ik ben je zeer dankbaar voor het intense en degelijke overleg dat we hadden bij het opstarten van het onderzoek, het uitvoeren van de vele pilotstudies, de data analyses en uiteindelijk de artikelen. Ik vind het jammer dat de dingen niet altijd gelopen zijn zoals ze gepland zijn. 
De beoordelingscommissie wil ik bedanken om zich de tijd te nemen voor het doornemen van mijn thesis. My appreciation goes to the promotion commission who took the time to read my thesis.

Alle mensen op de afdeling Longziekte wil ik bedanken voor de fijne samenwerking en de gezelligheid. Vooral de 'oudere' collega's maakten het mij in het begin niet gemakkelijk als eerste Belg op de kamer. Toch heb ik genoten van deze tijd, waarvoor mijn dank aan Harry, Frits, Roelinka, Diederick, Ramon, Juanita, Mieke, Marja en Eva. Later kwamen de andere collega's terug van Amerika en vonden jullie nieuw plaagvoer. Dus ook bedankt aan jullie: Jos, Kim, Astrid, Roy en Marco. Misschien iets minder gezien, maar daarom niet minder graag mee samengewerkt zijn Alex, Jodil, Pascal, Dily en Niki. Alle longartsen en arts-assistenten van toen en nu wil ik graag bedanken voor de hulp naar het zoeken van geschikte patiënten voor mijn onderzoeken. Ook het secretariaat m.n. Gabie, Manon, France, Winny en Fabienne wil ik bedanken voor de fijne samenwerking.

Werken in samenwerking met verschillende afdelingen is niet altijd gemakkelijk maar wel bevordelijk voor het onderzoek. Het metabolic research center van de afdeling Algemene Heelkunde ben ik grote dank verschuldigd. Mick Deutz, ik wil je graag bedanken voor de vele deskundige uitleg die je me gaf om me wegwijs te maken in de tracerwereld. Hans, Gabrie, Dennis, Dennis, Paul, Marcella en Jean, bedankt voor het analyseren van zoveel monsters. Moest ik nog eens promoveren, dan zou ik een aminozuur zoeken dat gemakkelijker te analyseren is! Verder heb ik genoten van de tracerbesprekingen en de congresuitjes met vele andere van de groep m.n. Yvette, Yvonne, Iris, Marcel, Dick, Darren en Maaike. Zeker wil ik Jos Senden van de afdeling Humane Biologie bedanken voor het jarenlange lenen van de ergometer. Ondanks enkele haperingen heb ik er veel mensen op kunnen laten trainen.

In Hornerheide ben ik gekomen en gegaan en vaak was ik er te weinig om iedereen goed te leren kennen. Toch ben ik iedereen dankbaar, in eerste instantie voor de deelname aan een onderzoek dat ik heb uitgevoerd met medewerkers, en later voor de fijne samenwerking gedurende mijn laatste jaar wanneer ik het saaie schrijven heb kunnen afwisselen met praktisch werk. 
Met z'n drie zaten we een tijdlang in afzondering aan de Noord- of Belgenkant. Roelinka, ik vond het fijn om bij jou op de kamer te zitten. Jij hield die kamer tenminste nog een beetje Nederlands. Toen jij eenmaal gepromoveerd was, kon ik net zo goed in België werken. Nee Evi, zeker geen belediging. Ik ben blij dat we mekaar weer zijn tegengekomen na al die jaren. We kunnen dan wel veel van elkaar verschillen, toch kan ik genieten van onze babbels, onze koffie-avonturen en onze loopjes tijdens de middagpauze!

Kirsten, ik weet niet in welke alinea ik je moet benoemen. Jij past overal in. Toen je kwam werken op de universiteit was jij als Belgische collega mijn ruggesteun. Later was je betrokken bij zowel de uitvoer als de analyses van elk onderzoek, maar ook als maatje weet ik je zeer te waarderen! Carmen, for one year, you assisted me with the performance of two studies. I realize that that was not easy and that it is amazing what you did! Besides work, we visited some cities together and I really enjoyed the time we spent together.

Marja, Renate, Kris, Inge, Mike en alle vrienden en vriendinnen aan het thuisfront hebben mij direct of indirect gesteund met het vervolledigen van dit schrift. Zoals nog steeds kan ik enorm genieten van alle ontspannende momenten die me telkens weer de energie gaven om ermee door te gaan! Een aantal mensen die mij in het verleden geholpen hebben met het leggen van de juiste basis, wil ik zeker niet vergeten te benoemen: Gerda Meerten, Paul Hotterbeeks, Chris Narinkx en Twan Lemmens.

Ma en pa, om jullie te bedanken zou ik een nieuw boek kunnen schrijven. Ik weet dat jullie geen dank vragen, maar als ik jullie wil evenaren in de opvoeding van mijn kinderen, zal dat weer een hele uitdaging zijn. Jullie zijn fantastische ouders die mij alle kansen hebben gegeven, waarvoor mijn grote dank! Christophe, zoals geen ander weten wij: 'waar een wil is, is een weg'! Ik kan niet wachten om samen aan een toekomst te werken!

En nu: de boeken toe! 